

\section{EU Cohesion Policy \& Accountability}

Coverage, Context, Content \& Costs

in the case of ERDF in the Netherlands

Maaike Damen - Koedijk 
Dit proefschrift is goedgekeurd door

Prof. dr. N.S. Groenendijk (promotor)

Copyright (C) 2016 Maaike Damen - Koedijk. All rights reserved.

This thesis was printed by Optima Grafische Communicatie B.V., Rotterdam

All rights reserved. No part of this book may be reproduced or transmitted, in any form or by any means, electronic or mechanical, including photocopying, microfilming, and recording, or by any information storage or retrieval system, without prior written permission of the author.

ISBN: 978-90-365-4026-1

DOI: $10.3990 / 1.9789036540261$ 


\title{
EU COHESION POLICY AND ACCOUNTABILITY COVERAGE, CONTEXT, CONTENT AND COSTS IN THE CASE OF ERDF IN THE NETHERLANDS
}

\author{
PROEFSCHRIFT \\ ter verkrijging van \\ de graad van doctor aan de Universiteit Twente, \\ op gezag van de rector magnificus, \\ prof.dr. H. Brinksma \\ volgens besluit van het College voor Promoties \\ in het openbaar te verdedigen \\ op donderdag 11 februari 2016 om 14.45 uur \\ door \\ Maaike Jennifer Damen - Koedijk \\ geboren op 12 februari 1980 \\ te Leeuwarden
}




\section{COMPOSITION OF THE GRADUATION COMMITTEE}

Prof. dr. N.S. Groenendijk, University of Twente

Prof. dr. M.L.P. Groenleer, University of Tilburg

Prof. dr. M.A. Heldeweg, University of Twente

Prof. dr. W.T.M. Molle, Erasmus University Rotterdam

Dr. L. Polverari, University of Strathclyde

Prof. dr. Th. A.J. Toonen, University of Twente

Prof. dr. R.A. Wessel, University of Twente 


\section{TABLE OF CONTENTS}

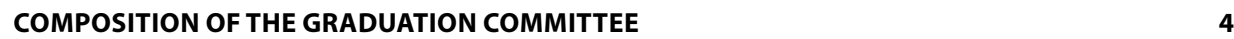

$\begin{array}{lr}\text { TABLE OF CONTENTS } & 5\end{array}$

$\begin{array}{lr}\text { LIST OF ABBREVIATIONS } & 9\end{array}$

$\begin{array}{lr}\text { ACKNOWLEDGEMENTS } & 11\end{array}$

$\begin{array}{ll}\text { CHAPTER } 1 & 17\end{array}$

Introduction: Cohesion Policy, multilevel governance and agency theory

$\begin{array}{lll}1.1 & \text { Why this research? } & 17\end{array}$

1.2 What is Cohesion Policy? - An introduction 20

$\begin{array}{ll}\text { 1.2.1 The rationale for Cohesion Policy } & 20\end{array}$

1.2.2 Cohesion Policy 2007-2013: facts and figures 22

$\begin{array}{ll}\text { 1.2.3 Cohesion Policy 2014-2020 } & 28\end{array}$

$\begin{array}{llr}1.3 & \text { Theoretical angle } & 29\end{array}$

$\begin{array}{ll}\text { 1.3.1 Accountability and agency theory } & 30\end{array}$

1.3.2 What is multilevel governance? $\quad 32$

1.3.3 Why multilevel governance in Cohesion Policy? 33

1.4 Empirical focus and research questions 35

$\begin{array}{lll}1.5 & \text { Outline of the thesis } & 37\end{array}$

$\begin{array}{ll}\text { CHAPTER } 2 & 41\end{array}$

Accountability within the EU

$\begin{array}{lll}2.1 & \text { Introduction } & 41\end{array}$

2.2 Agency theory $\quad 42$

\begin{tabular}{ll}
2.3 & The concept of accountability \\
\hline
\end{tabular}

2.3.1 The process of accountability $\quad 49$

$\begin{array}{ll}\text { 2.3.2 Characteristics of accountability } & 51\end{array}$

2.3.3 The elements of accountability 53

2.3.4. Different types of accountability 56

$\begin{array}{ll}\text { 2.3.5. Accountability deficit and overload } & 57\end{array}$

2.4 Accountability in the EU according to academic literature $\quad 59$

2.4.1. Elements of accountability in the EU 59

$\begin{array}{ll}\text { 2.4.2. Limitations of accountability in a multilevel context } & 63\end{array}$

$\begin{array}{llr}2.5 & \text { Conclusions } & 69\end{array}$ 
Normative framework for 'good accountability'

3.1 Introduction

3.2 Single and systemic dimension 73

\subsubsection{Single dimension}

3.2.2 Systemic dimension

3.3 'Good accountability': coverage, context, content and costs

3.4 Application of the framework in this research

The Dutch case - actors, relationships and accountability characteristics

4.1 Introduction

4.2 The actors on European, national and regional level

90

4.2.1 The European level

90

4.2.2 The national level

92

4.2.3 The regional level

97

4.2.4 Schematic overview of actors, and further approach

4.3 The relationships in the European cluster

4.3.1 Citizens and the European Parliament

4.3.2 The European Parliament and the European Commission

$\begin{array}{ll}\text { 4.3.3 The Council and the European Commission } & 107\end{array}$

$\begin{array}{ll}\text { 4.3.4 Other actors in the European cluster } & 110\end{array}$

4.3.5 Conclusion on accountability in the European cluster 111

$\begin{array}{lll}4.4 & \text { The relationships in the national cluster } & \mathbf{1 1 4}\end{array}$

$\begin{array}{ll}\text { 4.4.1 Citizens and the national parliament } & 114\end{array}$

4.4.2 The national parliament and the national government 115

$\begin{array}{ll}\text { 4.4.3 The national parliaments and the Council } & 118\end{array}$

$\begin{array}{ll}\text { 4.4.4 The national government and the Council } & 119\end{array}$

4.4.5 The national parliaments and the European Commission 120

$\begin{array}{ll}\text { 4.4.6 Other actors in the national cluster } & 122\end{array}$

4.4.7 Conclusion on accountability in the national cluster 124

$\begin{array}{ll}\text { 4.5 The relationships in the national-European cluster } & 127\end{array}$

4.5.1 The European Commission and the member state 127

4.5.2 The national government and the Managing Authority 136

4.5.3 The European Commission and the Managing Authority 139 
4.5.4 The European Commission and the Certifying Authority, the Audit Authority and the Managing Authority

4.5.5 Conclusion on accountability in the national-European cluster

4.6 The relationships in the regional cluster 154

4.7 Preliminary conclusion on the relationships in the system 156

\section{CHAPTER 5}

Talking to the people: interviews with actors on Cohesion Policy

5.1 Introduction

5.2 Methodology, research strategy and field work

5.3 The European cluster 165

5.3.1 The European Parliament and the European Commission 166

5.3.2. The Council and the European Commission 169

5.3.3 Other actors in the European cluster 172

5.3.4 Conclusion from interviews on accountability in the European cluster

5.4 The national cluster 174

5.4.1 The national parliament and the national government 175

5.4.2 The national parliament and the Council 178

5.4.3 Other actors in the national cluster 179

5.4.4 Conclusion on accountability in the national cluster 179

5.5 The national-European cluster 180

5.5.1 The European Commission and the member state 180

5.5.2 The national government and the Managing Authority 184

5.5.3 The European Commission and the Managing Authority 185

5.6 The European Commission and the Audit Authority 189

5.6.1 The national government and the Audit Authority 190

5.6.2 Conclusion on the relations in the national-European cluster 192

5.7 Preliminary conclusion from the interviews 193

5.7.1 The requirements of 'good accountability' 194

5.7.2 General perception of accountability situation 196

CHAPTER 6

Accountability and Cohesion Policy in the Netherlands

6.1 Introduction

6.2 Coverage: accountability relationships 203

6.3 Context: transparency, democracy and legal constraint 206

6.4 Content: the 3E's - economy, efficiency and effectiveness 
6.5 Costs: absence of accountability deficit or overload 211

6.6 Summary and answer to the main research question 220

CHAPTER 7

Discussion and outlook for further research

$\begin{array}{llr}7.1 & \text { Introduction } & 223\end{array}$

$\begin{array}{llr}7.2 & \text { Discussion } & 223\end{array}$

7.2.1 A radical rethink of Cohesion Policy 224

7.2.2 Improvements in the current system of Cohesion Policy 226

$\begin{array}{llr}\text { 7.3 } & \text { Possibilities for further research } & 234\end{array}$

$\begin{array}{llr}7.4 & \text { Final words } & 236\end{array}$

$\begin{array}{lr}\text { LITERATURE LIST } & 239\end{array}$

$\begin{array}{lr}\text { ANNEX } & 251\end{array}$

$\begin{array}{lr}\text { ANNEX I - Questionnaire used for the interviews } & 247\end{array}$

ANNEX II - Interviews: defining the questions per actor 253

ANNEX III - List of respondents $\quad 255$

NEDERLANDSE SAMENVATTING 259

$\begin{array}{ll}\text { ABOUT MAAIKE DAMEN } & 269\end{array}$ 




\section{LIST OF ABBREVIATIONS}

\begin{tabular}{|c|c|}
\hline AA & Audit Authority \\
\hline$A B$ & Algemeen Bestuur (General Board) \\
\hline AAR & Annual Activity Report \\
\hline ACR & Annual Control Report \\
\hline ADR & Audit Dienst Rijk (Audit Authority of the State) \\
\hline Awb & Algemene Wet Bestuursrecht (General Administrative Law Act) \\
\hline $\mathrm{BC}$ & Bestuurscommissie (Board Committee) \\
\hline $\mathrm{CA}$ & Certifying Authority \\
\hline CdK & Commissaris van de Koning (Commissioner of the King) \\
\hline CF & Cohesion Fund \\
\hline CGD & Commissie Goede Diensten (Commission of Good Services) \\
\hline CONT & Committee on Budgetary Control of the European Parliament \\
\hline CoR & Committee of the Regions \\
\hline CPR & Common Provisions Regulation \\
\hline CSG & Community Strategic Guidelines \\
\hline DAS & Declaration of Assurance \\
\hline DB & Dagelijks Bestuur (Daily Board) \\
\hline $\mathrm{DC}$ & Deskundigencommissie (Commission of Experts) \\
\hline DG & Directorate General \\
\hline EAFRD & European Agricultural Fund for Rural Development \\
\hline EC & European Commission \\
\hline ECA & European Court of Auditors \\
\hline ECJ & European Court of Justice \\
\hline ECU & European Currency Unit \\
\hline EMFF & European Maritime and Fisheries Fund \\
\hline ERDF & European Regional Development Fund \\
\hline ESF & European Social Fund \\
\hline $\mathrm{ESI}(\mathrm{F})$ & European Structural and Investment (-Funds) \\
\hline ETC & European Territorial Cooperation \\
\hline EU & European Union \\
\hline$E Z$ & Economische Zaken (Economic Affairs) \\
\hline FR & Financial Regulation \\
\hline FWG & Financiële Werkgroep (Financial Working Group) \\
\hline GDP & Gross Domestic Product \\
\hline GNI & Gross National Income \\
\hline GR & Gemeenschappelijke Regeling (joint arrangement) \\
\hline GS & Gedeputeerde Staten (Provincial Executive) \\
\hline
\end{tabular}


GOV Government

KR Key Requirement

MA Managing Authority

MC Monitoring Committee

MCS Management and Control System

MEP Member of European Parliament

MFF Multiannual Financial Framework

NERPE (Wet) Naleving Europese Regelgeving Publieke Entiteiten (referring to NERPE law, which stands for (Law for) compliance of European Regulations by public authorities)

NL The Netherlands

NSRF National Strategic Reference Framework

OP Operational Programme

PMO Programma Managers Overleg (Meeting of Program Managers)

PS Provinciale Staten (Provincial Council)

REGI Committee on Regional Affairs of the European Parliament

RIS Regional Innovation Strategy

RUG Rijksuniversiteit Groningen

RVO Rijksdienst voor Ondernemend Nederland

SEA Single European Act

SF Structural Funds

SNN Samenwerkingsverband Noord-Nederland

SZW Sociale Zaken en Werkgelegenheid (Social Affairs and Employment)

TK Tweede Kamer (the Dutch House of Representatives) 


\section{ACKNOWLEDGEMENTS}

Writing this section of my thesis is the last part before finishing it, I have been looking forward to this moment. I feel delighted having finished my thesis after all those years. And of course, there are a lot of people who contributed to this, and they deserve my gratitude and many thanks.

First of all, Nico Groenendijk. This thesis would not have been there without you. It all started with a letter you wrote me, I guess it was 2006. At that time, you were just appointed as professor and approached some of your graduate students to question them on their interest in starting a PhD research, next to their daily job. In 2008 , after our oldest daughter Noor was born, I decided to start this research, although I did not have a specific idea what to work on. After many talks, discussions, and hours the topic of this thesis came across and I think it captured you as much as it captured me. Thank you for your supervision and coaching during this delightful (and at times challenging) journey. I'm very grateful for your support, time, help and valuable thoughts and ideas, I hope we can stay in contact and see whether we can work together in the future as well.

Then I also owe my gratitude to the employers I had during these years. I started with this research during my time at PNO Consultants. Also my subsequent employers Rijksuniversiteit Groningen and Stichting Icare gave me the opportunity to spend some working hours on my research, which I'm grateful for. SNN, my current employer, has been most supportive, giving me the opportunity to also spend working days at the UT, allowing me to finish this research in 2015. Especially during the last few years I received a lot of support from SNN.

At the time of writing, the major issue with ERDF in the Netherlands is the enormous pressure of controls within the system. This research touches sideways upon this pressure, making it relevant to the work we do at SNN. For both beneficiaries of ERDF in the Netherlands and to my colleagues at SNN and other MA's, this thesis gives insight in what really lies beneath this problem. I had fruitful discussions with my colleagues, addressing our experiences of the previous years and formulating what my research contributes to addressing this issue of the pressure of controls. Thank you, Rob, Eise, Roelof and Henk for making it possible for me to finish my research in a short period of time. All my other colleagues at SNN and other MA's: thank you for your interest in the topic and the discussions we had!

And this research would have been nowhere without the respondents, mentioned in Annex III, willingly to be interviewed. Thank you for your cooperation! 
Of course my friends and family also have been very supportive and made it possible for me to reach the finalization of my thesis. Although I guess you did not experience that much 'problems' of my research, during the last year I did make some choices to be at home more often to write. Dirk-Jan and Yvonne, Marleen and Lambertus, Jikke and René, Beate and Jeroen, thank you for your patience with me! And a special thanks also to my assistant (paranimf) Anneke (and of course to Dick). I'm very grateful you would like to support me during the public defence ceremony ('verdediging') of this research.

My family has been invaluable to me throughout these years. For just being there, being interested in my work and also to take care of Noor and Bente when we needed support. Thank you Martin and Irene, Jorick and Dorina and of course special thanks to Jeannette and Gerrit for always standing beside us.

Special words also to my parents, Marti and Madeleine. I know you're very proud of me, I still remember mum, how you managed to get a small article in the Leeuwarder Courant when I graduated. I'm glad you are here to share this moment with me. Thank you for your support throughout the years, for just being there for me (and for Onno and the kids). I love you!

And then some final words for the people most dear to me: my own family. Noor and Bente, you've grown up with me doing my research ('mama moet studeren'), I hope I have not bothered you too much with this strange 'hobby'. It brought me to lovely places, but l'd rather go there with you. I love you!

Onno, you are the best that has ever happened to me. You've made it possible for me to finish this research and end up here: to take time to work in the attic, to travel to conferences, to give me serenity when I couldn't find it myself. You have never complained about all those issues that come across with finishing a PhD. I'm very thankful for you support, and I'm proud you are my paranimf. You were always there when I needed some time to work on my thesis. Now it is finally finished, I'll be there again for you.

'Voor mij ben jij de liefde

Voor mij ben jij het beste wat er is

En iets meer dan ik zou willen

Je bent alles voor mij.'

(Guus Meeuwis - Jij bent de liefde)

Thank you, I love you. 




\section{1}

\section{Introduction: Cohesion Policy, multilevel governance and agency theory}

\subsection{Why this research?}

This research is about Cohesion Policy, with its goals of both stimulating financial solidarity and economic integration, and organizing cohesion between the member states of the European Union (EU), or 'to promote overall harmonious development." For a long time, Cohesion Policy has encountered serious accountability problems. A first problem, which has also gained a lot of attention in the academic literature, is the alleged lack of effectiveness of the policy concerned. ${ }^{2}$ The question has been asked - and more or less answered - whether Cohesion Policy really achieves what it promises: does it really alleviate the economic disparities in the EU? Interestingly, the views from various academics on this deeply-researched topic indicate that there is no clear indication of the effects: there are studies that show a positive effect, but also studies that show the opposite. ${ }^{3}$

1 See preamble and art. 174 of the Treaty on the EU.

2 See for instance contributions in the last decade from Ederveen, S., H.L.F. de Groot and R. Nahuis 2006. 'Fertile soil for Structural Funds? A Panel data Analysis of the Conditional Effectiveness of European Cohesion Policy', KYKLOS, 59, 17-42, Beugelsdijk, M. and S.C.W. Eijffinger 2005. 'The Effectiveness of the Structural Policy in the European Union: an Emperical Analysis for the EU-15 in 1995-2001', Journal of Common Market Studies, 43, 37-51. Bachtler, J., I. Begg, L. Polverari and D. Charles 2013. 'Evaluation of the Main Achievements of Cohesion Policy Programmes and Projects over the Longer Term in 15 Selected Regions (from 1989-1993 Programme Period to the Present)'. Glasgow and London: European Policies Research Centre, University of Strathclyde and London School of Economics, and Becker, S., P. Egger and M. Ehrlich 2010. 'Going NUTS: the effect of EU Structural Funds on regional performance ', Journal of Public Economics, 94, 578-590.

3 See for instance Molle, W. 2007. European Cohesion Policy. Routledge. The research by Polverari, L., J. Bachtler, S. Davies, S. Kah, C. Mendez, R. Michie and H. Vironen 2014. 'Balance of Competences 
A second problem which is present in the field of Cohesion Policy concerns financial management. Over the last two decades, and since its introduction in 1995, the European Court of Auditors (ECA) never has issued a positive DAS (Déclaration d'Assurance, or Statement of Assurance). This DAS is the formal document in which the ECA publishes its opinion on the reliability of all revenue and expenditure of the EU accounts. The ECA uses a level of materiality of $2 \%,{ }^{4}$ but Cohesion Policy has not been below that threshold since the rates were published. Compared to other policy areas, the error rate of Cohesion Policy is very high and persistently has been above the materiality threshold, and even above the $5 \%$ threshold. ${ }^{5}$

Third, regarding management information, the focus within Cohesion Policy is primarily on financial management, i.e. on the compliance with the procedural and financial obligations that are set. The current monitoring arrangements focus particularly on the absorption of resources, rather than on strategic management, ${ }^{6}$ causing other issues related to performance not receiving the attention they should.

Moreover, in the Netherlands, a history of problems with Structural Funds (SF) exists. In 2001, problems came up in the Netherlands with the allocation of funds from the European Social Fund (ESF), connected to the former public service Arbeidsvoorzieningen. ${ }^{7}$ These problems have created cautiousness within the Netherlands to start using ESF, which also had its effect on the other funds, such as the European Regional Development Fund (ERDF). The experience with ESF has led to the perception that the SF are in fact about a good administration with above all receipts and supporting documents and to a lesser extent on what these Structural Funds (SF) really achieve in the form of visible results.

My own experience also contributes to these perceptions. During my first encounter with SF, I was rather confused by the complexities and overwhelmed by all the obligations set for receiving funds and the complexity of all those obligations. Whereas the public authorities in the Netherlands have introduced the 'Single information single

Cohesion Review: Literature Review on Cohesion Policy', a literature overview of different contributions on the issue of effectiveness of the policy, shows there is a slightly positive effect.

4 See European Court of Auditors 'The European Court of Auditors. The DAS Methodology'. p. 11.

5 See for most recent data annex 5.1 on p. 170 of European Court of Auditors 2014. 'Annual report on the implementation of the budget'. Luxembourg: European Court of Auditors.

6 See for instance Mairate, A. 2006. 'The 'Added-Value' of European Union Cohesion Policy', Regional Studies, 40.2, 167-177, and Mendez, C. and J. Bachtler 2011. 'Administrative reform and unintended consequences: an assessment of the EU cohesion policy 'audit explosion", Journal of European Public Policy, 18, 746-765.

7 See for instance Feenstra, P. 2001. 'ESF subsidies moesten wel mis gaan', Trouw. and 2001. 'RapportKoning over ESF overtuigt Brussel niet', NRC. 
audit' (SISA) principle, which was set up to prevent too much checks and controls for beneficiaries receiving funds, it seems that the European rules are becoming more strict, surely not more flexible and easy to work with. The practice at European level seems to be at odds with developments following the SISA principle, with harsh and even stricter regulations, which could prevent beneficiaries from using European funds. And why do authorities not seem to use the checks and audits that already have been carried out, why are they duplicating controls, sometimes leading to findings that have not even been found in earlier controls? Why do we see some sort of 'roofing-tile construction,' ${ }^{, 8}$ where authorities let their responsibility flow into the responsibility of another authority, basing their work on the possible findings of other authorities?

With these accountability problems in mind and building on the perceptions of the implementation of SF in the Netherlands, this research started with the idea of finding out where these problems with Cohesion Policy originate from and whether the situation in the Netherlands is specific, or if these problems are common in other member states as well. This issue is forming the basis of this research and leads to the research question, as is elaborated in section 1.4.

The issue of accountability on European level in general is known from academic literature, but it has been taken up by European institutions as well. In 2014 the ECA has issued for the first time a 'landscape review' on EU accountability and public audit arrangements. ${ }^{9}$ In this report, the ECA gives 'pointers to issues which need to be addressed by European policymakers, legislators and the audit community. ${ }^{10}$ This shows that accountability is an important topic and is also recognized on European level as important element of public policy making.

This chapter first introduces EU Cohesion Policy (section 1.2) and subsequently outlines the main theoretical perspectives to be used in this research: accountability, agency theory and multilevel governance (section 1.3). The empirical focus and research questions are discussed in section 1.4, followed by an outline of the thesis (section 1.5).

8 Translated from the Dutch word 'dakpanconstructie.'

9 European Court of Auditors 2014. 'Gaps, overlaps and challenges: a landscape review of EU accountability and public audit arrangements'. Luxembourg: European Court of Auditors. 


\subsection{What is Cohesion Policy? - An introduction}

\subsubsection{The rationale for Cohesion Policy}

This research deals with Cohesion Policy (or: 'Regional Policy') and its Structural Funds (SF), ${ }^{11}$ which form a large part of the budget of the EU. With a total budget of $€ 347$ billion for the 2007-2013 period approximately 35\% of the total budget of the EU is used for Cohesion Policy. ${ }^{12}$ This makes the SF even larger than the market related expenditure and direct aids, such as the spending on agriculture and rural development.

With the coming-into-being of the Single European Act (SEA) in 1988, the concept of 'Cohesion Policy' was introduced, which is also directed 'to work towards the balanced and sustainable development of Europe's regions'. ${ }^{13}$ Since then, both the wordings 'Cohesion Policy' and 'Regional Policy' are used, which effectively come down to the same: the policy of the EU which aims at a sustainable development in all Europe's regions. In this research, we primarily use the term Cohesion Policy.

The SF are in fact the instruments of Cohesion Policy of the EU. The ultimate goal of this policy, originating from the early years of European integration, is to reduce the gaps between the member states, support the least favored regions ${ }^{14}$ and to stimulate economic growth throughout the complete EU. More recently this goal has been translated by Barca in the following way: 'all regions must be given the opportunity to achieve their full potential (efficiency), and all citizens must be given the opportunity to live a life worth living independently of where they are born (equity).'15

As has been argued by different researchers, ${ }^{16}$ there are various rationales for Cohesion Policy. According to Tondl, the main argument is that unequal development endangers the project of European integration. More specific there are two

11 Cohesion Policy consists of different Structural Funds and the Cohesion Fund. The names are often used interchangeably. We use the term Cohesion Policy for the complete policy area and the term Structural Funds for all the funds concerned, including the Cohesion Fund.

12 European Commission (2014, 2014-09-12). "EU Cohesion Policy - key statistics." Retrieved 09-122014, from http://ec.europa.eu/regional_policy/thefunds/funding/index_en.cfm.

13 Foreword of Dirk Ahner, Director-General for Regional Policy in: European Commission (2008). EU Cohesion Policy 1988-2008: Investing in Europe's future. Inforegio - Panorama, European Commission, DG Regio: 1-44.

14 See art. 174 of the Treaty on the EU.

15 Barca, F. 2009. 'An agenda for a reformed cohesion policy - a place-based approach to meeting European Union challenges and expectations', p.3.

16 For instance by Tondl, G. (2007). Regional Policy. The Economics of the European Union. M. Artis and F. Nixson, Oxford University Press: 171-199, and Martin, R. (1999). Regional Policy. European Economic Integration. New York, Addison Wesley Longman limited: 209-237. 
main arguments for Cohesion Policy to be targeted on the European level, possible externalities and reduction of disparities between member states.

\section{Externalities}

The EU is a complex set of interests and policies, in which all policies interact with each other, within a context of highly integrated domestic economies. This means that a problem in a specific country could easily harm other countries; solving a problem in one specific member state can benefit other countries as well. These externalities are important incentives for the EU to act.

The division between rich and poor countries also means that poor member states have insufficient or at least less resources to overcome their regional problems themselves. With the accession of member states such as Romania and Bulgaria, the differences between the members of the EU have even more increased. Taking into account the fact that financial support in one specific country also has its effects on other EU countries, this means that Cohesion Policy has a larger effect than only distributing the funds.

\section{Disparities}

It is clear that the countries of the EU benefit on a different level from integration. The Netherlands for instance, as a relatively open economy, benefits more from the internal market than for instance France, which is a less open economy. According to the new trade economy, these differences are not overcome by the economic system itself, but this requires central redistribution of some sort. Cohesion Policy of the EU takes care of this redistribution.

Also a political factor played a role in the creation of - at that time - Regional Policy. The benefits of different EU policies are not spread evenly across all EU countries. The Single European Market for instance, created in 1992, especially benefits the already richest countries in the EU. With the SEA, signed in Luxemburg in 1986, the Regional Policy conducted since 1975 was given a new legal basis under the newly inserted section $V$ 'economic and social cohesion.' ${ }^{17}$ Since the signing of the SEA, the term 'Cohesion Policy' came into use, ${ }^{18}$ but is still used additional to the term Regional Policy.

It is to be suspected that the creation of Cohesion Policy was constituted to compensate the less developed member states or regions for the operationalization of the Single European Market and the European Monetary Union. ${ }^{19}$ Regional Policy

17 Van der Giessen, M. 2014. Coping with complexity. Cross-border cooperation between The Netherlands and Germany. p. 84, art. 130a-130e.

18 Ibid.p. 85.

19 Ibid.p. 84 and 85. 
would alleviate adjustment problems and improve the competitiveness of these countries through public investment. ${ }^{20}$ Since 2007, Regional or Cohesion Policy is also expected to contribute to the Lisbon agenda ${ }^{21}$ and for the 2014-2020 period also to the Europe2020 strategy for smart, sustainable and inclusive growth. ${ }^{22}$

Whether the policy really delivers what it is aimed at, reducing disparities and promoting growth in the EU, is difficult to measure and has led to a broad academic debate on the effects of the policy. ${ }^{23}$ This is because the main question of this kind of research is always whether changes in regional disparities and growth can be (directly) attributed to the influence of Cohesion Policy, since a lot of other factors (for instance wider economic policy changes and domestic regional policies) also contribute to these changes. ${ }^{24}$ Literature research by Polverari and Bachtler ${ }^{25}$ has shown that based on four methodological research methods ${ }^{26}$ a (slight) positive impact of Structural Funds can be seen on national and regional economic development. However, this impact is not clear-cut, some studies using regression analysis show no statistically significant evidence, while the degree of the effect in other studies varies.

\subsubsection{Cohesion Policy 2007-2013: facts and figures}

This research focuses primarily on the 2007-2013 period, but we also address the 2014-2020 period, when relevant. When focusing on the SF period 2007-2013, it is important to make a distinction between the objectives on the one hand and the funds (SF) itself on the other hand. The objectives are the goals of the policy that the $\mathrm{EU}$ is aiming at and they form the framework in which all the funds fit.

20 Tondl, G. (2007). Regional Policy. The Economics of the European Union. M. Artis and F. Nixson, Oxford University Press: 176.

21 Consideration 2 of Regulation 1083/2006.

22 Consideration 30 of Regulation 1303/2013.

23 See for instance Molle, W. 2007. European Cohesion Policy. Routledge. and Polverari, L., J. Bachtler, S. Davies, S. Kah, C. Mendez, R. Michie and H. Vironen 2014. 'Balance of Competences Cohesion Review: Literature Review on Cohesion Policy' for an overview of different contributions on the effectiveness of Cohesion Policy.

24 Polverari, L., J. Bachtler, S. Davies, S. Kah, C. Mendez, R. Michie and H. Vironen 2014. 'Balance of Competences Cohesion Review: Literature Review on Cohesion Policy'. p. 13.

25 lbid. p. 13-48.

26 The methods used are macroeconomic modeling, regression analysis, micro-economic studies using control groups and qualitative case studies. 


\section{Objectives}

In the 2007-2013 period Cohesion Policy focused on three objectives: convergence, competitiveness and cooperation. ${ }^{27}$ These three objectives are linked to the Lisbon agenda, which aims at providing growth and jobs by:

- making countries and regions more attractive for investments by improving accessibility, providing quality services and preserving environmental potential; and

- encouraging innovation, entrepreneurship and the knowledge economy through the development of information and communications technologies.

The biggest part of the funds in Cohesion Policy were allocated for the convergence objective ( $81 \%)$, followed by the objective of stimulating regional competitiveness and employment (16\%). The objective of territorial cooperation was the smallest, with less than $3 \%$ of the total budget of the funds.

Following these objectives of Cohesion Policy, three funds have been created to realize these objectives. These are the European Regional Development Fund (ERDF), the European Social Fund (ESF) and the Cohesion Fund (CF). These funds contribute to the objectives in the following way (Figure 1) $:^{28}$

\section{Objectives, Structural Funds and instruments}

2007-2013

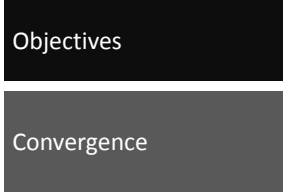

Structural Funds and instruments

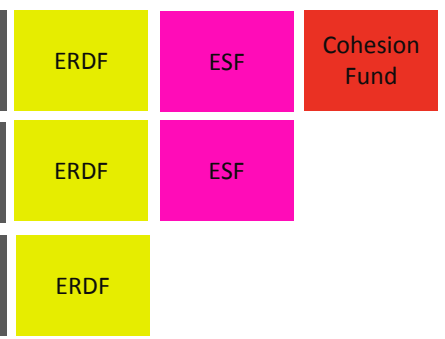

Figure 1. Connection between the objectives of the Regional Policy and the SF

27 European Commission 2014. 'EU cohesion funding - key statistics'. Retrieved at 23-11-2014 from http://ec.europa.eu/regional_policy/thefunds/funding/index_en.cfm

28 European Commission, "Regional Policy - Inforegio. Key objectives." Retrieved at 29-12-2009, from http://ec.europa.eu/regional_policy/policy/object/index_en.htm. 
- Convergence

The aim of the convergence objective was to 'to promote growth-enhancing conditions and factors leading to real convergence for the least-developed member states and regions'. ${ }^{29}$ These activities focused mainly on the 84 regions in Europe (in 17 member states) with a GDP less than 75\% of the Community average and a phasing-out in another 16 regions with a GDP slightly above the threshold;

- Regional competitiveness and employment

Outside these convergence areas, the objective of Regional competitiveness and employment aimed at strengthening competitiveness, attractiveness and employment by two approaches; first by strengthening regions in innovation and the promotion of the knowledge society, entrepreneurship, the protection of the environment, and the improvement of their accessibility. Secondly, jobs were supported by adapting the workforce and investing in human resource;

- European Territorial Cooperation

The European Territorial Cooperation aimed at strengthening cross-border operation by supporting local and regional initiatives.

The Cohesion Fund only applied to the member states that were below the threshold of $90 \%$ of the average gross national income (GNI) in the EU. Both the ERDF and ESF in the Convergence objective applied to regions in all countries in the EU with a gross domestic product (GDP) below $75 \%$ of the average in the EU.

\section{Funds}

As just mentioned, Cohesion Policy in the 2007-2013 period consisted of three funds. The goals and measures that were targeted with the funds are mentioned in Table 1.

What follows from these characteristics is that ERDF is targeted especially on economic and social cohesion, whereas ESF is aimed at improving employment and job opportunities. The Cohesion Fund is specifically directed at the least developed member states in the EU. 
Table 1. Overview of goals and measures of the funds in Cohesion Policy for the 2007-2013 period.

\begin{tabular}{|c|c|c|c|}
\hline & \multicolumn{3}{|c|}{ FUND } \\
\hline & ERDF & ESF & Cohesion Fund \\
\hline GOAL & $\begin{array}{l}\text { strengthen economic } \\
\text { and social cohesion in } \\
\text { the European Union by } \\
\text { correcting imbalances } \\
\text { between its regions }\end{array}$ & $\begin{array}{l}\text { sets out to improve } \\
\text { employment and job } \\
\text { opportunities in the } \\
\text { European Union }\end{array}$ & $\begin{array}{l}\text { support member states with } \\
\text { an Gross National Income per } \\
\text { inhabitant below } 90 \% \text { of the } \\
\text { Community average }\end{array}$ \\
\hline \multirow{4}{*}{ MEASURES } & $\begin{array}{l}\text { direct aid to investments } \\
\text { in companies (in } \\
\text { particular SMEs) to } \\
\text { create sustainable jobs; } \\
\text { infrastructures linked } \\
\text { notably to research and } \\
\text { innovation }\end{array}$ & $\begin{array}{l}\text { adapting workers and } \\
\text { enterprises: lifelong } \\
\text { learning schemes, } \\
\text { designing and spreading } \\
\text { innovative working } \\
\text { organisations }\end{array}$ & $\begin{array}{l}\text { trans-European transport } \\
\text { networks, notably priority } \\
\text { projects of European interest } \\
\text { as identified by the Union }\end{array}$ \\
\hline & $\begin{array}{l}\text { telecommunications, } \\
\text { environment, energy and } \\
\text { transport }\end{array}$ & $\begin{array}{l}\text { access to employment } \\
\text { for job seekers, the } \\
\text { unemployed, women and } \\
\text { migrants }\end{array}$ & $\begin{array}{l}\text { environment; Cohesion Fund } \\
\text { can also support projects } \\
\text { related to energy or transport, } \\
\text { as long as they clearly present } \\
\text { a benefit to the environment }\end{array}$ \\
\hline & $\begin{array}{l}\text { financial instruments } \\
\text { (capital risk funds, local } \\
\text { development funds, etc.) to } \\
\text { support regional and local } \\
\text { development and to foster } \\
\text { cooperation between towns } \\
\text { and regions }\end{array}$ & $\begin{array}{l}\text { social integration of } \\
\text { disadvantaged people and } \\
\text { combating discrimination } \\
\text { in the job market }\end{array}$ & \\
\hline & $\begin{array}{l}\text { technical assistance } \\
\text { measures }\end{array}$ & $\begin{array}{l}\text { strengthening human } \\
\text { capital by reforming } \\
\text { education systems and } \\
\text { setting up a network of } \\
\text { teaching establishments }\end{array}$ & \\
\hline SOURCE & Regulation $1080 / 2006$ & Regulation $1081 / 2006$ & Regulation $1084 / 2006$ \\
\hline
\end{tabular}

\section{Framework}

With regard to the SF, special arrangements have been made between the EC and the member states.

On European level, priorities for Cohesion Policy were established in the Community Strategic Guidelines (CSG). These guidelines set the framework for all national and regional programs that were drafted by the member states. A specific decision has been adopted by the Council on Community strategic guidelines on cohesion. ${ }^{30}$ The decision states:

30 Council of the European Union 2006. 'Decision of 6 October 2006 on Community Strategic Guidelines on Cohesion'. 
'In accordance with the integrated guidelines for growth and jobs of the renewed Lisbon agenda, the programmes supported by cohesion policy should seek to target resources on the following three priorities: ${ }^{31}$

- improving the attractiveness of member states, regions and cities by improving accessibility, ensuring adequate quality and level of services, and preserving the environment,

- encouraging innovation, entrepreneurship and the growth of the knowledge economy by research and innovation capacities, including new information and communication technologies, and

- creating more and better jobs by attracting more people into employment or entrepreneurial activity, improving adaptability of workers and enterprises and increasing investment in human capital.'

Therefore, the emphasis of the Cohesion policy of the EU was on the attractiveness of member states, innovation and the labor market.

Each member state then had its own National Strategic Reference Framework (NSRF) which described the specific priorities of the member state for the years 2007-2013. The EC had to approve these plans, to make sure that these fit into the framework (CSG) of the EC. ${ }^{32}$

After these national plans had been approved, the regions within the member states got the opportunity to draft their own Operational Programs (OP). The regions in the EU elaborated the specific priorities of the regions in delivering the funds. The priorities that were set in the OPs needed to fit in the framework set by the member states. As for the NSRFs, the OPs also had to be adopted by the EC.

The process of the adoption of both the NSRF and OPs on the national and regional level were often long and led to a politically heavy burdened debate between respectively the EC and the member states and for the OPs between the regions, the member states and the EC.

31 Communication to the Spring European Council 'Working Together for growth and jobs - a new start for the Lisbon Strategy' COM(2005) 24, 2-2-2005.

32 A summary of the NSRF's of all member states has been given by the EC: European Commission 2008. 'Cohesion Policy 2007-2013. National Strategic Reference Frameworks'. Brussels: European Commission. It can also be found at http://ec.europa.eu/regional_policy/atlas2007/fiche/nsrf.pdf, retrieved at 23-11-2014. 


\section{Financial figures}

Financially, the Structural Funds ERDF, ESF and CF have formed an ever increasing part of the Community's total budget. From circa 20\% in the period 1989-1993 (14 billion ECU), it has grown to circa $35 \%$ of the total budget in the period 2007-2013 (about 347 billion Euro).

As can be seen in Figure 2, Poland is the country receiving by far the biggest part from the SF in the period 2007-2013 with more than 27\% of the total budget. The six countries Poland, Spain, Italy, the Czech Republic, Germany and Hungary together receive more than $85 \%$ of the total SF budget. The Netherlands is receiv-

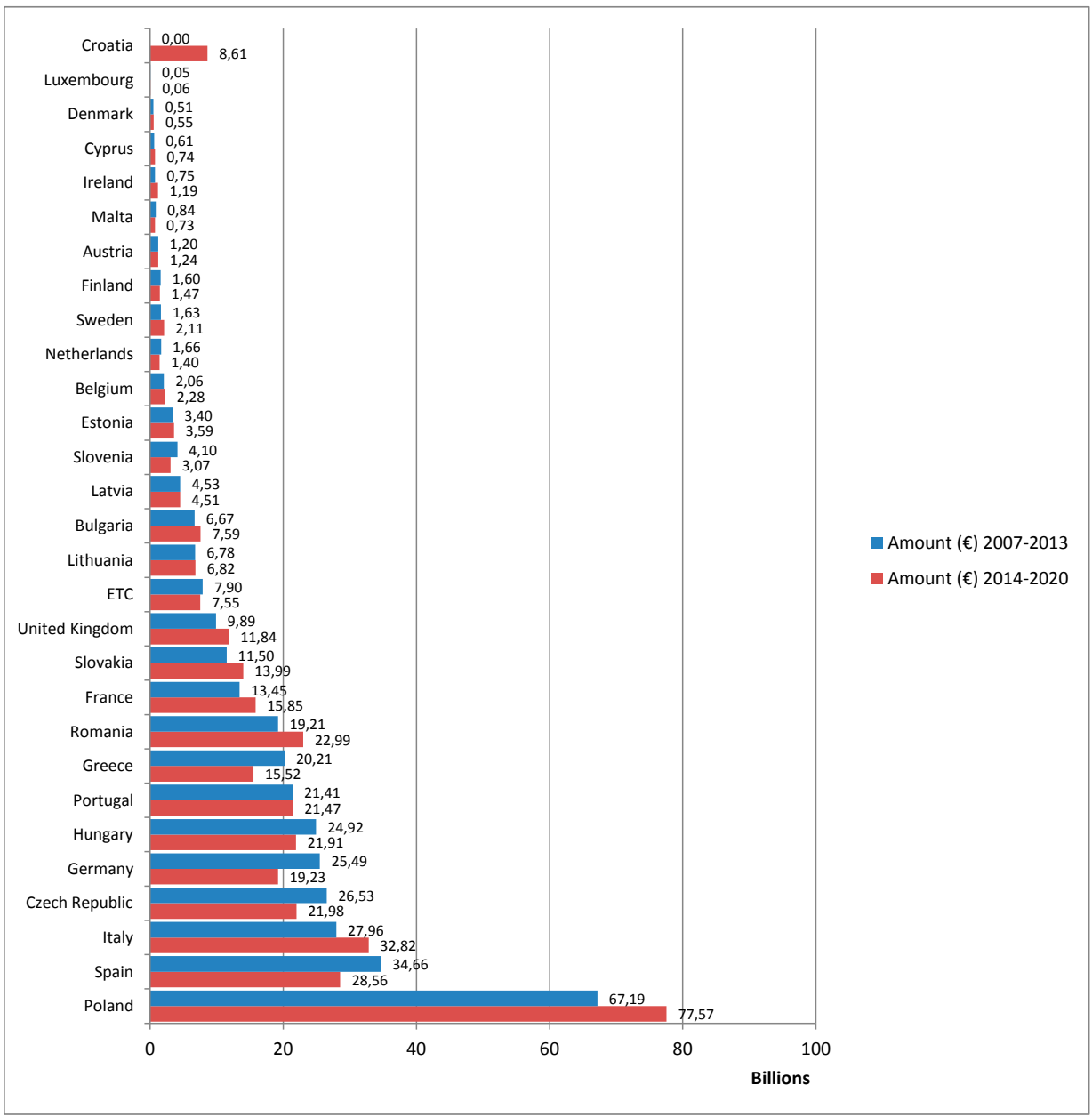

Figure 2. Overview of financial allocations per member state in the 2007-2013 and 2014-2020 period, in million Euros

Information retrieved from http://ec.europa.eu/regional_policy/thefunds/funding/index_en.cfm at 12-9-2014 and http://ec.europa.eu/regional_policy/en/funding/available-budget/ retrieved at 28-10-2015. 
ing $€ 1,66$ billion $(0,48 \%$ of the total SF budget). Next to the budget per member state, this table also shows the budget for the Interregional projects (ETC).

\subsubsection{Cohesion Policy 2014-2020}

The EC has introduced some changes in the 2014-2020 period. What has not changed is the focus on 'reducling] disparities between the levels of development of the EUs various regions by promoting economic growth, job creation and competitiveness. ${ }^{33}$ The policy is targeted at regions, cities and the real economy and is to be the 'EUs principle investment tool for delivering the Europe 2020 goals: creating growth and jobs, tackling climate change and energy dependence, and reducing poverty and social exclusion. ${ }^{34}$

The main changes compared to the 2007-2013 programme are summarized as follows. $^{35}$

First, as can be seen from the main regulation, the $\mathrm{CPR},{ }^{36}$ it has been set up to incorporate the five European structural and investment funds ERDF, ESF, CF, EAFRD and EMFF. As stated by the Council conclusions on the adoption of the new framework: 'The common strategic framework also represents the single European reference frame for better coordination between the European structural and investment funds and other EU instruments. ${ }^{37}$

A second change is the use of partnership agreements between the EC and the member states as a basis for the setting up of OPs. These partnership agreements in fact take the place of the NSRFs in the 2007-2013 period.

Also, minimum thresholds are set for certain thematic objectives (for instance low-carbon economy, in developed regions there is a minimum of $20 \%$ to be used for this objective) and funds (a minimum of $23,1 \%$ of the SF is to be allocated for ESF). This leads to a focus on themes that are important to the Europe 2020 goals of the EU.

A fourth major change is the obligated use of a performance reserve of $6 \%$, which should lead to a stronger result orientation. ${ }^{38}$

33 See European Council 2014. 'Council adopts cohesion policy package for 2014-2020', in European Council (ed). Brussels.

34 See the website of the EC, http://ec.europa.eu/regional_policy/archive/what/future/index_en.cfm, retrieved at 28-10-2015.

35 To be found at European Council 2014. 'Council adopts cohesion policy package for 2014-2020', in European Council (ed). Brussels.

36 Regulation 1303/2013.

37 See European Council 2014. 'Council adopts cohesion policy package for 2014-2020', in European Council (ed). Brussels.

38 See section 4.5.3 The European Commission and the Managing Authority. 
Fifth, the EC introduced ex-ante conditionalities, a framework of conditionalities that is set to ensure that necessary preconditions are met before an OP is accepted by the EC and a programme can start. This is an important tool in the hands of the EC to ensure a basic level of conditions to be met is set, 'to ensure that investments can be made in the most effective manner and that the selected thematic objectives and investment priorities are properly implemented. ${ }^{39}$

Finally, an instrument that has been brought into Cohesion Policy is the use of macro-economic conditionalities. This connects Cohesion Policy and the budget available from SF to the European semester and EU governance, which in fact means that when a member states is having problems with its macro-economic policies, according to the EU institutions, it may lead to the interruption or cancellation of payments from the SF. This means that regions can be 'punished' by not receiving SF money when on member state level a member state does not perform as it should be, according to the EU institutions.

\section{Financial figures}

When looking at the funds available, in the 2014-2020 period the total amount for Cohesion Policy has grown to $€ 351,8$ billion. After Poland, with a budget of $€ 77,57$, the member states receiving the highest share of the Cohesion Policy budget are Italy (€32,82 billion), Spain ( $€ 28,56$ billion), Romania (€22,99 billion), Czech Republic $(€ 21,98)$ and Hungary $(€ 21,91)$. The Netherlands is receiving $€ 1,4$ billion. Table 1 also gives an overview of the amounts available for the member states in the 2014-2020 period.

After this brief introduction of Cohesion Policy, we now turn to the academic literature that deals with Cohesion Policy. First we discuss the literature on multilevel governance, which is inherently connected to Cohesion Policy. Subsequently, we will have a look at agency theory, which lies at the basis of the analytical framework of this research.

\subsection{Theoretical angle}

In this research, the problems of accountability within Cohesion Policy, characterized by multilevel governance, are elaborated. Therefore, the research uses the concept of accountability as described by Bovens, ${ }^{40}$ focusing on 'Who, to whom, on what and why does the actor feels compelled to render account?' Next to using

39 See European Council 2014. 'Council adopts cohesion policy package for 2014-2020', in European Council (ed). Brussels.

40 Bovens, M. 2007. 'Analysing and Assessing Accountability: a Conceptual Framework', European Law Journal, 13, 447-468. 
this typology of accountability, agency theory is used to describe the relationship between the various actors in the system. This combination of both the description of accountability and agency theory shows how accountability in Cohesion Policy can be characterized and what constitutes 'good accountability'. Before we will be able to elaborate this as we will do in chapter 2, we will first shortly describe what accountability stands for, how it is used in public governance and how it relates to agency theory (1.3.1), what multilevel governance is (1.3.2) and how multilevel governance can be understood in Cohesion Policy (1.3.3).

\subsubsection{Accountability and agency theory}

As a concept, accountability has a long tradition in political science and financial accountability, but it has relatively recently been picked up in public administration, ${ }^{41}$ focusing on processes of general scrutiny and rectification. ${ }^{42}$ In public administration it is used 'in the sense that there is intuitive agreement that public institutions or authorities should render account for the use of their mandates and for the manner in which they use public resources. ${ }^{43}$ It is seen to promote transparency and trustworthiness, ${ }^{44}$ being essential elements of public governance.

Accountability can be seen as 'a general term for any mechanism that makes powerful institutions responsive to their particular publics. ${ }^{45}$ In daily life, we rely on others to do things we cannot do ourselves. 'Once we have entrusted other people or institutions to act on our behalf, what guarantee have we that they will pursue our interests rather than their own?'46 'How can those who delegate (or 'principals') check the actions of those whom they delegate (their 'agents')? ${ }^{47}$ And what options does a principal have to ensure the agent acts as he is supposed to do? Thus, as described by Mulgan, 'the full core sense of accountability [...] includes the right of the account-holder to investigate and scrutinize the actions of the agent by seeking information and explanations and the right to impose remedies and sanctions. ${ }^{48}$

41 Lindberg, S.I. 2013. 'Mapping accountability: core concept and subtypes', International Review of Administrative Sciences, 79, 202-226. p. 203. See also Mulgan, R. 2003. Holding Power to Account. Palgrave MacMillan. p. 6.

42 Mulgan, R. 2003. Holding Power to Account. Palgrave MacMillan. p. 6.

43 Curtin, D., P. Mair and Y. Papadopoulos 2010. 'Positioning Accountability in European Governance: An introduction', West European Politics, 33, 929-945. p. 929.

44 lbid. p. 930.

45 Mulgan, R. 2003. Holding Power to Account. Palgrave MacMillan. p. 8.

46 lbid. p. 8.

47 lbid. p. 8

48 lbid. p. 10. 
Accountability is closely related to agency theory. As is explained in chapter 2, agency theory is an economic theory used to describe relationships between actors and explain their behavior vis-à-vis each other. The theory starts with the principal, thriving for a certain result and an agent that is contracted by the principal to achieve the result wished by the principal. The basis of the theory is that both actors have different preferences which lead in the end to a welfare loss for the principal. The main question in this theory is what actions the principal can take to steer the agent in the envisioned direction, but also what measures the agent can take to maintain as much freedom as possible to act according to its own preferences. At the same time, and that is where accountability is introduced as a concept, the agent has to inform the principal on its actions and achieved results. This shows that the concept of accountability is closely connected to agency theory.

Schematically, this leads to the following figure (Figure 3).

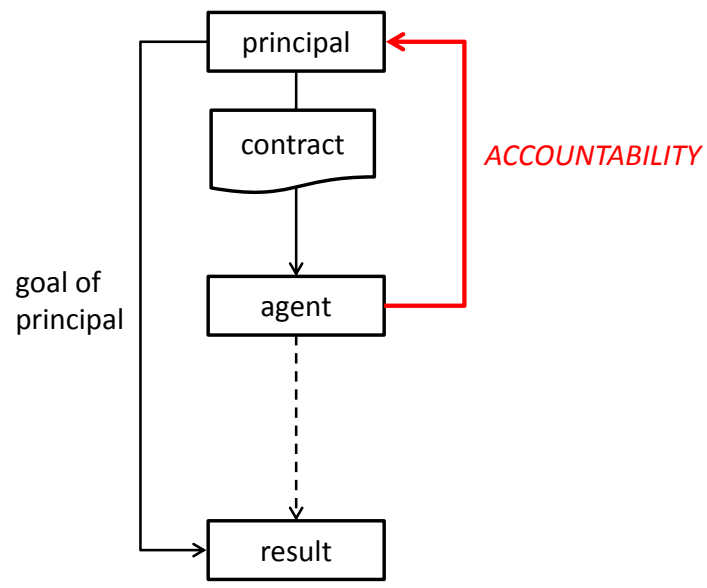

Figure 3. A principal agent relationship and the connection with accountability

Agency theory is based upon a one-dimensional situation with one principal and one agent. It gets more interesting in a situation with multiple actors and multiple relationships. Looking at Cohesion Policy and the multilevel context of this policy area, it is quite interesting to use agency theory as perspective on the different actors on European, national and regional level and the way they behave. More specifically, we are interested in the accountability situation of Cohesion Policy, for which it is essential to look at the principal-agent relationships within the system. As 
can be seen in Figure 3 and is elaborated more thoroughly in chapter 2, an essential element of agency theory is the obligation of the agent to inform the principal on its behavior and the results achieved, thus leading to an accountability situation of the agent vis-à-vis the principal. To be able to look at the situation of accountability, we need the perspective of agency theory. The multilevel character of Cohesion Policy and the characteristics of agency theory make it even more interesting to use this perspective.

\subsubsection{What is multilevel governance?}

Multilevel governance is also an important perspective in this research. Within multilevel governance, decision-making competencies are shared between different actors on all levels. This not only refers to the different levels of government, leading in fact to multilevel government, but also to the active involvement of actors from non-public actors, which leads to multilevel governance. ${ }^{49}$ Also, decision-making means that actors need to accept that there are winners and losers, because consensus needs to be reached and this is only possible with some 'give and take.' Another important characterization of multilevel governance is that the arenas in which the actors operate are intertwined, rather than separated. Also, non-public actors can play a role in the governance of a policy field, which leads to the creation of 'policy networks', 50 in which both public actors from different levels of government and non-public actors are represented.

Traditionally, the literature on EU public governance is largely dominated by different models concerning integration within the EU. The three dominant models (federalism, liberal intergovernmentalism and neofunctionalism), have evolved over time but nowadays all take a specific place within the literature on integration in the EU.

Multilevel governance as such is not a theory of European integration, but it has elements in common with some of these integration theories, mostly with the theory of neofunctionalism. As opposed to the intergovernmentalist view, which sees separate domestic and international arenas, neofunctionalism sees links between arenas and actors, both in and across the domestic and international arenas. This means there can be a connection or link between a subnational actor and the European Commission (EC), whereas the state-centric model of intergovernmentalism places

49 Papadopoulos, Y. 2010. 'Accountability and Multilevel Governance: More Accountability, Less Democracy?', West European Politics, 33, 1030-1049.p. 1031.

50 See Börzel, T.A. 1998. 'Organizing Babylon - On the different conceptions of Policy Networks', Public Administration, 76, 253-273. for more information on policy networks. 
the state/central government as a dominant actor in both arenas. ${ }^{51}$ It is however important to note that the multilevel governance perspective does not do away with the role of states; as such it does not challenge the sovereignty of states. ${ }^{52}$ Instead of focusing entirely on the role of the nation states, as the intergovernmentalists do, multilevel governance notes that other actors also have an important role in the policy-making process within the EU. As Hooghe puts it: 'Multilevel governance does not confront the sovereignty of states directly. Instead of being explicitly challenged, states in the European Union are being melded into a multi-level polity by their leaders and the actions of numerous subnational and supranational actors. ${ }^{53}$

\subsubsection{Why multilevel governance in Cohesion Policy?}

There are a few characteristics of Cohesion Policy which make this policy area different, compared to the other policy areas in the EU, and specifically suitable to use a multilevel governance perspective.

To start with, Cohesion Policy is connected to and touches a lot of other policy areas with the possibility to use funds, for instance R\&D, education, environment, transport or agriculture. ${ }^{54}$ It is not so much an isolated policy area, but it is really 'at the heart' of policy making in the EU. It is part of an integrated approach to policy making, ${ }^{55}$ which means that various policies are combined to ultimately reach one goal, that of reducing the gap between the member states. Cohesion thereby becomes a standard concern for all other policies. ${ }^{56}$ In practice this means that in specific policy areas where SF are being used, there will be involvement of civil servants of the EC from both DG REGIO and the policy DG concerned.

An important principle in Cohesion Policy is the partnership principle. This principle prescribes that all authorities concerned, national, supranational and subnational authorities, have their own responsibilities concerning the implementation of the measures and they are obliged to arrange this in close cooperation and consultation. The effect of the introduction of this principle was that the subnational authorities

51 Characterization derived from Hooghe, L. and G. Marks 2001. Multi-level Governance and European integration. Rowman and Littlefield Publishers Inc. p. 4.

52 lbid.p. 27.

53 Ibid.p. 27.

54 Hooghe, L. 1996. 'Reconciling EU-Wide Policy and National Diversity', in L. Hooghe (ed), Cohesion Policy and European Integration: building multilevel governance, pp. 1-24. p. 10.

55 Hooghe, L. 1996. 'Building a Europe with the Regions: The Changing Role of the European Commission', in L. Hooghe (ed), Cohesion Policy and European Integration: Building multilevel governance pp. 89-126. p. 101. 
in the member states were empowered, especially in those member states where the subnational, both local and regional, government was rather weak. ${ }^{57}$ The idea was in fact to reach a 'uniform pattern of subnational involvement,' although this was a rather ambitious goal. ${ }^{58}$ Although the picture within the EU regarding the role of the subnational governments is multiform rather than uniform one can claim that regional authorities have been participating more in EU policy making throughout the years because of the existence of Cohesion Policy. This process is often also outside the control of the national authorities, traditionally the 'gatekeeper' of the involvement of the member states. ${ }^{59}$ The partnership principle therefore has led to the involvement of multiple actors from all levels of government. Research has also shown that a characteristic of Cohesion Policy, derived from the partnership principle, is that where in most policy areas different actors have a coordinating role in a specific stage of the policy cycle, in Cohesion Policy all actors are involved in all stages, although to a variable degree. ${ }^{60}$ This aspect of the multiplicity combined with the other policy areas connected to Cohesion Policy further complicates the implementation of Cohesion Policy and contributes to the number of actors involved, not having one actor solely responsible for the implementation of Cohesion Policy.

Within Cohesion Policy the EC also has a special role. In most policy areas the EC plays a coordinating role, leaving the implementation of the policy to the member states. But in Cohesion Policy, the EC is involved in the implementation, which is explicitly different compared to other policy areas. This is also known as the principle of shared management. Next to Cohesion Policy, this principle also affects Agricultural Policy. It has been laid down in the General Provisions of the Funds ${ }^{61}$ that the management of the SF is a shared responsibility between the EC and the member states. As Ingeborg Grässle, rapporteur in the Committee of Budgetary Control has stated in a Working Document from the European Parliament, ${ }^{62}$ there is a certain tension 'between both Article $274^{63}$ of the Treaty ("The Commission

57 Hooghe, L. 1996. 'Reconciling EU-Wide Policy and National Diversity', in L. Hooghe (ed), Cohesion Policy and European Integration: building multilevel governance, pp. 1-24. p. 5.

58 Hooghe, L. 1996. 'Building a Europe with the Regions: The Changing Role of the European Commission', in L. Hooghe (ed), Cohesion Policy and European Integration: Building multilevel governance pp. 89-126. p. 90.

59 Ibid. p. 121

60 Hooghe, L. and G. Marks 2001. Multi-level Governance and European integration. Rowman and Littlefield Publishers Inc. See p. 102 and 103 for an overview of the stages and the influence of the actors .

61 See art. 14 of Regulation 1083/2006 on the ERDF, ESF and Cohesion Fund.

62 Gräßle, I. 2008. 'Working document on the role and functioning of supervisory and control systems for structural operations': European Parliament, pp. 1-10. p. 2.

63 Currently article 317 of the Treaty on the Functioning of the European Union. 
shall implement the budget, (...) on its own responsibility (...)") and Article 5 (subsidiarity and proportionality)' which leads to a sort of 'Governance-pendulum, swinging between the Member State position (Article 5) and the Commission position (Article 274). The more the pendulum moves towards Article 5 the higher delegation risk for the Commission and the more difficult it becomes for the Commission to implement the budget "on its own responsibility". On the other hand, the more the "Governance-pendulum" moves towards Article 274 the less subsidiarity there is.' This shows that the partnership principle, leading to the involvement of also subnational actors, combined with the principle of shared management, which puts the responsibility of the EC on par with those of the member states, complicates the implementation of Cohesion Policy.

\subsection{Empirical focus and research questions}

Facing the problems of Cohesion Policy, as mentioned in section 1.1, this research focuses on accountability within Cohesion Policy. It focuses on ERDF in the Netherlands, specifically on the regional OPs. Since Cohesion Policy is characterized by a multilevel structure, as mentioned in section 1.3.3, it is important to capture all levels relevant in the implementation, which means that the research should include the European, national and regional level. This also means it is important to focus on one or more specific OPs or member states, to be able to completely describe the implementation of the policy. We have chosen to focus on the Netherlands, because of the perceived complex situation experienced on regional and national level, probably (partly) originating from the problems with Arbeidsvoorzieningen, ${ }^{64}$ around the year 2000. As we will explain in chapter 7, it would be interesting to also apply the framework of this research to other member states in a comparative approach, but given the complexities of the topic, this research focuses on one member state only, the Netherlands, with which we are most familiar. Also, by focusing on one of the (old) EU-12 member states we can judge the system without having to take difficulties with new systems in account, as would possibly be the case in the (new) EU-16 member states. ${ }^{65}$

As we have described in section 1.2, the SF consist of three funds: ERDF, CF, and ESF. The CF is not applicable to the Netherlands. The ESF is implemented in the Netherlands on the national level, which means that the regional level is not involved. In light of our focus on multilevel governance the ERDF is most suited to use in this research, as it encompasses all three levels: European, national and regional level.

64 See section 1.1.

65 See also section 7.3 on the possibilities for further research. 
With regard to the timeframe, this $\mathrm{PhD}$ research has started in 2009. At that time, it was logical to focus on the 2007-2013 period, being in the second half of the implementation period, ${ }^{66}$ with the negotiations for the 2014-2020 period not having decided upon yet. ${ }^{67}$ Although the research thus primarily focuses on the 2007-2013 period, when relevant, we also discuss in each section the developments that are seen in the 2014-2020 period.

This research develops a normative framework on 'good accountability', based on academic literature on accountability, agency theory and multilevel governance. This framework on 'good accountability' consists of four requirements and describes what an ideal situation of accountability would have to look like. This ideal situation refers to a situation where all necessary elements are present, and there is not a situation of 'too much' or 'too less' accountability (based on the ideas of accountability overload and accountability deficit, as is elaborated in chapter 2). When a situation of 'good accountability' is absent, support for Cohesion Policy and thus also for the EU in general, is expected to erode. Thus, a situation of 'good accountability' is vital for the EU and its policies.

This framework is then applied to the described situation of Cohesion Policy in the Netherlands, focusing on the actors active in the policy area, the relationships between those actors and the characteristics of these relationships. Although there is a vast volume of academic literature on accountability in the $\mathrm{EU}$, there are hardly any examples where the concept of accountability is applied to a specific case study. This makes this research of considerable added value to the academic literature and makes it possible to use this operationalization of the concept of accountability in other research, for instance in research on accountability of other policy areas. Although the research focuses on the Netherlands, giving insights in the specific situation and issues in this member state, it is also giving input for discussion of the situation in other member states. Also, this analysis of the Dutch situation enables actors to get insight in processes and the field of influences of actors, giving opportunity for better understanding and hopefully leading to improvements within the system.

As far as methods are concerned, the research mainly uses three methods: analysis of academic literature, document research and interviews. The analysis of academic

66 With regard to the fact that in the Netherlands the OPs became operational in 2008 and projects are eligible until $31^{\text {st }}$ of December 2015.

67 Those were decided upon in December 2013 with the adoption of the 2014-2020 regulations, of which the CPR, Regulation 1303/2013. 
literature is used mainly for the development of the normative framework. Subsequently, when diving into the specific situation of the Netherlands, it is important to take legal and government documents into account, to be able to describe the specific situation of the Netherlands. It is however important to not only take these documents into account, but also the perceived opinions and considerations of the actors concerned, which have been gathered by means of interviews.

Summarizing, the research focuses on ERDF in the Netherlands for the 2007-2013 period, and relevant changes for the 2014-2020 period, based on a normative framework on 'good accountability'. This then leads to the following main research question:

To what extent is there a situation of 'good accountability' within Cohesion Policy when looking at the regional European Regional Development Fund Operational Programmes in the 2007-2013 period and beyond within the Netherlands?

The sub-questions of this research are structured as follows:

a. What does the academic literature say on accountability, and on accountability within a multilevel setting? (Chapter 2)

b. What constitutes 'good accountability'? (Chapter 3)

c. Which actors are involved in Cohesion Policy in the Netherlands and how can the relationships between these actors be characterized? (document review, chapter 4)

d. How do EU and domestic actors within Cohesion Policy judge the situation of accountability within Cohesion policy in the Netherlands? (interviews, chapter 5)

e. What conclusions can be drawn from both the document review and the interviews regarding 'good accountability' in Cohesion Policy in the Netherlands? (Chapter 6)

f. What possible policy implications does the analysis of the situation of accountability within Cohesion Policy in the Netherlands have, and what suggestions can be done for further research? (Chapter 7)

\subsection{Outline of the thesis}

The composition of this research is as follows. Following this introduction, chapter 2 will discuss the literature on accountability in detail. We will discuss the concept of accountability and the process, characteristics, elements and different types of accountability. We will also discuss the terms accountability deficit and accountability overload. Moreover, we will outline and discuss the literature on accountability in the EU specifically. 
In chapter 3 we will introduce the normative framework of this research. We will discuss the method of the process-based approach to accountability that is used and describe how we use this approach to identify the accountability relationships in Cohesion Policy in the Netherlands. We also describe the requirements of 'good accountability' that will be used in the empirical part of this research, which are: coverage, context, content and costs. All four elements focus on a specific element of accountability and together are necessary in a situation of 'good accountability'.

Chapter 4, based on document research, then focuses on the situation of Cohesion Policy in the Netherlands, focusing on actors on all levels: European, national and regional level. ${ }^{68}$ We describe the actors and the accountability relationships between them and we discuss them according to the requirements of 'good accountability' as mentioned in chapter 3 , coverage, context, content and costs. We will argue that eight relationships can be seen as an accountability relationship (coverage), that the democratic and legal element of accountability are primarily lacking, but transparency is improving (context), that the focus of the accountability relationships is primarily on compliance (content) and that there are some risks to be seen for an accountability overload (costs).

Chapter 5 will deal with the outcome of the semi-structured interviews that were conducted with respondents from all three levels. The chapter will start with an introduction on the methodology used for these interviews. In general, the interview findings correspond to the findings from the analysis of the documents, in the way that according to the respondents the focus of accountability mechanisms is specifically on compliance (content) and that there are some risks for an accountability overload (costs).

Chapter 6 then puts the results of the chapters 4 and 5 into the normative framework as elaborated in chapter 3 . This leads to the conclusion, that there is not a situation of good accountability in Cohesion Policy, specifically focusing on regional ERDF OPs, in the Netherlands.

Finally, chapter 7 deals with specific issues that came up during the research and deals with possibilities for further research.

68 As outlined in section 4.2.4, we will discuss the actors and relationships in three clusters: European, national and national-European cluster. This last cluster focuses on the relationships between EC, EZ, $M A$ and $A A$. 




\section{2}

\section{Accountability within the EU}

\subsection{Introduction}

Over the last decade, a debate has emerged on the issue of accountability in the EU. From a democratic point of view, the relationship between voters and the legislative order is an important one: democratic theory implies that voters transfer their rights through the electoral process to elected representatives. At the same time, these elected representatives have the task to monitor the activities of the executive powers on behalf of the voters. In both cases, this implies a principal-agent relationship in which the principal - being the electorate in the former and the legislative power in the latter - is delegating powers to the agent - respectively the elected representatives and the executive branch. Given these principal-agent relationships an accountability regime occurs. ${ }^{69}$

Following the introduction of this research in chapter 1, this second chapter deals with the fundamentals of agency theory, the literature on accountability, and the characteristics of accountability in the (multi-leveled) EU.

To start with, in section 2.2, we describe the basics of agency theory, which also is used in the following chapters on the accountability relations in the Dutch context of ERDF.

69 We can distinguish between three types of regimes concerning accountability, following Mashaw, J.L. 2006. 'Accountability and institutional design: some thoughts on the grammar of governance', in M.W. Dowdle (ed), Public Accountability. Designs, Dilemma's and Experiences, pp. 115-156. There is the regime of public governance, directed at governance structures, the regime connected to the market which is directed at product, capital and labor markets and finally social accountability which focuses on the relations between people. This research has its focus on the regime of accountability in public governance, leaving the other regimes aside. 
In section 2.3 the concept of accountability in its core form is analyzed, consisting of the assignment of responsibilities to the agent, reporting obligations of the agent, information seeking or investigation and also verification by the principal, followed by some form of direction or control. We also deal with the characteristics of accountability relationships and the elements of an accountability relationship, which are the actors, the object and the enforcement mechanisms in place. In section 2.4, we focus on considerations from the academic literature on accountability in the European context and within multilevel governance.

\subsection{Agency theory}

Agency theory deals with principal agent relationships. Although it originates from new institutional economics, ${ }^{70}$ it is also used in other academic disciplines, such as management, political science, law and to a lesser extent also in sociology. ${ }^{71}$ It has especially been used in situations where delegation plays a role. Although the basics of the theory are the same in all those disciplines, the focus may be on different aspects.

Agency theory is about the exchange of resources in a relationship between two actors. It starts with the principal, who has specific results to achieve. The principal considers whether to act by himself to achieve the result, or to contract an agent to act on his behalf to achieve the result. This is a situation where the principal-agent relationship can be found, a situation of delegation. A contract is set between the agent and the principal, which describes what the agent should do and what the principal is doing in return, or what the reward for the agent is.

The theory assumes that both actors are acting in their self-interest and are not being fully transparent about their preferences and both are maximizing these preferences. They are acting rationally and opportunistic.

The principal thus knows one thing for sure: his preferences and those of the agent are different, which will ultimately lead to different outcomes than when the principal would have acted by himself. As Sharma puts it: 'Agents are autonomous and are prone to maximizing their own interests at the expense of principals. ${ }^{72}$

70 Braun, D. and D.H. Guston 2003. 'Principal-agent theory and research policy: an introduction', Science and Public Policy, 30, 302-308. p. 303.

71 See Shapiro, S.P. 2005. 'Agency Theory', Annual Review of Sociology, 31, 263-284 for a perfect example of agency theory in a typical working situation.

72 Sharma, A. 1997. 'Professional as Agent: knowledge assymetry in agency exchange.', The Academy of Management Review, 22, 758-798.p. 759. 
Also, there is information asymmetry; the principal and agent do not have the same information, often the agent has more information than the principal, and he is not always willing to share this information with the principal.

This anticipated behavior of the agent in particular leads to two problems for the principal. At first there is the problem that the principal does not have a good view on the agents that are available to perform the task. ${ }^{73}$ Of course he wants the best agent to act in his behalf, but the principal does not know which agent is best suited to act. Information is lacking for the principal on the abilities, performance and preferences of the agents available. This problem, in fact a problem of information asymmetry, is known as adverse selection or hidden information. ${ }^{74}$

Another problem for the principal is the fact that he is not assured whether the agent he has chosen to delegate tasks to, is really acting to its best abilities to achieve the goal the principal has set, especially not in the situation where it is costly for the agent to reach the goal of the principal. ${ }^{75} \mathrm{He}$ cannot directly make a connection between the actions of the agent on the one hand and his achievements on the other, or in other words: he does not know whether the actions of the agent fully determine the achieved outcome. This is known as moral hazard or hidden action. ${ }^{76}$ Acting not fully in the interest of the principal is called agency slack ${ }^{77}$ and takes the form of shirking ${ }^{78}$ meaning the agent is not working hard enough or is not acting to its best abilities, or slippage, when an agent shifts away from its principals preferred outcome. ${ }^{79}$ In fact, the agent has an inclination to put as less effort as possible in achieving the minimum preferred outcome of the principal, thus leading

73 Braun, D. and D.H. Guston 2003. 'Principal-agent theory and research policy: an introduction', Science and Public Policy, 30, 302-308. p. 304.

74 See for instance lbid. p. 304, Waterman, R.W. and K.J. Meijer 1998. 'Principal-Agent Models: An Expansion?', Journal of Public Administration Research and Theory, 8, 173-202. p. 177 and Arrow, K.J. 1984. 'The Economics of Agency'.

75 Bachtler, J. and M. Ferry 2013. 'Conditionalities and the Performance of European Structural Funds: A Principal-Agent Analysis of Control Mechanisms in European Cohesion Policy', Regional Studies.

76 See for instance Braun, D. and D.H. Guston 2003. 'Principal-agent theory and research policy: an introduction', Science and Public Policy, 30, 302-308. p. 304, Waterman, R.W. and K.J. Meijer 1998. 'Principal-Agent Models: An Expansion?', Journal of Public Administration Research and Theory, 8, 173-202. p. 177 and Arrow, K.J. 1984. 'The Economics of Agency'.

77 Hawkins, D.G. 2006. 'Delegation under anarchy: states, international organizations, and principal-agent theory', in D.G. Hawkins, D.A. Lake, D.L. Nielson and M.J. Tierney (eds), Delegation and Agency in international organizations. Cambridge: Cambridge University Press, pp. 3-38. p. 8

78 Braun, D. and D.H. Guston 2003. 'Principal-agent theory and research policy: an introduction', Science and Public Policy, 30, 302-308. p. 303.

79 Hawkins, D.G. 2006. 'Delegation under anarchy: states, international organizations, and principal-agent theory', in D.G. Hawkins, D.A. Lake, D.L. Nielson and M.J. Tierney (eds), Delegation and Agency in international organizations. Cambridge: Cambridge University Press, pp. 3-38. p. 8. 
to the minimum acceptable outcome for the principal for less costs for the agent. Agency theory thus assumes that the principal will have to accept welfare loss when leaving the action to an agent, thus leading to a sub-optimal result. See Figure 4 for a schematic overview.

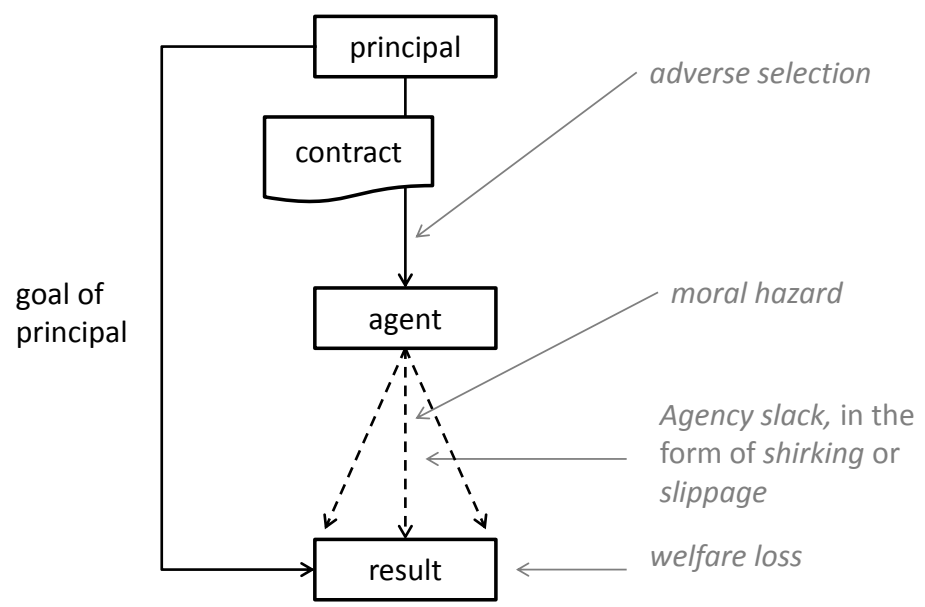

Figure 4. Agency theory and its dilemmas

Because of these problems, the principal has to consider whether he will act by himself, or whether he will ask the agent to act on its behalf. If he leaves the task to the agent, the principal needs mechanisms to be assured that the agent is not (or to a lesser extent) shirking, thereby lowering his welfare loss. The principal can use three measures for this. ${ }^{80}$ First, the principal can use persuasion, to direct the outcome of the agent's actions to coincide (as much as possible) with the principals preferences. Secondly, he can use incentives to encourage the agent to act in its best interest. Incentives can take the form of positive or negative measures, thus leading to respectively rewards when achieving the desired result of the principal, or penalties when not achieving the desired result. Thirdly, there is the mechanism of direction, thus reducing the discretion of the agent. It implies that the principal is instructing the agent directly and is restricting its possibilities in achieving the results desired by the principal. An additional mechanism to be used by the principle

80 See Groenendijk, N. 1997. 'A principle-agent model of corruption', Crime, Law \& Social Change, 207229. 
is the use of a monitoring agent. In this case, the principal decides to hire an extra agent, who gets the responsibility for monitoring and reporting to the principal on the behavior of the agent responsible to achieve the result aimed at by the principal.

All these mechanisms bear monitoring costs, consisting of both inspection and prevention costs, which are in fact costs that the principal has to take into account to be assured that the outcome of the actions of the agent come as close to the preferences of the principal as possible. By using these means, the principal will try to minimize the sum of his monitoring costs and his residual loss. ${ }^{81}$ This can be put in a figure, see Figure 5.

This figure shows the costs of the principal, on the one hand the curve for inspection costs (Ip) and prevention costs $(\mathrm{Pp})$, with on the other the curve for failure costs (Fp), or the principal's welfare loss. Where the principal increases its inspection and prevention activities, leading to higher costs for inspection and prevention, the failure costs will be lower. The principal will seek for costs minimization (TCp, the accumulation of both curves $\mathrm{Fp}$ and $\mathrm{Ip}+\mathrm{Pp}$ ), thus seeking to the optimum (Op), the lowest point on the TCp curve.

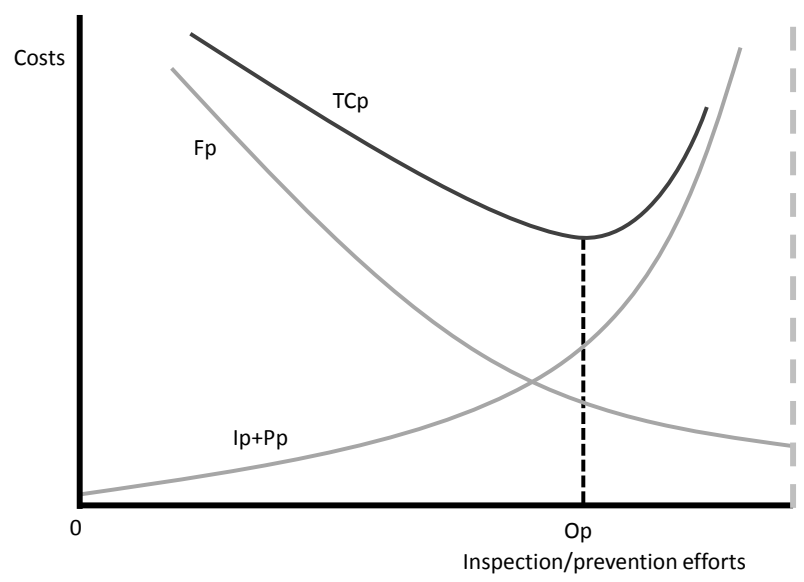

Figure 5. Inspection costs, prevention costs and failure costs, based on Groenendijk (1997) lbid.p. 215.

At the same time, the agent is also bearing costs and risks. As mentioned before, it is expected the agent will show shirking behavior, in the way the agent will thrive for the minimum result desired by the principal, at lowest costs for the agent as pos- 
sible. Shirking will lead to maximum welfare for the agent. But, as we just mentioned, the principal is expected to use measures to reduce the shirking behavior of the agent. These measures will lead to welfare loss for the agent, compared to the situation without inspection/prevention by the principal. He will try to please the principal to use less heavy measures, in the way that it may lead to higher welfare for the agent, and thereby camouflaging its own acting. It will lead the agent to make additional costs to stimulate the principal to reduce the measures to be used, thus leading to bonding costs. By this, the agent will try to influence the principal. He can use mechanisms for bonding such as explaining its behavior and showing its effort, all directed at pleasing the principal.

This leads to exactly the same figure as figure 5, but with a curve for concealment and diversion costs, thus bonding costs, (a Ca+Da curve instead of the Ip+Pp curve in figure 5 ) and a curve for the failure costs of the agent ( $\mathrm{Fa}$ instead of $\mathrm{Fp}$ ). ${ }^{82}$

Interestingly, both the actions of the agent and the principal affect the slope and the placement of the curves: when the agent invests more in concealment and diversion of the principal, thus leading to a higher level of information asymmetry, the failure costs of the principal, the Fp curve, will shift to the right. The effect is that the TCp curve also changes and a new optimum arises for the principal (Op1), leading to higher inspection and prevention costs, see Figure 6.

At the same time, the effect of increased inspection and prevention efforts of the principal is that the welfare loss of the agent increases, thus also shifting the $\mathrm{Fa}$ curve in the figure of the agent to the right. At the same time, this leads to a change in the TCa curve and thus to another optimum for the agent, shifting towards more concealment and diversion. In the end, all other things being equal, the principal and agent will end up in a downwards spiral, ${ }^{83}$ leading to increasingly higher levels of inspection and prevention and concealment and diversion.

The principal and the agent thereby both are confronted with risks and costs in this theory: both are bearing costs, monitoring costs and residual loss by the principal and bonding costs and residual welfare loss by the agent. The principal has the advantage that he can prescribe the conditions for the relationship between both, the contract, while the agent on the other hand can take advantage of the fact that

82 We have not enclosed this figure separately, because it would look the same as figure 5. Instead, the curves would have a different name.

83 Although this figure shows an upwards spiral, instead of a downwards spiral, with a situation leading to higher costs, we mention this as a downwards spiral, because of the fact that these higher costs are to be seen as a negative effect, thus as an unwanted situation, which corresponds more with a downwards movement than with an upwards movement. 


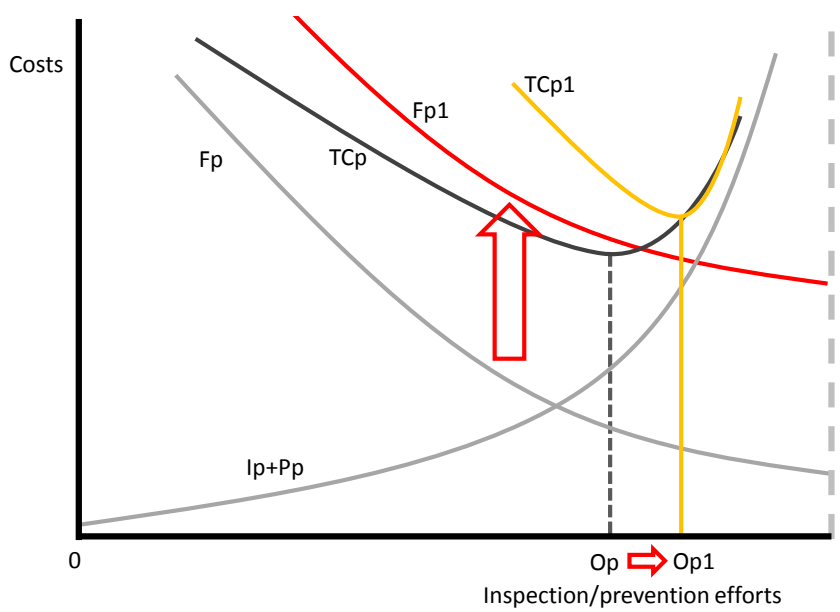

Figure 6. Changes in effects of behavior of the agent

the principal has limited information on the actions of the agent and the link between those actions and the outcome. ${ }^{84}$

The main question in agency theory thus is how to prevent an agent from shirking behavior, taking into account the fact that both the principal and agent have different preferences and that there is a situation of information asymmetry between both actors. At the same time, from the perspective of the system as a whole, taking the implications for both the principal and agent into account, it is important to make sure that both actors do not force each other into a situation of high levels of agency costs, leading to a possible situation of overload. This possible situation of an overload is also important when we discuss accountability, to which we will turn now.

\subsection{The concept of accountability}

A distinction can be made between accountability 'the word' and accountability 'the concept. ${ }^{185}$ Accountability 'the word' is synonymic for a lot of other concepts;

84 Groenendijk, N. 1997. 'A principle-agent model of corruption', Crime, Law \& Social Change, 207-229. p. 214.

85 Dubnick, M.J. and J.B. Justice 2004. 'Accounting for Accountability', 2004 Annual Meeting of the American Political Science Association. p. 5. See also Bovens, M. 2010. 'Two concepts of Accountability: Accountability as a virtue and as a Mechanism', West European Politics, 33, 946-967 on the same distinction. However, not all authors agree there is a real distinction, see for instance Willems, T. and W.v. Dooren 2012. 'Coming to terms with Accountability', Public Management Review, 14, 1011-1036. p. 1013. 
its actual meaning depends on different cultural and contextual factors and can vary from person to person. Often, accountability is used as 'active accountability' ${ }^{186}$, because it concerns the actions of actors, more specifically public actors. In this sense it is broad and normative in its essence: accountability as 'a set of standards for the evaluation of the behavior of public actors. ${ }^{187}$ It has different dimensions, such as transparency, liability, controllability, responsibility and responsiveness. ${ }^{88}$ Again, in this context, the word accountability is primarily used as a normative concept to describe the actions of organizations or officials. This makes it an ideal word to be used for rhetoric purposes, but not per se for (empirical) research on accountability.

On the other hand, accountability as a concept refers to 'a primary characteristic of governance in contexts where there is a sense of agreement and certainty about the legitimacy of expectations of community members. ${ }^{89}$ The European view ${ }^{90}$ on this concept is directed at accountability as a description of the institutional process, focused at 'whether [agents] are or can be held accountable ex post facto by accountability forums. ${ }^{\prime 11}$ It is also called 'passive accountability', because of the fact that the actor is to be held accountable. ${ }^{92}$ Bovens describes the definition of this kind of accountability as 'a relationship between an actor and a forum, in which the actor has an obligation to explain and to justify his or her conduct, the forum can pose questions and pass judgement, and the actor may face consequences'. ${ }^{93}$ Put in the words of agency theory, the actor is the agent and the forum is the principal. In this view of accountability it is undefined and it has to be assessed in each situation which actor is the principal, or the actor to whom the conduct of the agent is justified. As we have mentioned in the introduction, this thesis will focus on public

86 Bovens, M. 2010. 'Two concepts of Accountability: Accountability as a virtue and as a Mechanism', West European Politics, 33, 946-967.p. 949.

87 Ibid.p. 947.

88 Koppell, J.G.S. 2005. 'Pathologies of Accountability: ICANN and the Challenge of 'Multiple Accountabilities Disorder., Public Administrations Review, 65, 94-107. p. 96.

89 Dubnick, M.J. and J.B. Justice 2004. 'Accounting for Accountability', 2004 Annual Meeting of the American Political Science Association. p. 12.

90 Shared by Canadian, Australian and British scholars.

91 Bovens, M. 2010. 'Two concepts of Accountability: Accountability as a virtue and as a Mechanism', West European Politics, 33, 946-967. p. 948.

92 lbid. p. 951.

93 Bovens, M. 2007. 'Analysing and Assessing Accountability: a Conceptual Framework', European Law Journal, 13, 447-468 p. 450. See also for a similar definition Rubin, E. 2006. 'The Myth of nonbureaucratic accountability and the anti-administrative impulse', in M.W. Dowdle (ed), Public Accountability. Designs, Dilemma's and Experiences, pp. 52-82. p. 74, and Mulgan, R. 2003. Holding Power to Account. Palgrave MacMillan. p. 10. 
governance, which ultimately always has to do with the democratic principles with voters or citizens in the end - or in fact the beginning - of the chain of accountability.

\subsubsection{The process of accountability}

Accountability can be regarded as a process, consisting of four main steps;

a) Assignment of responsibilities;

b) Reporting by the agent;

c) Information seeking or investigating and also verification by the principal; and

d) Direction or control by the principal, possibly posing sanctions on the agent. ${ }^{94}$

This process is graphically shown in Figure 7.

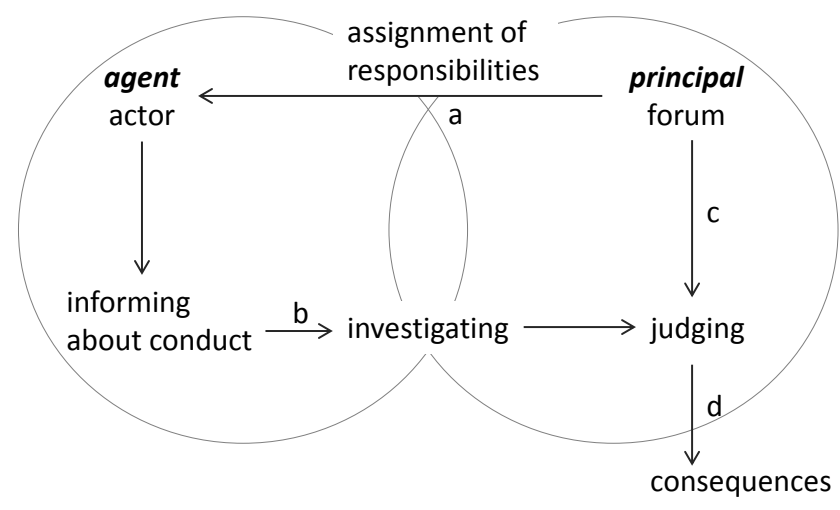

Figure 7. Process of accountability

Based on the figure drawn up by Bovens in Bovens, M. 2007. 'Analysing and Assessing Accountability: a Conceptual Framework', European Law Journal, 13, 447-468, p. 454.

In the first step, the principal is assigning responsibilities to the agent. These responsibilities form the basis of the accountability relationship. Ideally, these are

94 Based on Mulgan, R. 2008. 'The Processes of Public Accountability', Australian Journal of Public Administration, 56, 25-36.p. 19, Fisher, E. 2004. 'The European Union in the Age of Accountability', Oxford Journal of Legal Studies, 24, 495-515, p. 497, following Davies, A. 2001. Accountability: A Public Law Analysis of Government by Contract. Oxford: Oxford University Press and Thomas, P.G. 1998. 'The Changing Nature of Accountability', in B. Guy Peters and D.J. Savoie (eds), Taking Stock: Assessing Public Sector Reforms Canadian Centre for Management Development, pp. 348-393, p. 352. A similar definition, however differently formulated, is mentioned by Polverari, L. 2015. 'Does Devolution Increase Accountability? Emperical Evidence from the Implementation of European Union Cohesion Policy', Regional Studies, 49, 1074-1086. 
based upon agreed-upon goals or purposes. ${ }^{95}$ Secondly, there is an obligation for the agent to inform the principal on the aspects of what the agent is accountable for. This means that the process starts with the agent after an accountability relationship has been established. The third step refers to an action of the principal: he should either search for (extra) information by himself on the aspects the agent is accountable for, or at least he should investigate the information handed over by the agent. This leads to a set of information available for the principal to form an opinion on. This then is followed by verification by the principal. Based on the information provided by the agent and/or collected by the principal, the principal takes a stand on the behavior of and the results achieved by the agent. Finally, this verification leads to the final step, where the principal is acting towards the agent following its actions. This may be in the form of sanctions or other mechanisms, however mostly negative in its basic principle. ${ }^{96}$

It is important to keep in mind that the principle of accountability relates to the possibility for the agent to be called to account and held accountable for its actions by the principal; someone in fact can be accountable without actually having been called to account, it is about the 'shadow' of sanctions. ${ }^{97}$ As Mulgan puts it: 'Accountability is not so much being called to account as the expectation of being called to account. ${ }^{198}$ Or put differently: 'the whole point of being held to account is to avoid being sanctioned; in theory, being sanctioned for bad conduct is the whole point of being held to account. ${ }^{99}$

95 Thomas, P.G. 1998. 'The Changing Nature of Accountability', in B. Guy Peters and D.J. Savoie (eds), Taking Stock: Assessing Public Sector Reforms Canadian Centre for Management Development, pp. 348-393, p. 352.

96 In the academic literature there is discussion on whether sanctioning is a necessary element of accountability. See for instance Harlow, C. and R. Rawlings 2007. 'Promoting Accountability in Multilevel Governance: A Network Approach', European Law Journal, 13, 542-562, p. 545. Harlow considers sanctioning not a necessary element, but considers that 'the machinery should [...] operate so as 'to put matters right if it should appear that errors have been made,' where quoting Oliver, D. 1991. 'Government in the United Kingdom: The Search of Accountability, Effectiveness and Citizenship': Open University Press. p. 22. In this research we do consider sanctioning as a necessary element.

97 Papadopoulos, Y. 2007. 'Problems of Democratic Acountability in Network and Multilevel Governance', European Law Journal, 13, 469-486, p. 470.

98 Mulgan, R. 2003. Holding Power to Account. Palgrave MacMillan. p. 10 and 11

99 Abromeit, H. 2009. 'Accountability and democracy', in S. Gustavsson (ed), The Illusion of Accountability in the European Union: Routledge. p. 29. 


\subsubsection{Characteristics of accountability}

Accountability has three necessary characteristics. ${ }^{100}$ The first is transparency. ${ }^{101}$ This concept refers to the fact that decision-making is opened up to the public, in the way that decision-makers should explain what decisions they have taken and why. 'Transparency ensures that decisions are taken out of the "backroom."102 Or put differently: 'how can the public hold public authorities accountable if the public is not allowed to know what goes on within the public authorities, or if what goes on is obscure? ? $^{103}$

Transparency can have different forms, such as clear drafting, simplification of regulation, debate, efforts to trace the influence of interest-groups in the decision making process, transparent enforcement procedures, freedom of expression of servants, whistle-blower protection and probably the most important function: public access to documents. ${ }^{104}$ In the White Paper on governance the EC mixes up the concepts of accountability and transparency, ${ }^{105}$ and it happens more often that transparency is mixed up with the concept of accountability. ${ }^{106}$ We agree with Fisher that transparency is an essential element of accountability and therefore should not be confused with accountability.

100 Fisher, E. 2004. 'The European Union in the Age of Accountability', Oxford Journal of Legal Studies, 24, 495-515, p. 501-508 mentions four types of accountability processes, the three mentioned here are based on Fisher's typology. The fourth process as mentioned by Fisher, 'checks and balances that arise due to the interrelationship between different institutions,' is specifically connected to the EU and not to the general idea of accountability. This process is therefore not included in this categorization. We see her categorization not specifically as processes, but as principles of accountability, because they are or should be in place in case of accountability relationships. Connection can also be made with the functions and forums of an accountability relationship mentioned by Willems, T. and W.v. Dooren 2012. 'Coming to terms with Accountability', Public Management Review, 14, 1011-1036. Although we have a somewhat different categorization of the characteristics and elements of accountability, not using the concepts functions and forums, the elements mentioned in this paper are the same.

101 See Mulgan, R. 2003. Holding Power to Account. Palgrave MacMillan. p. 98-103.

102 Fisher, E. 2004. 'The European Union in the Age of Accountability', Oxford Journal of Legal Studies, 24, 495-515, p. 503, following Slaughter, A.-M. 2000. 'Agencies on the Loose? Holding Government Networks Accountable', in G. Bermann, M. Herdegen and P. Lindseth (eds), Transatlantic Regulatory Co-operation: Oxford University Press. p. 523-524.

103 Dyrberg, P. 2002. 'Accountability and Legitimacy: What is the Contribution of Transparency?', in A. Arnull (ed), Accountability and Legitimacy in the EU: Oxford University Press, pp. 81-96, p. 83.

104 Ibid. p. 84.

105 This in contrary to the conclusion of the Council of December 10, 2010 on 'Mutual Accountability and Transparency: A Fourth Chapter for the EU Operational Framework on Aid Effectiveness' 177769/10, to be found on http://register.consilium.europa.eu/pdf/en/10/st17/st17769.en10.pdf, retrieved at 1611-2015.

106 Bovens, M. 2007. 'Analysing and Assessing Accountability: a Conceptual Framework', European Law Journal, 13, 447-468, p. 453. 
The second characteristic is democracy, the connection between institutions and the public. In public governance 'the people' are characterized as the ultimate principals and therefore play an important, though not always visible, role. Institutions or specific actors are put in place to act on behalf of the people; all the relationships within the accountability framework of public governance have a direct or indirect connection with the democratic relationships between elected officials and voters or citizens, thus 'the public.' ${ }^{107}$ However, the difficulty is that there is no such thing as 'the people' or 'the public,' elected officials are accountable to a multitude of people, but as a group its meanings and intentions are almost always unclear and opaque: ${ }^{108}$ there is no such thing as 'the meaning of the people,' the perceptions and ideas of voters are too diverse and ambiguous. This makes it very difficult to assess the element of democracy, to see whether elected officials are really (possible to be) held accountable by the public.

Finally, we end up at the third important characteristic of accountability, which is legal constraint. This principle is all about the legal boundaries that are set and the need for public-policy makers to stay within these boundaries. Courts then are the institutions to enforce these rules. In the European context, an important role is set in this respect for the European Court of Justice (ECJ) and the General Court. ${ }^{109}$ In fact, this characteristic has the goal to prevent unfairness or abuse of power. ${ }^{110}$

All these three principles are essential in an accountability relationship. There should be a right balance between all three principles, to ensure that these individually do not lead to an unwanted situation with too less attention for the democratic principle, too less transparency or illegal situations. These three principles should all be taken into account when studying an accountability relationship.

107 See for instance Mulgan, R. 2008. 'The Processes of Public Accountability', Australian Journal of Public Administration, 56, 25-36, p. 29 and Dowdle, M.W. 2006. 'Public accountability, conceptual, historical and epistemic mappings', in M.W. Dowdle (ed), Public Accountability. Designs, Dilemma's and Experiences: Cambridge University Press, pp. 1-29, p 3.

108 Dowdle, M.W. 2006. 'Public accountability, conceptual, historical and epistemic mappings', in M.W. Dowdle (ed), Public Accountability. Designs, Dilemma's and Experiences: Cambridge University Press, pp. 1-29, p. 3.

109 Before the Treaty of Lisbon known as Court of First Instance.

110 Corresponding with the constitutional function of accountability, as mentioned by Willems, T. and W.v. Dooren 2012. 'Coming to terms with Accountability', Public Management Review, 14, 1011-1036, p. 1023. 


\subsubsection{The elements of accountability}

As we considered in the previous subsection, the process of accountability consists of four phases. We can also look at the elements of accountability and look at what accountability is in fact all about. This leads us to three important questions to be identified in an accountability relationship:

1. Who are the actors in an accountability relationship?

2. What is the accountability relationship all about (object)?

3. And what is the enforcement mechanism in the accountability relationship?

We will further discuss these three questions below.

Ad 1. Who are the actors involved?

Accountability is in fact a concept clearly linked to the principal-agent theory and therefore points at a description of both the principal and the agent in relationship concerned. The principal has delegated its powers to an agent, to act in its behalf. At the same time, the principal wants to be assured that the agent does what he is told to do and that he really acts in the interest of the principal. Since there is no equilibrium in the information between both actors, in fact there is an information asymmetry, there is also some sort of unbalance between them. At the same time the relationship is hierarchical, which makes is possible for the principal to call the agent to account for its actions.

The 'who' can be either individual or collective. In the case of individual accountability, one can think of a politician, for instance an elected politician facing voters, as opposed to government agencies or firms in the case of collective accountability. Networks in this sense create problems in attributing the 'who' question to a specific organization or person and are therefore a complicating factor in an accountability analysis. ${ }^{111}$

A fourfold categorization can be given of the forums that can be concerned, when looking at an accountability relationship in public governance: ${ }^{112}$

111 Mulgan, R. 2003. Holding Power to Account. Palgrave MacMillan.p. 23 and 24.

112 Based on the distinction given by Willems, T. and W.v. Dooren 2012. 'Coming to terms with Accountability', Public Management Review, 14, 1011-1036, and Mulgan, R. 2008. 'The Processes of Public Accountability', Australian Journal of Public Administration, 56, 25-36, p. 29, following Finn, P. 1993. 'Public Trust and Public Accountability', Australian Quarterly, 65, 50-59, p. 53 and 54. Mulgan distinguishes between the public, agencies or superior officers. Agencies in fact are an organization formed by bureaucrats, and as such mentioned in this distinction. As regards superior officers, this can also be connected to bureaucrats, but can also be seen as a form of social accountability, and is therefore put aside (see the introductionof this chapter). 
a. To members of the public, either as individual or as a community, acting as voters; ${ }^{113}$

b. To politicians;

c. To judicial courts or tribunals; ${ }^{114}$

d. To bureaucrats, ${ }^{115}$ such as agencies or specific institutions, acting on behalf of the public.

In case of public governance, 'the people' will always be the ultimate 'whom' or principal, ${ }^{116}$ no matter whether a specific body or organization is placed between the agent and the principal (the people). In complex societies often government bodies will be put in place to perform the principal-function of 'the people.'117

\section{Ad 2. What is the object?}

The function or assignment that the principal is responsible for is the object of the accountability relationship. This can be general by nature, defining that the agent should act according to the preferences and interests of the principal. Another option is that the principal is more precise and focused in the assignment he has given to the agent, which makes it particular accountability. ${ }^{118}$

Although in the literature different distinctions are made, there is some consensus on the objects of an accountability relationship, which can also be connected to the policy-process-chain, as shown in Figure $8 .{ }^{119}$ At first, the focus can be on financial accountability, directed at value-for-money in the narrow sense, focusing on the aspect of economy, or prevention of 'waste'. This is connected mainly to the inputs in the policy chain. A second object is process or efficiency accountability, which refers to the question whether the process has been carried out in such a way that the appropriate outputs have been produced and that the ratio between inputs and outputs is beneficial. The third possible object of an accountability relationship is performance or effectiveness accountability. This refers to the question whether

113 Combining the political and public forum, as mentioned by Willems, T. and W.v. Dooren 2012. 'Coming to terms with Accountability', Public Management Review, 14, 1011-1036, p. 1019.

114 See lbid. p. 1019 and Mulgan, R. 2003. Holding Power to Account. Palgrave MacMillan, p. 45 and 46.

115 Mulgan, R. 2000. "Accountability': an ever expanding concept?', Public Administration, 78, 555-573, p. 556.

116 See for instance Papadopoulos, Y. 2007. 'Problems of Democratic Acountability in Network and Multilevel Governance', European Law Journal, 13, 469-486, p. 472, and also Willems, T. and W.v. Dooren 2012. 'Coming to terms with Accountability', Public Management Review, 14, 1011-1036, p. 1019.

117 Mulgan, R. 2003. Holding Power to Account. Palgrave MacMillan, p. 25.

118 lbid. p. 28.

119 lbid. p. 31, following amongst others Day, P. and R. Klein 1987. Accountabilities. Five public services. Travistock Publications Ltd, p. 26 and 27. A distinction of different types of accountability, which connects with the distinction given here, is also made by Bovens, M. 2007. 'Analysing and Assessing Accountability: a Conceptual Framework', European Law Journal, 13, 447-468, p. 455-457. 


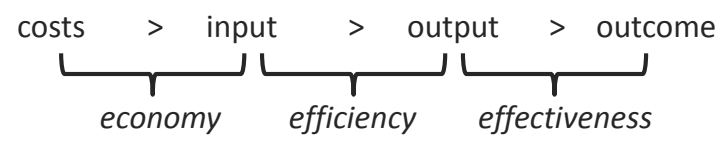

Figure 8. Policy-process-chain

Based on Van Dooren, W., G. Bouckaert and J. Halligan 2010. Performance Management in the Public Sector. Routledge, p. 18.

the intended outcomes have been produced. This shows that accountability can be directed at different stages of the policy process chain, as mentioned above in figure 8 , and therefore has a different object as focus of its relationship. ${ }^{120}$ The concept of 'sound financial management', which is also often used in European public governance, also is based on this chain. ${ }^{121}$

\section{Ad 3. Enforcement mechanisms}

An accountability mechanism can have different forms, such as a specific report on the general performance of a policy area or a response to a specific inquiry or investigation. To be able to reach a certain level of accountability, there are various mechanisms thinkable that may vary from weak to strong on a continuum. ${ }^{122}$ The ends of the continuum consist of monitoring (weak) and imposing sanctions (strong). In between there are various mechanisms to be seen in different contexts, such as (from weak to strong) monitoring documents, calling hearings, posing penalties and withdrawing the authorization of the principal.

Accountability mechanisms can be classified in three stages, information (reporting, investigating), discussion (justification and critical debate) and rectification (imposition of remedies and sanctions). ${ }^{123}$ Often, as described earlier, the possibility of being sanctioned for bad conduct is enough for the agent to act according to the preferences of the principal. This characteristic of accountability can also have an ex ante effect, because of the expectations of the agent. Knowing that there is a possibility to be called to account for its actions, the agent will be more likely to do what he is told to do. Also positive elements, such as rewards or compensations can be

120 In the article Willems, T. 2014. 'Democratic accountability in public-private partnerships: the curious case of Flemish school infrastructure', Public Administration, 92, 340-358, Willems refers to three functions of accountability: the constitutional, democratic and performance function. These overlap with the actors and objects, as mentioned in this chapter.

121 See for instance European Court of Auditors 2013. 'Annual Report on the Implementation of the Budget'. Luxembourg: European Court of Auditors, p. 254.

122 Karlsson, C. 2009. 'EU Treaty Reform and Accountability', in S. Gustavsson (ed), The Illusion of Accountability in the European Union, p. 69.

123 Mulgan, R. 2003. Holding Power to Account. Palgrave MacMillan, p. 30. 
used as an accountability mechanism. ${ }^{124}$ But the strongest force in an accountability relationship is the possibility of sanctions.

\subsubsection{Different types of accountability}

Bovens $^{125}$ has made a distinction between various types of accountability. In his typology some of these are linked to the actors in the accountability relationship, being both the forum (principal) and the actor (agent). This brings him to a list of different kinds of accountability relationships, which can be put in a figure (Figure 9) as follows:

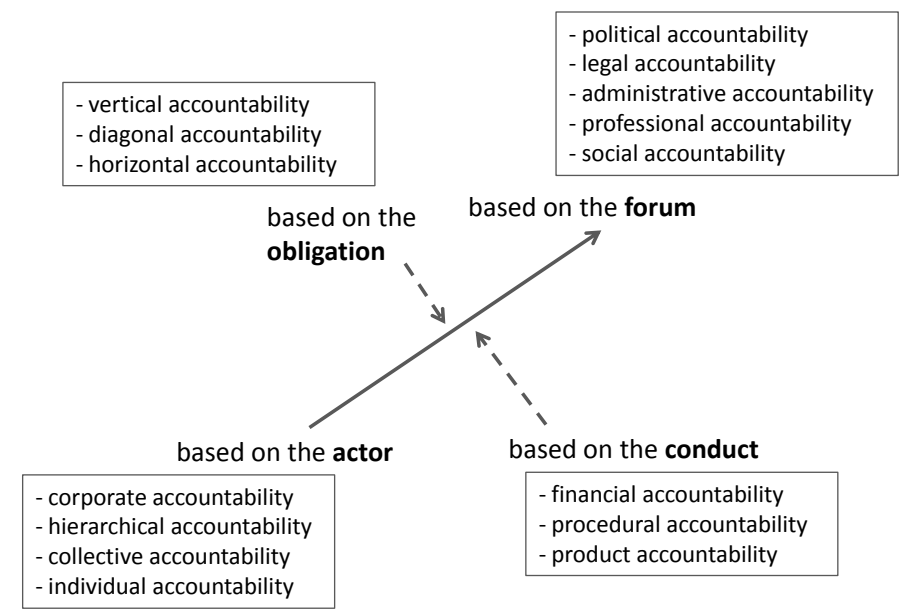

Figure 9. Types of accountability

Based on the list of accountability types as given by Bovens, M. 2007. 'Analysing and Assessing Accountability: a Conceptual Framework', European Law Journal, 13, p. 461.

When looking at the actors in the process, Bovens gives an overview of various types, based on either the forum or the actor concerned. Although we acknowledge the fact that it is important to be able to describe the nature of an accountability relationship based on obligation or conduct, we are more interested in a more evaluative process of accountability to see whether the relationship concerned really is

124 Thomas, P.G. 1998. 'The Changing Nature of Accountability', in B. Guy Peters and D.J. Savoie (eds), Taking Stock: Assessing Public Sector Reforms Canadian Centre for Management Development, pp. 348-393, p. 352.

125 Bovens, M. 2007. 'Analysing and Assessing Accountability: a Conceptual Framework', European Law Journal, 13, 447-468. 
an accountability relationship, according to the characteristics mentioned in section 2.3.1.

Interesting to see is that the distinction connected to the accountability based on conduct seems to show a focus on different objects, seemingly not specifically related to the policy-process-chain. But when looking to this distinction in more detail, by referring to the work of Day, Bovens in fact also seems to be pointing at the processes of the policy-process-chain, consisting of 'the 3 E's' economy, efficiency and effectiveness (see Figure 8). ${ }^{126}$

\subsubsection{Accountability deficit and overload}

It is important to note that accountability is in fact a relative concept and hard to measure directly. The concept of accountability is characterized by its chameleon quality ${ }^{127}$ and is given different meanings in different contexts. This means that it will be difficult in empirical research to pinpoint the exact status of an accountability situation; instead it refers to a more relative situation compared to other situations. Next to describing such an ideal situation, here referred to as 'good accountability', we can describe the situation according to 'more accountability' or 'less accountability', leading to, at its extremes, a situation of overload - too much accountability - or deficit - too less accountability. Good accountability is in fact the ideal situation, situated between those two poles. One can therefore think of some sort of continuum, with the extremes on both ends: on the one hand 'accountability overload' and on the other 'accountability deficit,', ${ }^{128}$ and in between these undesired situations the idea of 'good accountability', as shown by the following figure (Figure 10).

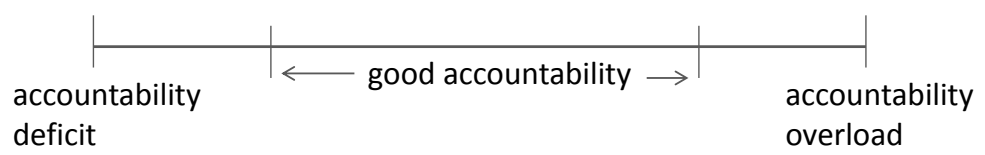

Figure 10. Accountability deficit versus accountability overload and the situation of 'good accountability'

126 This also connects with the performance function of accountability as mentioned by Willems, T. and W.v. Dooren 2012. 'Coming to terms with Accountability', Public Management Review, 14, 1011-1036, p. 1023.

127 Sinclair, A. 1995. 'The Chameleon of accountability: forms and discourses', Accounting, Organizations and Society, 20, 219-237, p. 219.

128 Bovens, M., T. Schillemans and P. 't Hart 2008. 'Does public accountability work? An assessment tool', Public Administration, 86, 225-242, p. 229 and 230. 
Regarding the end of the continuum that refers to an 'accountability overload', Bovens refers to four elements that make the situation even worse when all four are in place. ${ }^{129}$ These four elements are visible when a regime:

a. imposes extraordinarily high demands on their limited time and energy;

b. contains a comparatively large number of mutually contradictory evaluation criteria; $^{130}$

c. contains performance standards that extend way beyond their own and comparable authorities' good practices;

d. contains performance standards that seem particularly conducive to goal displacement or subversive behavior. ${ }^{131}$

These four elements all point at too much, contradictory, wrong or diverting criteria that are set for the agent to be accountable on. As may be clear, the extremist pole of accountability overload means that all four elements are in place.

On the other end, there is the 'accountability deficit', which refers to a situation 'where those who govern us are not sufficiently hemmed in by requirements to explain their conduct publicly to [...] forums who have some sort of power to sanction them.'132 One can think of the fact that the executive power has grown enormously and has become more complex, compared to the legislative power. This makes it extremely difficult for the forum, in public governance often the parliament, to really control the executive power. At the same time, networking governance systems have emerged in public governance, causing in fact the same problem: ${ }^{133}$ blurring of functions and responsibilities, also because private actors have entered

129 lbid. p. 229.

130 Also referred to as 'professional disorientation', in the way that 'no way of acting is ideal, because different forums assess his/her actions from competing perspectives,' by Vesely, A. 2013. 'Accountability in Central and Eastern Europe: concept and reality ', International Review of Administrative Sciences, 79, 310-330, p. 318. Another term that is referred to in the literature is 'multiple accountabilities disorder', see Koppell, J.G.S. 2005. 'Pathologies of Accountability: ICANN and the Challenge of "Multiple Accountabilities Disorder"', Public Administration Review, 65, 94-108.

131 Also referred to as 'accountability trap', which means the agent tends to improve the measurements on the assessment criteria that are set by the principal, whereas the agent not necessarily succeeds in terms of attaining its public mission, see Vesely, A. 2013. 'Accountability in Central and Eastern Europe: concept and reality ', International Review of Administrative Sciences, 79, 310-330, p. 318.

132 Bovens, M., T. Schillemans and P. 't Hart 2008. 'Does public accountability work? An assessment tool', Public Administration, 86, 225-242, p. 229.

133 See Ibid. p. 229, and for instance Papadopoulos, Y. 2007. 'Problems of Democratic Acountability in Network and Multilevel Governance', European Law Journal, 13, 469-486. 
the public sphere in policy making. ${ }^{134}$ Recent research however shows that public private partnerships can also lead to improved accountability. ${ }^{135}$

In that regard it is important to note that the description of the balance within an accountability situation by Bovens refers to a one dimensional relationship between a principal and an agent. As figure 4 also shows, and Bovens also mentions in his work, the principal agent theory and accountability as a concept especially suit the simple situation of the relationship between one principal and one agent. However, it gets more complicated when multiple actors are involved, thus leading to a principal agent network. At the one hand, this is because these multiple actors will have multiple relationships with different actors, thus showing multiple and different principal-agent relationships. On the other, it is known that externalities or other relationships within the principal agent network have an influence on other relationships, thus leading to extra influencing factors on the separate principal-agent relationships. This also makes it important to look at accountability in a situation with multiple actors, as we discuss in section 2.4.2.

\subsection{Accountability in the EU according to academic literature}

This section focuses on the academic literature on accountability in the EU. Since there is hardly any literature on Cohesion Policy and accountability, we focus on what has been written on accountability and the EU in general; some of these more general observations are also applicable to Cohesion Policy. We start in section 2.4.1 with discussing the elements of accountability (as put forward in section 2.3.2) in the context of the EU. Subsequently, in section 2.4.2, we look at what has been written on accountability in a situation with multiple actors; although specific literature on accountability in a situation of multilevel governance is lacking, there is research available on network governance, which can be seen as a proxy for multilevel governance because it describes a situation with multiple actors.

\subsubsection{Elements of accountability in the EU}

Regarding the elements of accountability, as mentioned in section 2.3.3, there have been different observations in the academic literature regarding problems with accountability in the EU in general.

134 Bovens, M., T. Schillemans and P. 't Hart 2008. 'Does public accountability work? An assessment tool', Public Administration, 86, 225-242, p. 229 and for instance Koppell, J.G.S. 2005. 'Pathologies of Accountability: ICANN and the Challenge of "Multiple Accountabilities Disorder"', Public Administration Review, 65, 94-108.

135 Willems, T. 2014. 'Democratic accountability in public-private partnerships: the curious case of Flemish school infrastructure', Public Administration, 92, 340-358. 


\section{Ad 1. Actors}

As important as it is to be aware of the actors in an accountability relationship, it is often also difficult to identify these actors. As mentioned before, 'the people' are seen by a lot of academics as the ultimate principal, ${ }^{136}$ and therefore in a direct or more indirect form to be seen as an actor. But this also poses a problem: who are 'the people'? In the EU a common identity, culture, language and history are lacking, ${ }^{137}$ there is no European demos. This makes it difficult, also for decisionmakers, to really be accountable to 'the people'. In fact, on European level, control by 'the people' is in fact not a viable option, ${ }^{138}$ because of this lacking of a common background.

What contributes to this difficulty is that for outsiders it is often difficult to find out who the actor or agent is in a relationship. Because policy decisions cross different desks before they are implemented, it is specifically hard to unravel which actor is to be held accountable. This is also known as the problem of many hands. ${ }^{139}$ This phrase is used in public governance especially when focusing on regional and national level, in the EU context this problem is even more complex because of the involvement of actors on European, national and regional level, thus on three levels instead of two, which even creates more fuzziness on the involvement of actors.

An important 'puzzle' on the European level, as Curtin describes, ${ }^{140}$ is the fact that accountability mechanisms are in place on the national level, but that these mechanisms are lacking on the European level. Curtin gives examples of issues that have been present on the European level during the last decade, such as the influenza pandemic, climate change and bonuses in the banking sector, which used to be dealt with on a national scale but have become more and more prominent on the European agenda. The actors that used to deal with these issues on the national level, such as governments, ministers and civil servants, use their authority, backed-up by accountability processes on the national level, also on the European stage. But they in fact lack a European mandate. ${ }^{141}$ This points to a need for more

136 See for instance Mulgan, R. 2003. Holding Power to Account. Palgrave MacMillan.and Gustavsson, S. C. Karlsson and T. Persson eds. 2009. The illusion of accountability in the European Union. Routledge.

137 Abromeit, H. 2009. 'Accountability and democracy', in S. Gustavsson (ed), The Illusion of Accountability in the European Union: Routledge. p. 24 and 25.

138 Fisher, E. 2004. 'The European Union in the Age of Accountability', Oxford Journal of Legal Studies, 24, 495-515, p. 501.

139 Bovens, M. 2007. 'Analysing and Assessing Accountability: a Conceptual Framework', European Law Journal, 13, 447-468, p. 457.

140 Curtin, D., P. Mair and Y. Papadopoulos 2010. 'Positioning Accountability in European Governance: An introduction', West European Politics, 33, 929-945, p. 933.

141 lbid. p. 934. 
accountability mechanisms on the European level to match these existing (national) executive orders.

An important characteristic of accountability in the EU, connected to the three characteristics mentioned in section 2.3.1, is institutional balance. ${ }^{142}$ This characteristic refers to the principle that each European institution has to act in accordance with the division of powers set by the Treaties. In a national situation, there is the division (or: separation) of powers into the legislative, executive and judiciary branches; within the EU context this principle is put into the principle of institutional balance. The principle itself is laid down in the Treaty ${ }^{143}$ and also follows from judgments by the Court of Justice. ${ }^{144}$ It prohibits the institutions to use powers that are attributed to other institutions, thereby assuring that they stay within the boundaries of their own powers. As can be derived from the fact that rulings from the Court of Justice have brought this principle in the open, the Court guards the implementation of the principle.

As Fisher points out, in fact the web of different institutions within the EU can in itself also been seen as a form of accountability. ${ }^{145}$ Because of this balancing of powers, derived from the principle of institutional balance, all institutions are in fact constantly being called to account by the other institutions or in fact by the system itself.

\section{Ad 2. Object of accountability}

In the literature special attention has been given to political or democratic and to financial accountability in the EU, both related to the object of accountability.

The main problem that is identified in the literature with democratic accountability in the EU has to do with the (supposed) democratic deficit. This democratic deficit is caused by an increase of executive power on the European level, while at the same time a decrease is seen in national parliament control. ${ }^{146}$ On the European level, parliamentary control by the EP has also said to be weak, ${ }^{147}$ although with the Treaty of Lisbon the EP has gained powers. Also, the distance between voters and their political representation on the European level is very large, in the fact that voters lack a real opportunity to vote on European issues. However, with national issues

142 Fisher, E. 2004. 'The European Union in the Age of Accountability', Oxford Journal of Legal Studies, 24, 495-515, p. 506-508.

143 See article 13 paragraph 2 of the Treaty on the European Union.

144 See the Meroni Case (C 9-56) and case C 70-88.

145 Fisher, E. 2004. 'The European Union in the Age of Accountability', Oxford Journal of Legal Studies, 24, 495-515, p. 507.

146 Follesdal, A. and S. Hix 2006. 'Why There is a Democratic Deficit in the EU: a Response to Majone and Moravcsik', Journal of Common Market Studies, 44, 533-562, p. 534.

147 lbid. p. 535. 
playing a role in European elections, the European policy making cycle is very different from the national process. ${ }^{148}$ Voters therefore feel that the policy outcome on the European level is not what the majority would want. ${ }^{149}$ With respect to democratic accountability, this also means that citizens do not feel recognized, in the sense that they are unsure whether politicians are acting in their common interest.

Financial accountability relates to 'the control and elimination of waste and corruption and involves compliance with legal procedures, as well as the use of external audit mechanisms. ${ }^{150}$ This form of accountability is connected to the first stage in the policy-process-chain (see figure 8), thus to the principle of economy. There has been an increase of the attention for financial accountability in the last decade, based on detailed EU rules. Checks by the EC and ECA have also increased. ${ }^{151}$ There are suggestions that an increased focus on financial accountability - and thus economy - might affect the net impact of Cohesion Policy, ${ }^{152}$ leading to less attention for efficiency or even effectiveness. As the EC has put it in the fifth report on economic, social and territorial cohesion: 'A recurrent evaluation finding across all areas of investment was a preoccupation with 'absorption', i.e., with spending the money more than focusing on what the programmes were actually designed to achieve. While the former is obviously a pre-condition for success, the latter is ultimately what matters. ${ }^{153}$

\section{Ad 3. Enforcement mechanisms}

Gustavsson ${ }^{154}$ poses (and answers) an important question in this regard: 'Do EU citizens have real opportunities to hold decision-makers accountable, or does the current institutional set-up in the Union merely create an illusion of accountability , $^{155} \mathrm{He}$ points out that there are democratic mechanisms in place which make it possible for citizens to use their democratic rights: they can vote in favor of the European politician (MEP) of their choice. However, the problem is that the European elections, the elections for members of the European Parliament, do

148 lbid. p. 536.

149 lbid. p. 537.

150 Davies, S. and L. Polverari 2011. 'Financial Accountability and European Union Cohesion Policy', Regional Studies, 45, 695-706, p. 697.

151 lbid. p. 703.

152 lbid. p. 703.

153 European Commission 2010. 'Investing in Europe's future. Fifth report on economic, social and territorial cohesion': European Commission. p. XXI and XXII.

154 Gustavsson, S., C. Karlsson and T. Persson eds. 2009. The illusion of accountability in the European Union. Routledge.

155 Gustavsson, S., Christer Karlsson and T. Persson 2009. 'Examining the illusion of accountability', in S. Gustavsson (ed), The Illusion of Accountability in the European Union: Routledge. p. 1. 
not work well on the European level. On both the European and the national level, where national parliaments should hold the representatives in the Council of ministers (indirectly) accountable, European policies are largely absent in the election debates, because national problems and issues are dominant, also in EP elections, and European issues are in practice not present. ${ }^{156}$ In fact, no real European parties exist for politicizing European issues, ${ }^{157}$ in fact on the European level - visible in the EP - coalitions of national parties are formed based on their political direction. Gustavsson concludes that there are mechanisms available for monitoring and evaluating the actions of EU-decision makers, but they are rather weak.

The argument of Gustavsson therefore is that there seems to be a good institutional context which makes it possible for citizens to hold decision-makers accountable, but in fact real opportunities are lacking. Following $\mathrm{Hix},{ }^{158}$ he pleads for stimulation of opposition on the European level. Without opposition there is not a real choice in the democratic process, citizens do not have a real possibility to show in elections what they really feel about the policies concerned. In fact, this may lead them to turn away from their democratic rights, not feeling recognized, and in fact leading to a democratic deficit. And, as Gustavsson mentions, 'without opposition not even strong accountability mechanisms can offer EU citizens real opportunities to hold their representatives to account in practice. ${ }^{159}$

Curtin recognizes this lack of 'an explicit and effective mechanism of sanctions when people are dissatisfied.' ${ }^{160}$ She stresses that in fact none of the elected members of the EP - and non-elected actors in the European arena - members of the Council and the EC - are really accountable to the public.

\subsubsection{Limitations of accountability in a multilevel context}

As we have described in the introduction of this section, there is no significant specific literature available on accountability in a situation of multilevel governance. However, there is attention for the problems concerning accountability within network governance. Although network governance is not the same as multilevel governance, it can be seen as a proxy: where multilevel governance focuses on the different institutions on different levels (European, national regional), network

156 Hix, S. 2008. What's wrong with the European Union and how to fix it.

157 Abromeit, H. 2009. 'Accountability and democracy', in S. Gustavsson (ed), The Illusion of Accountability in the European Union: Routledge, p. 24.

158 Hix, S. 2008. What's wrong with the European Union and how to fix it.

159 Gustavsson, S., C. Karlsson and T. Persson 2009. 'Taking accountability seriously', in S. Gustavsson (ed), The Illusion of Accountability in the European Union, pp. 170-175, p. 174.

160 Curtin, D., P. Mair and Y. Papadopoulos 2010. 'Positioning Accountability in European Governance: An introduction', West European Politics, 33, 929-945, p. 937. 
governance focuses on the cooperation between public and private institutions. The focus of the literature on network governance on the limitations of accountability, makes it also applicable to a situation of multilevel governance. In this section, we discuss work on this topic of Papadopoulos, Harlow, Busuioc and the ECA.

Papadopoulos has mentioned four problems with respect to democratic accountability within network governance, which also holds for multilevel governance. ${ }^{161}$ The first is the fact that on the one hand 'decisional procedures are often informal and opaque' and on the other hand the fact that 'networks dilute responsibility among a large number of actors'. ${ }^{162}$ This leads to problems with visibility, the fact that controllers lack the possibility to watch and monitor behavior and coupling, which means that they have limited possibility to influence the ex ante behavior of the agent or sanction it ex post. ${ }^{163} \mathrm{He}$ describes that for democratic accountability the fact that decision making is exercised by actors not subject to democratic scrutiny causes problems, specifically because of the fact that it is not clear who is deciding on what and who is responsible for what.

The second problem Papadopoulos mentions has to do with the composition of policy networks. He argues that different actors active in policy networks, being public or non-public actors, in themselves are not (fully) accountable to citizens or the people they represent. ${ }^{164}$ Papadopoulos argues that politicians may not show responsive behavior and other actors may only be indirectly accountable because of a lengthy 'chain of delegation.'165

Third, Papadopoulos speaks of 'two-level games', ${ }^{166}$ meaning that participants in a policy network are both accountable to constituents, but also to their negotiation partners. In fact they have to satisfy multiple 'forums.'

Finally, the last problem is connected to 'peer accountability', referred to be 'based on mutual monitoring of one another's performance within a network of groups, public and private, sharing common concerns.'167 Papadopoulos stresses that

161 Papadopoulos, Y. 2007. 'Problems of Democratic Acountability in Network and Multilevel Governance', European Law Journal, 13, 469-486, and also Papadopoulos, Y. 2010. 'Accountability and Multilevel Governance: More Accountability, Less Democracy?', West European Politics, 33, 1030-1049. We focus here on the first mentioned paper by Papadopoulos.

162 Papadopoulos, Y. 2007. 'Problems of Democratic Acountability in Network and Multilevel Governance', European Law Journal, 13, 469-486, p. 473.

163 lbid. p. 474.

164 Ibid. p. 476-478.

165 lbid. p. 476.

166 lbid. p. 480.

167 Goodin, R.E. 2003. 'Democratic accountability: the Distinctiveness of the Third Sector', European Journal of Sociology, 44, p. 378. 
policy networks are more effective where they are of pluralist nature, representing all preferences. Whether this is really the case is doubted by Papadopoulos which also limits the optimality of resource allocation. As he describes, 'mutual accountability in peer groups can hardly be achieved without some loss of accountability 'at home.' ${ }^{168}$

As a solution, Papadopoulos proposes a stronger role for democratic elected institutions, but also for experts and citizens and finally also a mutual leaning process between network members, political representatives and citizens. ${ }^{169}$

It should be noted that the problems mentioned by Papadopoulos are directly connected to network governance. Although he implies that multilevel governance is similar to network governance, it is questionable whether all these problems also are present in Cohesion Policy.

Another example is the use of different agencies that are given powers to act in behalf of the EU. ${ }^{170}$ But also the involvement of private actors makes it necessary for official EU (or national) institutions to find solutions to solve the accountability deficit. ${ }^{171}$ Kickert ${ }^{172}$ in this way speaks of 'networks of accountability' where a vacuum in the accountability situation, caused by the fact that the hierarchy has declined, is filled by 'self-responsibility'. As Harlow describes, for example in a situation of the Open Method of Coordination, there are hardly any strong obligations or sanctioning mechanisms for the EC to be used. ${ }^{173}$ Harlow $^{174}$ mentions four solutions for this problem of an accountability gap. In the first solution, mentioned by Harlow as the most conventional, gaps caused by the transfer of functions from the national to the transnational level are filled in by new institutions and a process of gradual integration. The second solution is to comprise actor in the prior phase of public policy making. Harlow however considers this not as an adequate substitute for $e x$ post facto accountability. The third solution, of which Harlow is not very enthusiastic either, is about strengthening the checks and balances within the network. State agents can thereby 'operate as a control device to limit opportunistic behavior by

168 Papadopoulos, Y. 2007. 'Problems of Democratic Acountability in Network and Multilevel Governance', European Law Journal, 13, 469-486, p. 482.

169 Ibid. p. 485-486.

170 lbid. p. 482.

171 See Harlow, C. and R. Rawlings Ibid.'Promoting Accountability in Multilevel Governance: A Network Approach', 542-562.

172 Kickert, W. 1993. 'Complexity, Governance and Dynamics: Conceptual Explorations of Network Management', in J. Kooiman (ed), Modern Governance: New Government-Society Interactions: Sage, p. 275, see also Harlow, C. and R. Rawlings 2007. 'Promoting Accountability in Multilevel Governance: A Network Approach', European Law Journal, 13, 542-562.

Harlow, C. and R. Rawlings 2007. 'Promoting Accountability in Multilevel Governance: A Network Approach', European Law Journal, 13, 542-562, p. 543. Ibid. p. 543-545. 
private parties and ensure respect for the public interest,' leading to behavioral pressures. ${ }^{175}$ The last solution is the creation of 'accountability networks,' which Harlow defines as 'a network of agencies working specializing in a specific method of accountability [...] which come together or coalesce in a relationship of mutual support fortified by shared professional expertise and ethos. ${ }^{176}$ As an example of this last solution, Harlow mentions the European Ombudsman.

The research of Busuioc ${ }^{177}$ shows that European agencies do not operate as independent, unaccountable agents, as is sometimes supposed, but instead they are subject to various accountability arrangements that are often in place. The research identifies different accountability regimes, clustered around various accountability forums, such as management boards, the EP, the Council, the ECA or the EC. In the case of European agencies, these are often confronted with different forms of accountability, based on a multitude of obligations (such as reports and hearings), targeted at a broad variety of forums, in some cases even part of a complex accountability cycle, such as the discharge process. Her research shows that there are agencies, especially in the first pillar, that are confronted with an accountability overload, 'with some small agencies subject to a similar set of controls as an institution like the European Commission', ${ }^{178}$ whereas especially in the third pillar, agencies are confronted with a situation of accountability deficit, because of the fact that supranational institutions in their role as 'forum' not always (can) take the needed role in the accountability relationship. She also points to the fact that these different accountability arrangements in place are not always in harmony: several instances of 'Multiple Accountabilities Disorder' are identified in the research. ${ }^{179}$

The research also pinpoints to three essential problems when it comes to accountability of European agencies. ${ }^{180}$

A first problem is the existence of situations of accountability overload, as just mentioned. She considers that 'accountability procedures already in place for the main

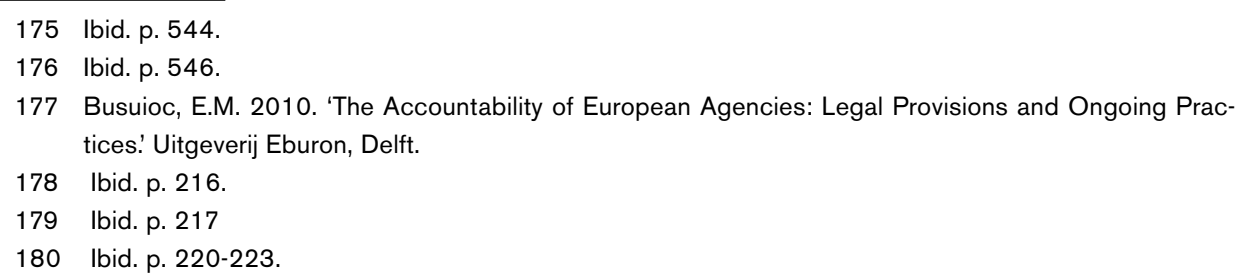


EU institutions were simply transplanted without much forethought as to the extent to which they were compatible with these smaller scale executive organisms.' ${ }^{181}$

Secondly, there are also examples of failure in practice, referring to the role of 'the forum': it should have the time, resources and interest to take its role as principal seriously.

Third, when problems with accountability of European agencies arise, there is often a poor set up of the agency system: 'principals [also] bear shared responsibility for the accountability system they have put in place.'182

The solution that is proposed refers to 'better fine tuning and consolidating some of the arrangements already in place by clarifying, improving and streamlining them for categories of agencies, as well as on clarifying the role of the various institutional actors.' ${ }^{183}$ Also, 'a change in the culture, outlook and mindset of the forum in line with their new roles at the European level ${ }^{184}$ is needed. Since this is an evolutionary process, it will require time to have these changes reaching effect.

In this context, although it does not concern academic literature, it is also important to point at a recent publication of the ECA which concerns a landscape review of EU accountability and public audit arrangements. ${ }^{185}$ The report is the first landscape review issued by the ECA and states 'this review aims to foster further consideration and debate about a topic which is of real importance to the democratic legitimacy of the EUs institutional system. ${ }^{186}$ The report is using the same concept of accountability as is used in this research, based on the work of Bovens ${ }^{187}$ and identifies six elements for a strong accountability and audit chain, which are: ${ }^{188}$

i. clear definition of roles and responsibilities,

ii. management assurance about the achievement of policy objectives (financial and performance reporting);

\footnotetext{
181 lbid. p. 220.

182 lbid. p. 222.

183 lbid. p. 228.

184 lbid. p. 229.

185 European Court of Auditors 2014. 'Gaps, overlaps and challenges: a landscape review of EU accountability and public audit arrangements'. Luxembourg: European Court of Auditors. 2014.

186 lbid. section 5.

187 Bovens, M. 2007. 'Analysing and Assessing Accountability: a Conceptual Framework', European Law Journal, 13, 447-468.

188 European Court of Auditors 2014. 'Gaps, overlaps and challenges: a landscape review of EU accountability and public audit arrangements'. Luxembourg: European Court of Auditors. 2014, section 14.
} 
iii. full democratic oversight;

iv. existence of feedback loops to allow for corrective action/improvements;

v. a strong mandate for independent external audit to verify accounts, compliance and performance; and

vi. implementation of audit recommendations and audit follow-up.

What is interesting, however not very surprising, is that the ECA in these elements is emphasizing the role of public audit in public accountability. ${ }^{189}$

Next to these elements for strong accountability, the report also mentions six important areas where the EU faces accountability challenges, which are:

i. coordinated actions by EU and member states, ${ }^{190}$ focusing on shared responsibility in policy making on both European and national level, such as the implementation of the EU2020 strategy, fiscal and economic coordination under the European semester and the use of intergovernmental instruments, such as the EMU;

ii. funds managed in partnership with others, ${ }^{191}$ pointing at partnerships with institutions outside of the EU and the use of private sector finance;

iii. instruments applicable to a multi-speed $E U,{ }^{192}$ pointing for instance at the Schengen and Euro area;

iv. accountability arrangements for EU institutions and bodies, ${ }^{193}$ focusing on the EU institutions, the origin of their funding and discharge process;

v. EU financial management and control arrangements, ${ }^{194}$ focusing on the accountability mechanisms that are already in place, such as national controls, shared management, sound financial management and the legal framework in place; and

vi. EU policy impact and results, ${ }^{195}$ pointing at a lacking focus on the impact of EU policies, and a strong connection that is needed in evaluation between ex-ante and ex-post assessments.

189 Although we agree with the role public audit can have, we do not necessarily consider public audit to be an element of 'good accountability', but more a means to contribute to public accountability.

190 European Court of Auditors 2014. 'Gaps, overlaps and challenges: a landscape review of EU accountability and public audit arrangements'. Luxembourg: European Court of Auditors, sections 30-42.

191 Ibid. sections 43-65.

192 lbid. sections 66-76.

193 Ibid. sections 77-114.

194 lbid. sections 115-139.

195 lbid. sections 140-149. 
This analysis of the essential elements for strong accountability and areas where the EU faces accountability challenges leads the ECA to the conclusion that accountability should be improved with: ${ }^{196}$

i. a more collaborative system of scrutiny, both on EU and national level;

ii. a more consistent and comprehensive set of across all EU policies, instruments and funds;

iii. better management and control systems on both EU and national level;

iv. a focus on measuring EU policy impact and results; and

v. Reducing costly audit overlaps.

After this overview of the literature on accountability issues in the EU in general, in chapter 3 we turn to accountability in the setting of Cohesion Policy and start with the analytical framework of this research.

\subsection{Conclusions}

This chapter has linked agency theory, accountability literature and the literature on accountability in the EU. Accountability as a concept involves principal agent relationships, where the agent is accountable to the principal. In this chapter, first of all we have mentioned the basics of agency theory, thus the characteristics of a principal-agent relationship. We mentioned the dilemmas of such a relationship, being adverse selection and moral hazard and the risk of the agent showing shirking behavior. These dilemmas and preferences of the actors lead to welfare losses for both the principal and the agent. To prevent these losses, both actors bear investments: the principal in the form of inspection and prevention costs, the agent in the form of bonding costs. As we have shown in section 2.2, in such a situation there is the risk of ending up in a downwards spiral, leading to increasingly higher levels of costs for both actors.

When focusing on the concept of accountability, as discussed in the literature, we have mentioned the four steps of an accountability relationship, the characteristics and elements of such a relationship and the concept of accountability deficit and overload. These different angles of accountability are to be used in the following chapters, when focusing on the accountability relationships in ERDF in the Netherlands.

Finally, we also discussed in this chapter the characteristics and limitations of accountability in the context of the EU. Because of the fact that significant specific literature on accountability in Cohesion Policy is lacking, we have focused on the 
literature on accountability in the EU in general. We have seen that a multilevel governance context creates additional complications regarding accountability.

This research thus contributes to the academic literature on accountability, but instead of remaining on a theoretical and more general level, it focuses on a specific policy area, on Cohesion Policy. Translating the academic literature into a framework for practical use in a policy area will enable researchers - also on other policy areas - to discuss the accountability situation. This makes it possible to further deepen the academic literature on accountability. 




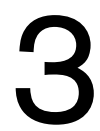

\section{Normative framework for 'good accountability'}

\subsection{Introduction}

After looking at the literature on agency theory, on accountability and on multilevel governance, we will now look at the normative aspect of accountability. Or, in other words, what are the necessary elements of accountability that contribute to a situation of 'good accountability'? The literature on accountability is often abstract and not being used in a specific situation on policy level. ${ }^{197}$ In this research, we translate the elements and characteristics of accountability derived from academic literature into a framework to be used in a specific policy situation, that of ERDF in the Netherlands. Thus, this chapter is addressing 'good accountability' in the context of Cohesion Policy.

We start with discussing the dimensions of accountability, after which we discuss the requirements of 'good accountability' derived from academic literature and we translate these into specific questions to be answered in assessing the situation of Cohesion Policy in the Netherlands.

\subsection{Single and systemic dimension}

As has been described in the previous chapter, accountability consists of different steps, elements, and characteristics. In this research, we focus on Cohesion policy, thus we are looking at a specific policy area. The difficulty, as has been mentioned in the previous chapter, is that accountability in the literature has been described as a unilateral, single relationship between two actors. But when looking at a policy area, and specifically when looking at Cohesion Policy, the situation is more complicated

197 An exception is Polverari, L. 2015. 'Does Devolution Increase Accountability? Emperical Evidence from the Implementation of European Union Cohesion Policy', Regional Studies, 49, 1074-1086. 
because multiple actors and relationships are present, and entail both vertical relationships (between different levels of government, such as European, national and regional) and horizontal relationships (different actors on one level of government). This shows a discrepancy: although the concept of accountability as elaborated in the literature refers to one single relationship, we aim at assessing the situation of accountability within a whole policy area. How will we do that?

Connected to agency theory, the accountability situation of Cohesion policy 'on the ground' consists of all the separate relationships between all actors in the policy area. All these relationships taken together give a view of the accountability situation in practice and enables us to form an opinion on the situation. To be able to judge the accountability situation of Cohesion policy, we use the 'process-based approach to accountability', ${ }^{198}$ describing all relevant actors and forums, thereby exposing the dynamics between the actors. We describe the actors and separate relationships between them, followed by identifying whether there is an accountability relationship. When such a relationship is identified, we look at what that specific relationship consists of and on what issue(s) the agent is to be held accountable for.

Since the accountability situation of a policy sector is not simply an add-up of all the separate single relationships, we should also look at how they interact which each other and what these separate relationships contribute to on the policy level. One can imagine that not all relationships are in fact accountability relationships, and not all accountability relationships show the same characteristics. This means that we should first look at the single dimension, being the relationship between two actors. We look at the nature of the relationship and identify whether the relationship is an accountability relationship or not. This single relationship can have different characteristics, which can be described by asking the questions: who is accountable to whom on what issue(s) and how is the principal using its power to judge?

Second, after we have described all the relationships within the system and characterized them as accountability (or not), we turn to the systemic dimension, where we look at all the different relationships and actors within the system. We use specific characteristics of what both the single and the systemic dimension of a situation of 'good accountability' should look like, which gives us the possibility to give a judgment on the situation of accountability within the policy area. Both aspects of accountability, the bilateral situation between two actors and also the situation on the policy area as a whole, refer to different dimensions of the concept, or put differently, to different angles to look at in the situation of accountability. The single

198 Willems, T. and W.v. Dooren 2012. 'Coming to terms with Accountability', Public Management Review, 14, 1011-1036, p. 1032. 
dimension refers to relationships between two actors, the systemic dimension to the situation of the complete policy area.

This idea of cohesion between the single and systemic dimension is shown in Figure 11, with dots as actors and arrows between them as (possible) accountability relationships.

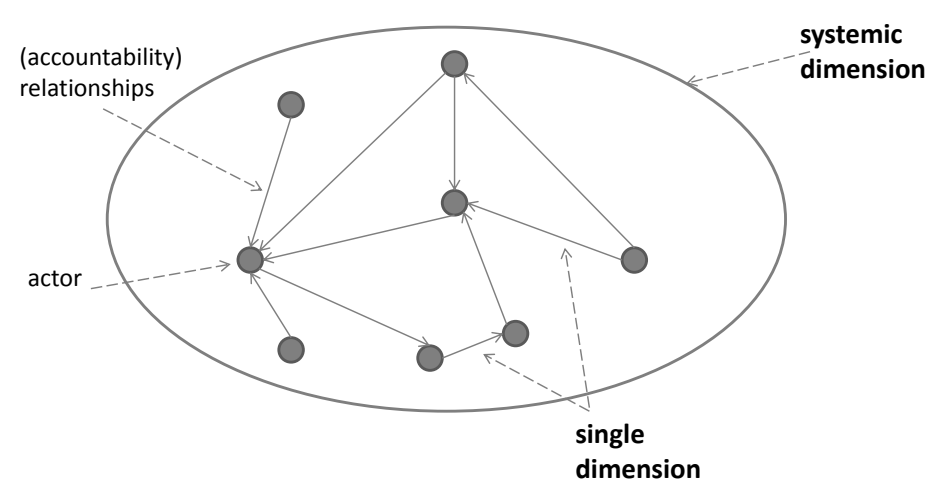

Figure 11. Cohesion between the single and systemic dimension

The single dimension is presented as lines between the actors (dots) and the situation on the policy area level, the systemic dimension, is described by a large circle, containing all the relationships in it.

\subsubsection{Single dimension}

To start with, when looking at the single dimension, which is about the relationship between two actors within the system, it is important to realize there are in fact three levels within the policy area in which such single relationships can occur. This can be on the European, the national or on the regional level. Actors within the system can be positioned within a level, and relationships between all levels can exist. Moreover, even relationships between actors on the European and regional level can exist, which is typically for multilevel governance. ${ }^{199}$ Describing the actors and relationships between all actors leads to the following picture (Figure 12).

All descriptions and classifications of these separate (accountability) relationships give an impression of the situation of accountability within these relationships.

199 Hooghe, L. 1996. 'Reconciling EU-Wide Policy and National Diversity', in L. Hooghe (ed), Cohesion Policy and European Integration: building multilevel governance, pp. 1-24, p. 7. 


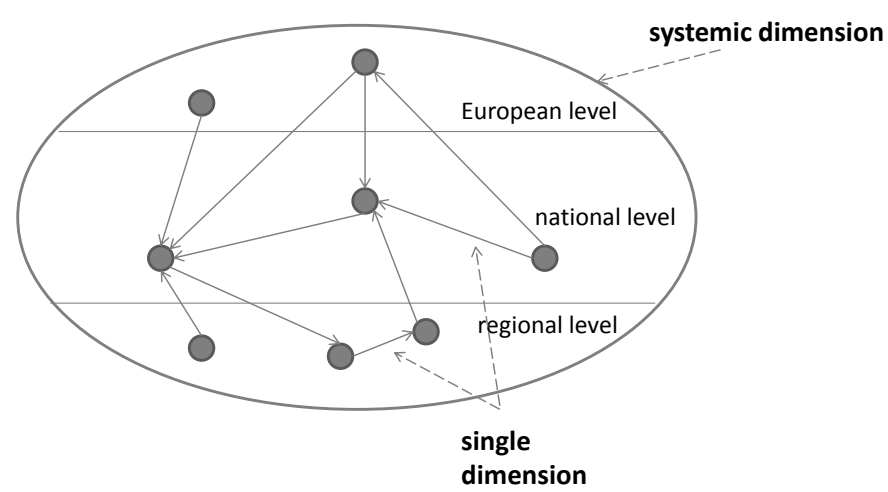

Figure 12. The levels within the systemic and single dimension in this research

\subsubsection{Systemic dimension}

Taking all these single relationships together and looking at specific characteristics of the policy area as a whole enables us to give an opinion on the situation on policy level, thus the systemic dimension. We will be able to describe the situation on this dimension when we have studied the situation on all separate levels. It is important to note that within the systemic dimension, some elements need not necessarily to be visible on all levels, it can be sufficient to be only visible on one level. This means that some elements of accountability should be present somewhere in the system, on at least one of the levels. This is described in Figure 13.

Some of these arrows, being the relationships between the actors on the different levels, can be seen as an accountability relationship (marked in red), or as an informal accountability relationship (blue), or are not to be seen as an accountability relationship at all (grey). Classifying these accountability relationships will enable

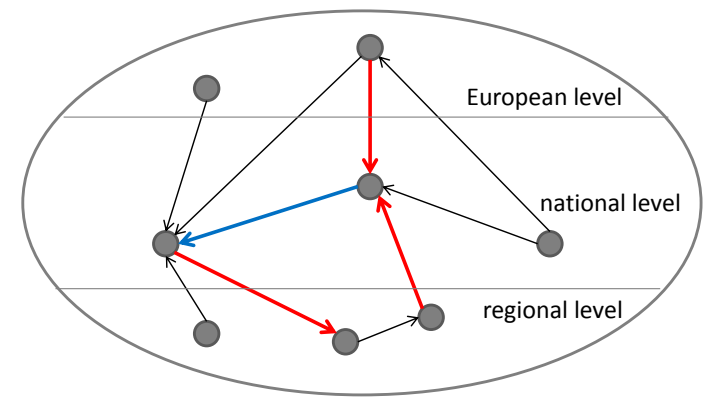

Figure 13. Hypothetical relationships between actors 
us to describe the situation of accountability within the policy area as a whole, i.e. the systemic dimension. Still, whether such a situation can be assessed as 'good accountability' or not, requires that we look into the nature of these relationships. This is done in the following section, where we identify the requirements of 'good accountability' (section 3.3) after which we translate these conditions into questions to be asked and answered on both the single and systemic dimension (section 3.4).

\section{3 'Good accountability': coverage, context, content and costs}

We have formulated four requirements that, following the identification of actors and accountability relationships, enable us to form an opinion on the situation of accountability. These requirements are related to coverage, context, content and costs, as elaborated below.

\section{Coverage: accountability relationships on all levels}

First, we should identify an essential precondition, before being able to judge the accountability situation of a policy area and describing the requirements of 'good accountability'. The basic premise of the idea of 'good accountability', is that there is the existence of accountability relationships within the system. Without these relationships on all levels in the system, there can be no situation of 'good accountability'. We classify the relationships between the actors within the policy area according to the four components as described in the previous chapter, which are:

a) Assignment of responsibilities;

b) Reporting by the agent;

c) Information seeking or investigating and also verification by the principal; and

d) Direction or control by the principal, possibly posing sanctions on the agent. ${ }^{200}$

In practice, we see there are in fact three possibilities when a relationship is judged on the criteria for an accountability relationship. The first conclusion is that a relationship cannot be characterized as an accountability relationship, the characteristics as just mentioned are not visible. Secondly, there is the situation where the relationship does tick all the boxes of an accountability relationship. And finally, the third option

200 Based on Mulgan, R. 2008. 'The Processes of Public Accountability', Australian Journal of Public Administration, 56, 25-36, p. 19, Fisher, E. 2004. 'The European Union in the Age of Accountability', Oxford Journal of Legal Studies, 24, 495-515, p. 497, following Davies, A. 2001. Accountability: A Public Law Analysis of Government by Contract. Oxford: Oxford University Press, and Thomas, P.G. 1998. 'The Changing Nature of Accountability', in B. Guy Peters and D.J. Savoie (eds), Taking Stock: Assessing Public Sector Reforms Canadian Centre for Management Development, pp. 348-393, p. 352. See also section 2.3.1. 
is that the relationship satisfies one or more of the criteria, but not all of them. This third option can appear as one of the following three options:

- It satisfies the first three criteria of an accountability relationship, but not the fourth one, on the sanctioning mechanism. As derived from literature, we consider the expectation of being called to account ${ }^{201}$ as the core element of an accountability relationship, thus with the possibility being faced with sanctioning mechanisms. But even without sanctioning mechanisms, the principal should be able to act upon the behavior of and results achieved by the agent. We therefore distinguish between accountability relationships with and without sanctioning mechanisms (formal or complete, as mentioned in the second possibility above, versus informal accountability relationships);

- Secondly, as we will see later on, there is also the option that what seems to be an explicit accountability relationship, where all four steps are present, in practice is not really an accountability relationship, for instance because an agent is being held accountable towards a principal for the actions of another agent, or because the agent is not practicing its role as a principal. We call these relationships indirect accountability relationships;

- Finally, we will also identify relationships where the agent is giving an opinion on the functioning of one or more actors or the system as a whole. In that case, we will not be classifying this relationship as an accountability relationship. However, these relationships are important to also incorporate in the research, because these actors, in fact monitoring agents, ${ }^{202}$ also have a role and influence on the actors and relationships within the system. We call these relationships monitoring relationships.

In connection to this essential precondition, we consider that, in order to have a situation of 'good accountability', there should be accountability relationships present in the system on all levels. Without these accountability relationships in the system, there can be no situation of 'good accountability'.

The first and basic requirement of 'good accountability' is thus that there are in fact (complete) accountability relationships within the system and that they are visible on all levels. This does not necessarily mean that all relationships within the system should be able to be assessed as accountability relationships, but that at least some of them should. This leads us to the first requirement: 


\section{Requirement 1.}

On every level - European, national and regional - at least one actor should be present in an (complete) accountability relationship: either with an actor on the same level or on another level. Also, it should be clear of all accountability relationships which actors are accountable on what.

\section{Context: elements of transparency, democracy and legal constraint}

As derived from the literature, important elements of accountability are transparency, democracy and legal constraint. These elements give some sort of counterweight to single accountability relationships and therefore can be seen as essential requirements of 'good accountability'. To start with, without transparency, it is not possible for actors to hold an agent really to account. As Dyrberg has put it: 'how can the public hold public authorities accountable if the public is not allowed to know what goes on within the public authorities, or if what goes on is obscure? ${ }^{203}$ Thus transparency brings information into the open and makes it possible for (other) actors to hold an agent to account. In a situation of 'good accountability', there is thus a certain amount of transparency, to give a counterweight to a single principal-agent relationship.

Regarding the element of democracy we also expect a counterweight balancing effect. Democracy is also an important element of accountability. In public governance 'the people' are characterized as the ultimate principals and therefore play an important role, all relationships within the accountability framework of public governance do end up with voters or citizens in the end. ${ }^{204}$ Elections give a pressure on actors subject to elections, knowing they can be voted away by voters. Since elected actors also have a role in the policy area of Cohesion Policy, we also expect pressure from this democratic element, although in practice this might be limited. ${ }^{205}$

Finally, legal constraint as an important element also plays a role in 'good accountability'. The function of legal constraint is (also) a counterbalance to the principalagent relationship, in the way that there is a possibility to bring a case before court.

203 Dyrberg, P. 2002. 'Accountability and Legitimacy: What is the Contribution of Transparency?', in A. Arnull (ed), Accountability and Legitimacy in the EU: Oxford University Press, pp. 81-96, p. 83.

204 See for instance Mulgan, R. 2008. 'The Processes of Public Accountability', Australian Journal of Public Administration, 56, 25-36, p. 29, Dowdle, M.W. 2006. 'Public accountability, conceptual, historical and epistemic mappings', in M.W. Dowdle (ed), Public Accountability. Designs, Dilemma's and Experiences: Cambridge University Press, pp. 1-29, p 3 and Gustavsson, S., Christer Karlsson and T. Persson 2009. 'Examining the illusion of accountability', in S. Gustavsson (ed), The Illusion of Accountability in the European Union: Routledge. p. 4.

205 See Gustavsson, S., Christer Karlsson and T. Persson 2009. 'Examining the illusion of accountability', in S. Gustavsson (ed), The Illusion of Accountability in the European Union: Routledge. p. 4. 
Thus there is another actor that has a possibility to rule in a certain case and can have an influence on the accountability relationship concerned. In the system as a whole in a situation of 'good accountability', we consider there should be a role for legal actors to also, next to transparency and democracy, provide a counterweight in a single accountability relationship. This leads us to the second requirement:

\section{Requirement 2.}

The elements of transparency, democracy and legal constraint should be visible and give enough pressure as a counterweight within the system.

\section{Content: the 3 E's - economy, efficiency and effectiveness}

The third requirement points at the object of an accountability relationship. As has been described in the previous chapter dealing with the academic literature on accountability, an important question is what the object of accountability is, or what an accountability relationship is all about. On the one hand there can be a focus on procedural or compliance elements of a policy area, also called legality. This means that the relationship focuses on issues related to the procedures connected to compliance issues, such as timely reporting or whether an agent is respecting legal rules. On the other hand, there should be a focus somewhere in the system on the content of accountability, thus at the ' $3 \mathrm{E}$ 's,', ${ }^{206}$ not only on process-elements. What can be seen in practice is that determining efficiency or effectiveness is very difficult, which leads to a 'prolaps' back into the chain, thus a focus on economy, which - in terms of the monitoring and management activities needed - generally combines well with a focus on legality. ${ }^{207}$ However, all three elements of the policy process chain are important in accountability. An accountability relationship thus should not (solely) be about the process, but actually also on (at least one of) the elements of the policy process chain, on economy, but specifically also on efficiency or effectiveness.

Not necessarily all relationships within the system need to have a focus on the policy process chain, but within the system as a whole, there should be some relationships visible that focus on the chain. Moreover, on all levels in the system, on European, national and regional scale, these three elements of the policy process chain should be visible somewhere, or put differently, on all levels one of these three

206 See figure 8 on the policy process chain, focusing on economy, efficiency and effectiveness, thus the 3E's.

207 Damen, M. and N. Groenendijk 2012. 'Performance auditing in EU Cohesion Policy: what do we know and what should we know?', ECSA-C 9th Biennial conference 'Europe in an Age of Austerity: Integration, Desintegration, or Stagnation?'. Ottawa, pp. 1-12, p.2. 
elements should be visible, to have all levels connected in the accountability chain of the policy area. This leads to the third requirement:

\section{Requirement 3.}

Economy, efficiency and effectiveness should all be visible somewhere in the system and on all levels at least one of the three elements should be visible.

\section{Costs: absence of accountability deficit or overload}

Finally, the last precondition is directed at the extremes of an accountability situation: it should be balanced, in the way that there is no situation of accountability deficit or overload. ${ }^{208}$ This mainly relates to the cost aspect of an accountability situation. The question now is how we classify these situations. We describe three conditions that lead to a situation of accountability overload or deficit, thus not leading to 'good accountability'.

The first condition refers to the match between the mechanisms used by the principal to influence the agent and the preferences of both actors. By using mechanisms of direction, the principal is trying to direct the agent at achieving the best results for the principal. We have also seen that the agent is showing shirking behavior, which is a risk to the principal and the achievement of its desired results. It is important that the mechanisms used by the principal to direct the agent match the risk of the agent showing shirking behavior. This risk on shirking behavior by the agent is higher in a situation where the preferences of the principal and the agent diverge. On the other hand, when their preferences converge, this risk will be lower. The principal will have to match the mechanisms it uses to influence the behavior of the agent with this shirking risk and thus with the degree of convergence (or divergence). When there is an imbalance between these mechanisms and the shirking risk, it will lead to extra costs for the principal and/or high burdens for the agent. Thus in a situation of 'good accountability', there is a balance between both the mechanisms used by the principal and the shirking-risk of the agent. We can show this in Figure 14.

It shows that there is a situation of accountability overload when in a situation of convergence between the principal and the agent, the principal is using strong mechanisms to influence the behavior of the agent. On the other hand there is a situation of accountability deficit when in a situation of divergence between the principal and the agent the principal is using weak instruments to influence the 


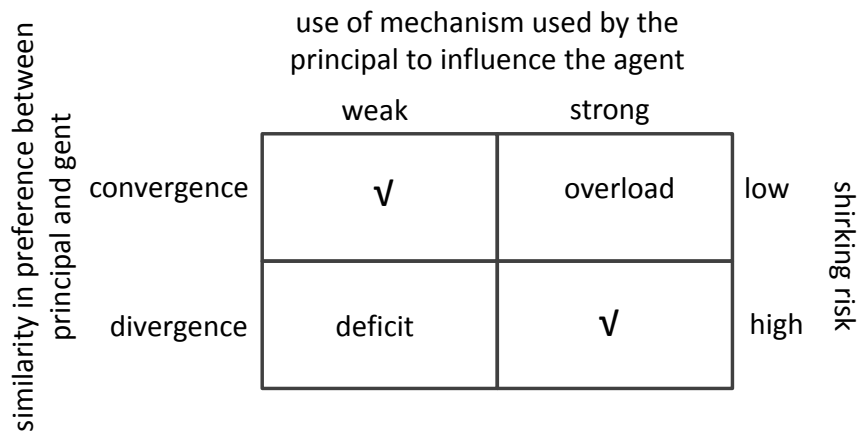

Figure 14. Relationship between preferences and mechanisms

behavior of the agent. Both situations are undesirable and do not constitute a situation of 'good accountability'.

Another important condition is connected to the costs of a principal agent relationship. As we have seen in section 2.2., both the principal and the agent bear costs in a principal agent relationship. The principal is confronted with monitoring costs, whereas the agent is bearing bonding costs. We have also seen that such a situation between a principal and an agent is having the risk of ending up in a downwards spiral with both high monitoring and bonding costs. There is the risk that both actors are maximizing these activities without it leading to more welfare for one or both of them. When this is the case, the costs in the policy area will rise excessive. This is a typical situation of accountability overload. In a situation of 'good accountability' there is a healthy balance between the costs of both actors, thus staying away from the potential downwards spiral.

Additionally as a third condition, as has been described by Bovens, ${ }^{209}$ there are explicit elements that indicate a situation of accountability overload, when a regime:

a. imposes extraordinarily high demands on the agent's limited time and energy;

b. contains a comparatively large number of mutually contradictory evaluation criteria for the agent;

c. contains performance standards that extend way beyond their own and comparable authorities' good practices; 
d. contains performance standards that seem particularly conducive to goal displacement or subversive behavior.

The extremist position is when all four elements are in place. When we identify at least one of these four criteria, we classify the situation as accountability overload, thus leading to an undesirable situation. This then leads to our final requirement:

\section{Requirement 4.}

The situation within the policy area should be balanced in the way that there is no situation of accountability deficit or accountability overload.

\subsection{Application of the framework in this research}

To be able to answer the question whether there is a good situation of accountability in Cohesion Policy, focusing on ERDF in the Netherlands, the empirical part of this research is divided into three components.

The first component focuses on identifying the actors and accountability relationships within the system. This section is based on documents research and can be found in section 4.2 .

After having identified the actors, we look at the relationships between them and at some specific questions to be answered on the single dimension, referring to individual accountability relationships. The questions to be answered on single level are:

a. What (kind of) documents are produced by the actors in the accountability relationship and are these publicly accessible?

b. How is the accountability relationship connected to democratic elements (such as elections)?

c. Are there legal possibilities to be used in the accountability relationship, and if so, which?

d. Which elements of the policy process chain are visible in the accountability relationship?

e. What are the preferences of both the principal and the agent and to what extent do they converge or diverge?

f. What mechanisms are used by the principal in the accountability relationship and to what extent do they match the preferences?

g. Can a downwards spiral be seen in the monitoring costs of the principal versus the bonding costs by the agent?

$h$. Is any of the four elements of accountability overload visible in the accountability relationship? 
In chapter 4, answers are given on these questions on the single dimension for all accountability relationships that are identified, based on document research. Chapter 5 then also focuses on these questions on the single dimension, but these are based on interviews with actors active in the policy area of Cohesion Policy in the Netherlands, focusing on ERDF, as identified in section 4.2. Both chapters 4 and 5 then give answers to the questions on single dimension.

With this information available, it is possible to answer the questions on the systemic dimension and in fact test whether the requirements we have formulated in this chapter are visible and thus whether there is a situation of 'good accountability' in ERDF in the Netherlands. This is the third component of the research, which is elaborated in chapter 6.

The following questions are answered when looking at the systemic dimension:

A. Is an actor present in an accountability relationship on every level (European, national and regional) or not?

B. Are all three mentioned elements visible in the system and leading to (external) pressure on the accountability relationship?

C. Are all elements of the policy process chain visible somewhere in the system?

D. Are there one or more accountability relationships within the system where the mechanisms used by the principal do not match the preferences of both actors?

E. Are there one or more accountability relationships within the system where a downwards spiral in higher monitoring and bonding costs can be seen?

F. Are any of the four elements of accountability overload visible within the system?

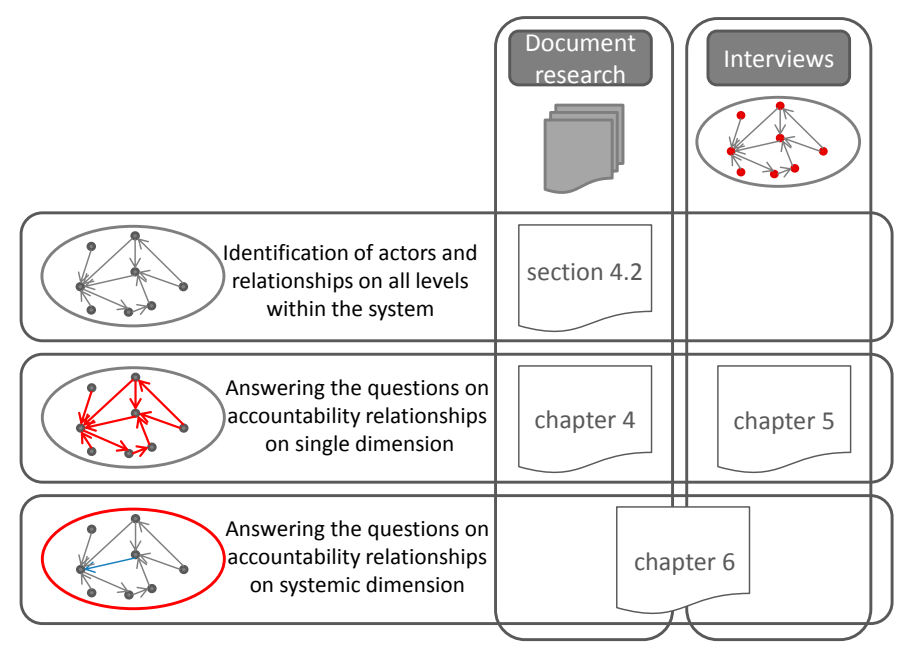

Figure 15. Overview of the components of this research 


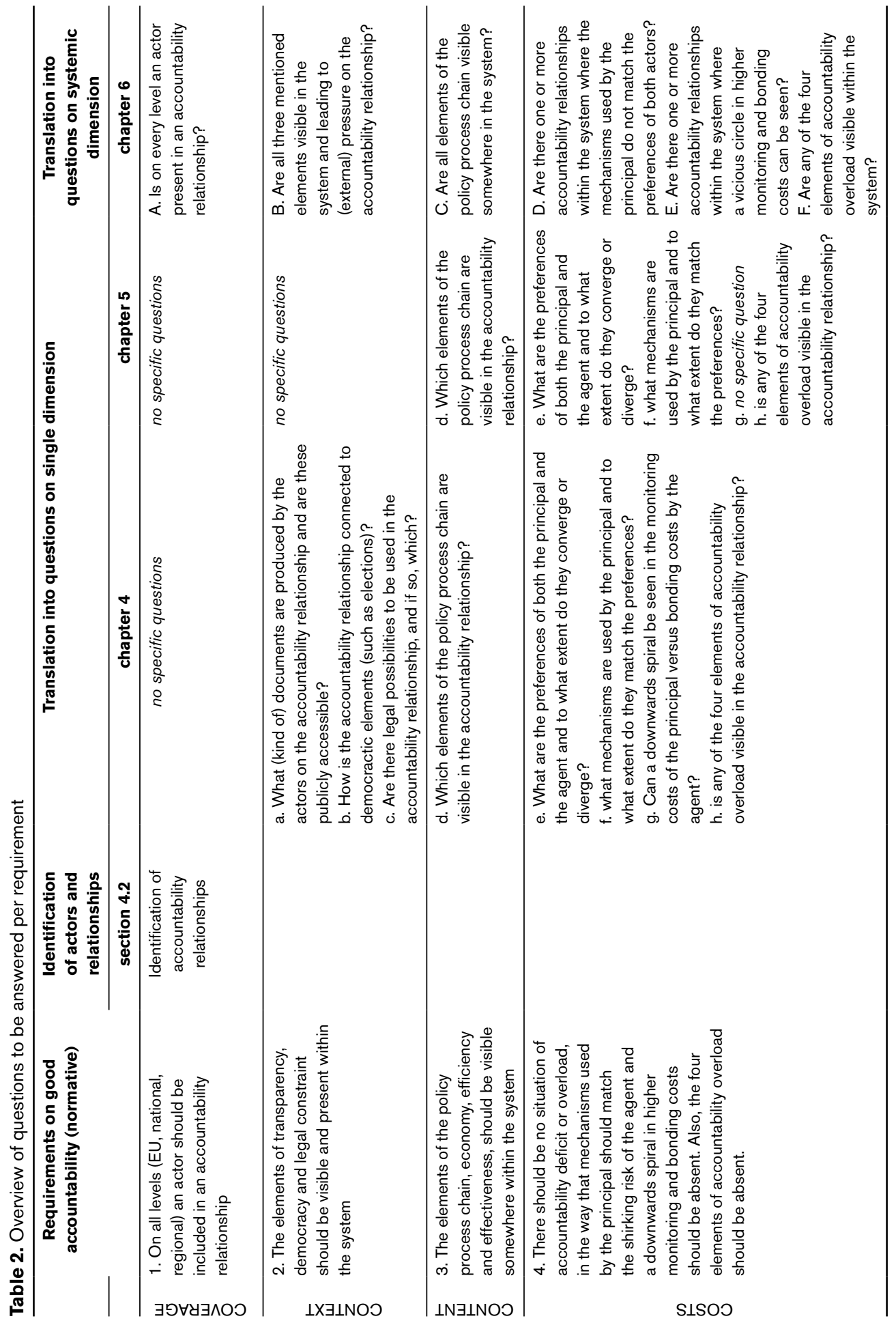


This chapter then is based on information both from documents as from the interviews and allows us to give a judgment on the accountability situation in the Netherlands, based on the questions on the systemic dimension. These three components of this research can be found in Figure 15.

Summarizing, this leads to an overview of the questions that are answered in the different components of this research, as shown in Table 2.

\subsection{Conclusions}

This chapter has given an outline of the framework of this research, based on agency theory and the academic literature on accountability. Four requirements have been formulated for having a situation of 'good accountability', which can be put in a figure as follows in figure 16. We look at both single (individual relationships within the system) and systemic dimension (all relationships together) to see whether there is a situation of 'good accountability' within Cohesion Policy, specifically focusing on ERDF, in the Netherlands.

\section{GOOD ACCOUNTABILITY}

On every level - European, national and regional- at least one actor should be present in an (complete) accountability relationship: either with an actor on the same level or on another level. Also, it should be clear on all accountability relationships which actors are accountable on what

The elements of transparency, democracy and legal constraint should be visible and give enough pressure as a counterweight within the system

Economy, efficiency and effectiveness should all be visible somewhere in the system and on all levels at least one of the three elements should be visible

The situation within the policy area should be balanced in the way that there is no situation of accountability deficit or accountability overload.

Figure 16. Requirements of 'good accountability' 
These four requirements are translated in sub-questions and are used in this research to assess the situation of ERDF in the Netherlands. Every relationship between actors that are identified in section 4.2 in the following chapter is judged according to the answers on the questions as just formulated and thus on the requirements of 'good accountability'. The results of this analysis allow us to give a classification of accountability within Cohesion Policy, specifically focusing on ERDF in the Netherlands. 



\section{4}

\section{The Dutch case - actors, relationships and accountability characteristics}

\subsection{Introduction}

After having described the analytical framework, we now turn to the Dutch case. As a characteristic of multilevel governance, it is a fact that implementation of policies differ across the member states within the EU. Every member state has its own institutional characteristics, which has its influence on the different actors and their relationships, on the national and regional or local level, and thus on the way of implementation of Cohesion Policy. In this research, we focus specifically on the Netherlands, which means we will have to look at the specific institutional characteristics of the Netherlands as a member state and at the specific characteristics of the implementation of Cohesion Policy in this member state.

We identify the accountability situation of ERDF operational programmes by elaborating the situation on the European, national and regional level. When we look at the regional level, or when illustrating a specific situation, we use OP 'Noord-Nederland' ('OP Noord'), directed at the three Northern Provinces Fryslân, Groningen and Drenthe. This is done in a specific textbox.

To be able to describe the situation of ERDF in the Netherlands, we start by identifying all relevant actors in the system of Cohesion Policy and the relations between them in section 4.2. After that, in sections 4.3, 4.4, 4.5 and 4.6, we turn to the second component as mentioned in chapter 3 with describing and identifying the accountability relationships within the system (on respectively European, national, clustered European and national and finally on regional level) and answering the questions we have drafted for this component of the research. We focus in this research on the 2007-2013 period, but where changes are to be seen in the 2014-2020 period, we mention these in the specific sections. This is specifically to 
be seen in the section on the relationships on the national-European cluster (section 4.5), where major changes in the 2014-2020 period have significant effects.

As far as possible we focus on the specific situation of Cohesion Policy. However, it is not possible in all relationships to focus on this policy area, because of the fact that Cohesion Policy is sometimes only a small part of policy making or implementation when it comes to a specific relationship, for instance in the relationship between the Council and the European Commission. When this is the case, it is addressed explicitly.

\subsection{The actors on European, national and regional level}

Before turning to the accountability relationships within the system of Cohesion Policy for ERDF in the Netherlands, we first identify the most important organizations that play a role. After that, we turn to the national and regional institutions and focus on those directly involved in Cohesion Policy. We also briefly describe the relationships between the actors.

Although we do not mention them separately at the different levels, it is important to start with 'the people', because they are also an actor in the accountability system of Cohesion Policy. In public governance 'the people' are characterized as the ultimate principals ${ }^{210}$ and therefore play an important, though not always visible, role. Since citizens can use their power in elections for members of parliament, being on European, national or regional level, we also mention the relationship with 'the people' briefly on each level, although these relationships are not the focus of this research.

\subsubsection{The European level}

\section{European Commission}

The most important actor in Cohesion Policy on the European level is the EC. Its main responsibilities are laid down in article 17 of the Treaty on the European Union, ${ }^{211}$ which describes in section 1 that the EC amongst others 'shall execute the budget and manage programmes.' Regarding Cohesion Policy, more specific tasks are laid down in regulation 1083/2006, where it is stated that Cohesion Policy is appointed as a policy area where shared management ${ }^{212}$ is used, as a means to express the responsibilities of both the EC and the member states. This makes the EC an influential actor in implementing Cohesion Policy. The EC has relationships

210 See also sections 2.3.2 and 4.3.1.

2112012 . 'Treaty on the European Union and the Treaty on the functioning of the European Union ', 2012/C $326 / 01$.

212 Art. 1 and 14 of Regulation 1083/2006. 
with all actors on European level, but also on national level with the member states and on regional level with the management and audit authorities. This makes the EC one of the key institutions in Cohesion Policy.

\section{European Parliament}

As in all legislation, the EP also has an important role. The EP 'shall exercise functions of political control and consultation ${ }^{213}$ and therefore also has a central role in Cohesion Policy. The Committee on Regional Development in the EP ${ }^{214}$ (REGI) is responsible for Cohesion Policy matters. Issues on Cohesion Policy are also dealt with in the CONT committee, on budgetary control. Decisions of the EP are however made in plenary sessions where all parliamentarians can vote on the issues concerned.

\section{(European) Council'15}

Both the European Council, consisting of the heads of state or government of the member states, and the Council (of ministers), consisting of representatives of each member state on the ministerial level, have an important role in policy making on European level. Both are representative organs of the member states, where the former defines the general political directions and priorities ${ }^{216}$ of the EU and the latter exercises legislative and budgetary functions, together with the EP. ${ }^{217}$ Decision making on Cohesion Policy in the European Council is mainly limited to the multi annual framework every seven year period. More specific issues are dealt with in the Council, although there is no specific configuration dealing with Cohesion policy within the Council. Preparation of Council meetings is done by the Committee of Permanent Representatives of the Governments of the member states to the European Union (Coreper). It has more than 150 highly specialised working parties and committees, known as the 'Council preparatory bodies,' ${ }^{218}$ of which some focus on Cohesion Policy. ${ }^{219}$

213 Art. 14 of the Treaty on the Functioning of the EU.

214 See for more information the website of the Committee: http://www.europarl.europa.eu/committees/en/ regi/home.html, retrieved at 28-10-2015.

215 Since the involvement of the European Council in Cohesion Policy decision is rather limited, we specifically focus on the Council (of ministers). When we do focus on the European Council, this is mentioned explicitly.

216 Art. 15 section 1 of the Treaty on the Functioning of the EU.

217 Art. 16, section 1 of the Treaty on the Functioning of the EU.

218 See for more information the website of Coreper: http://www.consilium.europa.eu/en/council-eu/ preparatory-bodies/, retrieved at 28-10-2015.

219 For instance Working Party on Competitiveness and Growth and Working Party on Structural Measures. 


\section{European Court of Justice}

The judicial actor on the European level is the ECJ, responsible for the interpretation and application of the law. ${ }^{220}$ It is therefore a reactive actor, meaning it is only present in the field of Cohesion Policy when specific cases are brought for the ECJ, or for national courts in the case of preliminary rulings.

\section{European Court of Auditors}

Finally, an important institution on the European level for Cohesion Policy is the ECA. It is carrying out the Unions audits. ${ }^{221}$ It provides the EP and the Council with a statement of assurance as to the reliability of the accounts and the legality and regularity of the underlying transactions. ${ }^{222}$ It has not been able to provide a positive declaration of assurance since its introduction in 1995. The ECA uses a level of materiality of $2 \%$, but Cohesion Policy has not been below that threshold since the rates were published. Compared to the other policy areas, the error rate of Cohesion Policy is very high and persistently has been above the materiality threshold, and even above the $5 \%$ threshold.

\subsubsection{The national level}

The implementation of Cohesion Policy on national level in the 2007-2013 period leans for a great deal on regulation 1083/2006 (afterwards 'the Regulation'), where provisions are set for the implementation, also on national level. It describes the functions of different bodies that are to be designated in the execution of Cohesion Policy. To start with, it is important to note that the Regulation points at the EC and the member states as the main institutions responsible for the implementation and the management of Cohesion Policy. ${ }^{223}$

\section{The member state (Ministry of EZ)}

The Regulation mentions the member states as an actor, which means in the case of the Netherlands the Ministerie van Economische Zaken (Ministry of Economic Affairs, EZ) ${ }^{224}$ for ERDF and the Ministerie van Sociale zaken en werkgelegenheid (Ministry of Social Affairs and Employment, SZW) for ESF. Both Ministers leading these ministries are responsible for the execution of the policy and the use of the respective SF. When looking at the regulation, when it says 'member state', the

220 Art. 19, section 1 of the Treaty on the Functioning of the EU.

221 Art. 285 of the Treaty on the Functioning of the EU.

222 Art. 287, section 1 of the Treaty on the Functioning of the EU.

223 See for instance art. 11 of Regulation 1083/2006.

224 See the website of EZ for more information: http://www.rijksoverheid.nl/onderwerpen/europesesubsidies/structuurfondsen-versterken-regio-s, retrieved at 12-02-2015. 
ministry concerned is meant. In the case of ERDF in the Netherlands, it then refers to the Ministerie van Economische Zaken (further on mentioned as 'EZ').

There is also a role for the Minister of Finance in the implementation of Cohesion Policy in the Netherlands, because he signs the National Declaration of Assurance (DAS) on behalf of the government. Since the national DAS is not obligatory, the role of the Minister of Finance and the national DAS has not been laid down in the $1083 / 2006$ regulation. ${ }^{225}$

\section{The parliament and the government}

Next to being a kingdom, the Dutch system is called a parliamentary democracy. This means the ultimate power within the system rests with the parliament, consisting of two chambers, Eerste Kamer (the Senate) and Tweede Kamer (the House of Representatives, further on also referred to as ' $T K$ '), represented by respectively 75 senators and 150 members of parliament. ${ }^{226}$ The members of parliament of TK are chosen in direct elections by the citizens, ${ }^{227}$ the members of the Eerste Kamer are indirectly chosen by the representatives that have been chosen - directly - in the twelve provincial councils. ${ }^{228}$

As has been laid down in the constitution, laws are adopted by the government and the parliament together. ${ }^{229}$ Although both chambers are responsible for decisionmaking, the most important chamber in terms of handling and adjustment of legislation is the TK; in this research we therefore specifically focus on this chamber when talking about the role of the parliament, unless otherwise stated. The role of the Eerste Kamer, as a chambre de reflection is more on preventing 'hasty legislation.'230

The government consists of the ministers and the King, who also has to sign for laws. However, he is not supposed to have direct influence on the decision-making within the government. As De Jong describes, 'under pressure of an improvingly stronger parliament, the emphasis within the government has shifted from the non responsive king to the responsive minister. ${ }^{231}$ This means that although the King

225 But, as we mention in section 4.5.1, in the period 2014-2020 the national DAS is mentioned as an option to be used in the $1303 / 2013$ regulation.

226 Article 51 of the Dutch constitution.

227 Article 54, section 1 of the Dutch constitution.

228 Article 55 of the Dutch constitution.

229 Article 81 of the Dutch constitution.

230 Denters, S.A.H. 1995. 'De parlementaire democratie', in J.W. Van Deth and P.A. Schuszler (eds), Nederlandse Staatkunde. Een elementaire inleiding.: Countinho, pp. 85-103, p. 86.

231 De Jong, H.M. Ibid.'De Constitutionele Monarchie', in J.W. Van Deth and P.A. Schuszler (eds): Coutinho, p. 70, translated from Dutch. According to article 42 section 2 of the Dutch Constitution, the King is 
has a function within the government, as laid down in the constitution, in practice the ministers solely perform the function of the government.

\section{Other actors on national level}

Within the Netherlands, ERDF is implemented by four regional authorities, which all have drafted an Operational Programme (OP). They relate to the four quarters of the compass: North, East, West and South. ${ }^{232}$ ESF is implemented on a national scale, which is managed by Agentschap SZW. Since our research focuses on ERDF, we leave the details of ESF behind. As has been laid down in article 59 of the Regulation, the member state has to designate for each OP a managing authority (MA), a certifying authority (CA), and an audit authority (AA).

\section{Managing Authority}

For the implementation of ERDF in the regions four MAs have been appointed, one for each region and for each OP.

\section{OP Noord-Nederland}

With Besluit EFRO programmaperiode 2007-2013 (EFRO Resolution), the Northern Netherlands Provinces alliance (Samenwerkingsverband Noord-Nederland, afterwards 'SNN'), has been appointed as MA. The organization is an alliance between the three Northern provinces Fryslân, Groningen and Drenthe, which was established as a joint operating agency in 1992.

The tasks of an MA are extensively defined in the Regulation. ${ }^{233}$ In short, the MA is responsible for managing and implementing the OP. Its specific obligations are:

a. Ensuring that the projects are selected according to the criteria set, and that these projects comply with all relevant rules;

b. Verifying that the products and services that are subsidized are delivered and that costs declared have been occurred and comply to all relevant rules;

insusceptible.

232 Next to these regional OPs, there is also an international OP for European Territorial Cooperation (ETC), which is called Interreg. In this research, as stated in chapter 1, we primarily focus on the four regional EDRF OPs.

233 See specifically art. 60 of Regulation $1083 / 2006$, but also art. 13 of Regulation 1828/2006. 
c. Recording and storing accounting records on the implementation of the programme and ensuring that relevant data are collected;

d. Ensuring that beneficiaries maintain relevant data;

e. Ensuring that evaluations are carried out according to the rules;

f. Setting up procedures to ensure an adequate audit trail;

g. Ensuring the CA receives all relevant information for its work;

h. Guiding the work of the monitoring committee of the OP;

i. Drawing up and submitting the annual and final reports of implementation;

j. Ensuring compliance with the information and publicity requirements;

k. Providing the EC with information on major projects.

This means the MA is responsible for the day-to-day management of the programme, and that it can decide upon granting a financial contribution from ERDF to projects . $^{234}$

The MA has a direct connection with the Ministry of $E Z$, the CA and AA. On European level most contacts are with the EC.

\section{Certifying Authority}

Dienst Regelingen ${ }^{235}$ is appointed as CA for the regional ERDF OPs in the 20072013 period in the Netherlands, which has also been laid down in resolution EFRO programmaperiode 2007-2013. ${ }^{236}$ The CA has been appointed for all five ERDF $\mathrm{OPs}^{237}$ in the Netherlands. The task of the CA has been laid down in article 61 of the regulation. In short, its task is to certify the statements of expenditure that are to be send by the MA to the EC. The specific obligations as laid down in article 61 of regulation $1083 / 2006$ are:

a. drawing up and submitting certified statements of expenditure and applications for payment;

b. verifying that the statement of expenditure is accurate, reliable and verifiable, and that the expenditure complies with all relevant rules;

c. ensuring it has received adequate information of the MA on the procedures and verifications;

d. taking account of the results of all audits carried out by the audit authority;

e. maintaining accounting records of the expenditure;

f. keeping an account of amounts recoverable and amounts withdrawn.

234 Article 6 of Besluit EFRO programmaperiode 2007-2013.

235 As of 1-1-2014, Dienst Regelingen has been merged with AgentschapNL and is now named Rijksdienst voor Ondernemend Nederland (RVO).

236 Article 8, section 1 of Besluit EFRO programmaperiode 2007-2013.

237 The fifth OP, next to the four regional ones mentioned, is the European territorial cooperation programme, INTERREG. 
This means that the CA comes into the system when an MA is sending a statement of expenditure to the EC and is asking for a payment. This is often done a few times a year. The CA has direct relations with the MA, but it is also audited by the $A A$, just like the MA is. Because it is part of the Ministry of $E Z$, it also has close relations with this ministry.

\section{Audit Authority}

Auditdienst Rijk (the Audit authority of the Ministry of Finance) is appointed as AA for all four regional ERDF OPs in the 2007-2013 period in the Netherlands. ${ }^{238}$ As with the CA, the AA is appointed in the Resolution by the Minister of EZ.

The AA is responsible for audits on the management and control system of ERDF and performs audits on specific projects that are subsidized by the OPs. It acts on the basis of an audit strategy that has been agreed upon with the EC. ${ }^{239}$ More specifically, the tasks of the AA are: ${ }^{240}$

a. carrying out audits on the management and control system of the OP;

b. carrying out audits on operations within the OP (which means on specific projects that are subsidized);

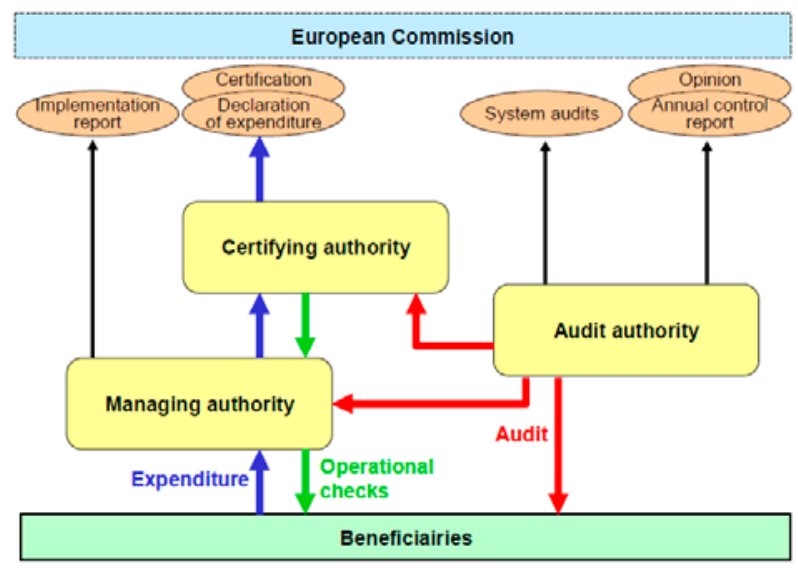

Figure 17. The governance system of Cohesion Policy

Source: European Commission 2013. 'Annual Activity Report 2012': DG Regional and Urban Policy. p. 30.

238 Article 9, section 1 of Besluit EFRO Programmaperiode 2007-2013.

239 See article 73 of Regulation 1083/2006.

240 Article 62 of Regulation 1083/2006. 
c. presenting the EC an audit strategy at the start of the OP, which should be agreed upon with the EC;

d. submitting an annual control report on the audits carried out and issuing an opinion on the management and control system;

e. submitting a closure declaration at the end of the programming period.

To recapitulate, the relationship between MA, AA and CA is graphically outlined by the EC in Figure 17.

\section{Algemene Rekenkamer}

Next to these organizations that play a role on the national level, the Dutch Court of Auditors, de Algemene Rekenkamer (AR), also is involved in Cohesion Policy in the Netherlands. As an institution appointed in the constitution for doing research on the revenues and expenditures of the state, ${ }^{241}$ it also pays attention to the use of EU funds in the Netherlands. It even has an extra task within Cohesion Policy in the Netherlands, compared to other national Courts of Auditors, because it issues a yearly report on the EU finances within the Netherlands, called 'EU-Trendrapport', ${ }^{242}$ which deals with the status of and issues concerned with the EU finances within the Netherlands. This report then accompanies the annual Declaration of Assurance ${ }^{243}$ that is being sent to the EC by the Dutch Minister of Finance, on the spending of SF in the Netherlands.

\subsubsection{The regional level}

The third level we describe in this research is the regional level. The ERDF MAs in the Netherlands, which have been mentioned on the national level, effectively operate on the regional level. Because it is mentioned in the regulation and it is appointed on national level, just as the $C A$ and $A A$, we have described it in the previous section.

It is important to note that the situation for OP Noord-Nederland is a bit different from the other regional ERDF OPs in the Netherlands. In the

241 Article 76 of the Dutch constitution.

242 For the latest version, see Algemene Rekenkamer 2015. 'EU Trendrapport 2015'. Den Haag: Algemene Rekenkamer.

243 Algemene Rekenkamer 2015. 'Rapport bij de Nationale verklaring 2015'. Den Haag: Algemene Rekenkamer. 
regions East and South, 'Gedeputeerde Staten' (the provincial executive) of respectively the provinces Gelderland and Noord-Brabant are appointed as MA, whereas in West the 'College van Burgemeester en Wethouders' (municipal board of the municipality) of Rotterdam is appointed. In North, on the other hand, SNN is appointed as a joint arrangement or alliance between the three northern provinces of Fryslân, Groningen and Drenthe. Because SNN is an alliance between three provinces, there is also a role for on the one hand the three Gedeputeerde Staten (provincial executives) and on the other the three Provinciale Staten (provincial councils) of the three provinces concerned.

Also, just like on the European and national level, on regional level within the Northern part of the Netherlands, there is a regional Court of Auditors, 'Noordelijke Rekenkamer', which is also dealing with issues concerning local governments' finances.

\subsubsection{Schematic overview of actors, and further approach}

In Figure 18, all institutions on all levels are shown, where also the relations are identified.

Not all institutions have an equal important role in the accountability relationships within the system. We now turn to the single dimension as described in chapter 3 and look at successively the European, national and regional level.

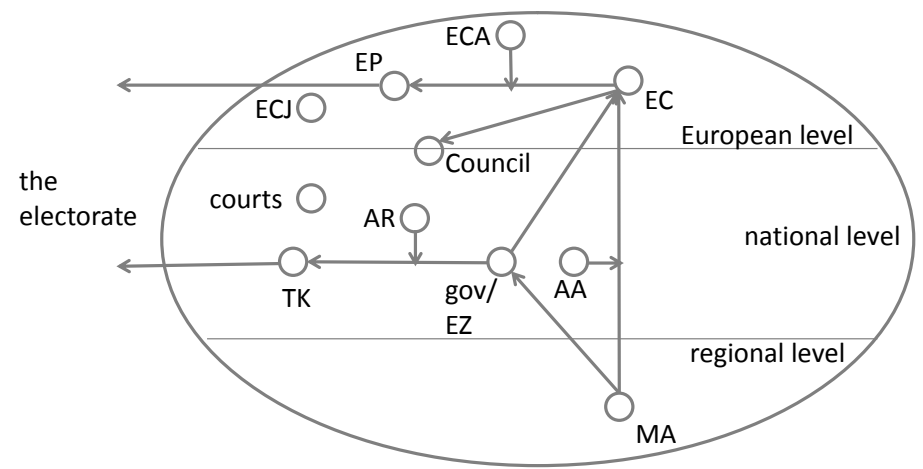

Figure 18. Schematic overview of actors and relationships 
We will describe the relationships on all levels of the system, and identify whether these are accountability relationships or not. As has been mentioned in chapter 2, the relationship between a principal and an agent is lying on the basis of the concept of accountability. Accountability as a concept can be regarded as a process, consisting of four main steps, as mentioned earlier;

a) assignment of responsibilities;

b) reporting by the agent;

c) information seeking or investigating and also verification by the principal; and

d) direction or control by the principal, posing sanctions on the agent. ${ }^{244}$

Although we have mentioned there are three levels in the implementation of Cohesion Policy, on European, national and regional level, further on we discuss the relationships in three clusters: the European cluster with all actors and relationships on European level, the national cluster with all actors and relationships on national level and the national-European cluster with all relationships between actors that cross the clusters, thus on European, national and regional level.

In the remainder of this chapter we discuss the relationships in these three clusters (in section 4.3 the relationships in the European cluster, in section 4.4 the relationships in the national cluster and in section 4.5 the relationships in the nationalEuropean cluster)and discuss them according to the steps just mentioned, focusing on the single dimension. Chapter 6 then focuses on the systemic dimension.

\subsection{The relationships in the European cluster}

At first we focus on the actors and relationships on European level, as graphically shown in Figure 19.

In this section, we discuss all institutions active in Cohesion Policy in the European arena, such as the EC, the Council, the EP, the ECJ and the ECA.

244 Based on Mulgan, R. 2008. 'The Processes of Public Accountability', Australian Journal of Public Administration, 56, 25-36, p. 19, Fisher, E. 2004. 'The European Union in the Age of Accountability', Oxford Journal of Legal Studies, 24, 495-515, p. 497, following Davies, A. 2001. Accountability: A Public Law Analysis of Government by Contract. Oxford: Oxford University Press. And Thomas, P.G. 1998. 'The Changing Nature of Accountability', in B. Guy Peters and D.J. Savoie (eds), Taking Stock: Assessing Public Sector Reforms Canadian Centre for Management Development, pp. 348-393, p. 352. See also section 2.3.1. 


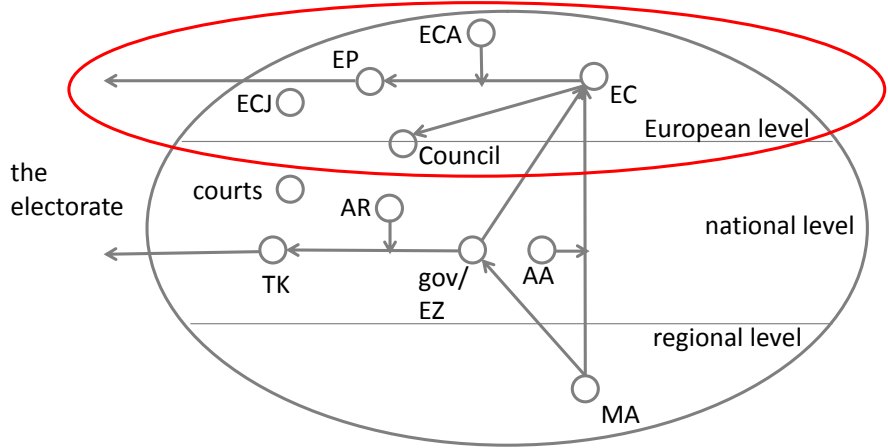

Figure 19. The actors and relationships on European level

\subsubsection{Citizens and the European Parliament}

As Gustavsson ${ }^{245}$ describes, the citizens are the ultimate principals, also on European level. Citizens have the opportunity to vote on a five-year basis for MEPs ${ }^{246}$ representing them in the EP. Elections are the core accountability mechanism in a representative democracy. ${ }^{247}$ In the period before elections, politicians are to report on their actions regarding the policy that has been persued. In that way, they report to the citizens by acting in the public sphere (in parliament and also indirect by news items in newspapers, magazines or on television), making it possible for citizens to get the information necessary for them to be able to assess their position and preparing to cast their vote at the next elections. That is at the same time also the sanctioning mechanism by the citizen: casting a vote on a specific MEP, belonging to a certain party, and thus not voting for other MEPs. Voters for the EP only have the possibility to vote for representatives for their country, leading to a specific amount of seats for a specific country. Although voting is done on a certain candidate for the EP, 'voters normally use their vote to indicate a preference for a nationwide political party, making election primarily a means of holding parties [...] to account. ${ }^{1248}$ Gustavsson is quite critical on the effectiveness of these EP elections. He agrees there is a strong mechanism for accountability in place, being a formal accountability mechanism, but 'the real opportunities for citizens to hold

245 Gustavsson, S., Christer Karlsson and T. Persson 2009. 'Examining the illusion of accountability', in S. Gustavsson (ed), The Illusion of Accountability in the European Union: Routledge. p. 4. See also Mulgan, R. 2003. Holding Power to Account. Palgrave MacMillan. p. 13.

246 Art. 14, section 3 of the Treaty on the EU and art. 20 of the Treaty on the functioning of the EU.

247 Mulgan, R. 2003. Holding Power to Account. Palgrave MacMillan. p. 41.

248 lbid. p. 41. 
MEPs accountable are sharply limited by the fact that EP elections are secondorder national contests fought out on domestic rather than European issues. ${ }^{249} \mathrm{He}$ argues that although a formal mechanism is in place, this mechanism is undermined by the fact that there is no European arena where electoral issues are fought out. $\mathrm{He}$ argues: 'EP elections have simply given national parties an additional opportunity to rehearse national politics with campaigns focused mainly on domestic - rather than European - concerns and preferences. ${ }^{250}$ On the other hand, there are also academics who contest this view of the EU in general showing an accountability deficit. ${ }^{251}$ We conclude that there is a formal accountability relationship, directly connected to the democratic element, not sure whether it is a real opportunity.

Although we feel it is important to look at this relationship as the most closely connected one to democracy, we moreover consider this relationship between the EP and the voters of secondary importance, because we are more interested in the accountability relationship between the institutional actors rather than with the public. This is also shown by the fact that it is difficult in research to enclose 'the public' as an actor, since it is difficult to interpret the preferences and actions of 'the public' as an actor. This means we do not go into the details of this relation regarding the requirements of 'good accountability' and leave this relationship mainly aside in the rest of this research.

\subsubsection{The European Parliament and the European Commission}

The second relationship that we describe is the one between the EC and the EP. We start with looking at the general relationship between both institutions. Later on, we focus specifically on the relationship regarding Cohesion Policy.

\section{Coverage: is there an accountability relationship?}

The relationship between the EP and the EC is a typical accountability relationship, in which the EP is the principal and the EC the agent. When discussing the four characteristics of an accountability relationship, the typical accountability elements

249 Gustavsson, S., Christer Karlsson and T. Persson 2009. 'Examining the illusion of accountability', in S. Gustavsson (ed), The Illusion of Accountability in the European Union: Routledge. p. 4, based on Reif, K. and H. Schmitt 1980. 'Nine second-order national elections. Conceptual framework for the analysis of European election result. ', European Journal of Political Research, 3-44, and Hix, S. 2008. What's wrong with the European Union and how to fix it.

250 Stratulat, C. and J.A. Emmanouilidis 2013. 'The European Parliament elections 2014. Watershed or, again, washed out?', Discussion Paper: European Policy Centre. p. 2.

251 See for instance Moravcsik, A. 2002. 'In Defence of the 'Democratic Deficit': Reassessing Legitimacy in the European Union', Journal of Common Market Studies, 40, 603-624, p. 605. 
become clear. To start with, the responsibilities of the EC are set in the Treaty. ${ }^{252}$ Secondly, the EC has a formal duty to be responsible to the EP. ${ }^{253}$ This means that the EC has to inform the EP on the questions the EP is asking to the EC. Also, the Treaty on the Functioning of the EU orders the EC to report to the EP and the Council ${ }^{254}$ every three years on the application of the provisions. ${ }^{255}$ More specifically on economic, social and territorial cohesion, which is also a specific task of the EU, in the Treaty on the Functioning of the EU it is laid down that the EC should inform the EP and the Council ${ }^{256}$ every three years on the progress made. ${ }^{257}$ The EC also has the obligation to submit annually to the EP and the Council the accounts of the preceding financial year and a financial statement of the assets and liabilities of the EU. ${ }^{258}$ Also, the EC has the obligation to reply to questions of the EP. ${ }^{259}$ This is a very clear expression of the first and second step, reporting by the agent, in this case the EC.

The third step is about information seeking or investigating and verification by the principal, in this case the EP. This is also present in the REGI committee within the EP. This committee is, as can be found on its website, ${ }^{260}$ amongst others responsible for the instruments of the EUs Regional Policy and the coordination of the instruments. The committee initiates position papers and (external) studies, holds hearings and most importantly drafts reports to be voted on in plenary sessions. These activities show that the EP is investigating the policy area, broader than only trusting on the EC. It is using its independent powers to be active in the policy area. The EP is also assessing the information it has been given by the agent or it has gathered itself, followed by taking a stand on the behavior of the EC. This stand is formally acknowledged in a motion or a report, which can, once adopted in plenary session, call upon the EC to act in a certain way. It can, as has been laid down in the Treaty on the Functioning of the EU, 'request the Commission to submit any appropriate proposal on matters on which it considers that a Union act is required $[\ldots]^{, 261}$

252 Art. 17 of the Treaty on the EU.

253 Art. 17, section 8 of the Treaty on the EU.

254 And also to the Economic and Social Committee, but this is not as relevant to this topic.

255 Art. 25 of the Treaty on the Functioning of the EU.

256 And also the Economic and Social Committee and the Committee of the Regions, but this is not as relevant to this topic.

257 Art. 175 of the Treaty on the Functioning of the EU.

258 Art. 318 of the Treaty on the Functioning of the EU.

259 Art. 230 of the Treaty on the Functioning of the EU.

260 See http://www.europarl.europa.eu/committees/en/regi/home.html, retrieved at 23-12-2013.

261 Art. 225 of the Treaty on the Functioning of the EU. 
Finally, the last step is about direction or control of the agent. With regard to the budget, the EP shall give a discharge to the EC, acting on a recommendation of the Council. ${ }^{262}$ Literally, as the AR has described, 'this means that the European Commission is discharged of its responsibility for the budget. In practice, it means that Parliament approves the EU accounts for a particular year and the use of EU funds in that year.' ${ }^{263}$

This is also a possible pressure method of the EP, which has not been used in practice, because the EP has discharged the EC every year until now. It has been used however, to put pressure on the EC to make further improvements in the financial management. The discharge procedure is very much connected to Cohesion policy, because of the financial dimension of the policy, being almost a third of the EU budget, and also because for years Cohesion Policy has shown a high error rate.

In a more general way, the EP also has a lot of power in this principal-agent relationship in the way that it has the option to vote on a motion of censure of the $\mathrm{EC}^{264}$ which effectively means the EP can send the EC home. This is an excessive possibility, and will only be used in rare circumstances. But having the opportunity to use this, means a pressure on the EC to act according to the preferences of the EP.

We can conclude this analysis by identifying the relationship between the EP and the EC as an accountability relationship. Given the means of the EP to hold the EC accountable, by using for instance hearings, draft reports, request the EC to act in a certain way, withhold discharge of the EC and in the end using the means of the possibility of censure, this is a typical accountability relationship.

\section{Context: elements of transparency, democracy and legal constraint}

Decisions on Cohesion Policy are prepared by DG REGIO, the DG of the EC responsible for Regional Policy. When looking at the information publicized by the EC, it becomes clear that a lot of information is made publicly available. ${ }^{265}$ Also, legislation and legislation in preparation by the European institutions can be found on the internet and thereby is publicly available. ${ }^{266} \mathrm{~A}$ good source of information to see what the EC is and has been working on in a specific year is the Annual Activity Report (AAR) ${ }^{267}$ This report, annually publicized in March, gives an overview of the

262 Art. 319, section 1 of the Treaty on the Functioning of the EU.

263 See http://www.eu-accountability.nl/accountability/discharge-procedure, retrieved at 23-12-2013.

264 Art. 17, section 8 of the Treaty on the EU.

265 See for instance the website of DG REGIO at http://ec.europa.eu/dgs/regional_policy/index_en.htm, and art. 10 section 3 of the Treaty on the EU, 'cursief Retrieved at 1-11-2015.

266 See the website http://eur-lex.europa.eu, retrieved at 1-11-2015.

267 See for the latest version European Commission 2015. 'Annual Activity Report 2015 DG Regional and Urban Policy'. Brussels: European Commission. to be found at http://ec.europa.eu/atwork/synthesis/ aar/doc/regio_aar_2014.pdf, retrieved at 1-11-2015. 
activities of the $E C$ and the issues the $E C$ has been working on in the previous year. All these reports and information coming from the EC on Cohesion Policy are also discussed in the EP. For Cohesion Policy, there is a specific committee in the EP, the Committee on Regional Development (REGI). ${ }^{268}$ The EP is also very transparent, it is publicizing a lot of information on its website (the general EP website and the websites of the committees) and it is facilitating the following of debates in Parliament, sometimes even via live stream.

An important change during the 2007-2013 period is that the EC more and more is using 'naming and shaming', thus explicitly mentioning the member states where specific issues or problems have arisen. This has lead to increased transparency, although still not all problems are being addressed in the official documents. ${ }^{269}$

With regard to democracy, this relationship is not directly connected to it, althoughit is indirectly connected. Because the relationship between the EP and the citizens has been identified as an accountability relationship and the fact that the EP is directly chosen by the citizens, there is also a connection between the EC and the citizens. Since the MEPs are representing the citizens there is also pressure from the EP on the EC to act in a transparent way.

Finally, the aspect of legal constraint is not very visible in this relationship. This relationship between EP and EC is characterized as a typical accountability relationship, in the way that issues between both organizations are dealt with 'on the floor' of the EP. For this purpose, both institutions have set up a framework agreement on relations between the EP and EC. ${ }^{270}$ In the end, the EP does have the possibility to vote on a motion of censure of the EC. In acceptance of such a motion the EC has to resign. There is the formal possibility for the EP to bring a case before the ECJ, ${ }^{271}$ but since the EP is having a pressure medium in the form of the motion of censure this medium is not used often.

268 http://www.europarl.europa.eu/committees/en/regi/home.html, retrieved at 1-11-2015.

269 For instance the 2013 problems concerning the annual control report of OP EFRO West in the Netherlands, were not explicitly addressed in the 2013 AAR of the EC, only as a footnote, see footnote 86 on p. 62 of European Commission 2015. 'Annual Activity Report 2015 DG Regional and Urban Policy'. Brussels: European Commission. mission', OJ L 304: Official Journal of October 20th, 2010, pp. 47-62.

271 See art. 19 section 3 of the Treaty on the EU. 


\section{Content: the 3E's - economy, efficiency and effectiveness}

Then we turn to the 'three E's', and look at the focus of the relationship. When looking at the AARs of the EC, it is clear that the focus of the EC is especially on compliance and some economy aspects (related to the spending of the funds), not specifically linking to the elements efficiency or effectiveness. ${ }^{272}$ This also corresponds with the definition on European level used in the context of the revised FR in 2012, which says that accountability stands for 'ensuring enhanced sound financial management and the protection of the EU's financial interests', ${ }^{273}$ thus solely focusing on compliance and economy. It is also said that an 'audit explosion'274 can be seen in Cohesion Policy, leading to 'compliance exercise[s] with punitive characteristics rather than a genuine tool for stimulating learning about effectiveness. ${ }^{275}$ This is also apparent in the declaration signed by the Director General of the DG issued in the Annual Activity Report of the DG: ' ... that I have reasonable assurance that the resources assigned to the activities described in this report have been used for their intended purpose and in accordance with the principles of sound financial management, and that the control procedures put in place give the necessary guarantees concerning the legality and regularity of the underlying transactions. ${ }^{276}$ As the AR puts it: 'The reports [AARs]do not give any information on the effectiveness of the policy in the Member States. ${ }^{277}$ The EC does publish reports with more focus on effectiveness, but these are often specific reports, focusing on specific areas or periods. ${ }^{278}$

The EP on its turn is calling the EC and the member states to focus on the efficiency, effectiveness and impact of operations, ${ }^{279}$ because 'the emphasis of cohesion

272 Damen, M. and N. Groenendijk 2012. 'Performance auditing in EU Cohesion Policy: what do we know and what should we know?', ECSA-C 9th Biennial conference 'Europe in an Age of Austerity: Integration, Desintegration, or Stagnation?'. Ottawa, pp. 1-12.

273 European Commission 2012. 'Why was it necassary to change the budgetary and spending rules in the Financial regulation?': European Commission.

274 Mendez, C. and J. Bachtler 2011. 'Administrative reform and unintended consequences: an assessment of the EU cohesion policy 'audit explosion', Journal of European Public Policy, 18, 746-765, p. 754 and further.

275 lbid. p. 754.

276 See for instance European Commission 2011. 'Employment, Social Affairs and Inclusion Directorate General 2010 Annual Activity Report '. Brussels: European Commission.

277 Algemene Rekenkamer 2011. 'EU Trendrapport 2011'. Den Haag: Algemene Rekenkamer, p. 38.

278 Examples are ex post evaluations of different policies, for instance European Commission 2010. 'ExPost Evaluation of Cohesion Policy Programmes 2000-06 co-financed by the ERDF (objective 1\&2)': European Commission.

279 See for instance Article 1 of the motion for a EP resolution on the EC'S $7^{\text {th }}$ and $8^{\text {th }}$ progress reports on the EU Cohesion Policy and the Strategic Report 2013 on programme implementation 2007$2013(2013 / 2008 /(\mathrm{INI}))$, to be found at http://www.europarl.europa.eu/sides/getDoc.do?pubRef=\% 2f\% 2fEP\%2f\% 2fTEXT\%2bREPORT\%2bA7-2014-0081\%2b0\%2bDOC\%2bXML\%2bV0\%2f $\% 2 \mathrm{fEN} \&$ language $=\mathrm{EN}$ (retrieved at 12-2-2015) and point 4 under the heading 'Achievements and 
policy has up until now rather been on absorption than on defining and monitoring - and evaluating the achievement of - objectives [...].'280 In previous years, the call of the EP has also been on 'the application of stricter financial correction and recovery procedures. ${ }^{281}$ This shows that in the accountability relation between the EC and EP there is some sort of tension between the call of the EP to have more focus on the efficiency and effectiveness of the policy, whereas the EC focuses on the aspects of Cohesion Policy more related to economy and compliance, such as absorption and error rates. Still, the information that is produced in this accountability relationship is focused on economy and compliance issues, although we see a minor change in more focus on effectiveness towards the 2014-2020 period.

\section{Costs: absence of accountability deficit or overload}

Having identified this relationship as an accountability relationship, we also have to look at the preferences of the EC and EP. To really identify whether there is a situation of convergence or divergence, it is needed to ask actors from both institutions on their opinions. This has been done and is described in chapter 5. From a theoretical point of view, it is expected that more divergence than convergence will be visible, with the EC being more focused on the implementing of the policy and issues that arise from this implementation, and the EP calling for transparency, effective spending and low error rates.

The mechanisms that are to be used by the EP in this relationship towards the EC are formally considered as strong, not at least because the EC has the possibility to send the EC home. However, in practice, these are seen as weak because in Cohesion Policy, the instrument of sending the EC home will not be used. Cohesion Policy is not deemed to be that important.

When we look at the monitoring and bonding costs of respectively the EP and EC, we consider them acceptable and not on a rising scale. For years already, there is a yearly schedule of reports to be presented and issues to be discussed in EP, in general, but also on Cohesion Policy. There seems to be consensus between both institutions on the work to be done and the reports to be drafted.

challenges of cohesion policy in the context of the economic and financial crisis (programming period 2007-2013)', to be found in resolution 'Investment for jobs and growth: promoting economic, social and territorial cohesion in the Union' (2014/2245(INI), adopted on the $9^{\text {th }}$ of September 2015, to be found at http://www.europarl.europa.eu/sides/getDoc.do?pubRef=-\%2f\%2fEP\%2f\%2fTEXT\%2bTA\%2bP8TA-2015-0308\%2b0\%2bDOC\%2bXML\%2bV0\%2f\%2fEN\&language=EN, retrieved at 12-2-2015. Ibid. consideration $\mathrm{F}$.

281 Mendez, C. and J. Bachtler 2011. 'Administrative reform and unintended consequences: an assessment of the EU cohesion policy 'audit explosion', Journal of European Public Policy, 18, 746-765, p. 752. 
The EP also has a powerful pressure instrument, the motion of censure. The question is whether this mechanism is also necessary. Because decision-making on European level is shared between EP, EC and Council and the EC is the executive institution of the EU it is important that both the Council and the EP have strong mechanisms in place to really be able to hold the EC accountable. The mechanism of censurization therefore matches the shirking risk of the EC.

Finally, the elements of accountability overload are considered to be absent.

\subsubsection{The Council and the European Commission}

A third important relationship in the European cluster is the relationship between the Council as principal and the EC as agent. Following the relationship between the European Parliament and the EC, also in this relationship we focus on the general level, not on a specific policy area. Where we do look specifically at Cohesion Policy, this is explicitly mentioned.

\section{Coverage: is there an accountability relationship?}

Responsibilities of the Council are laid down in the Treaty on the EU. ${ }^{282}$ The Council exercises, together with the EP, legislative and budgetary functions. ${ }^{283}$ Regarding the first step of accountability, as we have seen in the description of the relation between the EP and EC, there are a lot of topics the EC is supposed to inform both the EP and the Council on. This means that the first and second step are present.

The third step is also present, but less clear as in the relationship of the EC with the EP. The Council does not have a specific configuration appointed for Cohesion Policy, which means that Cohesion Policy is dealt with in the General Affairs Council. ${ }^{284}$ Depending on the specific topic, the issues are prepared by the Permanent Representatives of the member states and decided upon in the general European Council, or in a specific configuration of the Council ${ }^{285}$ with representatives from the concerned ministries of the member states. ${ }^{286}$ In these configurations of the Council the information given by the EC is verified. The Council takes a stand, votes and when needed discusses with the EP on the possible outcomes of a specific proposal of the EC.

282 Art. 15 and 16 of the Treaty on the EU.

283 Art. 16 section 1 of the Treaty on the EU.

284 See http://www.consilium.europa.eu/policies/gac?lang=en, retrieved at 1-11-2015. However, the decision-making on Cohesion Policy is prepared in the council preparatory bodies, of which some specifically deal with Cohesion Policy.

285 See art. 16 section 6 of the Treaty on the EU.

286 Art. 16 section 2 of the Treaty on the EU. 
The last step however, is not present in the relationship between the Council and the EC: there is no possibility for the Council to hold the EC accountable. The Council does have specific powers in the appointment of the $E C,{ }^{287}$ but these do not relate to the moment in time where decision making is done and the EP, EC and Council have to work together. Its powers in the decision making progress are, according to the Treaties, lying in the discharge of the budget, on which the Council should give a recommendation to the EP. ${ }^{288}$ However, the EP has its own responsibility in this and can act opposite to the recommendations of the Council. With regard to the censurization of the $\mathrm{EC}$, the Council has no rights or possibilities. That means that no accountability relationship seems to be in place in this relationship, because not all four steps are present. However, we consider this relationship as an informal one, because on the one hand the member states use their influence, inside or outside the Council, to influence the decisions of the EC and holding the EC accountable whereas on the other hand the Council has no specific legal powers to sanction the EC. Thus, in practice this relationship is an accountability relationship, although formal powers are lacking. So although the Council does not have explicit censurization possibilities towards the $\mathrm{EC}$, in practice it has the power that it would derive from these kind of mechanisms.

\section{Context: elements of transparency, democracy and legal constraint}

Regarding the element of transparency, we can conclude that the Council seems to promotethe transparency of its decisions, ${ }^{289}$ as also has been laid down in the Treaty on the functioning of the EU. ${ }^{290}$ However, this reference refers especially to decisions that have been made and some documents relevant for meetings. When specifically searching for documents on Cohesion Policy, this is restricted to conclusions. When looking at the Rules of Procedure of the Council, ${ }^{291}$ it shows that until decided otherwise, deliberations of the Council are secret. ${ }^{292}$ Related to other information, for instance information related to 'legislative deliberations', is made publicly available. ${ }^{293}$ According to the Rules of Procedure of the Council, it becomes clear that it is self-evident that information is publicized.

The element of democracy is only very indirectly present; ministers that represent their member state in the Council might be elected by the citizens, but that is no

287 See art. 17 of the Treaty on the EU.

288 Art. 319 of the Treaty on the Functioning of the EU.

289 See http://www.consilium.europa.eu/documents?lang=en, retrieved at 1-11-2015.

290 Art. 15 of the Treaty of the Functioning of the EU.

291 2009. 'Council's Rules of Procedure'.

292 Art. 6 section 1 of the Council's Rules of Procedure.

293 Art. 7 of the Council's Rules of Procedure and also art. 8 and 9 for specific provisions. 
rule. The indirect democratic connection is present because of the fact that the national ministers in the Council are accountable to their national parliaments. This however is a very weak democratic element in this relationship.

There is the possibility for both institutions to bring a case before the European Court of Justice. ${ }^{294}$ This means that the element of legal constraint is also visible. This medium however is rarely used by the Council.

\section{Content: the 3E's - economy, efficiency and effectiveness}

Regarding the three E's it is difficult to find information on what the Council is aiming at and wants the EC to focus at. Since primarily conclusions of Council meetings are made publicly available and these hardly go into detail of what is going on in Cohesion Policy, we can only conclude that for the 2014-2020 period focus has been put on the effectiveness measures introduced in this programming period. At the same time, the Council calls upon the EC, just as the EP does, 'to fully assume their responsibilities in implementing the budget, so as to reassure Europe's citizens and taxpayers that EU funds are used in a responsible and accountable manner. In its view, the EU's new multiannual financial framework and the new financial regulation provide an opportunity to achieve major progress towards simplification and thereby lower the risk of error. ${ }^{295}$ This means that the Council is calling upon the EC to keep having a lot of attention on economy and compliance aspects.

\section{Costs: absence of accountability deficit or overload}

Although we do not consider this relationship to be a complete accountability relationship, but an informal one, it is interesting to look at the preferences of both actors and what the relationship focuses at. Regarding the preferences of both actors, we would theoretically expect a clear divergent view: the Council representing the member states, whereas the EC is responsible for the implementation of the policy. This will lead in practice to quite opposite preferences, for instance on accountability on the expenditure of SF. The EC is in principle in favor of a national declaration, ${ }^{296}$ especially because the EC is responsible for the implementation of

294 See for instance the opinion of Mr Advocate General Bot of September 12, 2013 at http://eur-lex. europa.eu/legal-content/EN/TXT/?qid=1419688757572\&uri=CELEX:62012CC0063, retrieved at 8-11-2015.

295 European Council 2014. 'Press Release of the 3294th Council meeting of Economic and Financial Affairs'.

296 Based on the fact that the EC has adopted the recommendations of the Working Group on National Declarations, see European Commission 2014. 'Communication from the Commission to the European Parliament, to the Council and to the European Court of Auditors on the adoption of the interinstitutional Working group recommendations for the establishment and use of National Declarations': European Commission. COM (2014) 688 final. 
the EU budget and Cohesion Policy is a shared responsibility of the EC and the member states. In the Council on the other hand, the member states plea in their own interest, leading to a rejection of this proposal, although there are member states, for instance the Netherlands, Denmark, Sweden and the UK, ${ }^{297}$ who are in favor and have produced such declarations for years already. As we have mentioned before, the Council has no strong mechanisms in place to get the EC to act in a certain way. The Council can call upon the EC, but has no specific mechanisms in place to enforce this.

We see no signs of a downward spiral and the characteristics of an accountability overload are also absent.

\subsubsection{Other actors in the European cluster}

The ECJ and ECA show no real accountability relationships vis-à-vis other actors on the European level. They both operate as an independent body, respectively judging and advising on accountability relationships within the system.

Among other things it is one of the obligations of the ECJ to judge on judicial disputes between the European institutions, member states and/or legal persons. This judicial role means that the ECJ has an independent role within the system, providing the third element of accountability, which is legal constraint. Without this element, there is no real accountability situation, which means the ECJ is providing the means for being able to have accountability relationships. In a formal way, the ECJ therefore is holding institutions accountable for their acting, but we consider that not as a basic accountability relationship, because it cannot do this by itself. $A$ case should always be brought before the court by an institution, member state or legal person. Also, this function is already comprised in the elements of accountability. There are no formal direct accountability relationships between actors within the system and the ECJ, in fact all institutions can be called to account before the ECJ, even without direct accountability processes being in place.

Regarding the ECA, this is also an institution with a special role within the system. Its task is to provide a statement of assurance on the accounts of the EU in a certain year. The statement is provided to the EP and the Council, which should take this opinion into account in giving a discharge to the EC in the implementation of the budget. ${ }^{298}$ This means the ECA in a way has an advising function to the EP, it is acting as monitoring agent for the EP and Council. It therefore has no authority in an accountability process, because the powers in the process of discharging of the

297 The UK has stopped issuing a national declaration in 2012.

298 Art. 319 of the Treaty on the Functioning of the EU. 
budget are set for both the EP and the Council. However its opinions are helping the principals EP and Council to act according to their responsibilities towards the $\mathrm{EC}$. This is why the ECA is not active as a principal or agent in an accountability relationship within the system. The focus of the ECA is put on compliance (the DAS), ${ }^{299}$ with some attention for economy. It is also issuing reports on specific issues, more related especially to effectiveness. The amount of these reports has grown during the last five years. ${ }^{300}$

\subsubsection{Conclusion on accountability in the European cluster}

To conclude, we have identified two clear accountability relationships within the European cluster, being the relationship between the citizens (principal) and the EP (agent) and between the EP (principal) and the EC (agent). Because within the system in the European cluster the EP is the only organization entitled to impose sanctions on another actor, being the EC, there are no other complete accountability relationships visible. The Council is responsible for policy making together with the EP but is missing the ability to impose sanctions. We therefore consider this relationship as an indirect accountability relationship.The ECJ is providing the means for an accountability relationship being in place (legal constraint) and therefore does not constitute an accountability relationship in itself. The ECA, at last, has no authority in the accountability process, but is providing the information for the EP to act upon.

The answers on the questions lead to the overview in Table 3.

299 See Algemene Rekenkamer 2015. 'EU Trendrapport 2015'. Den Haag: Algemene Rekenkamer, p. 20.

300 This has also been mentioned by the AR, in Algemene Rekenkamer 2011. 'EU Trendrapport 2011'. Den Haag: Algemene Rekenkamer, p. 36 it was mentioned that during 2009-2010 ten effectiveness reports were issued by the ECA, whereas in Algemene Rekenkamer 2015. 'EU Trendrapport 2015'. Den Haag: Algemene Rekenkamer, p. 45 it was stated that the amount has grown in 2014 to around 20. 


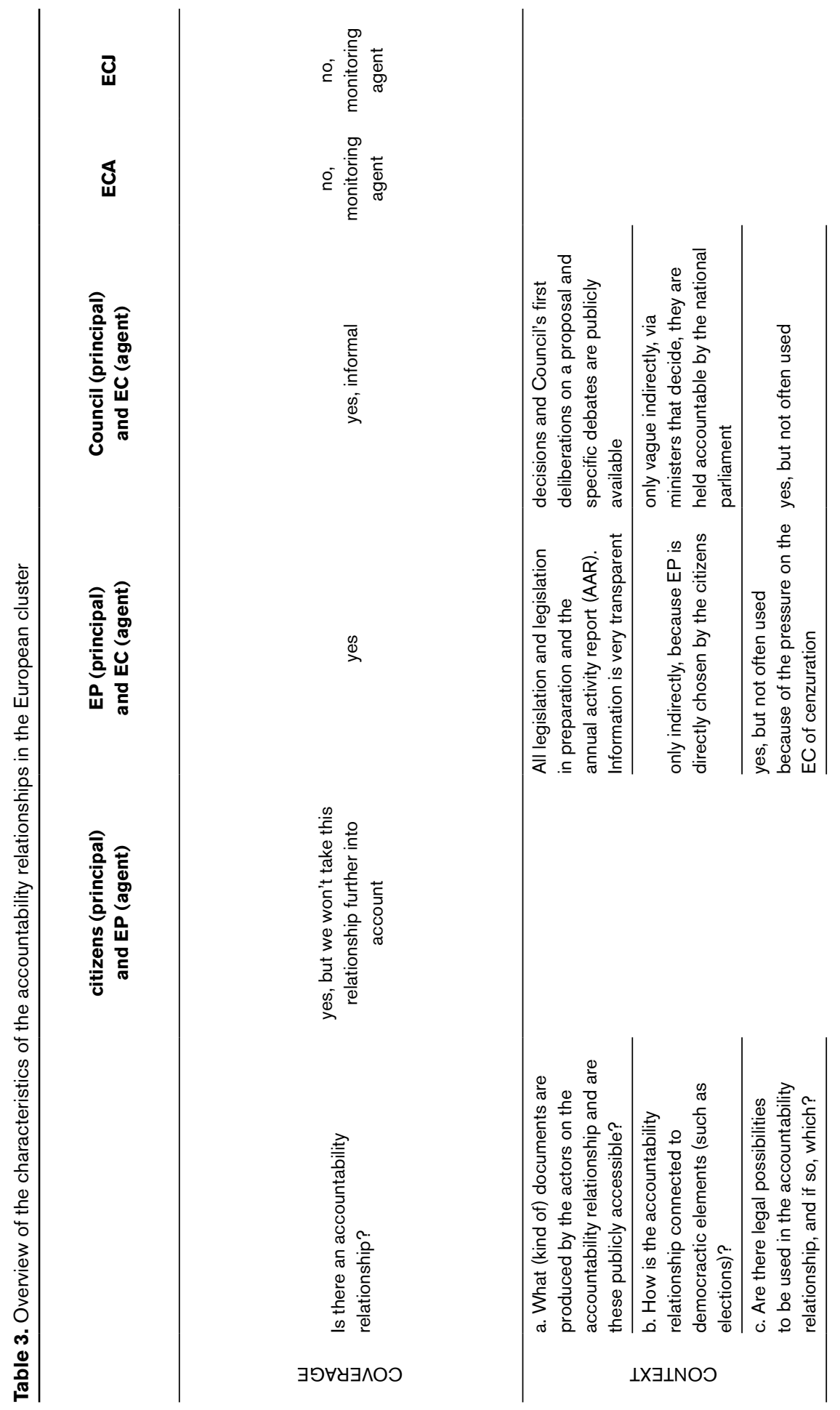




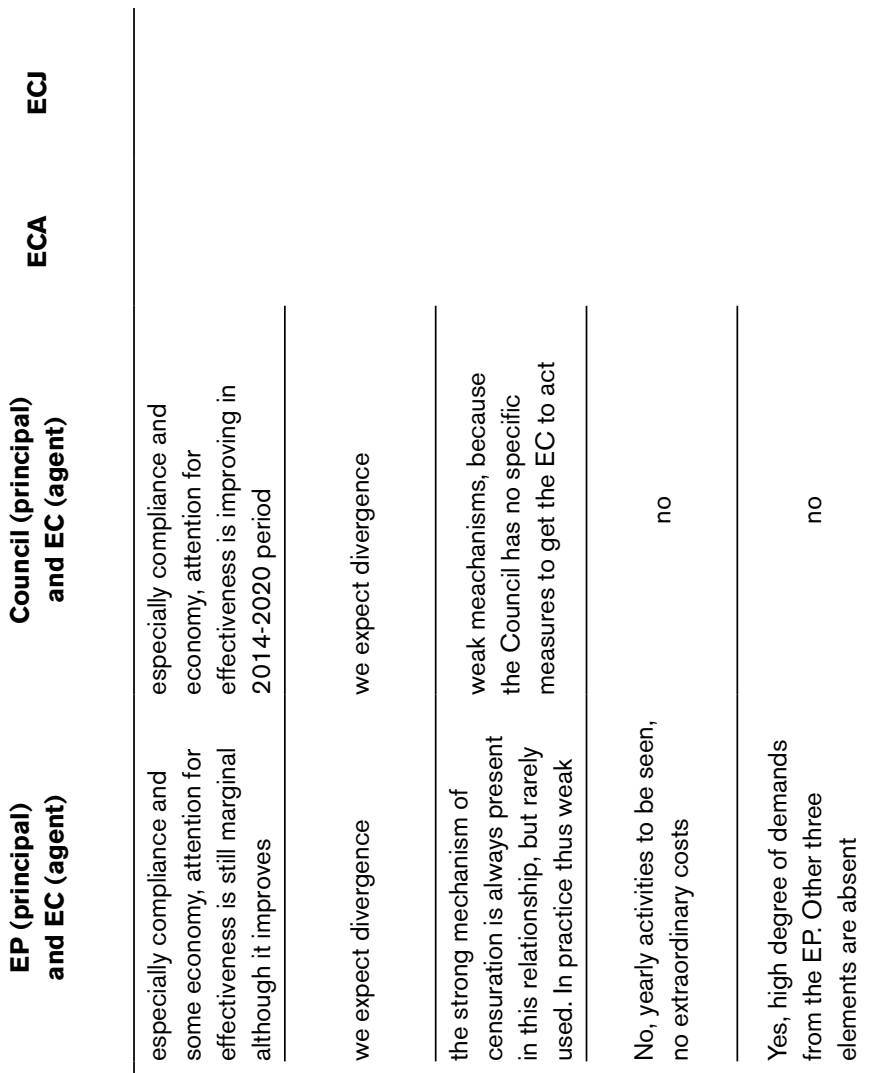

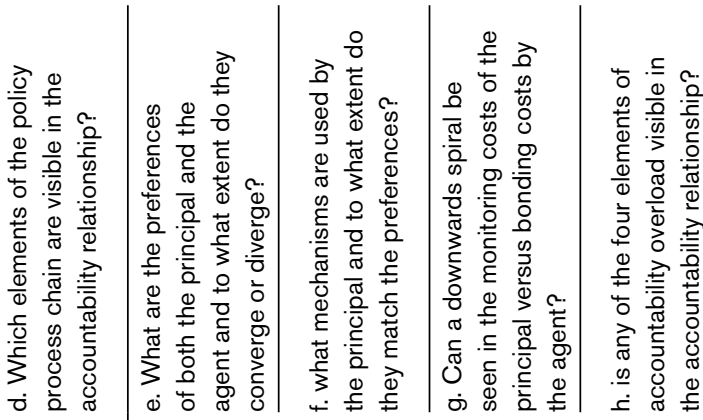
INヨINOO SISOO 


\subsection{The relationships in the national cluster}

This section focuses on the relationships on national level between the most important actors in Cohesion Policy in the Netherlands. This is shown in Figure 20.

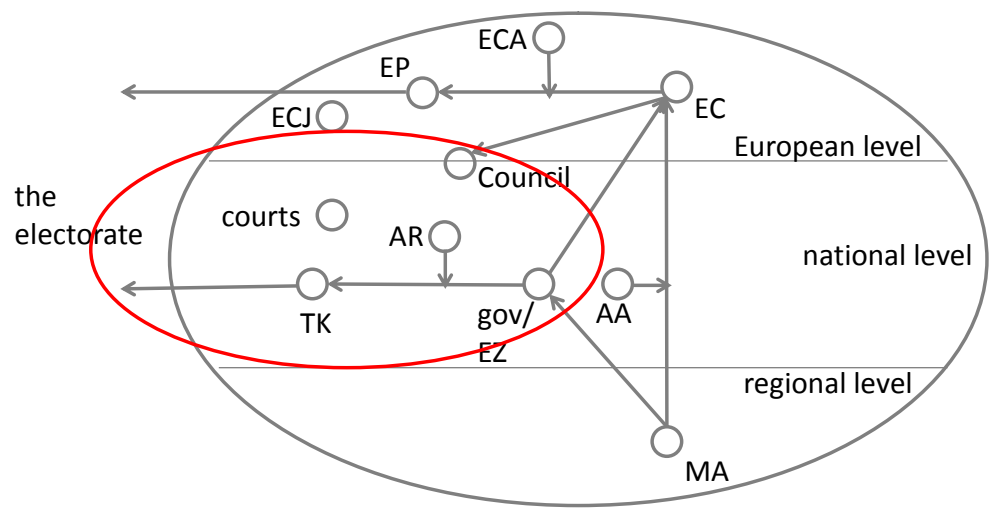

Figure 20. Schematic overview of actors and relationships in the national cluster

First, we look at the relationship between the citizens and the parliament, then moving on to the relationship between the parliament and the government. Because the Council is in fact a representation of the member states, we have chosen to mention in this section also the relation between both the parliament and the Council as well as the government and the Council. We also go into detail of the relationship between the national parliament and the EC. As will become clear, all three of these last mentioned relationships cannot be seen as an accountability relationship. Finally, we look at other actors in the system, which are the national Court of Auditors (AR) and national courts.

\subsubsection{Citizens and the national parliament}

In the Dutch Constitution it has explicitly been laid down that 'the Parliament is representing all the Dutch people. ${ }^{301}$ This means that an explicit reference to this accountability relationship has been made in the Constitution. As we described earlier, general elections are the core accountability mechanism in a representative democracy. ${ }^{302}$ 'Elections compel governments to explain and justify their actions

301 Art. 50 of the Dutch Constitution, in Dutch: 'De Staten-Generaal vertegenwoordigen het gehele Nederlandse volk.'

302 Mulgan, R. 2003. Holding Power to Account. Palgrave MacMillan. p. 41. 
and give citizens the opportunity to listen and impose a verdict. ${ }^{, 303}$ When we consider this relationship between the parliament as an actor and the citizens as the principal according to the four steps mentioned in chapter 2, we can see that this is a typically accountability relationship. To start with, the parliamentarians running for the next period are active in election campaigns and are seeking direct contact with citizens for discussion and justification of the policies executed in search for votes. ${ }^{304}$ At the same time, citizens are also gathering knowledge on the decisions made in parliament and the policies executed by the government, using various sources: information from the parliament and political parties itself but especially information from the media (newspapers, television, internet et cetera). Of course, not all citizens use these sources in the same intensity, and not all citizens do really use their right to vote. The next step is that the principal, in this case the citizens, is assessing the information and directing to the last step, control by the principal with the possibility of posing sanctions. In the case of elections, the sanction that can be posed by the citizens is to not reelect incumbent politicians. But, as we described earlier, the possibility of sanctions being posed is sometimes even more effective. As Mulgan describes, 'fear of electoral retribution is a powerful motive that affects many government decisions, particularly those that are perceived to have a major impact on voters' choices. ${ }^{, 305}$ This means that not only during election campaigns, but also during the four years period between elections the behavior of parliamentarians and ministers is determined by the possibility of being held accountable for the decisions that have been made.

As was argued when we discussed the relationship between citizens and the EP, we are primarily interested in the relationships between institutional actors, and thus we do not separately discuss the requirements of 'good accountability' with regard to this relationship..

\subsubsection{The national parliament and the national government ${ }^{306}$}

For this relationship, we also focus on the general relationship between both actors, when we do focus specifically on Cohesion Policy, this is beingmentioned.

303 lbid. p. 41.

304 lbid. p. 42 and 43.

305 Ibid. p. 43.

306 This section is based on section 4.7 of Denters, S.A.H. 1995. 'De parlementaire democratie', in J.W. Van Deth and P.A. Schuszler (eds), Nederlandse Staatkunde. Een elementaire inleiding.: Countinho, pp. 85-103. p. 96-103. 


\section{Coverage: is there an accountability relationship?}

The Dutch parliament, consisting of the TK and the Eerste Kamer, has different instruments to control the government and to hold it accountable. The TK as the House of Representatives has the most power in the forming legislation, the Eerste Kamer only has the right to reject or accept legislation, ${ }^{307}$ whereas the TK has the right of initiative ${ }^{308}$ and the right of amendment, ${ }^{309}$ which means the TK can suggest measures itself or amend legislation proposed by the government. If a minister has objections to amendments proposed by the TK, he can either accept the change or declare it unsatisfactory. In the latter situation, this means that the minister has to withdraw the legislation proposed. ${ }^{310}$ In important situations, this can even lead to the resignation of the minister or even the resignation of the whole cabinet. There is no explicit possibility for the TK to use 'a vote of no confidence,' but there is the principle of legitimate expectations. This principle, that has not been laid down in legislation, means that ministers have to step down when they have lost the confidence of the TK. ${ }^{311}$

When looking at the four steps of an accountability relationship, we also recognize this relationship as an accountability relationship. The responsibilities of the government have been laid down in the constitution ${ }^{312}$ and the government has to inform the parliament on the decisions that are taken and the legislation that is in preparation. These are the first and second step that both are present. The third step points at the principal, in this case the parliament, gathering information on the performance of the government, being able to also give a judgment on this performance. The final step, that of control by the principal possibly leading to sanctions, is also present in this case, as we have elaborated in this section. The TK has the possibility, although based on unwritten principles, to send the government home when it has no confidence in the government anymore.

In the case of Cohesion Policy, the execution of the ERDF and ESF funds are the responsibility of respectively the Minister of EZ (Economic Affairs) ${ }^{313}$ and the Minister of SZW (Social Affairs). ${ }^{314}$ This means that these ministers are responsible for the execution of these funds in the Netherlands and also accountable towards

307 Art. 85 of the Dutch Constitution.

308 Art. 82, section 1 of the Dutch Constitution.

309 Art. 84 of the Dutch Constitution.

310 Art. 86, section 1 of the Dutch Constitution.

311 Denters, S.A.H. 1995. 'De parlementaire democratie', in J.W. Van Deth and P.A. Schuszler (eds), Nederlandse Staatkunde. Een elementaire inleiding.: Countinho, pp. 85-103, p. 101.

312 Art. 42-49 of the Dutch Constitution.

313 As has been laid down in art. 1 under e of Besluit EFRO programmaperiode 2007-2013.

314 As has been laid down in art. 1 of Subsidieregeling ESF 2007-2013. 
parliament on these issues. The relationship between the parliament and the national government, and in the case of Cohesion Policy with the specific Ministers of EZ and SZW, can therefore also be classified as a clear accountability relationship.

Since this research focuses on ERDF, we focus in the following part of this chapter on the role of the Ministry of EZ when referring to the role of the national government.

\section{Context: elements of transparency, democracy and legal constraint}

As we also have described in the relationship between the national parliament and the citizens, there is a lot of transparency in the relationship between the government and the parliament. All information used for decision-making on national level is made publicly available on the internet. ${ }^{315}$ This means there is a lot of transparency .

Regarding the element of democracy, this element is indirectly present in this relationship, because the members of TK are directly elected by the citizens.

Finally, legal constraint is absent in this relationship. It is also not necessary, because the Parliament has its own mechanisms to hold the government accountable for its actions.

\section{Content: the 3E's - economy, efficiency and effectiveness}

As we have mentioned in the previous section, the Parliament in general has attention for all 3 E's, but the attention for Cohesion Policy in the Netherlands is limited. The Parliament and especially the TK has attention for all elements of the policy process chain.

\section{Costs: absence of accountability deficit or overload}

When we look at the preferences of both actors we find that in the general relationship there is divergence between both parties. However, in Cohesion Policy we expect convergence. Although the government is responsible for executing the policy and has to deal with implementing issues and the TK is more focused on the general aspects of implementing the policy, we expect that both actors are having the same preferences, directed at spending the funds within the Netherlands. As we have described in this section the TK has the right to send the government away, thus we consider that the parliament has strong mechanisms. However, just like in the European situation in the relationship between EP and EC, we expect those mechanisms are not used in the case of Cohesion Policy, because of the fact that it is not deemed such an important policy area. Thus, formally the convergent preferences and strong mechanisms (however in practice less strong in the case of 
Cohesion Policy) do not match. This means there is a potential for an accountability overload.

With regard to Cohesion Policy, there is an important factor that might also play a role on national level. In the general regulation on Cohesion Policy the decommitment rule is included, ${ }^{316}$ also known as the 'N+2'rule. ${ }^{317}$ This rule means that funds for year $x$ are decommitted, and thus refunded to the budget of the EU, when they are not (fully) used within two years after the year that has passed. Since member states do not want to loose funds that have been assigned to them, there is a pressure to use these funds timely, whether this is according to the rules or not. Since, from the perspective of the member state, the return of (unused) funds to the EU is not politically desirable, both the parliament and the government will urge for the funds to be used. In this respect, specifically on the issue of Cohesion Policy, we therefore consider there is convergence in the system between the parliament and the government.

We consider a downwards spiral to be absent, and when looking at the criteria for an accountability overload, we do not see any of these criteria present.

\subsubsection{The national parliaments and the Council}

Before we turn to the other actors in the national cluster, we look at the relationship between the national parliament and the Council. Although one might classify this as a relationship to be dealt with in section 4.5 on the national-European cluster, we deal with it here because it is connected to the role of the national parliament.

To start with, there is no direct possibility for national parliaments to hold the Council as a whole accountable for their actions and decisions. But there is the possibility for national parliaments to hold the national minister present in the Council and representing the member state accountable. ${ }^{318}$ This then is done by the mechanisms the parliament has to hold the government accountable, as just has been described in section 4.4.2. In practice, a lot of influence for decision making on European level of the national parliaments is practiced in the national EU Affairs Committees of the national parliament. ${ }^{319}$ In the national arena, these committees have influence on cabinet positioning, prior to meetings of the Council. Via this committee, the parliament gives the government a mandate to act in a certain way, but since decision

316 Article 93 of Regulation 1083/2006.

317 In the 2014-2020 period, this has changed into N+3, see art. 86 of Regulation 1303/2013.

318 This has even explicitly been laid down in art. 10 of the Treaty on the EU.

319 In case of the Netherlands, this refers to 'Vaste commissie Europese Zaken' of the Tweede Kamer, see http://www.tweedekamer.nl/kamerleden/commissies/EU/index.jsp retrieved at 1-11-2015. 
making in the Council takes place on the basis of majority voting and sometimes unanimity, the power of a minister within the Council is only limited. The second and third step of an accountability relationship are also present, because the national parliament, often by means of preparation in the EU Affairs Committee, is being informed on the discussions and ultimate decision making within the Council and they are forming their own opinion on that. Regarding the fourth step, since the European Council consists of representatives of the national governments and national parliaments have the possibility to remove national cabinets from power, decision making on European level can theoretically lead to the dismissal of a cabinet and/or specific ministers. A national parliament in this case can hold a minister accountable for its behavior in the European Council. ${ }^{320}$ But, since this only relates to the national representative in the Council, there is no direct possibility to hold the Council as a whole accountable, only the government. There is thus not an accountability relationship between the Council and national parliaments, but between the national parliament and the government.

Because there is no accountability relationship we do not discuss the other questions on the single dimension.

\subsubsection{The national government and the Council}

Finally, we separately discuss the relationship between the Council and the national government.

To start with, the relationship between the (European) Council and the national government is one of direct representation: member states are represented in the European Council by their heads of state or government ${ }^{321}$ and in the Council by a representative on ministerial level. ${ }^{322}$ This means that the European Council and the Council are formed by all national governments together.

We can see a reciprocal relationship between the national government and the Council. On the one hand, the member states have turned over legislative power to the European level, leading to decision-making on European level on certain policy areas as described in the Treaty on the Functioning of the EU. ${ }^{323}$ One can see this as a relationship with the national governments as principal and the Council as agent. When we look at the four steps of accountability, in this relationship between the Council and the national governments, these are not all present. There is no legal obligation for the Council to be accountable to the national governments. This

320 Bergman, T. 2000. 'The European Union as the next step of delegation and accountability', European Journal of Political Research, 37, 415-429., p. 416.

321 Art. 15, section 2 of the Treaty on the EU.

322 Art. 16, section 2 of the Treaty on the EU.

323 See articles 3 and 4 of the Treaty on the Functioning of the EU. 
means the first three steps are absent. But national governments can decide to step out of the EU, ${ }^{324}$ which can be seen as an expression of the last step, that of verification. Because the first three steps are absent, we do not consider the relationship between the national governments as principal and the Council as agent as being an accountability relationship.

But the other way around also a relationship can be seen, with the Council as principal and the national governments as agent. In this relationship, the national governments are responsible to the Council, but can this relationship be classified as an accountability relationship? Legally, if a member state is breaching the principles set out in article 2 of the Treaty on the EU, ${ }^{325}$ the Council can act, following a proposal by one third of the member states, the EP or the EC. ${ }^{326}$ This can lead to suspension of the rights of the member state in question. ${ }^{327}$

But, since this research focuses on Cohesion Policy, it is more important to look at specific provisions of the Council regarding this policy area. When looking at the Treaties and the general Regulation on Cohesion Policy ${ }^{328}$ there are no specific competences set for the Council. So although we consider some certain steps of the accountability process present in this relationship looking at it from a general perspective, these do not refer directly to Cohesion Policy, which means there is no accountability relationship present between the Council and the national governments regarding Cohesion Policy.

\subsubsection{The national parliaments and the European Commission}

Although this relationship is a relationship between a national and a European actor, we do consider it is most logical to deal with this relationship in this section.

The history of the national parliaments within EU decision making has been one of decline, because of the creation in 1979 of the European Parliament, and also due to the later reinforcement of the EP with the Treaties of Maastricht, ${ }^{329}$ Amsterdam $^{330}$,

324 Art. 50 of the Treaty on the EU.

325 Referring to the values of respect for human dignity, freedom, democracy, equality, the rule of law and respect for human rights, including the rights of persons belonging to minorities.

326 Art. 7, section 1 of the Treaty on the EU.

327 Art. 7, section 3 of the Treaty on the EU, for instance referring to voting rights of the member states in the Council.

328 Regulation 1083/2006.

329 Treaty on the European Union, 1992

330 Treaty of Amsterdam amending the Treaty on European Union, the Treaties establishing the EuropeanCommunities and certain related acts, 1997. 
Nice, ${ }^{331}$ and Lisbon, leading to more powers for the EP. But since the Treaty of Lisbon, the national parliaments also have been given a strengthened position, which is laid down in the first Protocol of the Treaty on the EU, on the 'Role of National Parliaments in the EU.' This protocol is now supposed to bridge the gap between national and European legislative processes. ${ }^{332}$ The treaties, including the protocol, give the national parliaments the right to: ${ }^{333}$

a. information; ${ }^{334}$

b. judge the implementation of the subsidiarity principle; ${ }^{335}$

c. take part in the evaluation mechanisms in the area of freedom, security and justice $;^{336}$

d. take part in the revision procedures of the Treaties; ${ }^{337}$

e. be notified of applications for accession of the EU; ${ }^{338}$

f. take part in the inter-parliamentary cooperation between national parliaments and the EP.

The second right of the national parliaments, as mentioned under $b$, is especially worth looking at. When a national parliament considers a proposal for EU action is not meeting the subsidiarity principle, ${ }^{339}$ it has the possibility to trigger a two stage procedure, also mentioned as the yellow or orange card procedure. This means that 'if one third of national parliaments consider that the proposal is not in line with subsidiarity, the Commission will have to re-examine it and decide whether to maintain, adjust or withdraw it. If a majority of national parliaments agrees with the objection but the Commission decides to maintain its proposal anyway, the Commission will have to explain its reasons, and it will be up to the EP and the Council to decide whether or not to continue the legislative procedure. ${ }^{340}$

331 Treaty of Nice amending the Treaty on European Union, the Treaties establishing the European Communities and certain related acts, 2001.

332 Zalewska, M. and O.J. Gstrein 2013. 'National Parliaments and their Role in European Integration: The EU's Democratic Deficit in Times of Economic Hardship and Political Insecurity', Bruges Political Research Papers. Bruges: College of Europe, p. 11.

3з3 Following art. 12 of the Treaty on the EU.

334 See also Protocol 1 of the Treaty on the EU and for instance the articles 69 and 71 of the Treaty on the EU.

335 See also art. 5 and 69 of the Treaty on the EU, and also protocol 2 of the Treaty on the EU.

336 See for instance the articles $81,85,88$

337 See also art. 48 of the Treaty on the EU.

338 See also art. 49 of the Treaty on the EU.

339 This means that the EU acts in areas where it has no exclusive power only on European level where it considers it to be more effective than on national level.

340 http://europa.eu/lisbon_treaty/glance/democracy/index_en.htm, retrieved at 05-01-2014. 
It is in this regard also interesting to mention the existence of COSAC, ${ }^{341}$ the Conference of Parliamentary Committees for Union Affairs of Parliaments of the European Union. It consists of representatives of the national parliaments of the member states dealing with EU affairs (6 from each parliament) as well as representatives of the EP. They meet every six months and discuss EU issues, such as the 'yellow card' ${ }^{342}$ procedure, referring to the procedure by which national parliaments can call upon the EC to review an earlier issued proposal. ${ }^{343}$

Although the national parliaments have acquired a special position in policy making on European level, they still have no right to dismiss a European institution, with the exception of its national representative in the Council of ministers (or the prime minister in the European Council). Since the only possibility for national parliaments, together with other national parliaments, is to have the EC to re-examine its proposals, upon request of the parliaments, we see hardly any steps of an accountability relationship. This relationship is therefore not considered as an accountability relationship.

\subsubsection{Other actors in the national cluster}

An institution that is also involved with Cohesion Policy in the Netherlands is the Dutch Court of Auditors, the AR. As mentioned in section 4.2.2, it is monitoring the revenues and costs of the State. ${ }^{344}$ It has its own agenda for monitoring the finances of the government; interesting to see is that it pays specific attention to SF and the responsibility for these funds. ${ }^{345}$ It is issuing an annual report on EU finances, called 'EU-trendrapport.' ${ }^{346}$ These reports, originating from 2003, are focusing every year on a different aspect of EU financial management and therefore are giving a clear view on the history of and actual problems of EU finances. Although technically this report is drafted by the AR and discusses the financial management of EU expenditure in the EU, the member states and the Netherlands, ${ }^{347}$ this report is lying on the basis of the accountability relation between the parliament and the government regarding SF, amongst which Cohesion Policy. This means the AR is

341 See www.cosac.eu, retrieved at 01-11-2015.

342 And ultimately leading to an 'orange card' procedure, when the legislator, national or European, rejects the legislative procedure, when it considers the proposal is not compatible with the principle of subsidiarity.

343 See article 12 of the Treaty on the EU.

344 Art. 76 of the Dutch Constitution.

345 See also their website, http://www.eu-accountability.nl/eu, retrieved at 10-11-2015.

346 See for the latest version Algemene Rekenkamer 2015. 'EU Trendrapport 2015'. Den Haag: Algemene Rekenkamer.

347 Algemene Rekenkamer 2014. 'EU Trendrapport 2014'. The Hague: Algemene Rekenkamer, p. 4. 
effectively being a monitoring agent, having a monitoring function for the parliament, comparable to the role of the ECA to the EP. ${ }^{348}$ The focus of the EU-trendrapport is on compliance, however in recent years more and more focus has been put on effectiveness. $^{349}$

Since 2006, the AR is also issuing a report following the national Declaration of Assurance (DAS) on SF, issued by the Dutch Minister of Finance. On the year 2011, four member states have issued such a national declaration, Denmark, the UK, Sweden and the Netherlands ${ }^{350}$ and the possibility is set in the Financial Regulation for other member states to issue such a declaration as well. ${ }^{351}$

The Dutch constitution ('Grondwet') also deals with the justice system. It determines that civil law is decided upon by judicial courts. ${ }^{352}$ For administrative law, on disputes between public authorities and civilians or disputes between public authorities, the constitution determines that these can be dealt with by courts or other non-judicial courts. ${ }^{353}$ In the Netherlands, there is a special law, de Algemene Wet Bestuursrecht $(A w b)$, for administrative law. ${ }^{354}$ Since most disputes in Cohesion Policy are cases with public authorities involved, the Awb is mostly applicable for Cohesion policy.

The Awb requires that an objection procedure is started by the public authority that has issued the decision that is under objection. ${ }^{355}$ After that procedure, if the public authority does not recall its decision, it is possible to go to court, in most cases at the administrative law sector of a district court. Appeal in the case of administrative law should be done at the administrative court of Raad van State (the Council of State).

As we have also seen when discussing the European Court of Justice, the courts are an essential element of the accountability structure, thus acting as an extra pressure within the system for all actors to act accordingly to the rules that have been set, ensuring legal constraint. In practice, the national courts especially play a role when it comes to disputes between public authorities, such as the MAs, and

348 See section 4.3.4.

349 See for instance chapter 4 on 'Understanding of the effectiveness of EU funds in the Netherlands' of Algemene Rekenkamer 2015. 'EU Trendrapport 2015'. Den Haag: Algemene Rekenkamer.

350 Algemene Rekenkamer 2013. 'EU Trendrapport 2013'. p. 15. The UK has stopped issuing a national declaration after 2011.

351 See art. 59 section 5 of Regulation 966/2012.

352 Art. 112 section 1 of de Grondwet.

353 Art. 112 section 2 of de Grondwet.

354 Based on article 107 section 2 of de Grondwet, that states (translated from Dutch): The law determines general rules for administrative law.

355 Art. 7.1 of de Algemene Wet Bestuursrecht 
beneficiaries. However, as we have also described in section 4.3.4 on the European cluster, the courts are not an actor in an accountability relationship.

\subsubsection{Conclusion on accountability in the national cluster}

As we have mentioned in the introduction of this chapter, the institutional characteristics of the member states differ, which also leads to differences in the implementation of Cohesion Policy in the member states. When looking at the Netherlands, we can see that the relationships between actors in the national cluster also have their impact on the implementation of Cohesion Policy.

We have identified two clear accountability relationships in the national cluster, being the relationship between the citizens (principal) and the national parliament (agent) on the one hand, and between the national parliament (principal) and the government (agent) on the other. The relationship between the national parliament and the Council is not considered to be an accountability relationship, because the parliament can only hold the national minister in the Council accountable, not the institution of the Council as a whole. Also, the relationship between the government and the Council is not seen as an accountability relationship, because the government provides a minister to act in the Council. Finally, the relationship between the national parliament and the $\mathrm{EC}$ is not considered to be an accountability relationship because the steps of an accountability relationship cannot be seen.

The AR can be seen as an advisory body in the relationship between the parliament and the government; its work provides the parliament with the necessary information to act as a principal in that relationship. Finally, the national courts constitute the legal constraint in the system.

The answers to the questions lead to an overview of the relationships as can be found in Table 4 . 


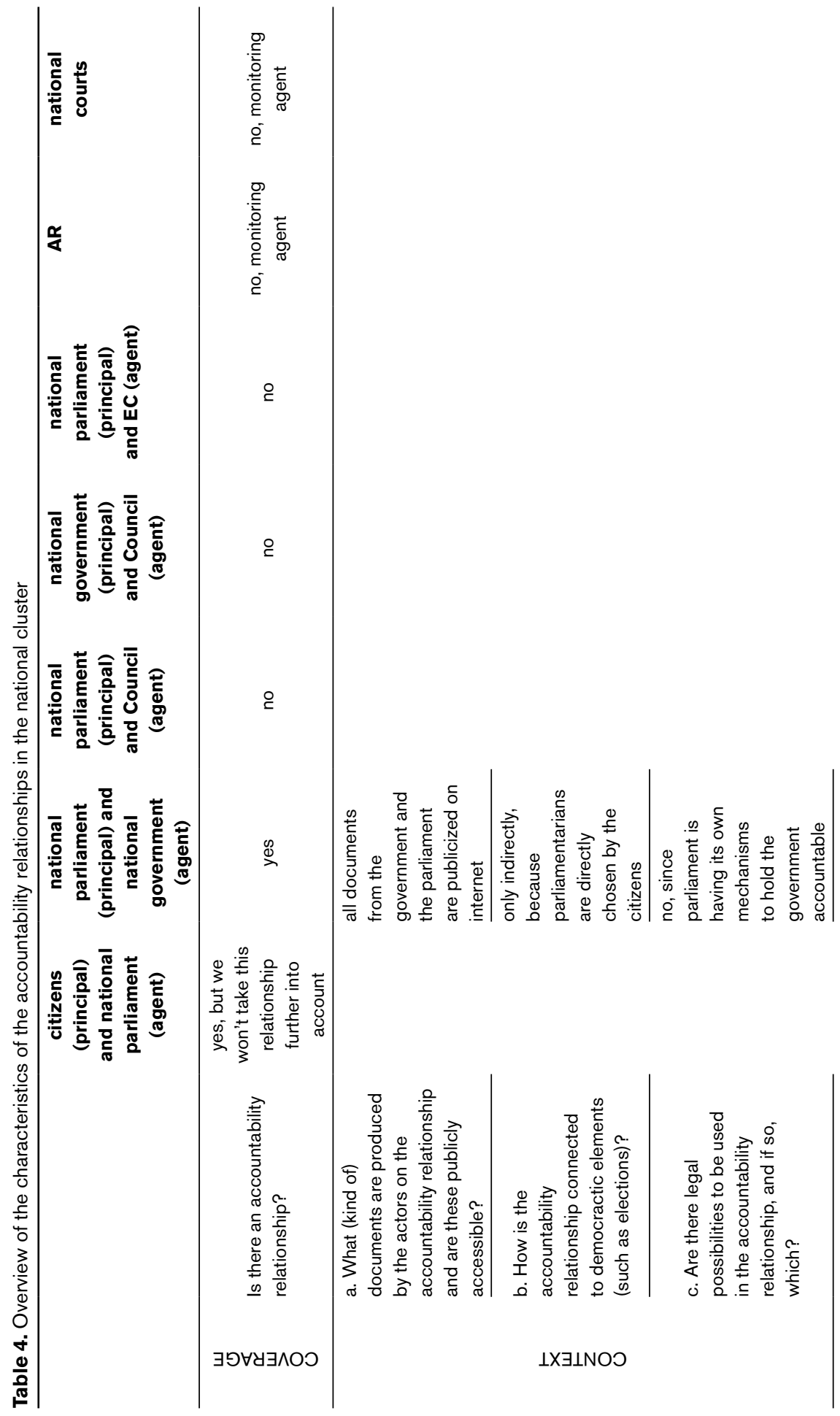




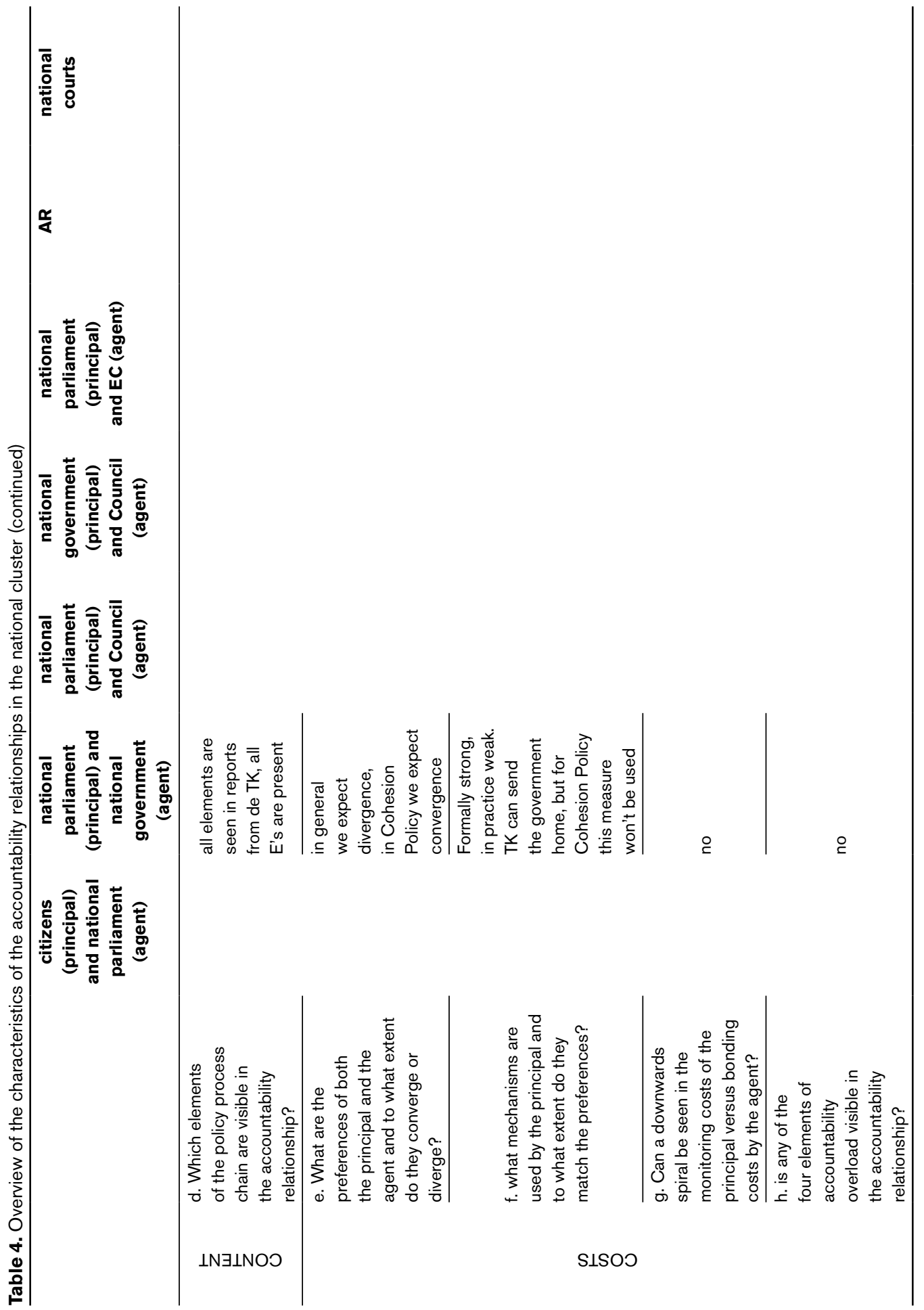




\subsection{The relationships in the national-European cluster}

There are also connections between the different levels, in this research mentioned as the national-European cluster. In this cluster, we have taken together all relationships between the three levels we have mentioned earlier: European, national and regional level. We discuss the relationships between the national government (or the specific responsible ministries), the MA and the EC, including the function of the AA. See Figure 21 for a schematic overview of these relationships.

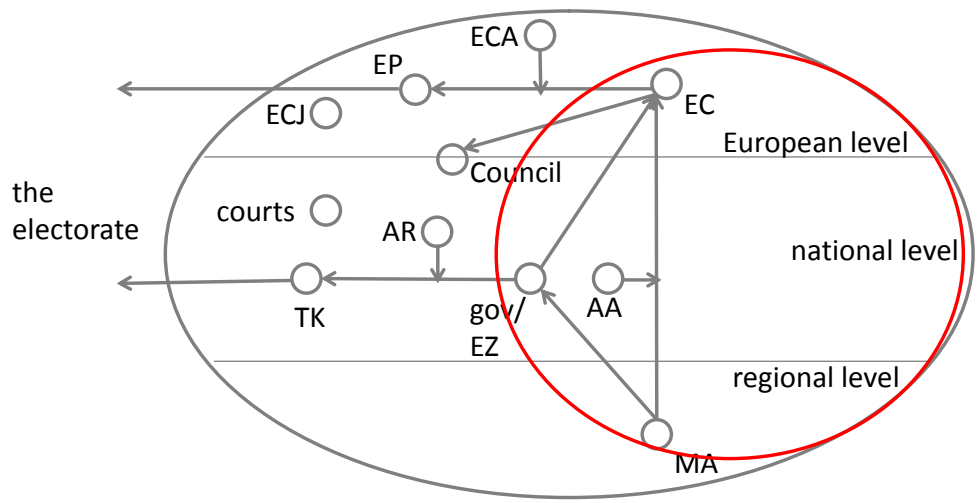

Figure 21. The actors and relationships in the national-European cluster

It is important to note that in this cluster 'the member state' is having a central role. It is however necessary to identify what the actor 'the member state' refers to. As mentioned earlier, in the case of the regional ERDF OPs in the Netherlands, the responsible ministry is the Ministry of $\mathrm{EZ}{ }^{356}$

\subsubsection{The European Commission and the member state}

\section{Coverage: is there an accountability relationship?}

In many policy areas the EC is dependent on the member states to execute the policies agreed upon at the European level. In fact, the principle of shared management $^{357}$ is a special expression of this, leading to cooperation and shared responsibilities between the EC and the member states in the implementation. However, the

356 See art. 1 under e of Besluit EFRO programmaperiode 2007-2013.

357 See art. 14 of regulation 1083/2006. 
EC, according to the Treaty, has the ultimate responsibility for the execution of the EU budget. Since governments are responsible for policy execution at national level, this leads to a relationship between the EC as principal, on the one hand, and the national governments as agents, on the other. On a general level, the Treaty on the Functioning of the EU describes that the EC shall deliver a reasoned opinion on the matter when a member state has failed to fulfill an obligation under the Treaties. ${ }^{358}$ This may lead, after consultation of the member state concerned, to a case which can be brought before the ECJ. ${ }^{359}$ Although the Regulation ${ }^{360}$ mentions obligations for the member state as well as for the MA, it is clear that the member state is the responsible actor for the implementation at the national and regional level. This is also laid down in the Financial Regulation (FR) ${ }^{361}$ that is also applicable for transfers devoted to the $\mathrm{SF}^{362}$ In the FR it is among other things laid down that the member states 'shall take appropriate measures to prevent irregularities and fraud and if necessary shall bring prosecutions to recover funds wrongly paid.' ${ }^{363}$ This obligation on the member states has also been laid down in the Regulation. ${ }^{364}$

In the field of Cohesion Policy, the relevant regulation foresees a number of specific obligations of the member states to inform the EC. ${ }^{365}$ This means that the first and second step of accountability in this relationship, assignment of responsibilities and reporting by the agent, are met. The third step, information seeking and verification by the principal, is also met in the situation of Cohesion Policy. The DGs of the EC concerned, in case of ERDF DG REGIO, investigate the information reported by the member states, analyzes it and form an opinion on the issues concerned.

Finally, when looking at the direction of control by the principal, in the ex ante phase of the 2007-2013 period the EC should adopt the national strategic reference frameworks, proposed by the member states. Without an NSRF, the member state cannot start with the execution of the policy. ${ }^{366}$ Also in this phase, the EC

358 Art. 258 of the Treaty on the Functioning of the EU.

359 Art. 260 of the Treaty on the Functioning of the EU.

360 Regulation 1083/2006.

361 See, for instance, art. 53 of Regulation 1605/2002 (FR). It has been repealed in 2012 by Regulation $966 / 2012$. The principles that are mentioned here referring to shared management are, although sometimes phrased differently, also laid down in the 2014-2020 regulation.

362 Art. 26 section 1 of the Financial Regulation, 1605/2002.

363 Art. 53 section 6 of the Financial Regulation, 1605/2002.

364 Art. 98 section 1 of Regulation 1083/2006. From jurisprudence of the ECJ (preliminary ruling in case С383/06, Vereniging Nationaal Overlegorgaan Sociale Werkvoorziening and others) it can be concluded that this recovery is an explicit obligation in the case of misuse and negligence, not an option.

365 See, for instance, art. 15 on additionality, art. 29 on reporting, art. 32 on preparation of programmes, art. 40 on major projects, and art. 71 on the setup of management and control systems, all of Regulation $1083 / 2006$.

366 Art. 28, section 3 of Regulation 1083/2006. 
should adopt the OPs proposed by the member states. ${ }^{367}$ And regarding major projects, these should be appraised by the EC and approved beforehand. ${ }^{368}$

However, since these are all measures in the ex ante stage, possibly leading to a postponement of the start of a programme, it is especially interesting to look at measures the EC can take during the implementation phase. In this respect, article 92 and 99 of the Regulation ${ }^{369}$ are important, giving the EC the possibility to respectively interrupt or suspend payments to an OP and/or pose financial corrections. Although the MA is directly affected by such a decision, it is formally directed at the member state. Suspending payments and posing financial sanctions are both possibilities for the EC to sanction a member state, although the effect is directly affecting the MA.

Considering the fact that the EC has quite strong mechanisms to be used in this relationship with the national governments, such as its role in approving OPs, interrupt or suspend payments and pose financial corrections, which are even more often used by the EC than in previous years, ${ }^{370}$ we consider this to be an accountability relationship. ${ }^{371}$

\section{Context: elements of transparency, democracy and legal constraint}

Regarding transparency, we can see that the situation has improved slightly since the 2007-2013 period, especially with the introduction of more 'naming and shaming'. Communication between the member state and the EC on Cohesion Policy is, as a general rule, not made publicly available by either of the two parties. There is no specific rule or regulation which says that it should be confidential, but a lot of information is not made publicly available. The EC however, does publish information on its activities and the performance of the member states in its Annual Activity Report (AAR). These reports have been published since $2004^{372}$ and have become more forthright throughout the years about the performance of specific member states. The EC also publishes its yearly Synthesis report in which information can be

367 Art. 32, section 5 of Regulation 1083/2006.

368 Art. 41 of Regulation $1083 / 2006$.

369 Regulation 1083/2006.

370 See for instance the Annual Activity Report of DG REGIO, European Commission 2013. 'Annual Activity Report 2012': DG Regional and Urban Policy, p. 44-50 on the suspension of payments and financial corrections applied by the EC.

371 It is important to note that this relationship can also been seen the other way around, with the EC being accountable to the member states, thus to the national governments. However, we consider this relationship as a relationship between the EC and the Council, where the Council is representing the member states and national governments on European level, see also section 4.3.3.

372 The first one to be found on the internet is the one of 2004, see http://ec.europa.eu/atwork/synthesis/ aar/aar2004/index_en.htm, retrieved at 12-02-2015. It is possible that earlier AAR's have been issued but these cannot be found in the internet. 
found on the performance of Cohesion Policy. ${ }^{373}$ However, still not all information is disclosed and the EC decides which information on the performance of the member states is made publicly available. But we do consider the fact that there is more openness to the performance of specific member states to be an improvement. There is transparency, but to a limited degree and issued only by the $E C$, often not by the member states themselves. A positive exception on this non-publication by the member states has been the publication in 2012 of the annual summaries of 14 of the 27 member states, amongst which the Netherlands. ${ }^{374}$ Following a request of the EP these member states have decided to publish these documents on the website of the EP. The AR has also concluded in 2015 this unfortunately has been a single action. ${ }^{375}$

Democracy is not in play in this relationship, neither the EC nor the member state is directly subject to the democratic process.

Regarding legal constraint, there is the possibility for either the member state or the EC to start a case before the ECJ. This means that there is legal protection possible for both actors.

\section{Content: the 3E's - economy, efficiency and effectiveness}

When looking at the nature of this accountability relationship, we see that the focus, as has also been described in the relationship between the EC and EP, is primarily on the aspect of 'economy', referring for instance to the implementation rate of the funds and on legality (compliance), looking at whether authorities are respecting the rules that are set. Member states have to comply with both European and national legal requirements. Non-compliance leads to reports, reinforced correction, interruption and suspension procedures, member states' action plans and their followup, increased scale and intensity of audits and more rigorous closure procedures. ${ }^{376}$ Efficiency is not an issue in this relationship since the member states do not have any obligation to inform the EC about efficiency issues. However, both the member

373 See, for the latest version European Commission 2015. 'Synthesis of the Commissions' management achievements in 2014': European Commission., http://ec.europa.eu/atwork/pdf/synthesis_report_2014_en.pdf, retrieved at 12-02-2015.

374 To be found at http://www.rijksoverheid.nl/bestanden/documenten-en-publicaties/brieven/2013/02/14/ structuurfondsen-2011-annual-summary-2011/as-structuurfondsen-2011.pdf, retrieved at 9-11-2015. Algemene Rekenkamer 2015. 'EU Trendrapport 2015'. Den Haag: Algemene Rekenkamer, p. 24.

376 Mendez, C. and J. Bachtler 2011. 'Administrative reform and unintended consequences: an assessment of the EU cohesion policy 'audit explosion", Journal of European Public Policy, 18, 746-765, p. 754. 
states and the EC address efficiency issues sometimes to a limited extent in their evaluations. $^{377}$

Regarding the effectiveness of the policy, evaluation is the main source of information. The European regulations oblige the member states to perform an ex ante evaluation $^{378}$ and also to evaluate during the implementation stage. ${ }^{379}$ The EC is using the information provided by the member states in its Cohesion report, which it publishes every three year. ${ }^{380}$ Moreover, it carries out a comprehensive ex post evaluation at the end of the programming period. The evaluations carried out ex ante and during implementation serve also as an input into these ex post evaluations.

To summarize, there is some attention for effectiveness of the policy concerned in this relationship between the member states and the EC, but the main focus of this relationship is put on compliance and financial (economy) issues.

\section{Costs: absence of accountability deficit or overload}

The preferences of the national government on the one hand and the EC on the other are expected to be more divergent than convergent, in general, depending on the member state concerned. The Netherlands for instance, is known to attach importance to accountability of the use of SF, whereas other member states might attach less importance to this subject. The EC is representing the EU and thus promoting a fair use and accountability of the use of the funds in all member states, whereas the member states always start looking at what a specific measure means for the member state itself. An example of this divergence between EC and the member states is the $\mathrm{N}+2$ rule, ${ }^{381}$ which gives the member states an incentive to spend these funds, whether this spending is (exactly) according to the EU rules or not. Because of this pressure on the spending of the funds, it can be expected that when push comes to shove, it will be more interesting for MAs to choose to fund projects that clearly meet the compliance obligations and deliver quick and clearly eligible costs than to fund projects that fit perfectly within the European policy priorities and that are both effective and efficient. This means that projects might not be

377 For instance, in European Commission 2013. 'Cohesion policy: Strategic report 2013 on programme implementation 2007-2013': European Commission, information on policy implementation (Technical Assistance) is only to be found on pp. 26-28 in the complementary Commission Staff Working Document, to be found at http://ec.europa.eu/regional_policy/sources/how/policy/doc/strategic_report/2013/swd_strat_report_2013_en.pdf, retrieved at 9-11-2015.

379 See art. 48 paragraph 3 of Regulation 1083/2006.

380 European Commission 2014. 'Investment in growth and jobs. Promoting development and good governance in EU regions and cities. Sixth report on economic social and territorial cohesion..'

381 Art. 93 of Regulation 1083/2006. It has changed into $N+3$ in the 2014-2020 period, see also footnote 317. 
selected on their deliverables, but on their compliance with the obligations and rules.

Altogether, the EC has quite strong mechanisms in hand to influence the actions of the member state and also the MA. They include the needed approval of the OP by the EC as well as the possibility to suspend payments and/or impose financial corrections. The last two mechanisms can be seen as especially strong since the EC has the ability to pose financial sanctions directly on the member states. The fact that the EC has strong mechanisms matches the shirking risk of the member states, which can be described as rather high.

Looking at the signs of a downwards spiral of costs between this principal and agent, these are not present. The obligations of the member states to inform the $E C$ are laid down in the regulation ${ }^{382}$ and do not lead to extra obligations or high administrative pressure on the member states.

Finally, when focusing on the characteristics of accountability overload, these are also considered to be absent.

\section{Changes in the 2014-2020 period}

Regarding the changes in the 2014-2020 period in this relationship, when focusing on the Netherlands, a first issue to focus on is the national declaration. In the Dutch context the national DAS has been an important issue in the accountability of the spending of SF. The Dutch Minister of Finance has issued a yearly DAS since 2006 on a voluntary basis, based on partial statements by the responsible ministries. The declaration is accompanied by a report of the AR. ${ }^{383}$ In 2014 , only two other member states issued such a declaration besides the Netherlands: Sweden and Denmark. The Dutch government has been lobbying to get the declaration as an obligatory element of the accountability within Cohesion Policy. However, in the Financial Regulation (FR) that was renewed in 2012, it is only mentioned as a voluntary instrument, which has been perceived as a small step forward compared to the previous period before the changing of the FR. ${ }^{384}$ Nevertheless, both the EP and the EC support the use of this instrument, following an advice of the 'Working group on National Declarations. ${ }^{385}$ For accountability to be strong, it is important that the

382 See for instance articles 29 (strategic reporting), 32 (approval of the OPs), 40 (major projects), 48 (ex ante evaluation) and 71 (setting up of MCS) of Regulation 1083/2006.

383 Algemene Rekenkamer 2015. 'Rapport bij de Nationale verklaring 2015'. Den Haag: Algemene Rekenkamer. The national Declaration of Assurance is an annex to the report of the AR.

384 Art. 59 paragraph 5 under b of Regulation 966/2012.

385 European Commission 2014. 'Communication from the Commission to the European Parliament, to the Council and to the European Court of Auditors on the adoption of the interinstitutional Working group 
politically responsible actors also take their responsibility, and this instrument serves this purpose. The future will show whether this instrument will become mandatory since many member states strongly oppose this instrument.

A second issue to highlight is the fact that the decommitment rule, also known as $\mathrm{N}+2$ rule, ${ }^{386}$ was extended during the 2014-2020 period to $\mathrm{N}+3{ }^{387}$ This gives more room for member states to spend the funds but at the same time still puts pressure on the system to spend in the end.

Third, of course the introduction of the (obligated) performance framework needs to be mentioned. We discuss this change in the 2014-2020 period in section 4.5.3 on the relationship between the EC and MA.

Fourth, it is important to mention that the use of NSRF, a national strategy covering all OPs in a member state, has been replaced by the obligatory use of a partnership agreement. As has been laid down in consideration 11 of Regulation 1303/2013, such a partnership consists of 'the representatives of competent regional, local, urban and other public authorities, economic and social partners and other relevant bodies representing civil society, including environmental partners, nongovernmental organisations and bodies responsible for promoting social inclusion, gender equality and non-discrimination, including, where appropriate, the umbrella organisations of such authorities and bodies.' As is described in the same consideration: 'the purpose of such a partnership is to ensure respect for the principles of multi-level governance, and also of subsidiarity and proportionality and the specificities of the Member States' different institutional and legal frameworks as well as to ensure the ownership of planned interventions by stakeholders and build on the experience and the know-how of relevant actors.' This obliges the authorities to also contract industry, academia and civil participants to be part of the governance and implementation of Cohesion Policy. This can be seen as a real change compared to the 2007-2013 period.

Fifth, in its information material, the EC points at simplification of the rules, in the way that one set of rules is put down for five funds: ERDF, ESF, CF, EAFRD and EMFF, together called the European Structural and Investment (ESI-) Funds. In the

recommendations for the establishment and use of National Declarations': European Commission. For more information, see also the website of the Working Group: http://ec.europa.eu/budget/biblio/documents/iwgnd/index_en.cfm, retrieved at 9-11-2015.

386 See section 4.4.2 The national parliament and the national government.

387 See art. 86 of Regulation 1303/2013. 
2007-2013 period, the rules for EAFRD and EMFF had been laid down in two separate Regulations. ${ }^{388}$ For the 2014-2020 period still some specific rules for the funds (mainly on the investment priorities and specific issues) are laid down in separate Regulations, ${ }^{389}$ but the general provisions of the funds are centralized into one Regulation, 1303/2013 (the 'Common Provisions Regulation', CPR).

Although this might be seen as a simplification, when looking at the CPR, it can also be said to have become more complicated in its structure, leading to more articles (154 versus 108 in 1083/2006) and also to a more complicated structure with the corresponding delegated and implemented acts, decisions and guidance documents issued by the EC. ${ }^{390}$ There is a lot of information available on the programming and execution of the ESI funds, spread over more than 40 separate documents and regulations, which does not seem to look like simplification.

Finally, the last major change to be mentioned here points at art. 23 of the Regulation, where it is said that the EC can ask a member state 'to review and propose amendments to its Partnership Agreement and relevant programmes, where this is necessary to support the implementation of relevant Council Recommendations or to maximize the growth and competitiveness impact of the ESI funds in Member States receiving financial assistance. ${ }^{391}$ Although this principle was already mentioned in the 2007-2013 period for Cohesion Fund, the article has now been put in the CPR, being applicable to all ESI-funds.

The idea behind these macro-economic conditionalities is to encourage member states to respect the agreements on European level, covering both fiscal policies (deficit and debt levels) as well as macro-economic policies (competiveness, internal and external imbalances). With this article in the Regulation, the EC has an extra sanctioning mechanism towards the member states that are not complying with the agreements and obligations following from these policies and rules.

It is meant to work as a two-sided conditionality, in the way that on the one hand Cohesion Policy spending can be suspended as specific economic governance

388 Respectively in Regulation 1698/2005 (EAFRD) and 1198/2006 (European Fisheries Fund).

389 Regulation 1301/2013 for ERDF, Regulation 1304/2013 for ESF, Regulation 1299/2013 for European Territorial Cooperation (ETC), Regulation 1300/2013 for CF and Regulation 1305/2013 for EAFRD.

390 See for an overview http://ec.europa.eu/regional_policy/en/information/legislation/regulations/, retrieved at 28-09-2015. At the end of September 2015 in total 6 delegated (and amending) acts, 14 implementing (and amending) acts, 6 decisions and multiple guidance documents had been issued by the EC.

391 Art. 23, section 1 of Regulation 1303/2013. 
requirements are not met, and on the other hand it can lead to easing of the cofinancing requirements if a country receives European financial assistance. ${ }^{392}$

The effects are that on the one hand the macro-economic conditionalities improve the effective use of Cohesion Policy funding, because fiscal or macro-economic imbalances impair long term growth perspectives and thus undermining the effectiveness of Cohesion Policy spending. ${ }^{393}$

On the other hand there are two negative consequences of the macro-economic conditionalities, as is pointed out by the report of the EP on the macro-economic conditionalities. ${ }^{394}$ There is the problem of 'a less fair Cohesion Policy.' ${ }^{395}$ It has the risk of targeting the wrong actors: member states are the actors not respecting the agreements and rules on European level, but regions are the actors hit by the macro-economic conditionalities, since they are the actors responsible for the implementation of Cohesion Policy in the member states. However, some programmes are executed on national level thus the conditionalities are partially targeting the correct actors. And especially in decentralized countries some regions have considerable economic policy-making responsibilities. Moreover, regions can also put pressure on the national level in the member state to avoid excessive deficits and thus improve the member state's overall fiscal position. Poorer regions and member states are also more likely to be hit by the macro-economic conditionalities. These countries rely heavier on Cohesion Policy, leading to a higher percentage of their GDP. ${ }^{396}$

The second negative effect is that Cohesion Policy becomes less reliable: project managers for projects know there is the risk of not receiving funding for a short orlonger period of time, depending on the behavior of the member state concerning economic policies. This is undermining the trustworthiness of Cohesion Policy.

Until September 2015, there have been no examples of the use of these macroeconomic conditionalities. Although there are member states that do not completely respect the Council Recommendations on Economic Governance, this sanctioning mechanism has not been used yet. The proof of the pudding is therefore in the eating.

392 European Parliament 2012. 'Macro-economic conditionalities in Cohesion Policy': European Parliament, Directorate General for Internal Policies.p. 32.

393 Ibid. p. 43 following European Commission 2010. 'Investing in Europe's future. Fifth report on economic, social and territorial cohesion': European Commission. p. XXV.

394 European Parliament 2012. 'Macro-economic conditionalities in Cohesion Policy': European Parliament, Directorate General for Internal Policies. chapter 4.

395 Ibid. section 4.4.2.

396 As the table on p. 45 of lbid. shows, this varies between 3,49\% of GDP (Hungary) and 0,02\% (Luxembourg). 


\subsubsection{The national government and the Managing Authority}

\section{Coverage: is there an accountability relationship?}

Another relationship on the national-European cluster, when looking at ERDF in the Netherlands, is the one between the MA at the regional level and the Ministry of Economic Affairs (EZ), representing the member state and responsible for the implementation of ERDF funds, at the national level. The Ministry of Finance is also indirectly involved, because its minister is signing the DAS on the EU finances, on behalf of the government. We however specially focus at the relationship between the MA and $E Z$.

The assignment of the MA is laid down in 'Besluit EFRO programmaperiode 2007-2013,',397 but specific relationships between all actors on national and regional level have been laid down in an agreement for every OP.

The agreement for OP Noord is called 'Convenant in het kader van het Operationeel Programma voor Noord-Nederland 2007-2013.' This agreement starts with mentioning the obligations of the MA (art. 3-9), the CA (art. 9-11) and the AA (art. 11). In the articles 12 until 24 the obligations of the minister, and in fact of the Ministry of EZ, are mentioned, which focuses on the tasks of the ministry in cases of incorrect use of funds and in sending information to the EC.

When looking at the specific elements of an accountability relationship, it is clear that the first two elements, assignment of responsibilities and reporting obligations, are present. Both the national legislation and the agreement signed by the authorities point at specific responsibilities that are assigned to the MA and what the MA should report on to the ministry. However, this reporting is not directly aimed at the ministry, but to the EC. Therefore, the ministry does not assess the information itself other than checking whether the information asked by the EC is comprehensive and seems correct ; it does not have all the detailed knowledge to assess whether the information is correct. Finally, the last element is present, but in a more or less implicit form. As we have seen before in the relationship between the EC and the member state, the member state has the obligation to prevent irregularities and fraud. ${ }^{398}$ In

397 Art. 5 section 3 of the decision, in Dutch Besluit EFRO programmaperiode 2007-2013.

398 Art. 53 section 6 of the Financial Regulation, 1605/2002 and art. 98 section 1 of Regulation 1083/2006 and see section 4.5.1. 
case of irregularities, the member state may pose sanctions on a MA to prevent this from happening again. Although this already follows from the regulation, ${ }^{399}$ it has also been laid down in national legislation in the NERPE law, ${ }^{400}$ which is - since its publication in May 2012 - also applicable to Cohesion Policy in the Netherlands. However, this possibility is probably only to be used in the case where European institutions, for instance the EC, order the reclaim of misused funds from the member state. It is therefore only a possibility to be used in rare cases.

Also, before 2014, the Minister could not retract the assignment as MA. However, this has changed with the adoption of the Uitvoeringswet EFRO in $2014 .{ }^{401}$ But until date, the Minister has not used its powers to do so.

This shows that the relationship between the national government and the MA in the case of the Netherlands does in a formal sense show all elements of an accountability relationship, but these are not used as in an accountability relationship. In practice, these control measures have not been used yet and probably will not be usedeither. Therefore, the ministry and thus the national government can be seen as some sort of 'service-hatch' of information being sent from the MA or member state towards the EC, and backwards; in the case of sanctions posed by the EC these will be put through to the MA to make sure that financial corrections are imposed. This makes it an indirect accountability relationship.

\section{Context: elements of transparency, democracy and legal constraint}

We have just concluded that EZ in this relationship is acting as a 'service-hatch' between the EC and the MAs. It has a coordinating role for the implementation of ERDF in the Netherlands. Information on the implementation from the side of EZ is difficult to find in public documentation. Most pronounced is the information send by EZ to the TK. However, no specific communication between EZ and the individual MAs is made publicly available by EZ. On the other hand, the same holds for the MAs, they do publish some information on their website on the progress made with the implementation, for instance annual reports, but specific documentation on communication between EZ and the MAs is not published.

Democracy can be said to be present in a very indirect way: because of the fact that the Minister of EZ is accountable to the TK. However, we consider that this connection is not playing a role in this relationship.

399 Art. 98 of Regulation 1083/2006.

400 Wet Naleving Europese Regelgeving Publieke Entiteiten (Law for compliance of European Regulations by public authorities) of May 24, 2012, to be found at http://wetten.overheid.nl/BWBR0031640/, retrieved at 28-08-2015.

401 Art. 3, paragraph 6 of Uitvoeringswet EFRO. 
Finally, with regard to legal constraint, there is the possibility for the MA to bring a case before court towards EZ. Also, as we already mentioned, the other way around EZ has the possibility to use the NERPE law ${ }^{402}$ to give a designation to the MA to act in a certain way, or, when the MA does not act accordingly, it can also go to court. However, this has not happened in the past, and it is not expected to happen either, specifically because the interests of both actors hardly diverge, as we will point out later on. This means in practice that sufficient legal possibilities are in place in this relationship.

\section{Content: the 3E's - economy, efficiency and effectiveness}

The same we have mentioned for the relationships between the EC and EZ also holds for this relationships between EZ and the MA: the focus is on compliance and economy (spending). The focus is primarily put on these two elements, there is almost no attention for efficiency. In 2012, when a concept Regulation was published during the negotiations for the 2014-2020 period, a study has been performed by a consultancy firm on the administrative impact of the new Regulation on Cohesion Policy in the Netherlands, and thus to a limited extent to its impact on efficiency of the programmes, especially focusing on the regional ERDF OPs. ${ }^{403}$ This is the only information to be found publicly on matters of efficiency.

Finally, on effectiveness we can also state that this does not get much attention in this relationship. As we have mentioned earlier, EZ is coordinating the implementation of ERDF in the Netherlands and it is mainly following the requests from the EC, that also primarily focus on compliance. Effectiveness thus is also having a low priority in this relationship.

\section{Costs: absence of accountability deficit or overload}

To start with, we expect the preferences of both EZ and the MAs to be more or less convergent, they do not differ much. In fact, both EZ and the MAs focus on spending the available funds, and both represent the national interests of not having to send money back to Brussels. When we look at the mechanisms that are available for EZ, we can see these are quite strong, especially the possibility to give a designation to an MA on the basis of NERPE law, ${ }^{404}$ or to recover funds unduly paid by the MAs can be seen as quite strong mechanisms.

402 See footnote 400.

403 Ketelaars, V., B.J. ten Berge, H.G.A.M. Cremers, P.J.A. Heuts and A.P.M. Linders 2012. 'Onderzoek naar de impact van de concept-Structuurfondsverordeningen 2014-2020 op de administratieve lasten en uitvoeringskosten van de Europese Structuurfondsen in Nederland': ERAC BV.

404 See footnote 400 . 
When we look at signs of a downwards spiral of costs between EZ and the MAs, we do not see these. Instead, it seems EZ is with the years ending up on a higher distance from the implementation itself, thus assumed likely to lead to lower costs. $E Z$ thus is not focusing on specific issues that lead to more implementation costs.

Finally, when focusing on the characteristics of an accountability overload, we feel these are absent in this relationship, because the primary attention on possible aspects of an accountability overload is not coming from EZ, but from the EC.

\section{Changes in the 2014-2020 period}

In the 2014-2020 period, there has been only one minor change in the relationship between the member state (in this case the Ministry of EZ) and the MA in the Netherlands. As mentioned previously, since 2014 the Minister of EZ has been given the possibility to retract the assignment of an authority with the coming into force of the Uitvoeringswet EFRO. In the Regulation for the 2014-2020 period it has been explicitly laid down that the member state has the possibility to end a designation of an authority. ${ }^{405}$ In case a body no longer fulfills the criteria relating to the internal control environment, risk management, management and control activities and monitoring, ${ }^{406}$ the member state is supposed to give the authority concerned a probation period in which necessary improvements should be implemented. When they fail to implement those improvements, this can lead to the ending of a designation. This possibility is new in the regulation on Cohesion Policy, and gives in this case the member state more power to act upon the behavior of the designated bodies. In the light of accountability, this is an asset to the powers of the member states vis-à-vis the designated bodies. In this case, the member state is the extension of the $\mathrm{EC}$, being responsible for the management within the member state. In the light of the shared responsibility between EC and the member state, which was already present in the 2007-2013 period, this possibility to be used by the member state is only logical. This means that the powers of the member state as responsible actor have even increased, not only on the national (NL) but also on the European level.

\subsubsection{The European Commission and the Managing Authority}

\section{Coverage: is there an accountability relationship?}

As mentioned earlier, it is clear that the formal relationship in implementing Cohesion Policy is set between the EC on the one hand and the member state on the 
other. ${ }^{407}$ However, when the Regulation discusses executing issues, it no longer speaks of 'the member state', but instead it refers to 'the member state or the managing authority ${ }^{\prime 408}$ or sometimes even directly of 'the managing authority. ${ }^{409} \mathrm{At}$ the same time, paragraph 4 of article 67 states that the EC informs the member state on its opinion on the annual reports of the MA, while article 68 mentions that 'the Commission and the managing authority shall examine the progress made in implementing the operational programme. ${ }^{410}$ This shows that the relationship between the EC, member state and MA is in fact a triangular one: formally, there is a direct accountability relationship between the EC as a principal and the member state as an agent, but there is also a relationship between the EC and the MA that encompasses the member state as well, making it blurred.

When looking at the four elements of an accountability relationship, it starts with the assignment of responsibilities of the agent. These are set in article 60 of Regulation 1083/2006. Reporting obligations, the second element, are also present, and the regulation also mentions various issues the MA should inform the EC. ${ }^{411}$ When receiving this information, the $\mathrm{EC}$ also has to verify it and form an opinion, leading to direction or control and possibly to sanctions. These sanctions may take the form of interruption of payments, ${ }^{412}$ suspension of payments, ${ }^{413}$ or financial corrections. ${ }^{414}$ Since the sanctioning mechanisms are directed at the member state, but having direct effect on the OP and thus on the MA, the relationship formally runs from the $M A$ via the member state to the EC. We thus consider the relationship between the $E C$ and the MA also as an accountability relationship. But, as we will also describe in the next section, the $\mathrm{AA}$ also has an important role in this relationship.

One of the obligations set in the Regulation ${ }^{415}$ is to set up a monitoring committee (MC) that is responsible for the approval of the selection criteria for the operations, for the review of progress of the programme, for examination of the results of

407 This can be seen for instance in art. 11 paragraph 1 of Regulation 1083/2006 where it says: 'The objectives of the Funds shall be pursued in the framework of close cooperation, [...], between the Commission and each Member State.' Another clear expression of this relationship is mentioned in art. 14, paragraph 1: 'The budget of the European Union allocated to the Funds shall be implemented within the framework of shared management between the Member States and the Commission, [...].'

408 See for instance art. 57 on durability of operations, art. 69 on information and publicity.

409 See for instance in art. 55 on revenue generating projects, art. 67 on annual and final report, art. 90 on availability of documents.

410 Art. 68 section 1 of regulation 1083/2006.

411 See footnote 409

412 Art. 91 of Regulation 1083/2006.

413 Art. 92 of Regulation 1083/2006.

414 Articles 99-102 of Regulation 1083/2006.

415 Regulation 1083/2006 
implementation; it considers and approves the annual and final reports to be send to the EC by the MA, it is to be informed on the Annual Control Report (ACR) issued by the $\mathrm{AA}$, it can propose revisions of the OP and finally it considers and approves any proposal to amend the content of the EC decision for the OP. ${ }^{416}$

Although the obligation to set up an $\mathrm{MC}$ is directed at the member state, in practice in the Netherlands this responsibility is picked up by the MA. That is the reason we mention this obligation in this section. The role of the $M C$ is quite strong in the Regulation, however in practice the role of the MC is limited. They meet twice a year to be informed and to formalize decisions that need to be taken. The real governing of the OP is done by the MA itself.

The MC of OP Noord for the 2007-2013 period consisted of representatives of the provinces and municipalities, the Ministry of EZ, educational organizations in the region, business organizations and employers. Advisors to the $\mathrm{MC}$ are representatives of the EC, $\mathrm{EZ}$ and the director of SNN. In the 2014-2020 period the MC of OP Noord is having an independent chair and consists of more experts in specific fields relevant to the OP and less of representatives of the government (provinces, municipalities and Ministry of EZ). It has been a deliberate choice to focus more on the quadruple helix, by connecting industry, academia and civil participants other then primarily inviting government representatives in the MC.

\section{Context: elements of transparency, democracy and legal constraint}

As we have described earlier in section 4.3.2, DG REGIO, responsible for Cohesion Policy, is issuing a yearly AAR on its own activities and the performance of the member states in implementing the policy. ${ }^{47}$ This is the main source of information

SNN publishes the annual report that is send to the EC also on its website, together with other relevant reports that are produced on the implementation and evaluation of the policy (to be found on www.snn.eu).

416 Art. 65 of Regulation 1083/2006.

417 The latest version is European Commission 2015. 'Annual Activity Report 2015 DG Regional and Urban Policy'. Brussels: European Commission. 
to be found on the status of Cohesion Policy. At the same time MAs also inform both the EC and the public on their performance. However, other information on discussions with the $E C$ or the $A C R$ issued by the $A A$ is not made publicly available.

The element of democracy is not visible in this relationship. The element of legal constraint is also directed via the member state. While there is no possibility for the MA to appeal against a decision of the EC, the member state can file an appeal. This means that also from the judicial standpoint, the relationship between the EC and the MA is running via the member state. However, since the preferences of the MA and the member state might differ, the possibility for a legal procedure is limited for the MA.

\section{Content: the 3E's - economy, efficiency and effectiveness}

When looking at the nature of this accountability relationship, it is clear that this is directly aimed at compliance and economy. All the issues the MA has to inform the EC on are connected to compliance elements, not to performance elements. The EC has been so far primarily interested in money spent, error rates and financial aspects of the programme, although the MA also needs to inform the EC on the progress made with the performance indicators of the programme. However, the MAs are not sanctioned for not reaching these indicators, ${ }^{418}$ while there are financial sanctioning instruments set on the compliance elements just mentioned ${ }^{419}$ Moreover, these performance indicators themselves do not directly refer to effectiveness of the policy, but only inform on the output of the policy. Efficiency, moreover, is not to be reported on by the MA.

\section{Costs: absence of accountability deficit or overload}

This relationship shows signs of divergence in the preferences of both actors. This originates from the fact that regional authorities often govern OPs and are more open to regional interests. Since these might be contradictory to the interests of the EU and the EC, for instance in awarding a grant to a project that is important to a region but that does not fit within the wider goals of the $E U$, there is a tendency toward divergence in this relationship. However, the EC hardly intervenes with the selection of projects, but it does have the possibility to assess later in the process whether projects are fitting into the framework, for instance when there is a suspicion

418 Regulation 1083/2006 mentions the possibility for member states to set up a national performance reserve of $3 \%$ of the budget, see articles 23 and 50 , but this reserve is voluntarily. In practice this reserve hardly has been used by member states in the 2007-2013 period, it has not been used in the Netherlands.

419 Decommitment, payment interruptions or suspensions and financial sanctions. 
of misuse of funds. In having this possibility, there is pressure from the EC on MAs to act according to its preferences. As also described previously, the EC therefore has strong mechanisms to influence the actions of the member states and also the MAs. These strong mechanisms then match the (possible) shirking risk of the MAs.

SNN, MA for OP Noord, is governed by the three northern provinces Fryslân, Groningen and Drenthe. Het Dagelijks Bestuur (DB, Daily Board) is formed by the three Commissarissen van de Koning (Commissioners of the King, CdK's) and decisions are therefore taken by the governors of the provinces, in some cases delegated to the Bestuurscommissie (Board Committee, BC).

In the 2014-2020 period, projects are assessed by a Deskundigencommissie (Commission of Experts, DC), consisting of independent experts on the labour market, innovation, business cases, sustainability and lowcarbon. It is expected that the DB or BC will take over the advice of the DC of which projects to select for granting funds.

In the 2000-2006 period, SNN had assigned Deloitte as external auditor, responsible for the verification of checks by the MA, which is currently the role of the AA. Furthermore, the certification function was executed within the MA, with separate personnel that was not involved with the work of the MA. Since the 2007-2013 period, separate institutions on national level for CA (Dienst Regelingen, later RVO, of Ministry of EZ) and AA (ADR) have been appointed, thereby increasing the institutionalization of controls.

When looking at aspects that might play a role in a downwards spiral of accountability, it is noticed that with each programming period the demands on the MAs get higher. In the 2000-2006 period the thresholds for management verifications and checks on the spot were less strict, in the 2007-2013 period, the $2 \%$ materiality threshold for the error rate ${ }^{420}$ during the programmes implementation period was enforced by the EC. 
The materiality threshold of $2 \%$ has resulted for OP Noord in a payment interruption that lasted for seven months in 2012, resulting from a multiannual cumulative error rate of more than $2 \%$, based on error rates of $2,03 \%$ and $2,94 \%$ in 2010 and 2011 , respectively. It took a lot of discussions and negotiations with all the actors involved - the EC, the Ministry of $E Z$, the $A A$, the $C A$ and $M A$ - resulting in action plans and measures to be taken before the interruption was lifted. It is questionable whether there really was such a big problem in the Netherlands at the time, whereas the interruption procedure launched by the EC was quite invasive.

As is described on the end of this section, the burden on authorities is further aggravated in the 2014-2020 period with the addition of obligations to report on the performance of the policy. Concluding, we do see signs in this relationship over time of a downwards spiral of accountability.

Finally, when looking at the aspects of accountability overload, three of the four aspects are considered to be present, however not all as harsh as mentioned by Bovens. $^{421}$

First, it is considered that there are a lot of obligations set for MAs, and this combination of a lot of separate demands leads to high demands. For instance on specific reporting obligations, specific obligations concerning payments requests, the obligation to report irregularities every three months and specific obligations concerning management verifications and other executive tasks. For the 2007-2013 period the EC has provided around 60 Guidance notes, all with specific (nonbinding) guidelines to be followed. ${ }^{422}$ All those obligations take a lot of the MAs time. It can be questioned whether these obligations really contribute to the good execution of the programme, which will probably also be the case without these heavy reporting obligations.

Second, when looking at the materiality threshold of $2 \%$ for the (yearly) error rate, as can be seen in the case of the interruption procedure of OP Noord mentioned above, it is questionable whether this is realistic in shared management. However,

421 Bovens, M., T. Schillemans and P.t. Hart 2008. 'Does public accountability work? An assessment tool', Public Administration, 86, 225-242, p. 229. See also section 2.3.5.

422 The list of guidelines for the 2007-2013 can be found on http://ec.europa.eu/regional_policy/en/ information/legislation/guidance/2007-2013, retrieved at 14-11-2015. 
this threshold does not seem to exceed the EC's own standards, the $2 \%$ threshold is used in general across all institutions and policy areas.

Third, goal displacement in the governance of the programmes can be seen. A focus on compliance elements and $\mathrm{N}+2$ means that MAs focus on projects that can meet the compliance obligations and deliver quick and clearly eligible costs. ${ }^{423}$ However, focus should be put on projects that deliver the best results and are contributing the most to the Cohesion Policy goals.

\section{Changes in the 2014-2020 period}

Regarding the changes in the 2014-2020 period, four issues are to be mentioned.

First, in the 2014-2020 period, the performance reserve that was mentioned in the 2007-2013 regulation as a voluntary instrument for the member states is set as an obligation. ${ }^{424}$ In total $6 \%$ of the resources allocated to the ESI funds ${ }^{425}$ are put into a performance reserve for every OP, and allocated to specific priorities. In 2019, the EC will take a 'performance review', together with the member states, 'to examine the achievement of the milestones of the programmes at the level of priorities. ${ }^{426}$ This means the performance reserve has turned obligatory, and the MAs had to set specific milestones in their OP to be achieved halfway. Following the pressure for more focus on the performance of Cohesion Policy, the EC has introduced this instrument 'to align the policy better [...] for achieving the agreed targets [.....$^{427}$ One would expect that not achieving these halfway milestones would lead to the loss of this performance reserve of $6 \%$, thus leading to an extra sanctioning mechanism available for the EC. When looking more closely, it gets clear, however, that this instrument is not as harsh as it possibly could work. In case programmes or priorities have not reached the milestones, the member state has the obligation to 'propose the reallocation of the corresponding amount of the performance reserve to [other] priorities [...] and other amendments to the programme which result from the reallocation of the performance reserve. ${ }^{428}$ This shows that there is more focus on performance elements, but the sanctions that are placed are probably not as harsh as they seem. To start with, member states have the obligation to agree with the EC on the allocation of the performance reserve when OPs have not achieved

423 See also section 4.5.1.

424 Art. 20 of Regulation $1303 / 2013$.

425 This new abbreviation has been introduced in the 2014-2020 programme and stands for 'European Structural and Investment' -Funds, see art. 1 of Regulation 1303/2013.

426 Art. 21 of Regulation 1303/2013.

427 European Commission, Q\&A on the legislative package for EU Cohesion Policy 2014-2020 (2013), to be found at http://europa.eu/rapid/press-release_MEMO-13-678_en.pdf, retrieved at 9-11-2015.

428 Art. 21 paragraph 4 of Regulation 1303/2013. 
the milestones for all programmes and priorities. Also, it is expected that the MAs anticipate on the milestones that are set in the OP, trying to make them as realistic - and maybe even as easy to reach - as possible. We will therefore have to see in the future whether this adaptation will have the effect it is supposed to have and will lead to more focus on the performance of Cohesion Policy.

Second, with regard to the elements of accountability overload or deficit, in practice the EC has tried to maximize its influence in the ex ante stage by assessing the draft OPs multiple times and making detailed recommendations before approving them. This shows the EC is taking all the means it has to make sure the implementation of Cohesion Policy is compliant with its policy goals. However, this only adds to the already strong mechanisms in place for the EC.

Third, in the Regulation for the 2014-2020 programming period ${ }^{429}$ it can be seen that the division between responsibilities of the member state and the MAs is sharpened, in the way that implementing issues have been assigned specifically to the $\mathrm{MAs},{ }^{430}$ whereas main responsibilities are assigned to the member state, ${ }^{431}$ which is less blurred than in the 2007-2013 period. ${ }^{432}$

Fourth, when looking at Regulation 1303/2013, it becomes clear that the EC has gained circumstances in which it can use the sanctioning mechanism also present in the 2007-2013 period, which are interruption and suspension of payments and making financial corrections. These are since the new period also connected to the partnership agreement and the macro-economic conditionalities, ${ }^{433}$ performance reserve $^{434}$ and the principle of additionality. ${ }^{435}$

429 Regulation 1303/2013.

430 See, for instance, arts. 36, 37 and 46 on financial instruments, art. 70 on eligibility, art. 101, 102 and 103 on major projects, art. 125 on functions of the managing authorities, art. 132 on payment to beneficiaries and art. 140 on the availability of documents of Regulation 1303/2013.

431 See, for instance, arts. 5 and 14 on partnership, 18 and 19 on thematic concentration, arts. 47, 50, 52, 54 and 57 on monitoring, reporting and evaluation, art. 122 on the responsibilities of the Member State, art. 123 on designation of bodies and art. 143 on financial corrections of Regulation 1303/2013.

432 See footnotes 408,409 and 410.

433 Art. 23, section 6 and further of Regulation 1303/2013. The Council has to decide on these situations.

434 Art. 22, section 6 and further of Regulation 1303/2013.

435 Art. 95, section 6 of Regulation 1303/2013. 


\subsubsection{The European Commission and the Certifying Authority, the Audit Authority and the Managing Authority}

The member state has to appoint a $C A^{436}$ and $A A^{437}$ for every OP, just as it has to appoint an MA. Both authorities form part of the governance of Cohesion Policy, but their role is that of a verification institution. The main responsibility of the CA is 'drawing up and submitting to the Commission certified statements of expenditure and applications for payment.' All its other tasks are derived from this responsibility. ${ }^{438}$ This means that communication from the MA to the EC on financial aspects, such as statements of expenditure, applications for payment and irregularities runs via the CA. Since the CA is also an institution of 'first line control,' together with the $M A$, it is also subject to verification by the AA. Because there is no accountability relationship between the $\mathrm{CA}$ and the $\mathrm{EC}$, we do not consider the role of the $\mathrm{CA}$ in further detail in this research.

Much more interesting is the role of the AA, in the Netherlands executed by the ADR, part of the Ministry of Finance. The AA is, according to the Regulation, responsible for (among other things) the carrying out of audits to verify the effective functioning of the management and control system (MCS) of the OP and the submitting of ACRs on the performance of the MA, and more specifically on the errors found in the OP. ${ }^{439}$ This means that the AA is in fact a monitoring agent to the EC: responsible for monitoring the performance of the MA and reporting to the EC on its findings. Sanctioning of the MA by the EC is primarily based on the reports of the $A A$. This also means there is no direct accountability relationship between the AA as agent and the EC as principal. Since we do not consider this relationship to be an accountability relationship, we do not discuss the other elements of accountability. However, we do want to discuss some other issues regarding this relationship.

Complementing the earlier mentioned decision Bes/uit EFRO programmaperiode 2007-2013, ${ }^{440}$ the responsibilities between the ministry, CA, AA and also the MA, have been laid down in a separate agreement between the organizations, as one agreement per OP. ${ }^{441}$ In this agreement it has been laid down that both the CA

436 Art. 61 of Regulation 1083/2006.

437 Art. 62 of Regulation 1083/2006.

438 Art. 61 under a of Regulation 1083/2006.

439 All tasks of the AA can be found in art. 62 of Regulation 1083/2006.

440 Decision on ERDF in period 2007-2013.

441 In the case of OP Noord 'Convenant in het kader van het Operationeel Programma voor NoordNederland 2007-2013'. This agreement is not publicly available. 
and $A A$ are responsible to the Minister of $E Z .{ }^{442}$ Because of changes in ministries resulting from a new cabinet in 2012, when the CA became part of the Ministry of $E Z$, the strange situation has developed that the Minister of $E Z$ is responsible to itself in its role as CA. Before 2012, the Minister of Agriculture was responsible for the CA, thus accountable to the Minister of EZ.

What we see in practice in the Netherlands is that the role of the AA has become more determining with the years. The $A A$ is expressing its role in the governance of Cohesion Policy in the Netherlands as being an independent institution responsible to the EC to inform it on the performance of Cohesion Policy in the Netherlands, focusing primarily on compliance issues. Since the EC with the years attached more and more value to the ACRs and the annual error rate stated in the report, which should not come above the materiality threshold of $2 \%$, the work of the AA has gained importance. As different MAs in the Netherlands have experienced, ${ }^{443}$ an annual error rate above $2 \%$ can have serious consequences, possibly leading to suspension and even interruption of payments. This is a strong mechanism to be used by the EC, since this may lead to the consequence that an MA is lacking financial means to be able to pay beneficiaries, an unwanted situation for all actors.

What is important to mention is that there is often a whole world to be found behind error rates. In the Netherlands in 2015 a committee appointed by EZ, called 'Commissie van Goede Diensten' (CGD, Commission of Good Services) has been appointed to perform research into the 'sore points' in the implementation of ERDF in the Netherlands, as experienced by MAs, AA and EZ. In its report, the CGD stated: 'Since the second half of 2012, frictions became apparent, specifically between the MAs and the $A A$, resulting in some cases of severe differences of opinions on the correctness of declarations. ${ }^{444}$ These frictions are related to assessment of declarations by the AA; in some cases the regulations, guidelines and other documentation issued by the EC are not clear enough, which may lead to discussion between MAs and the AA on how to interpret the rules, thus to a 'grey area'. Because nonetheless a decision has to be taken by the MA, it should decide whether a (grey) situation should be seen as white (correct) or black (irregular). It happens often that MAs contest the assessment of the $A A,{ }^{445}$ but formally the $A A$

442 To be found in the considerations of the agreement.

443 In 2012 OP Noord and OP Zuid had error rates above 2\% (see Algemene Rekenkamer 2013. 'EU Trendrapport 2013'. p. 70) and in 2013 and 2014 OP West had an error rate above $2 \%$ (see Algemene Rekenkamer 2015. 'EU Trendrapport 2015'. Den Haag: Algemene Rekenkamer. p. 23).

444 Veldman, W., P.M. van der Zanden and M.A. van Ruremonde 2015. ' 'Pijnpunten' in de controle van EFRO subsidies in Nederland. De middelen moeten het doel niet in de weg staan.: Commissie Goede Diensten. Non-public report, p.11.

445 See for instance Algemene Rekenkamer 2014. 'Rapport bij de Nationale verklaring 2014': Algemene Rekenkamer, p. 20 on the objections of the MAs towards the findings of the AA. 
As an example of such a grey area it is interesting to look at article 70 of the 1303/2013 Regulation. It states (paragraphs 1 and 2):

\section{Article 70. Eligibility of operations depending on location}

1. Operations supported by the ESI Funds [...] shall be located in the programme area.

2. The managing authority may accept that an operation is implemented outside the programme area but within the Union, provided that all the following conditions are satisfied:

(a) the operation is for the benefit of the programme area;

(b) the total amount allocated under the programme to operations located outside the programme area does not exceed $15 \%$ of the support from the ERDF [...] at the level of the priority [...];

(c) the monitoring committee has given its agreement to the operation or types of operations concerned;

[...].

The EC is also preparing a (non-binding) guidance note on the interpretation of this article, which had not been adopted yet at the start of the programming period.

In 2015, there have been discussions between the authorities (Ministry, $\mathrm{CA}, \mathrm{AA}$ and MAs) on how to interpret this article: when in an innovation project, that has applied for a grant from OP Noord, three partners are cooperating, working from three different regions, of which one is located in the area of OP Noord, on which conditions can a grant be awarded? Does such a project comply with article 70 paragraph 1, and if not, how is then decided whether such a project benefits to the programme area, and what amount should be used to calculate the paragraph 2 under $b$ amount of support outside the area?

It was suggested in a discussion that the idea of this article is to prevent financial flows from less developed areas to develop areas within a member states. However, all regions in the Netherlands are developed regions, which leads to the finding that this article leads to a lot of (possible) discussion and grey areas where it should be clear for Dutch authorities that it is possible to fund cooperation projects between partners from different regions within the Netherlands. 
is responsible for its assessment and the ultimate formulation of the $A C R$, and thus the information that is send to the EC.

In case of an unclear or 'grey situation', the MA has the responsibility to judge whether actions, projects or costs are correct, or whether it concerns errors that need to be corrected.

Following the regulation, the AA has an advisory role to the $\mathrm{EC}$ in verifying whether the management and control system of the OP functions effectively. ${ }^{446}$ This means the $A A$ has an independent role to provide the $E C$ as principal with information on the performance of the MA as agent. However, in practice at the national level, it was said by the AA that findings of the AA will have to lead to corrections that need to be included in the ACR. In its role as verification agent to the $E C$, one would expect that the EC as principal imposes sanctions, not the AA. In practice in the Netherlands, the AA has been given the authority to impose sanctions, instead of the EC. This means the relationship between the MA and the AA is somewhat blurred, not showing signs of the first three elements of an accountability relationship, but exhibiting the fourth element of imposing sanctions.

We argue that the position of the AA towards other institutions is quite blurred: on the one hand it is acting as monitoring agent for the EC, but it seems to be using sanctioning mechanisms, whereas other elements of an accountability relationship between MA and AA are absent. This means there is tension between authorities, where the blurry situation leads to uncertainty for the MAs and a lot of discussion on detailed issues. It is questionable whether this situation is contributing to a good performance of Cohesion Policy on national level.

\section{Changes in the 2014-2020 period}

A change with regard to the authorities is the set up and evaluation of the management system. While in the 2007-2013 period the EC asked the AA to verify the management of both the MA and CA by judging specific (separate) 'key requirements' (KR's) that were set for both institutions, in the 2014-2020 period the EC constructed a framework that is composed of KR's for MA, CA and AA. This change is reflecting the fact that also the $C A$ and $A A$ are part of the management system of the OP concerned and thus also should be judged in coherence with the KR's of all three institutions. As can be seen in the delegated regulation laying down common provisions on ERDF, CF, EAFRD and EMFF, ${ }^{447}$ when one or more of specific men- 
tioned KR's is judged as 'underperforming', this leads to a classification of 'serious deficiencies' in the programme, which in turn can lead to suspension, interruption of payments or financial corrections. The change is to be seen in the fact that the system from 2014 on is judged as a whole, instead of judgment of the separate bodies, but also in the fact that some specific KR's, more than in the previous period, have been appointed as crucial. This also means that the whole management system will be judged as insufficient, when one (critical) KR is judged as insufficient. In theory, the situation when only one specific critical KR of the $A A$ is judged negatively, can lead to the situation that the OP concerned, and thus the MA of the OP, is faced with suspension of payments or even financial corrections, whilst the MA itself is performing on a satisfactory level. Time will tell whether these situations will occur, but in theory it seems to be a possible negative consequence of the new rules.

\subsubsection{Conclusion on accountability in the national-European cluster}

We have seen that two explicit and one indirect accountability relationships can be identified on the national-European cluster.

First of all, there is the clear accountability relationship between the EC and the national government, in the case of ERDF the Ministry of EZ. We have seen that all four steps are present. Secondly, we have seen that the relationship between the EC and MA also can be classified as an accountability relationship. The indirect accountability relationship we have identified then refers to the relationship between $E Z$ and $M A$, in which all four elements are present, but are not used as in an accountability relationship. Combining these three relationships shows that there is one continuous relationship between the $E C$ and the MA, passing through $E Z$, making this last institution more or less a 'service-hatch'.448 Finally, we have discussed the $A A$ as a monitoring agent in the system.

The answers to the questions lead to the following overview in Table 5 on the accountability relationships in this cluster. 


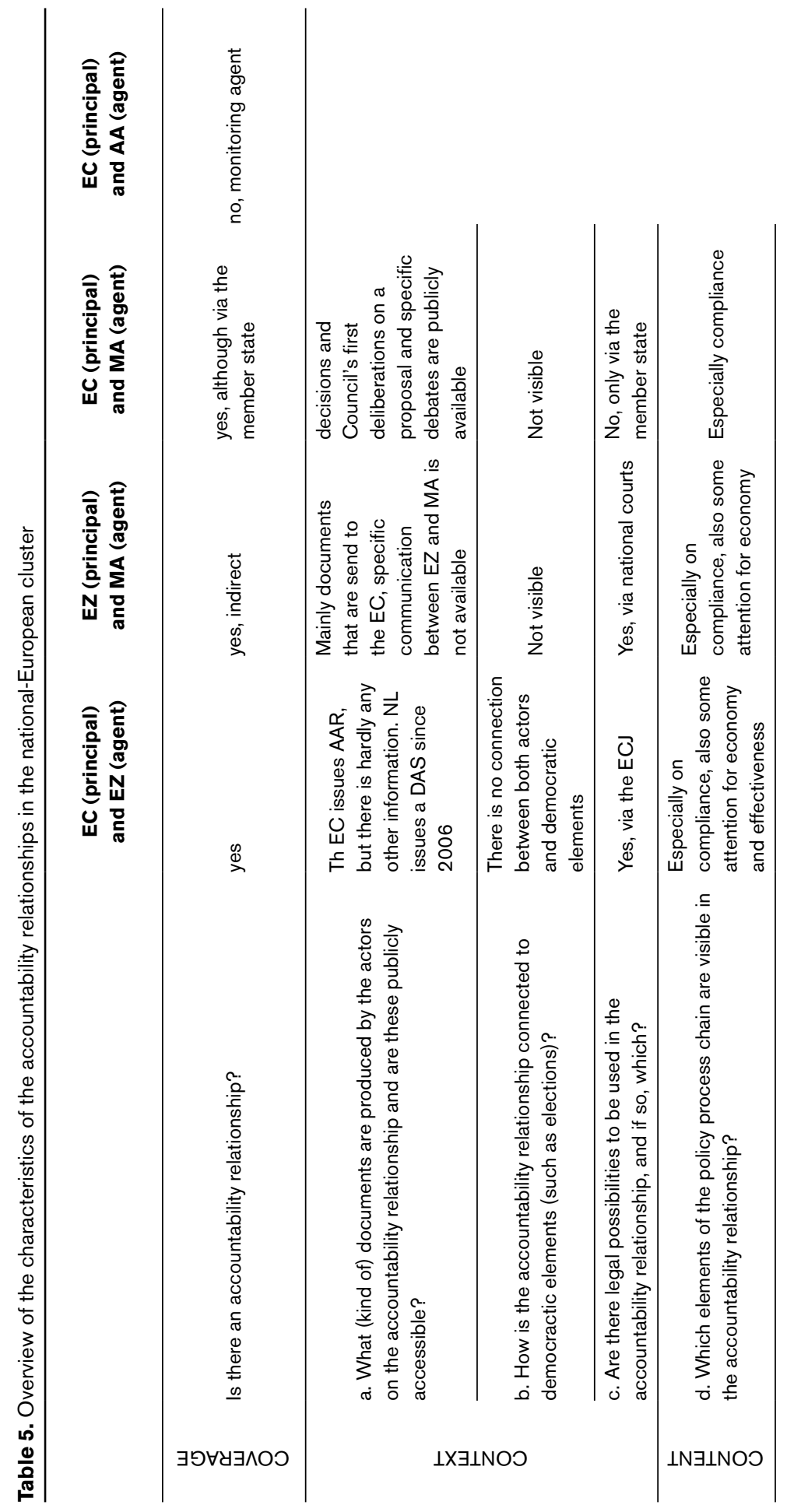


즣 山ै
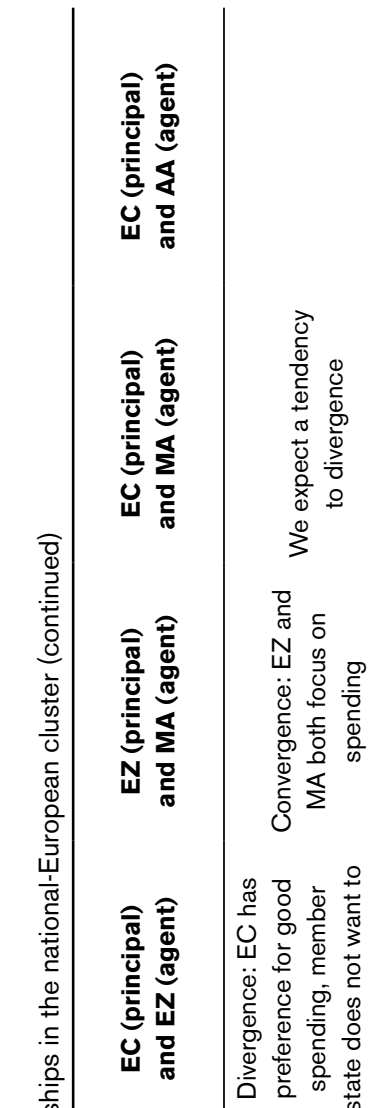

$\mid$

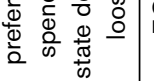

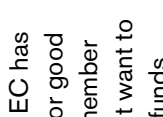

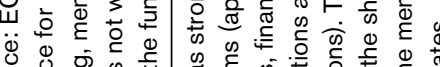

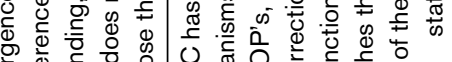

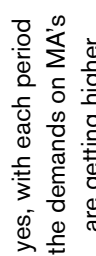

$\stackrel{\oplus}{=}$

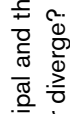

흘

$\stackrel{0}{\rightleftharpoons}$

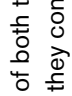

क 응

竞

这

$\stackrel{2}{\ddagger} \frac{5}{3}$

ㅎํ웡

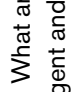

돌

ฮ

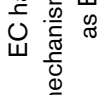

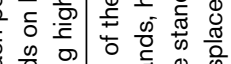

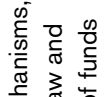

疍 恿

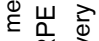

竞崖

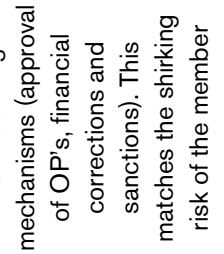

ळ

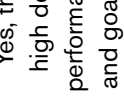

옴

ㅇ

은

$\stackrel{9}{9}$

\& 


\subsection{The relationships in the regional cluster}

In the previous sections we have been looking at the situation of Cohesion Policy in the European, the national and the national-European cluster. There is one cluster left, also relevant to the implementation of Cohesion Policy in the Netherlands. This cluster refers to the regions where the OPs are implemented. The way of implementation differs a lot between member states, depending of its structure and legal entity, and also between regions, depending on specific characteristics. As mentioned earlier, when using examples in this thesis, we refer to OP Noord and thus to SNN as MA. In this section, we therefore specifically look at the relationships between actors on regional level, thus to the relationship between the provinces and the MA (SNN).

In the northern part of the Netherlands, Samenwerkingsverband NoordNederland (SNN), managing authority for a regional ERDF programme, is appointed as a Gemeenschappelijk Regeling ('Gemeenschappelijke Regeling Samenwerkingsverband Noord-Nederland; abbreviated as $\mathrm{GR}$, in English joint arrangement), between the three northern provinces of Fryslân, Groningen and Drenthe. This cooperation is based on the Dutch 'Wet Gemeenschappelijke Regelingen' (Law on Joint Arrangements of December 20, 1984), which allows four different types of cooperation between local governments, whereas SNN is of the type of a public body with a general board (AB), an everyday management (DB) and a president (see art. 8 until 16 of Wet Gemeenschappelijke Regelingen).

The provinces are governed by Gedeputeerde Staten (GS), which consist of members of the coalition of the biggest parties within the Provinciale Staten (PS), the by the citizens directly elected organ. As head of a province, an (indirectly appointed) Commissaris van de Koning (CdK) is president of the GS and 'the face' of the province to the outside world. An accountability relationship is seen between GS and PS, whereas GS is accountable to PS, just like the Dutch government is accountable towards the TK. When looking specifically at the responsibilities and relationships in the context of SNN, we see that similar responsibilities are set in the GR, but then on a three-provinces-wide scale. The GR starts with the purposes that are assigned to SNN (art. 2 and 5). It also mentions that specific competences can be handed over from the provinces to SNN, but GS and the CdK have to inform PS on the transfer (art. 4, 
section 2). Then the GR appoints the members and tasks of the general board, the everyday management and the president. To start with the last one, the president is always one of the three CdK's of the provinces. $\mathrm{He}$ is appointed by the general board and he presides both the general board and the everyday management (Art. 24, section 1). The general board on its turn, consists of three members per PS ( 9 in total) and the everyday management, that consists of two members of GS's of the provinces (6 in total) and all three CdK's (Art. 9, section 1).

When comparing the GR to the elements of accountability, we can see that the first two elements are present: the responsibilities of SNN, in this case of the government of SNN by $A B$ and $D B$, are set in the GR. It is also mentioned that the agent, in this case SNN, is obliged to inform the principal, which are the PS's: members of PS can ask questions to the $A B$ (art. 10). The third element of investigation and verification of the information is a step that is to be done by PS, where SNN-issues are discussed. However, SNN as an MA is not really an issue in the meetings of PS's. Finally, the direction or control by PS is a difficult one. There is the possibility for PS members of $A B$ to be released from duty, when the member does no longer posses the confidence of PS (Art. 12). But this does not hold for the non-PS members of the AB. That means that effectively the relationship between PS as a principal and SNN as agent cannot be seen as an accountability relationship: there is no effective mechanism for PS to hold the AB of SNN accountable for its actions. In a way, the GR therefore outplaces specific competences of the provinces and positions these outside the scope of PS. We therefore do not consider this relationship as a pure accountability relationship.

Although the regional level is important in implementing Cohesion Policy, we focus in the rest of this research specifically on the European, national and the nationalEuropean cluster. This is because the relationships on those last three clusters are having the most impact on the implementation of Cohesion policy. We take the MA, in practice in the Netherlands in the ERDF system an actor on regional level, into account in the national-European cluster, making sure the most relevant relationships are covered in this research. This means we do not refer to the regional cluster anymore in the next chapters. 


\subsection{Preliminary conclusion on the relationships in the system}

As mentioned in the introduction, this chapter was based on document research, focusing on identifying accountability relationships and describing the elements and characteristics of these relationships. This section gives some preliminary conclusions on the relationships identified, which are complemented in chapter 6 with information from the interviews from chapter 5.

Below, we discuss the relationships we have identified in this chapter according to the requirements of 'good accountability'.

\section{Coverage: is there an accountability relationship?}

According to our analysis of the relationships within the system, we have seen eight accountability relationships:

- Between the citizens and the EP;

- Between EP and EC;

- Between the Council and the EC (being an informal accountability relationship because of the fact that direction or control mechanisms are formally lacking, although in practice the Council does have the power to influence the EC);

- Between the citizens and the national parliament (TK);

- Between the national parliament (TK) and the national government (EZ);

- Between the EC and the national government (EZ);

- Between the EC and MA;

- Between EZ and MA (being an indirect accountability relationship because of the fact that the MA in fact is accountable to the EC, but is using EZ as 'service-

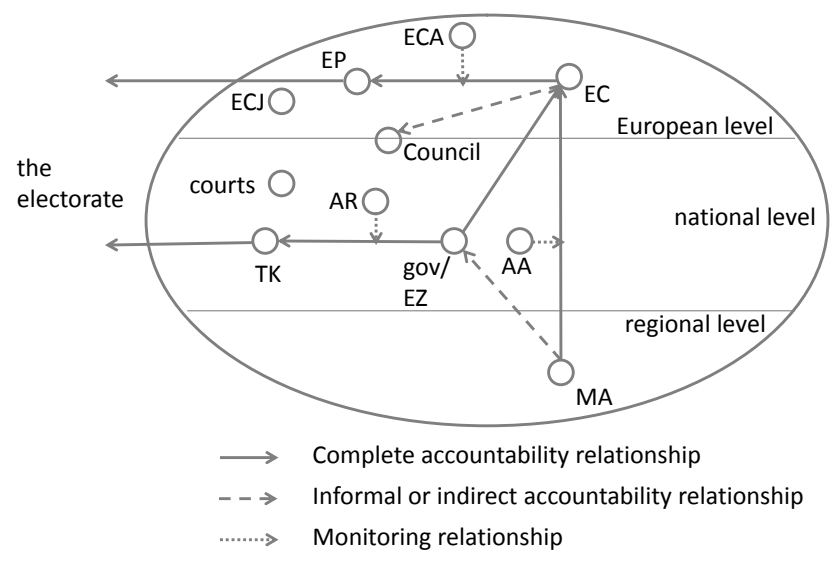

Figure 22. The actors and classification of relationships 
hatch' to send information to the EC and because of the fact that EZ does not use its formal mechanisms for direction or control, and staying more at a distance from the implementation of the policy on regional level).

Next to these eight accountability relationships, we have also identified three monitoring agents, being the ECA, AR and AA. In the regional cluster, we have not found any accountability relationships. A schematic overview of the actors and relationships can be found in Figure 22..

\section{Context: elements of transparency, democracy and legal constraint}

When looking at these elements, we have at first seen that democratic accountability on European level is lacking, because there is no European arena available for the electorate to hold MEP's really to account on European issues. On national level, we have seen that with the possibility of elections, the democratic element is present. Finally, when looking at regional level, we concluded that in PS, the function of the MA is not really an issue, thus the democratic element on regional level is lacking.

Regarding transparency, we have seen that a lot of information on Cohesion Policy is published by the EP, EC and the TK. Also, the MAs themselves publish information on the progress of the implementation of the policy. However, a lot of specific information that is exchanged between actors is not made publicly available.

Regarding legal constraint, we have concluded that the ECJ has an important role in establishing legal constraint. This is however barely done. On national level, national courts play a role, but often these are establishing legal constraint by disputes between grantor bodies, the MAs, and beneficiaries. We have also seen that legal possibilities for some of the actors, being the responsible actors on national level for the implementation, is lacking.

\section{Content: the 3E's - economy, efficiency and effectiveness}

We have seen that within the policy area, a lot of attention is directed at compliance issues. The accountability relationships between EC and EP, EC and Council, EZ and EC and especially EC and MA are focusing on compliance. Economy is also an issue, especially in the European (EC and Council) and the national-European cluster (EZ and EC), and attention for effectiveness is growing, especially with the use of the performance reserve in the 2014-2020 period. We have also seen that the monitoring agents focus specifically on compliance, with in the national cluster the AR that is also focusing on economy and effectiveness.

\section{Costs: absence of accountability deficit or overload}

When we finally look at what we have described on the cost-aspect of the requirements on 'good accountability', we can see that of the eight accountability relation- 
ships we have identified, four are seen to be balanced and two are seen to lead to a possible accountability deficit or overload. The two other relationships that are not classified, are concerned with the democratic aspect, between both the EP and the TK and the electorate. As mentioned earlier, we do not deal with these relationships further on.

The four relationships we consider to be in balance are the relationships between:

- EP and EC: with slightly more divergence than convergence and strong formal mechanisms in place, which are however in practice weak in Cohesion Policy. We do feel that the mechanisms in place are in balance with the preferences;

- $E Z$ and TK: we consider there is convergence to be seen in the preferences of both actors, which are matched by the strong formal mechanisms in place for the TK. However, in Cohesion Policy these are considered to be rather weak and thus match the expected convergence;

- EZ and EC: with clear divergence between the EU interests and the national interests, we see that the strong mechanisms in place for the EC to influence EZ match this divergence in preferences;

- MA and EC: equal to the relationship between EZ en EC, we expect divergence with a tendency to spend the money on both national and regional level. This is matched by the same strong mechanisms the EC has, but then on national level.

The two relationships in this chapter that are considered to be off balance are the relationship between the Council and the EC, which shows clear divergence between EU and national interests, but is not matched with strong mechanisms for the Council to really hold the EC accountable. This also matches up with the description in section 4.3.3 where we have described that the Council does not have formal mechanisms in place. As we have shown in Figure 14 in section 3.3, this relationship then shows a risk of an accountability deficit.

The second relationship that shows an imbalance is the relationship between $E Z$ and the MA. As we have described in section 4.5.2 the preferences of both actors are expected to show signs of convergence, in the way that both actors thrive at spending the available money as much as possible in the member state and region. At the same time, EZ as the coordinating ministry for ERDF has strong mechanisms in place to be able to influence the MAs and make sure they are doing what they should be doing. In potential, the fact that EZ has such strong mechanisms in connection to the expected convergence, is a potential risk for an accountability overload. $^{449}$ 
Now we turn to the questions whether a downwards spiral in higher monitoring and bonding costs between the principal and agent (in the different relationships) can be seen. We have described that in the relationships between the EC and MA a downwards spiral can be seen in both higher costs for the EC and the MA. ${ }^{450}$ Because of persistent high error rates in Cohesion Policy, there is pressure on the $\mathrm{EC}$ to make sure that the spending gets in conformity with the rules, thus which will have to lead to lower error rates. This pressure is then also transferred to the MAs which results in increasing demands for MAs, such as reporting obligations and stricter standards. What we have seen is that in the 2007-2013 period, and also in the changes in the 2014-2020 period, is that the requirements on the MAs are increasing: implementation of the $2 \%$ materiality threshold for the error rate, new independent controlling entities such as the $\mathrm{CA}$ and $\mathrm{AA}$ have become compulsory and also in the 2014-2020 period, extra demands, for instance on the performance reserve, are expected. So we do conclude that a downwards spiral is to be seen in this relationship.

Finally, when looking at the elements of accountability overload, we can see that in the relationship between the EC and MA three elements of an accountability overload are to be seen: high demands on the MA, high performance standards of the EC and finally also goal displacement. These elements are also discussed in chapter 5 , because they form part of the questionnaire that is used for the interviews with actors. After having explained the answers of the respondents on these issues, we deal in chapter 6 with the question whether these aspects really constitute an accountability overload. 



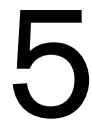

\section{Talking to the people: interviews with actors on Cohesion Policy}

\subsection{Introduction}

This chapter deals with the second part of the empirical research, that is with the interviews that are taken with all actors identified on European, national and regional level. This chapter goes into detail of the set up of the interviews relating to the case study of ERDF in the 2007-2013 period the Netherlands (section 5.2), and into the results of these interviews. The results are split into three sections referring to the three clusters as identified in the previous chapter, the relationships in the European cluster (section 5.3), in the national cluster (section 5.4) and finally in the nationalEuropean cluster (focusing on the relationships between EC, EZ, AA and MA in section 5.5). As a last section, preliminary conclusions based on the interviews as mentioned in this chapter are given (section 5.6). As mentioned in section 4.6, we leave the regional cluster aside in the rest of this research, because the relations and pressures in the European, the national and the national-European cluster are having the most effect on the situation of accountability within Cohesion Policy. The MA as regional actor is enclosed in the national-European cluster. We describe the findings according to the four requirements of 'good accountability' as mentioned in chapter 3, which are summarized in Figure 23.

In this chapter, as we argue in the following paragraph, we focus on coverage, content and costs, and leave the aspect of context aside.

After this chapter, we combine both the analysis of documents and legislation and the information gathered in the interviews in answering the question whether there is a situation of 'good accountability' in Cohesion Policy, specifically focusing on the regional ERDF OPs in the Netherlands. This is done in chapter 6. 


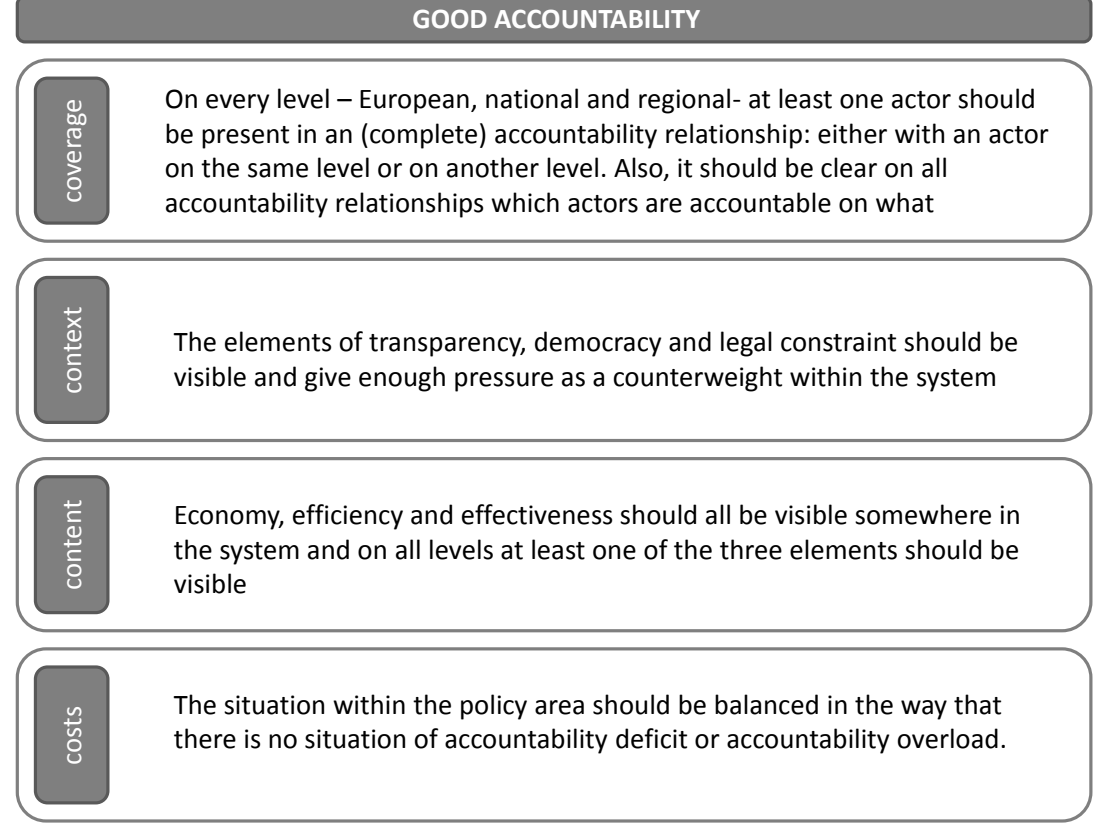

Figure 23. Requirements of 'good accountability'

Identical to figure 16 .

\subsection{Methodology, research strategy and field work}

It is always important in the research of multilevel governance to combine both analysis of documents with interviews with relevant actors. It is important to not only study documents and make an analysis based on these documents, but also look at the practical experiences and opinions of people working in the policy area, who are dealing with the situation in practice on a daily basis. This gives the best basis for academic analysis and recommendations.

To get more insight in the opinions, preferences and ideas of the actors in Cohesion Policy, supplementing the information gathered in the previous chapter on actors and relations, we have conducted interviews with the actors in the field of Cohesion Policy, as identified in section 4.2. Of course there is always the risk of respondents giving misleading accounts of their actions. It is therefore necessary to double-check the information gathered through interviews with other information, as mentioned before, ${ }^{451}$ but also to make sure that from all institutions (actors) that

451 Following Van der Giessen, M. 2014. Coping with complexity. Cross-border cooperation between The Netherlands and Germany, and Bache, I. 2008. 'Researching Multi-level Governance', CINEFOGO/ Univeristy ot Trento conference on The Governance of the European Union: Theory, Practices and 
have been identified at least two key respondents from the organization are interviewed. Also, in the interviews questions are asked to the respondents on their own institution, but also on their opinion on the relationships with other institutions, and the preferences they have. This means that possible bias from actors or institutions towards their own actions is cross checked by asking respondents working for other institutions on their views on the acting of other actors as well.

The interviews were performed as semi-structured interviews. This means that a questionnaire has been set up that was used during the interview, but there was also room for respondents to add their own views and opinions, as long as these were connected to the requirements of 'good accountability'. The questions in this questionnaire, as can be found in Annex I, are structured according to three of the four requirements of 'good accountability', mentioned in chapter 3 . Because of the relevance of the questions, and sometimes the short time available of the respondents, we have chosen to put the most important questions in the beginning of the interview. The questions therefore do not follow the same sequence as the framework.

The questionnaire starts with the first section on relationships, relating to the first requirement of 'good accountability'. The second section of the questionnaire relates to the 3E's, thus to the third requirement of 'good accountability'. The third section of the questionnaire then deals with the preferences of actors and the mechanisms to be used by the principals. This relates to the fourth requirement of 'good accountability'. Another part of this fourth requirement is on accountability deficit and/ or overload. These questions are dealt with in section 4 of the questionnaire. Finally, section five deals with legal constraint, relating to the second requirement of 'good accountability'. However, hardly any of the respondents was able to answer these questions on legal constraint. The elements of transparency and democracy, also part of the second requirement of 'good accountability', context, are not dealt with in the questionnaire, because of the fact that these are deemed as less important to be dealt with in the interviews, there was enough information available on these aspects from the documents and regulations that are studied. Asking respondents to their opinions on transparency and democracy would not add to the information already available on these issues. We have also left out questions on the downwards spiral in the interviews, because of the often limited time available and the expectation that the answers of the respondents on other questions might touch on this aspect as well.

Myths. Brussels, quoting Dowding, K. 2004. 'Interpretation, Truth and Investigation: Comments on Bevir and Rhodes., British Journal of Politics and International Relations, 6, 136-142. 
As can be seen from Annex II, which gives an overview of which sub-questions are put into the questionnaire and to which actor, the questions are adapted to the actor that we have been speaking with, to make sure that on all relevant relations questions are asked. This also meant that the interviews with actors from the European cluster were focusing primarily on the relationships between the European actors (EP, EC, Council and ECA), with actors from the national cluster on the relationships between the national actors (TK, EZ, AR) and with actors also present in the national-European cluster on the relationships between the $E C, E Z, M A$ and AA. This means that different interviews within one institution, especially within the $E C$, could be focusing on one or more of the clusters as just mentioned, leading to different questions.

For finding the best respondents, we have send emails to key-persons and asked people working in the field for the best suitable respondents for the interview per institution. Also, we have asked respondents that were contacted which persons within the organization would be willing to act as a respondent as well. Except for two MEP's and a member of TK, ${ }^{452}$ all requests were answered positively. In total 27 respondents were questioned during a timeframe of three months (mid March until mid June 2015). The interviews took 1,5-2,5 hours per interview, depending on the extensiveness of the respondent. They have, with one exception, all been performed in the buildings and/or offices of the respondents.

The (initial) respondents have all been chosen on the basis of their position and experience with Cohesion Policy in their organization, not on the basis of a statistical representative sample. On European level, it was quite difficult to find willing respondents. In some cases emails were forwarded to different people (e.g. within the EP) and in other cases we directly got contact with the persons most suited for an interview (e.g. ECA). As said, each actor is covered with at least two respondents to get as objective information as possible, when possible at least one person from a more political perspective (MEPs, Member of the ECA, Head of staff at EZ) and at least one in a more administrative capacity. In Annex III a list of interviewees and dates of the interviews can be found.

Regarding the content of the interviews, it sometimes proved difficult for respondents to give their opinion on specific issues. At the same time, during the interviews some questions turned out to be less relevant and were skipped. This specifically holds

452 One MEP and a member of the TK were refusing to participate and one MEP has not reacted on the request. 
for section 1, which was more or less an introducing section to get the respondent into the topic of accountability, questions 3.4 and 3.5 on the mechanisms used by other actors and the questions on whether there is need for stronger or weaker mechanisms and section 5, of which hardly any respondents had a view or answer. In this chapter we therefore focus on the answers on the questions that have been given, and we separately mention when on certain aspects no answer has been given.

\subsection{The European cluster}

This section deals with the relations between actors in the European cluster, as shown in Figure 24.

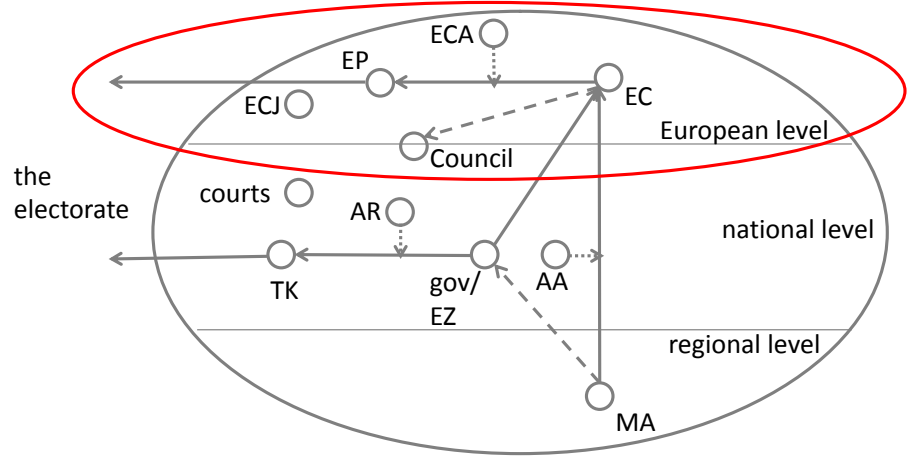

Figure 24. The actors and relationships in the European cluster

This means in this section we summarize the opinions and remarks made in the interviews on the relationships between the EC and EP, the EC and the Council and the role of the ECA. As mentioned in section 4.3.1, we leave the democratic relationship between the citizens and the EP aside, because of the fact that this research focuses directly on the relationships between the different (public) actors.

\subsubsection{The European Parliament and the European Commission}

\section{Coverage: is there an accountability relationship?}

Regarding the relationship between EC and EP it was mentioned that the EC on Cohesion Policy is accountable to the EP, and more specifically to the committees 
CONT (Committee of Budgetary Control) ${ }^{453}$ and REGI (Regional Development). ${ }^{454}$ The former is focusing on financial aspects of the policies of the EU and is especially dealing with the yearly discharge procedure of the budget of the $E U$, where the latter is the committee where regional affairs are dealt with and more focusing on the content of the policy and the results reached.

\section{Content: the 3E's - economy, efficiency and effectiveness}

A lot of focus of the EC and also the EP is put on compliance, this is agreed by all respondents. And that is not strange, because, as one of the respondents put it: 'everything in Cohesion Policy is law, it has regulation in its DNA.455

Within the EP, the focus of CONT is more on compliance, whereas REGI focuses more on effectiveness, although compliance is still also an issue in this committee. The problem with the EP and the labeling of its focus is, as one respondent puts it, that 'it depends on who the EP is, it is not a homogeneous institution. "456

But, as another respondent states, in general on the European level the institutions are very sensitive on financial efficiency, because the costs of executing the policy are always an issue in the discussions on this level, next to the question whether it is logical (and efficient) to make it an EU policy. ${ }^{457}$ Next to compliance, economy and efficiency, attention is growing for effectiveness of the policy with the performance framework in the 2014-2020 period, also in the EP and EC. However, the attention for performance is still quite weak, according to multiple respondents.

\section{Costs: absence of accountability deficit or overload}

Regarding the policy goals of both actors the general opinion of the respondents from the European cluster is that both the EC and the EP are focusing on fostering social and economic cohesion in the EU, in reducing the disparities between the member states. On this general level, almost all respondents agreed that the policy goals do not differ that much. But, when looking at the implementation level, the focus is specifically on 'the envelop,', ${ }^{458}$ which points at the money available, described as follows by a respondent: 'The EC promotes quality and results, it wants to have projects that really meet the objective, but it also has an objective to spend the

453 See for more information the website of the committee on http://www.europarl.europa.eu/committees/ en/cont/home.html, retrieved at 28-08-2015.

454 See for more information the website of the committee on http://www.europarl.europa.eu/committees/ en/regi/home.html, retrieved at 28-08-2015.

455 Mentioned by respondent 5.

456 Mentioned by respondent 5.

457 As mentioned by respondent 1 and agreed upon by respondent 2 .

458 Mentioned by respondents 6, 9, 10, 17 and 21 . 
money available. ${ }^{459}$ When looking at the EP, regional interests also play a role: two respondents mentioned that within the EP there are also MEPs taking an interest in making sure as much funding as possible flows to 'their' region or stays there. Although MEPs are not directly organized through regional lines, there is a tendency for MEPs to promote the interest of the region they come from or represent. ${ }^{460}$

Two respondents had a more opposite view: on the one hand it was argued by one of them that the EP in the negotiations for the 2014-2020 period was not really in favor of the element of thematic concentration, ${ }^{461}$ asking the member states and regions to focus on effectiveness, with a strong quest for the intervention logic. ${ }^{462}$ On the other hand, another respondent argued that within the EP a change is felt into more focus shifting from 'the envelop' to more focus on the 'European added value', which means that there should be added value in the achievement of EU goals before EU funding is used. As was stated: 'It is time to change, it is in the air. $^{463}$

Regarding sanctioning mechanisms of the EP in the direction of the EC, different mechanisms were mentioned (from weak to strong): using contacts within the EC, having a cup of coffee with the Commissioner, issuing a shopping list during the hearing with the new Commissioner, writing a report, asking questions to the Commissioner and EC (oral or written) and urging the EC to take action on a specific issue, especially effective when done during plenary. ${ }^{464}$ One of the respondents argued that the EP in fact has quite weak mechanisms in place, but that that is changing, starting with the Lisbon Treaty and ending up with the election of the current EC president, mister Juncker, in which the EP had a large voice, specifically when compared to former decisions. In this, it is important to note that the power of the EP is not formally laid down, but is evolving and expanding across time, and has informal aspects as well as formal. The fact that the EP 'can make a lot of noise 465 and can use 'transparency as a weapon, ${ }^{466}$ is giving the EP more power, although

459 Mentioned by respondent 2.

460 Mentioned by respondents 10 and 13.

461 Mentioned by respondent 10.

462 Defined as 'all the activities and expected effects (outputs, results and impacts) of an intervention, as well as the assumptions that explain how the activities will lead to the effects in the context of the intervention, as can be found on the following website of the EC: http://ec.europa.eu/europeaid/ evaluation/methodology/methods/mth_log_en.htm, retrieved at 28-08-2015.

463 Mentioned by respondent 21.

464 Although the weakest mechanisms mentioned by the respondents can be more seen as control measures.

465 As mentioned by respondent 1.

466 As mentioned by respondent 5. 
there is a 'delicate balance between promoting transparency and the use of it as a weapon.' $^{467}$

The fact that the EP has the right to send the complete EC away is not seen as a strong mechanism, rather as a 'brute force weapon'.468 It is seen by the respondents as a theoretical possibility, not a real one. What is clear is that the EC has to respond to (almost) all requests of the EP (and also of the Council), it is acting upon its requests.

With regard to the elements of accountability overload, the opinion of respondents in the European cluster is quite blurred, in the way that some respondents consider these elements present, and others do not. ${ }^{469}$ Therefore, we will primarily stick to the given examples, as we do below.

Considering the relationship between the EP and EC, the respondents are almost unanimous on the absence of the first element of extraordinarily high demands. Against one yes the respondents placed four no's. It is argued that the EP is getting more critical, but compromises are still possible. ${ }^{470}$ The example given by the respondent answering yes referred to the fact that a growing trend is to be seen to ask the EC to report on almost everything. ${ }^{471} \mathrm{~A}$ new request of the EP to the EC for instance is to report on the use of the Structural dialogue, as mentioned in article 53 of the CPR. The respondent ${ }^{472}$ doubts whether it is really useful to put precious time into these kind of requests.

On mutually contradictory evaluation criteria, performance standards that are too high and the effect of subversive behavior, the respondents in an equal amount answered 'yes' and 'no'. Examples given are comparable to the example just given, where the EP is asking more and more of the EC, thus considering it to be 'some kind of supergod: ${ }^{473}$ Because of the high demands of the EP, scarce time is getting even scarcer, which is making it more difficult for the EC to perform its tasks.

467 As mentioned by respondent 5 .

468 As mentioned by respondent 1 and acknowledged by respondents 5 and 10 .

469 It is also important to note that some respondents had no idea, or could not answer the question. In this section we therefore only refer the explicit answers on the question, thus a given yes or no.

470 Mentioned by respondent 1.

471 Mentioned by respondent 10.

472 Respondent 10.

473 Mentioned by respondent 5 . 


\subsubsection{The Council and the European Commission}

\section{Coverage: is there an accountability relationship?}

The respondents were clear on the fact that the EC is accountable to the Council. But multiple respondents mentioned there is a limitation to this accountability relationship. On the one hand, the Council hardly has a responsibility in the implementation phase of policies, leading to a limited role in the accountability within Cohesion Policy, mainly focusing on the legislative aspects of Cohesion Policy. ${ }^{474}$ This means that in the phase of creating new legislation, specifically prominent in the years before a new programming period started such as in 2012 and 2013 when the Regulations and the budget for the 2014-2020 were negotiated, the Council is very active as co-legislator and acting as a principal in the principal-agent relationship between Council and EC. In the implementation phase, in previous years the Council has been quite inactive, not being busy with implementation issues and in that role less acting as a principal. However, as one of the respondents mentioned, it is expected that in the 2014-2020 period the Council will become more active also in the implementation phase, in order to prevent that it needs to invest more in the last years of the programming periods, when it might get clear that targets will not be met, and a catch-up has to be started to prevent real problems when it might be already too late (as in the 2007-2013 period). ${ }^{475}$ This can already be seen in the fact that it has taken 'an active role in supervising the implementation of Cohesion policy, being an arena to the concerns of member states towards the EC. The Council is having a much bigger impact on the way money is spend then in the previous period. ${ }^{476}$ However, still a balance has to be found between the inactive and more active role of the Council: as one of the respondents states, still a lot of information and reports send to the Council are taken for granted by it.

On the other hand, the Council is also limited in its effect because of the fact that its position always is a compromise made between the 28 member states in the EU. This makes it hard for the Council to really act as a principal, as one respondent stated: 'the Council is only too glad when there is an agreement between the 28 member states, let alone this really reflects all member states.' ${ }^{\prime 47}$ As another respondent pointed out, the Council in fact has a 'dual role' because of the fact that on the one hand the interests of the member states are reflected in the Council,

474 Mentioned by respondents 5, 9 and 13.

475 Mentioned by respondent 9.

476 Quote of respondent 9.

477 Mentioned by respondent 1 and acknowledged by respondent 10 . 
but on the other that the Council is supposed to favor the European interests. 'The Council doesn't succeed in this. ${ }^{478}$

\section{Content: the 3E's - economy, efficiency and effectiveness}

As a respondent stated, 'the Council is really about politics, about the day-to-day affairs. ${ }^{479}$ The Council is mainly involved with legislation, and is diluting towards compliance and economy, mainly dealing with the general aspects of the amounts to be distributed between the member states, 'it remains pretty general. ${ }^{480}$ One of the respondents argued that the Council 'should deal more specific with the input for economic governance in the EU, also part of the European Semester. Cohesion Policy is increasingly seen as instrument of the Europe2020 strategy, although there is no shared vision on this. ${ }^{481}$ It is seen by multiple respondents that the member states are acting from the principle of 'what's in it for me,' thus leading to less attention for efficiency and effectiveness. ${ }^{482}$

Another remark on the focus of the Council is made by a respondent who emphasizes that the Council with regard to Cohesion Policy in fact consists of two main groups: 'net payers/friends of better spending and friends of cohesion policy (the main recipient countries). Whereas the requests of the net payers tends to go towards more efficiency, performance and rigor in the implementation of cohesion policy, the friends of Cohesion Policy frequently ask for more flexibility to adapt to specific needs of member states and regions. ${ }^{483}$

\section{Costs: absence of accountability deficit or overload}

Some of the respondents agree there is some similarity in the policy goals between the EC and the Council when it comes to the general goals of Cohesion Policy. ${ }^{484}$ As stated earlier, the EC is seen to focus on European social and economic cohesion and more specific on promoting good projects. However, the EC also has a goal to spend the money: it is unwanted by the EC that unspent funds flow back to the European budget. The Council on the other hand, is focusing specifically on the national interests in receiving as much funds as possible. This with a partly exception of the Netherlands, promoting Cohesion Policy to be solely directed at the member states lagging behind - and thus preventing funds to flow to 'the richer'

\footnotetext{
478 Mentioned by respondent 17 .

479 Mentioned by respondent 2.

480 Mentioned by respondent 5.

481 Mentioned by respondent 13.

482 Mentioned by respondents 3,13 and 17.

483 Mentioned by respondent 10 and acknowledged by respondents 2 and 5 .

484 Mentioned by respondents 1, 2 and 9 .
} 
member states. ${ }^{485}$ It might be clear that the effect of this schizophrenic position of the Dutch government is that less funds are attributed to the Netherlands.

Back to the Council, it is seen by the respondents that specifically the national interests, flowing across different coalition lines of net-payers and 'friends of Cohesion, ${ }^{486}$ (net-receivers) are playing an important role in Cohesion Policy in the Council, ${ }^{487}$ focusing on acquiring as much money as possible to flow into the national envelop. ${ }^{488}$ Thus, for both the EC and the member states acting in the Council, on the one hand spending the available money is the most important issue, but divergence is seen when it comes to the specific national interests in the Council.

Although it might seem that the Council is not having the strongest explicit and formal competences, various respondents argue that to their opinion, the Council is one of the strongest actors in the European arena. ${ }^{489}$ Although decisions in a lot of areas are made together by EC, EP and Council, based on a proposal of the $E C$, in fact it is mentioned by various respondents that the Council is having the most of power of these three. 'It has no strong direct powers, but behind doors it has. ${ }^{490}$ In the end, the Council can block all decisions. That is why, as a respondent mentioned, 'the EC never comes up with proposals that have not been discussed with the Council previously.491

Relating to the elements of accountability overload, we can say that for all four elements the majority of the respondents have given answers to the questions ${ }^{492}$ considering these to be absent in this relationship. The few 'yes' answers on these questions relate to the same point made in the previous section on the relationship between EC and EP, thus that the Council, just as the EP, seems to perceive the EC as the institution being responsible for answering all questions and solving all issues on Cohesion Policy on the European level.

485 See for instance Van 't Hof, S. 2011. 'Kabinet slacht kip met gouden eieren', Binnenlands Bestuur.

486 Which are Bulgaria, the Czech Republic, Croatia, Estonia, Greece, Hungary, Latvia, Lithuania, Malta, Poland, Portugal, Romania, Slovakia, Slovenia and Spain, as can be found on this website of the 2012 Slovakian presidency: http://www.vlada.gov.sk/friends-of-cohesion-joint-declaration-on-the-multiannual-financial-framework-2014-2020/, retrieved at 28-08-2015.

487 Mentioned by respondents 2, 5 and 10.

488 Mentioned by respondents 1,5 and 10.

489 Mentioned by respondents 1, 5, 9 and 10 .

490 Mentioned by respondent 10.

491 As mentioned by respondent 9.

492 As also mentioned in the previous section, some respondents had no idea, or couldn't answer the question. In this section we therefore only refer to the explicit answers on the question, thus a given yes or no. 


\subsubsection{Other actors in the European cluster}

At the same time, some respondents were mentioning that the EC is also accountable to the ECA regarding budgetary affairs, and to the European Economic and Social Commitee (ECSC) and the Committee of the Regions (CoR). Also 'the public' was mentioned as actor a few times by respondents, referring to political accountability of the EC, EP and even the Council.

The ECA is focused on the EC as auditee, but at the same time is focusing on the system of Cohesion Policy as a whole: including the role of the member states and regional authorities. The majority (approximately 80\%) of the effort of the ECA is focusing on the DAS, directed by the EP and Council, with its focus primarily on compliance. But as some respondents pointed out, the effect of the DAS seems to have disappeared. ${ }^{493}$ As a respondent pointed out, the work of the ECA should contribute to a 'learning cycle,' leading to improvements within the system on all levels. ${ }^{494}$ However, as the same respondent states, unfortunately in the current situation such a learning cycle is absent. Multiple respondents do point at the role of the ECA in the system and the fact that its yearly DAS does have a large effect on the political tensions within the system. ${ }^{495}$

\subsubsection{Conclusion from interviews on accountability in the European cluster}

\section{Coverage: is there an accountability relationship?}

We found that the respondents share the view that there is an explicit accountability relationship between the EP and the EC. But the respondents also consider there is an accountability relationship between the EC and the Council, although this is largely limited to the policy making stage.

The distribution of the Cohesion Policy budget is decided upon in negotiations between the Council, EP and EC, based upon a proposal of the EC. This process, as one of the respondents stated, ${ }^{496}$ is deemed to have a negative effect on the accountability within Cohesion Policy, because of this non-transparent procedure and negotiating result. Also, because of the focus on 'the (national) envelop,' a contradiction arises between promoting the European interests and a focus on European added value on the one hand and national, financially and compliance driven pressure on the other, leading to ambivalent tensions in both the Council and EP. Together with the fact that EU funds from Cohesion Policy are available,

493 Mentioned by respondents 3 and 24 .

494 Mentioned by respondent 24.

495 The strong role of the ECA is mentioned by respondents 16,19 and 27.

496 As mentioned by respondent 24 . 
and supposed to be used, this leads to pressure to spend these funds, no matter whether these are spend effectively.

\section{Content: the 3E's - economy, efficiency and effectiveness}

Regarding the 3E's (and compliance), the general idea of the respondents is that in the European cluster the focus is on compliance. It is said in general that all elements of the policy process chain are dealt with in the European cluster, but some other respondents doubt whether that is really the case. ${ }^{497}$ An example is the special report of the ECA (21/2014) on airport infrastructures, as an example mentioned by three respondents, ${ }^{498}$ with the conclusion that there is poor value for money. ${ }^{499}$ It was stated in the reports: 'Too many airports (which were often in close proximity to each other) were funded and in many cases the EU-funded infrastructures were oversized. Only half of the audited airports succeeded in increasing their passenger numbers and improvements in customer service were either not measured or not evidenced." ${ }^{500}$ As one of the respondents put it: 'Many of the member states still look at what has been spent and not enough to the results and whether it was worth spending the money. Although the EC and EP recently tried to prevent airports as possible actions from the Structural Funds, the member states kept trying to get them financed. It is locally and politically more convenient for them to use finance from the Structural Funds. But with what results ? ${ }^{501}$, As another respondent puts it: 'Regional policy is overscrutinized on efficiency and compliance, hardly on effectiveness. ${ }^{1502}$ However, there are also some respondents who feel there is enough attention within the system for efficiency and effectiveness. ${ }^{503}$

\section{Costs: absence of accountability deficit or overload}

Regarding the policy preferences, the results from the interviews are ambivalent. When looking at the relationship between the EC and EP there is no strong answer as to whether there is convergence or divergence to be seen: respondents on the one hand mentioned that in general convergence is seen, but with specific issues or national or regional interests coming from MEPs, divergence in some aspects is to be seen.

497 Mentioned by respondents 1, 2, 13, 17 and 21.

498 Mentioned by respondents 2, 22 and 23.

499 European Court of Auditors 2014. 'EU funded airport infrastructures: poor value for money', Special Report: European Court of Auditors.

500 Ibid. p. 5, executive summary III.

501 Mentioned by respondent 10.

502 Mentioned by respondent 5.

503 Mentioned by respondents 1, 5, 9 and 10 . 
With regard to the relationship between the EC and Council, respondents answered that also both convergence (in the preference to have the money spend) and divergence (in prevailing national interests in the negotiations in the MFF) are seen in this relationship.

When we look at what the respondents think of the mechanisms available for respectively the EP and Council, we see that it is considered that the EP has one formal strong mechanism in place, sending the EC away, which however is not really to be used, and multiple less strong mechanisms that are used more often. With regard to the Council, formally it has hardly any mechanisms available but the respondents feel that the institution does have strong mechanisms available towards the EC, although these are more informal then formal.

Regarding the powers between the institutions and the mechanisms available, a lot of respondents agree there is some sort of fragile equilibrium. Some are quite satisfied with the current situation, others are not. As one of the respondents stated: 'I'm not really satisfied, but it does work. When you turn on one of the many knobs, more will change, ${ }^{504}$ which may lead to a disrupted equilibrium. Another respondent argued that the position of the member states in this framework is too strong, the decision making and implementation should be less in the domain of the member states, there needs to be more focus for the European added value. In the view of this respondent, 'the current system is not functional anymore, everyone wants to have its voice heard, wants to have its own objectives and its favorite themes. This has increased the complexity of Cohesion Policy. ${ }^{1505}$

We can conclude that, although some examples on the high demands from the EP and Council on the EC were given, the elements of accountability overload are considered to be absent in the European cluster.

\subsection{The national cluster}

This section deals with the relationships between actors in the national cluster, as drawn in Figure 25.

In this section, we focus on the relationships between the national parliament and the national government, the Council and the national parliament and other actors. As mentioned in section 4.4.1, we leave the relationship between the citizens and the TK aside.

504 Mentioned by respondent 9.

505 Respondent 17. 


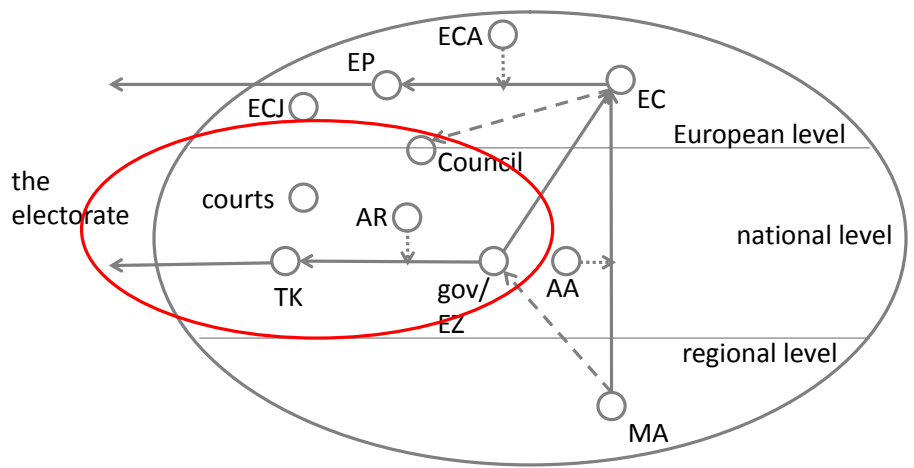

Figure 25. Schematic overview of actors and relationships in the national cluster

\subsubsection{The national parliament and the national government}

\section{Coverage: is there an accountability relationship?}

On the relationship between the TK (parliament) and the government (especially the Ministry of EZ, in case of ERDF), respondents explained that Cohesion Policy in general and ERDF more specifically are within the domain of different committees in the TK. On the one hand there is the committee of Economic Affairs (EZ), ${ }^{506}$ dealing for instance with the national regulation on ERDF. ${ }^{507}$ Next to this committee, there is the committee on Foreign Affairs (Buitenlandse Zaken), ${ }^{508}$ which dealt with the negotiations on European level on the Multiannual Financial Framework 2014-2020 (MFF). Also the Public Expenditure Committee (Rijksuitgaven) ${ }^{509}$ plays a role in Cohesion Policy, dealing with aspects related to regularity and efficiency of public expenditure, which include the SF. This is also the committee that deals with reports from the AR and ECA. Finally, there is the EU Affairs committee, ${ }^{510}$ dealing in a more methodical way with European issues. In practice, issues regarding Cohesion Policy are dealt with based on the specific content of the issue at hand (in any of the committees just mentioned) and there are EU advisors active in all committees, that also connect with the committee on EU affairs, to make sure that EU issues are dealt with in the TK in a sufficient way.

506 See http://www.tweedekamer.nl/kamerleden/commissies/eli, retrieved at 28-08-2015.

507 Uitvoeringswet EFRO, published in de Staatscourant on the $21^{\text {st }}$ of February 2014.

508 See http://www.tweedekamer.nl/kamerleden/commissies/buza, retrieved at 28-08-2015.

509 See http://www.tweedekamer.nl/kamerleden/commissies/ru, retrieved at 28-08-2015.

510 See http://www.tweedekamer.nl/kamerleden/commissies/eu, retrieved at 28-08-2015. 
According to some of the respondents, ${ }^{511}$ ERDF and Cohesion Policy are not arranged very well in the TK, there is often (only) a written debate that is hardly leading to real (oral) debate. The topic is thus quite invisible in the TK. This means that, according to one of the respondents concerned, a lot of issues are not really dealt with. As the respondent puts it: 'No one is responsible for both the money and the content, that means effectively no one is responsible at all. ${ }^{512}$ The respondent also concluded that Cohesion Policy in the Netherlands is not really a topic: 'As long as there will be no deaths, or people protesting in front of the TK on 'het Plein'513, there will be hardly any attention for Cohesion Policy in the Tweede Kamer.'

\section{Content: the 3E's - economy, efficiency and effectiveness}

The conclusion of the respondents on the 3E's in the relationship between the TK and the government (EZ) is that there is relatively low attention for Cohesion Policy in the TK in general, let alone for the 3E's. ${ }^{514}$ What is important to know in this respect is that the general tension in the Netherlands, especially in the TK, is that Cohesion Policy should be targeted at the member states that are lagging behind, not at developed member states, such as the Netherlands. ${ }^{515}$ This means that the primary attitude towards the SF in the Netherlands is 'we don't want the money,',516 or put differently: 'it is nothing more than money circulation. ${ }^{1517}$ But this attitude is also perceived to be ambivalent, also expressing the fact that it is also perceived as 'as long as there is money, we need to spend it.'

The focus of the TK is specifically problem-driven and since Cohesion Policy is quite complicated, it leads to a lot of misunderstandings in the TK. ${ }^{519}$ As a respondent puts it: 'for the TK, it doesn't matter where the money comes from, as long as it's enough.' ${ }^{520}$ Another quote: 'The TK is guided by excesses in the media.'521 The respondents agree that the (limited) focus on Cohesion Policy within the TK is directed primarily on efficiency ('what does it cost to execute the policy in NL?'), as long as compliance is sufficiently dealt with. ${ }^{522}$ At the same time, problems mostly

\footnotetext{
511 Mentioned by respondents 11 and 12 .

512 Mentioned by respondent 12.

513 Het Plein is the square in front of the TK, where there are often demonstrations.

514 Mentioned by respondents 4, 16 and 18.

515 See also section 5.3.2.

516 Mentioned by respondents 4, 7, 8, 16, $18,19,25$ and 26.

517 Mentioned by respondent 16.

518 Mentioned by respondents 25 and also confirmed by respondents 3, 7 and 12 .

519 Mentioned by respondents 22 and 25.

520 Mentioned by respondent 3.

521 Mentioned by respondent 8.

522 Mentioned by respondents 7, 8, 16, 18, 25 and 26.
} 
arise from compliance issues, and this also gets attention from the TK when there are problems. As a respondent mentioned, ' $80 \%$ of the questions of the TK on the $A R$ 'Report on the National Declaration' ${ }^{523}$ are directed at compliance issues, whereas $20 \%$ of these questions focuses on how to make it more easy for entrepreneurs to get access to ERDF funds. ${ }^{524}$ Multiple respondents would wish to have more attention of the TK for Cohesion Policy, not only for problems but especially for the positive results Cohesion Policy has also had in the Netherlands. But, as a respondent said, 'feel good issues are politically irrelevant.'

\section{Costs: absence of accountability deficit or overload}

Regarding the relationship between goals of both actors and the mechanisms available, the view of the respondents is that in general, all Dutch politicians represent a position of 'sending as less money back to the EU as possible. ${ }^{, 526}$ For the money that is available, the focus is primarily on compliance. The reports of the AR, focusing more and more on efficiency and effectiveness, do have their effect on the focus of the TK, although to a limited extent, taking the low attention for Cohesion Policy into account. The goals of both actors are therefore formulated on a high abstraction level and on this level hardly differ between both actors.

Regarding the focus of EZ, the respondents agree that it is on 'spending the money, with as less fuss as possible, and not having to pay money back to Brussels.,527 Respondents agree that the two priorities of the Ministry of EZ are spending the money on good projects, followed by preventing problems from happening, thereby protecting the interests of the Minister and the Secretary of State. ${ }^{528}$ As one respondent put it: 'Spending it badly is worse than not spending. ${ }^{529}$ However, since the MAs are responsible for the selection of projects, EZ hardly has any steering mechanisms to ensure this. The best instrument EZ has, is the use of 'Rijkscofinanciering', the national amount of co-funding money that is attributed to the MAs to cover as cofinancing for ERDF projects.

Regarding the mechanisms available for the TK two mechanism are mentioned in the interviews: calling the responsible minister to account, ${ }^{530}$ which can ultimately

523 See for the latest version Algemene Rekenkamer 2015. 'Rapport bij de Nationale verklaring 2015'. Den Haag: Algemene Rekenkamer.

524 Mentioned by respondent 27.

525 Mentioned by respondent 22.

526 Mentioned by respondents 7, 8, 18, 22 and 23.

527 Mentioned by respondent 8.

528 Mentioned by respondents 8, 16, 22, 23, 25 and 26.

529 Mentioned by respondent 23.

530 Mentioned by respondents 7, 25 and 26. 
lead to sending the government away ('ministerial accountability') ${ }^{531}$ and the 'restriction on treatment' ('behandelvoorbehoud'). ${ }^{532}$ Sending the government away is mentioned as an ultimate measure, not to be used often and more or less relevant because it presents a pressure within the system. Although it is quite comparable to the mechanism in place for the EP to send the (complete) EC away, this measure in the Dutch system is, although still not to be used often, more prominent than in the European cluster. However, it is not expected that Cohesion Policy will be a real factor to use this mechanism for.

Regarding the 'restriction on treatment,' which has been used in the negotiations on the 2014-2020 Regulations by the TK, this restriction means that in case of proposals for legislation, the government (Minister or Secretary of State) can only act in the Council after consultation of the TK. It is perceived as a weak instrument by the respondents. ${ }^{533}$

Regarding the elements of accountability overload, these are in general seen as being absent, because of the fact that the TK is operating on a high abstraction level. In a general sense the performance standards of the TK towards the government are high, and these are also perceived to be high on Cohesion Policy. In effect, the TK operates as if the government is directly responsible for the OPs and the selection of projects. ${ }^{534}$ But just as the implementation of Cohesion Policy is not done by the EC itself although it is responsible, on the national level the implementation is also not (directly) implemented by the government (EZ), but on regional level by the MAs. After having received agreement on the OP, the regional authorities are quite autonomous in the selection of projects.

\subsubsection{The national parliament and the Council}

Regarding the relationship between the Council, government (EZ) and the TK, respondents explained that the Secretary of State responsible for Cohesion Policy gets a mandate in a debate preceding a meeting of the Council on Cohesion Policy. ${ }^{535}$ This means the TK decides on the position of the Secretary of State. In practice, this mandate is often broad and not very specified, especially not on Cohesion Policy. ${ }^{536}$ This also has to do with the fact that the amount of funds the Netherlands is receiving is limited, but as a respondent put it, 'given the fact that the Netherlands

531 See also section 4.4.2, where it is mentioned as principle of legitimate expectations.

532 Mentioned by respondents 11 and 12 .

533 Mentioned by respondents 11 and 12 .

534 Mentioned by respondents 11 and 12 .

535 Mentioned by respondents 11 and 12 .

536 Mentioned by respondent 12. 
is net-payer to the EU, one would expect more interest of the TK on what goes on with Cohesion Policy in other member states. ${ }^{537}$

However, as we have mentioned earlier, this relationship is not directly one of accountability, because of the fact that only the national minister (or in case of Cohesion Policy in the Netherlands the Secretary of State) is accountable to the TK for the decision of the Council, not the Council as a whole.

\subsubsection{Other actors in the national cluster}

The AR is also an important actor in the national cluster in the Netherlands when it comes to accountability. The AR is serving the TK and with that indirectly also the Dutch citizens. As a High Council of State, independent of the government, it has its own responsibilities, directed at 'auditing whether central government revenue and expenditure are received and spent correctly and whether central government policy is implemented as intended. ${ }^{1538}$ It does not have a specific role related to Cohesion Policy, but does provide a declaration attached to the yearly national declaration, provided on the use of SF in the Netherlands. Since the press reacts on the reports issued by the AR, as an institution it has some kind of power, 'the power of words.' ${ }^{539}$ It is specifically focusing on the element of compliance (Report annex to the National Declaration), ${ }^{540}$ but more and more emphasizing the importance of efficiency and effectiveness (EU Trendrapport). ${ }^{541}$

\subsubsection{Conclusion on accountability in the national cluster}

To conclude, we have seen from the interviews with respondents on the national cluster that Cohesion Policy rarely has a role in the national system, especially not when there is not any 'fuss'. Also, the main accountability relationship in the national cluster that has been identified is the relationship between the TK and the government, more specific the Secretary of State of EZ and thus the Ministry of EZ.

For the TK, Cohesion Policy is not a priority issue, it is rarely receiving real attention in parliament. For the Ministry of EZ, the focus is specifically on spending the money on the best projects, although it hardly has a direct influence on this. This means that the focus of EZ within Cohesion Policy is specifically direct at efficiency (coming from the TK) and compliance (TK and EZ, especially with regard to prevent-

537 Mentioned by respondent 12.

$538 \mathrm{http}: / /$ www.courtofaudit.nl/english/Organisation, retrieved at 12-11-2015.

539 Mentioned by respondent 8.

540 See for the most recent version Algemene Rekenkamer 2015. 'Rapport bij de Nationale verklaring 2015'. Den Haag: Algemene Rekenkamer.

541 See for the most recent version Algemene Rekenkamer 2015. 'EU Trendrapport 2015'. Den Haag: Algemene Rekenkamer. 
ing problems with compliance). The policy goals of both actors are perceived by the respondents to match and the mechanisms in place for the TK to influence EZ that are mentioned in the interviews are the ministerial accountability and 'restriction on treatment. $^{, 542}$ These are perceived as weak instruments. Finally, the overload elements are perceived to be absent.

\subsection{The national-European cluster}

This section deals with the relations between actors on European, national and regional level, as drawn in Figure 26.

In this chapter we focus on the relationships between $E Z$ and $E C, M A$ and $E Z, M A$ and $E C$ and $A A$ and $E C$. We also mention the relationship between $A A$ and $E Z$.

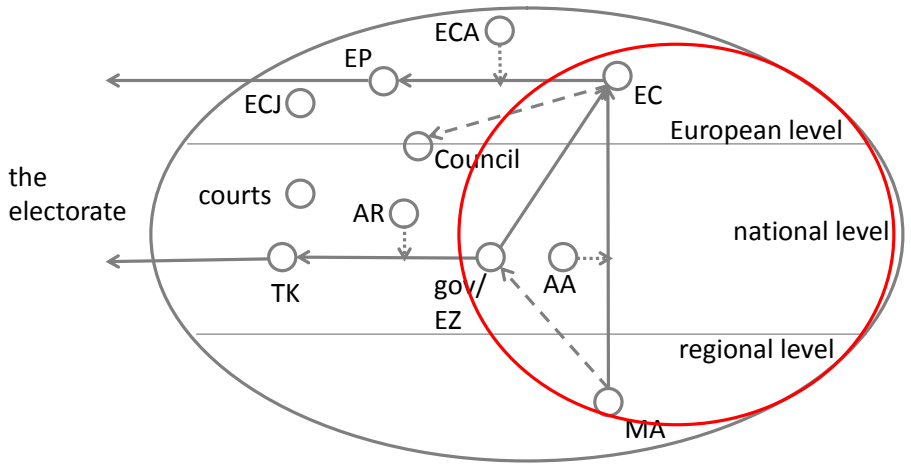

Figure 26. The actors and relationships in the national-European cluster

\subsubsection{The European Commission and the member state}

\section{Coverage: is there an accountability relationship?}

The respondents are not unanimous on the question whether there is an accountability relationship between EZ and the EC. Staff of EZ focus on its accountability relationship to the TK instead of to the EC and staff of the EC mention this relationship as an 'indirect' one, in the way that EZ is in the case of ERDF and the regional programmes responsible as member state, but not as an directly active actor in an accountability relationship. EZ is indirectly accountable to the EC by the reports the MAs are drafting and sending to the EC. The role of the responsible ministry on 
national level is fulfilled in different ways in the different member states. 'Compared to other member states, the role of EZ is not very pronounced. ${ }^{543}$

\section{Content: the 3E's - economy, efficiency and effectiveness}

Regarding the focus of both EZ and the EC in this relationship, a lot has been mentioned in answering the questions related to these aspects by the respondents. Based on the answers of the respondents, EZ seems to be focusing on all elements, but the respondents differ as far as what they perceive as the 'real' focus of EZ.

To start with, there is (limited) attention for economy at EZ because of the fact that the content of the OPs are primarily drawn up in a dialogue between EC and the MA, with a limited role for EZ. It does use its authority to make a proposal for the TK for the allocation amongst the MAs of the available funds for the Netherlands. The TK decides on this allocation. In contrast to its limited focus on economy, it has stronger authority in the use of the Rijkscofinanciering (national cofinancing); ${ }^{544} \mathrm{a}$ budget that is meant to be used as co-financing facility for ERDF funds in projects. That is thus the main instrument of $E Z$ to use its authority.

Regarding efficiency, as was already mentioned in the section on the relationship between the TK and EZ, ${ }^{545}$ there is also focus on this aspect, in the way that the position of the Netherlands in hesitating to make ERDF available for rich member states leads to focus within the member state itself on what it costs to have the policy executed. ${ }^{546}$ However, there is also one respondent ${ }^{547}$ that is of the opinion that EZ does not focus at all on efficiency. This relates to the fact that EZ has had a role in the discussions and regulations on national level, related to the efficiency in the use of national funds (not specifically related to Cohesion Policy), in which EZ is not showing an active position in the debates on SF. As one of the respondents stated: ' $E Z$ is not acting in a coordinating role to work towards efficient use of the funds. ${ }^{548}$

Effectiveness then is also mentioned as a focus of EZ. This was mentioned by multiple respondents as the main focus of $E Z$, or at least as an important one. ${ }^{549}$ Regarding the role of EZ towards this element, in the perception of some respondents it is focusing on how the funds can have the most impact. ${ }^{550}$ As is mentioned

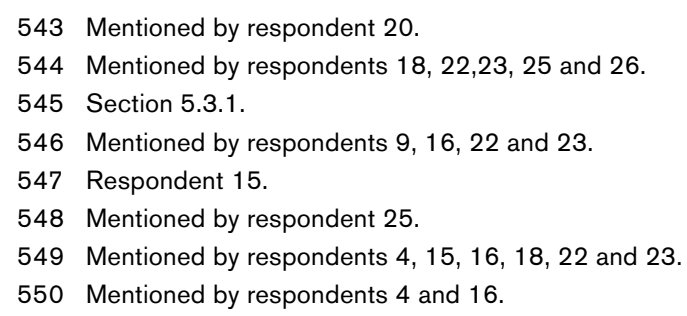


by one of the respondents: 'It would be wonderful if the perception of ERDF in the Netherlands not leading to anything can be turned over to show it really has effect. ${ }^{551}$

Finally, the attention of EZ for compliance is dividing the respondents: on the one hand there are a few respondents who mention this aspect as the main focus of $E Z,{ }^{552}$ and there are also respondents who point at the fact that compliance is not really an issue on national level, ${ }^{553}$ but on the other hand it is argued that compliance is an issue on the national level because the EC is focusing heavily on this aspect. ${ }^{554}$ This attention for compliance is also connected to the risk of political damage: potentially leading to problems for the responsible EZ politicians.. ${ }^{555}$ These respondents point at the fact that the $2 \%$ materiality threshold for errors gets a lot of attention on European level. ${ }^{556}$

Regarding the focus of the EC, it is perceived by respondents that the main focus of the EC is on compliance issues. ${ }^{557}$ As one of the respondents stated, quoting an EC official: "I am having the ECA auditors in my back." ${ }^{558}$ However, as one of the respondents mentioned, 'I don't have the impression there is only focus on compliance of the EC, especially not coming from the organization itself. ${ }^{559}$ It is stated that in the 2014-2020 period the focus of the EC will be put more on effectiveness ${ }^{560}$ and on efficiency, ${ }^{561}$ which can be seen in the enclosure of the performance reserve ${ }^{562}$ simplification measures ${ }^{563}$ and e-cohesion ${ }^{564}$ in the Regulation. ${ }^{565}$ It is also seen that from the political side accents have been put on different elements across time, which leads to focus of the EC on all elements, which is seen especially in the 2014-2020 period with an obliged focus on performance.

551 Mentioned by respondent 16.

552 Mentioned by respondents 20, 25 and 26.

553 Mentioned by respondents 23 and 28.

554 Mentioned by respondents 22 and 23.

555 Mentioned by respondents 22, 23 and 26.

556 See for instance the AAR of DG REGIO, where the error rates of the member states are published. See for the latest version European Commission 2015. 'Annual Activity Report 2015 DG Regional and Urban Policy'. Brussels: European Commission.

557 Mentioned by respondents 15, 16, 18 and 27.

558 Mentioned by respondent 15.

559 Mentioned by respondent 20.

560 Mentioned by respondent 19 and 20 .

561 Mentioned by respondent 19.

562 See articles 20-22 of Regulation 1303/2013.

563 See European Commission 2012. 'Simplifying Cohesion Policy for 2014-2020'.

564 See article 122 section 3 of Regulation 1303/2013. See also European Commission 2014. 'Implementation Guidance e-cohesion'.

565 Regulation 1303/2013. 


\section{Costs: absence of accountability deficit or overload}

With regard to the policy goals it is interesting that multiple respondents mention a perverse incentive that is baked into the regulations. The Regulation has specific articles referring to the decommitment rule, ${ }^{566}$ also referred to as $\mathrm{N}+2$ rule,which means that funds assigned to a specific year on OP level not being used are decommitted to the EU budget, therefore lost for the member state and region. ${ }^{567}$ According to the respondents, this rule is also having its effect on the actors: both on national level, referring to $E Z^{568}$ but also to the EC. ${ }^{569}$ As one of the respondents stated: ' $A$ newsitem in which it is stated that the Netherlands have not been spending a million euros is killing, ${ }^{570}$ This means that there is some kind of intrinsic motivation on national and regional level to make sure the funds are spend, more or less irrespective on what it is spend on. But, as we have seen in the section on the content, this picture is probably too 'black and white', since there is also attention of these actors for what the funds are spend on and this will only increase in the 2014-2020 period. As one of the respondents stated: 'The main goal is no longer absorption in itself, but taking care of the fact that in the future there will be 'better absorption."571 The majority of respondents therefore is of the impression that the main policy goals of both EZ and the EC are not varying that much, focusing especially on spending the funds, although there is also attention for effectiveness and the fact that projects should really contribute to the goals of the policy.

The mechanisms available for the EC are diverse, according to the respondents. It is interesting to see that most respondents did have problems with separating the mechanisms of the EC towards EZ and towards the MA. This also underlines the blurred relationship between those actors in the way that it is difficult to identify which responsibilities belong to the member state and which belong to the MA. Because of the fact that all mechanisms mentioned, except discussing issues on member state level with EZ, are focusing on OP level, we discuss these in section 5.5.3, on the relationship between EC and MA.

This also holds for the elements of accountability overload, we also discuss these in section 5.5.3, since the respondents connected these in most of their answers to

566 Articles 93 until 97 of Regulation $1083 / 2006$ and in the new period articles 86 until 88 of Regulation 1303/2013. See also sections 4.5.1 and 4.5.3.

567 This decommitment rule is also known as N+2 of N+3 rule (referring to the fact that funds are supposed to be used within 2 respectively 3 years). See also sections 4.5.1 and 4.5.3.

568 Mentioned by respondents 3, 7, 8, 16, 22, 23 and 27.

569 Mentioned by respondents 3. 16, 19, 20, 22, 23 and 28.

570 Mentioned by respondent 22.

571 Mentioned by respondent 20. 
the relationship between the EC and MA, although these formally are focusing on the member state.

\subsubsection{The national government and the Managing Authority}

\section{Coverage: is there an accountability relationship?}

Respondents consider there is also some sort of accountability relationship between the MAs and EZ, in the way that EZ has to appoint the authorities and also has mechanisms to manage the implementation of the policy, especially through the use of Rijkscofinanciering as national cofinancing funds next to the SF. ${ }^{572}$ However, in the 2007-2013 period the cofinancing funds have been delegated to the MAs. EZ does have mechanisms to guide the acting of the MAs, such as using the NERPE law, ${ }^{573}$ retract the appointment as MA, ${ }^{574}$ using its vote in the MCs of the OPs ${ }^{575}$ or using more 'soft' powers in the national committees in which all actors in the national cluster (EZ, MAs, CA and AA) work together. ${ }^{576}$ However, although EZ does have powers, its role in the implementation in the 2007-2013 period has been limited. ${ }^{577}$ As one of the respondents mentioned: 'The member state is the main responsible actor for the implementation of Cohesion Policy on national level. But it seems [EZ] doesn't want to have that responsibility, because it's referring to the delegation of powers in the direction of regional authorities. How is it possible to give up a responsibility that lays upon you ?578 $^{578}$

To conclude, in the interview some respondents did go into detail of the relationship between MA and EZ, however, the conclusion of most of them was that EZ does have mechanisms in place, particularly focusing in this respect on the Rijkscofinanciering, ${ }^{579}$ but that $E Z$ is hardly using these powers it has.

\section{Content: the 3E's - economy, efficiency and effectiveness}

Some of the respondents feel there is hardly a focus at EZ. ${ }^{580}$ The most important focus of the ministry, as was said, is not directly connected to the policy process

572 Mentioned by respondents 3, 15, 18, 22 and 23.

573 Mentioned by respondents 3,15 and 18, referring to the fact that based on the NERPE law EZ can give a prescriptive instruction to an MA with an obligation to act in a certain way. See also section 4.5.2.

574 Mentioned by respondents 18, 22 and 23.

575 Mentioned by respondent 15.

576 Mentioned by respondents 15, 18, 22, 23 and 28, referring to Financiële Werkgroep (FWG) and Programmamanagers overleg (PMO).

577 Mentioned by respondent 4.

578 Mentioned by respondent 3.

579 Mentioned by respondents 3, 7, 15, 18, 22, 23, 25, 26.

580 Mentioned by respondents 15, 25 and 26. 
chain, but to the prevention of fuzz, or said otherwise 'to be in control'. ${ }^{581}$ As far as there is attention for Cohesion Policy, the respondents are quite clear on the focus of both $E Z$ and the MA in this relationship: with a focus on compliance ${ }^{582}$ there is less attention for the other elements of the policy process chain, although it can't be said these do not get any attention. ${ }^{583}$

\section{Costs: absence of accountability deficit or overload}

With regard to the preferences between both actors, these are considered to be convergent, ${ }^{584}$ directed at spending the money on the best projects fitting into the goals of both the member state and the region. Most respondents consider that these goals of both EZ and the MA show an overlap.

When we look at the mechanisms available for EZ, most respondents mention the use of Rijkscofinanciering, ${ }^{585}$ which gives EZ direct possibilities to intervene when they feel funds are not spend correctly. However, since Rijkscofinanciering is coinciding with ERDF funds and EZ focuses primarily on these funds, the influence of EZ on the spending of ERDF is limited. Other mechanisms mentioned available for EZ are the NERPE law ${ }^{586}$ and the informal influence of EZ in national working groups. $^{587}$

Finally, the respondents had no specific remarks on the elements of an accountability overload, connected to this relationship.

\subsubsection{The European Commission and the Managing Authority}

\section{Coverage: is there an accountability relationship?}

Various respondents specifically mentioned the relationship between MAs and EC as a clear accountability relationship. ${ }^{588}$ The MAs have the obligation, following the CPR, to report to the EC on the implementation of the OP. As mentioned earlierand explicitly mentioned by some respondents, ${ }^{589}$ the formal responsibility for the accountability within Cohesion Policy on national level is laid down at the member state, since this actor is the main attribute of the shared management relationship within Cohesion Policy. At the same time, the member state, in the case of regional

\footnotetext{
581 Mentioned by respondent 16, and acknowledged by respondents 22, 23, and 27 .

582 Mentioned by respondents 7, 8, 15, 16, 20 and 28.

583 The other elements are also mentioned by respondents 16, 19, 20, 22 and 23.

584 Based on answers given by respondents 4, 7, 8, 14, 15, 18, 27 and 28.

585 Mentioned by respondents 3, 15, 18, 23, 25 and 26.

586 Mentioned by the same respondents as in footnote 585 .

587 Mentioned by respondents 15, 18, 26 and 28, referring to PMO and FWG.

588 Mentioned by respondents 15, 18, 19, 20, 27 and 28.

589 Mentioned by respondents 3, 19 and 20.
} 
ERDF OPs the Ministry of EZ, has delegated the authority of implementing Cohesion Policy to the MAs. This makes the MAs directly accountable to the EC.

\section{Content: the 3E's - economy, efficiency and effectiveness}

We discussed the focus on elements of the policy process chain in the nationalEuropean cluster (EZ versus EC) in section 5.5.1, leading to the conclusion that the focus of the EC is said to be on compliance, also with its primary influence mechanisms on these aspects. But the other elements were also said to be present, although in a less extensive form. Since this focus of the EC has the same effect on regional level, the respondents consider this focus also applicable on the relationship between EC and MA.

Regarding the MAs, the respondents consider that the primary focus is on compliance ${ }^{590}$ especially because 'they are assessed on compliance."591 As one of the respondents put it: '[MA's] work like hell for the receipts, but there is hardly any attention for the effects of the policy. ${ }^{592}$ However, there is also some focus on the other elements. Economy is primarily related to the aspect of 'sound financial management' and gives the MAs the obligation to assess the eligibility of costs. ${ }^{593}$ According to the respondents, it is quite difficult for MAs to focus on effectiveness, ${ }^{594}$ because of the fact that there is a measurement problem: it is very difficult on a detailed level of OPs to assess the effectiveness of the policy. That is also why the EC is performing evaluations of Cohesion Policy especially on European level. A second problem with effectiveness is that it is not interesting for the actors concerned to show the positive side of Cohesion Policy: "no one is accountable on the positive effects. ${ }^{595}$

\section{Costs: absence of accountability deficit or overload}

The policy goals the respondents attribute to the EC relate to two aspects: ${ }^{596}$ at first a focus on the broader goals of Cohesion Policy, related to the EU2020 goals. On the other hand, respondents mentioned the perverse incentive of the decommitment rule, leading to a pressure on both the EC and member states to make sure funds are spend.

\footnotetext{
590 Mentioned by respondents 10, 15, 18, 19, 20, 22, 23, 25, 26 and 27.

591 Mentioned by respondent 23.

592 Mentioned by respondent 25 and confirmed by respondent 18 .

593 Mentioned by respondent 15.

594 Mentioned by respondents 15 and 18 .

595 Mentioned by respondent 15.

596 As also mentioned in sections 5.3.1 and 5.5.1.
} 
Regarding the policy goals of the MAs, the respondents are mentioning both aspects as are attributed to the EC: the regional goals of enforcing the economy and employment, ${ }^{597}$ and the fact that funds should be spend. ${ }^{598}$ As one of the respondents put it: 'The role of the MAs is to make it possible to spend funds on projects.' $^{599}$

Considering these replies on the questions from the questionnaire, we feel that the respondents consider the policy goals of both the EC and the MAs to be similar.

When looking at the mechanisms available for the EC to influence the actions of the MA, a lot of mechanisms were mentioned by the respondents. These vary from strong mechanisms like payment interruptions and corrections ${ }^{600}$ and the use of the performance framework in the 2014-2020 period $^{601}$ to weak instruments like acting on reports ${ }^{602}$ and organizing visits and meetings. ${ }^{603}$ Also, the ECs role in the monitoring committees (MCs) was mentioned, ${ }^{604}$ although the EC only has an advisory role in these committees. Practice shows however, that the $\mathrm{EC}$ is taking its advisory role in the $\mathrm{MC}$ very serious, leading to a balancing act on the edge of advising and instructing. At the same time, a respondent was mentioning that it is very difficult for the $\mathrm{EC}$ to have a good view on the implementation: 'without a good $A A$ the $E C$ is nowhere to be found. ${ }^{160}$ This respondent is in fact mentioning the AA as a mechanism for the EC to make sure the MA is acting according to the Regulation.

Regarding the questions on the elements of accountability overload, the respondents are not uniform in their opinions. Starting with the question on extraordinarily high demands, multiple respondents agree the demands are high, ${ }^{606}$ but almost none of them consider these extraordinarily high. As one of the respondents stated: 'the demands are explainable high. ${ }^{607}$ Another respondent mentioned that the demands in itself are not too high, but the combination of multiple high demands is (almost)

\footnotetext{
597 Mentioned by respondents 4, 15, 18, 23 and 27.

598 Mentioned by respondents 15, 18, 25 and 26.

599 Mentioned by respondent 26.

600 Mentioned by respondents 18, 20, 25 and 26.

601 Mentioned by respondents 7 and 20 .

602 Mentioned by respondent 8 .

603 Mentioned by respondent 8 and 18 .

604 Mentioned by respondents 4, 19 and 20 .

605 Mentioned by respondent 8.

606 Mentioned by respondents 3, 7, 8, 16, 18, 19, 22, 23, 27 and 28.

607 Mentioned by respondent 3.
} 
getting extraordinarily high. ${ }^{608}$ And another respondent mentioned that the demands are considered to be 'on the edge of endurability. ${ }^{609}$

Two examples given by respondents on the possible existence of mutually contradictory evaluation criteria relate to simplification and the trade-off between errors and results. To start with the simplification, two respondents gave an example related to the wish for simplification in the Regulation but the actions of the EC to regulate all room for interpretation: ${ }^{610}$ for instance on financial instruments (FIs) and the use of tariffs from Horizon2020 projects, the EC has produced comprehensive guidance notes with information whereas it is supposed to work towards simplification. The other example is related to the trade-off between errors and results: 'If you have an error rate of 0\%, but the programme hasn't reached any results, it is a pity. But if the programme has reached a lot, but has an error rate of $10 \%$, that is considered as deadly. ${ }^{\prime 11}$ This means that MA's are guiding on error rates, as one of the respondents put it: 'The goal of the managing authorities is to get a positive opinion of the $A A$, without creating too much fuss. ${ }^{612}$ Also, it was mentioned by a respondent that the EC does not have one voice: often one DG can interpret the Regulation in one way, whereas the other does it in another way. ${ }^{613}$ Although this is not related to mutually contradictory criteria, it has the same effect: confusion at the agent on which goal it should focus.

In general, the respondents do not consider the performance standards to be too high. $^{614}$

Finally, the main example given by respondents as an illustration of subversive behavior following from the criteria used by the EC is referring to the trade-off just mentioned, especially after the awarding phase of grants. ${ }^{615}$ It is considered not to be advantageous for MAs to focus on anything else than compliance when grants are awarded to projects, whereas the MA risks the funds to be paid back to the EC because of the decommitment rule. ${ }^{616}$ This means the MAs are likely to prioritize safe projects, which are less likely to lead to compliance problems, however not necessarily leading to high effectiveness.

\footnotetext{
608 Mentioned by respondent 22.

609 Mentioned by respondent 19.

610 Mentioned by respondents 8 and 28 .

611 Mentioned by respondent 22.

612 Mentioned by respondent 8.

613 Mentioned by respondent 7.

614 Except for respondent 16, who considers them to be too high.

615 Mentioned by respondents 7, 8, 22 and 28.

616 See sections 4.5.1 and 4.5.3.
} 


\subsection{The European Commission and the Audit Authority}

\section{Coverage: is there an accountability relationship?}

This section focuses on the relation between the $E C$ and $A A{ }^{617}$ The $A A$ is also mentioned by some respondents as an accountable actor to the EC. ${ }^{618}$ The AA sends the reports on the performance of the programmes to the $E C$, and in that way is considered accountable to the EC. However, since they are judging the work of the MAs, they are informing the EC on the performance of the programmes, but they are accountable themselves on the way they have executed their task as AA. This accountability is specifically directed at the audit directorate within DG REGIO, Directorate C.

After the issuing of the reports by the AA, the EC acts on the findings mentioned in the report, for instance by applying financial corrections. The EC is also instructing in a very detailed manner how the AA should perform its role. In these instructions, having the form of implementing or delegated acts or guidance notes, the EC is guiding the $A A$ to assess rule based. ${ }^{619}$ This is considered by some respondents as quite strange: on the one hand the $E C$ is recognizing the professional position of the $A A$, but on the other hand it is proscribing 'to two decimal places' how the $A A$ is supposed to perform its duties. ${ }^{620}$

In a formal way they are thus only accountable to the EC on the way they execute their task.

\section{Content: the 3E's - economy, efficiency and effectiveness}

All respondents are clear on the fact that the $A A$ is considered to inform the EC only on compliance of the OPs, and thus of the work of the MAs. In their work they also incorporate the principle of economy, relating to the aspect of sound financial management. ${ }^{621}$ It is considered that in the 2014-2020 period the AA will also get a role in assessing the performance of the programmes, but this is still to be developed how this is being done. One should consider that evaluating the effectiveness of a programme is work for evaluators, not for auditors. ${ }^{622}$

617 As we have mentioned in section 4.5.4, the CA is part of the first line controls within Cohesion Policy. We do not deal with this actor in this chapter, because it has no separate responsibility outside these first line controls.

618 Mentioned by respondents 27 and 28.

619 As opposed to principle based, which is more common in auditing in the Netherlands.

620 Mentioned by respondent 27.

621 Mentioned by respondents 16, 22 and 23.

622 Mentioned by respondent 18. 


\section{Costs: absence of accountability deficit or overload}

Regarding the policy goals of the EC and the AA, these are considered to be almost comparable, according to the respondents. The main issue, as was mentioned by some of the respondents, ${ }^{623}$ is that the AA is a national authority, but acting according to the principles of the EC and strictly instructed and monitored by the EC. In this respect, there is some tension between the national and European interests at the $A A$, but these are considered to be relatively low, since the $A A$ is quite strict in this, 'taking its role very serious.' 624

Regarding the mechanisms for the $E C$ to influence the $A A$, although we have not asked a specific question on this, some respondents gave their opinion on this aspect. ${ }^{625}$ It was stated by multiple respondents that the norms the EC is giving to the AAs and the way they are instructed is very detailed and leaving hardly any room for the $A A$ to interpret. This means that the $E C$ has quite strong mechanisms to influence the $A A$, although another respondent considered there is room for AAs to interpret the norms of the EC. ${ }^{626}$

Regarding the elements of accountability overload, since the respondents have answered these questions on member state level, not specifically related to one of the actors, and the fact that we've described those answers in the previous section (5.5.3), we do not deal with these aspects in this section.

\subsubsection{The national government and the Audit Authority}

\section{Coverage: is there an accountability relationship?}

The respondents were quite unanimous in what the relationship between $E Z$ and the $A A$ is all about: $E Z$ is appointing the $A A$ and, as has been mentioned in the agreements per OP ('convenanten'), ${ }^{627}$ the $A A$ should send information on its quotation of man-hours and costs spend to $E Z$. In this way, ' $E Z$ is the client and the $A A$ contractor, EZ pays the bills, but it has no control on the $A A$ whatsoever. ${ }^{628}$ The $A A$ is considered to be independent. ${ }^{629}$

\footnotetext{
623 Mentioned by respondents 15 and 27.

624 Mentioned by respondents 7 and 8 .

625 Mentioned by respondents 7, 8, 22, 23, 27 and 28.

626 Mentioned by respondent 19.

627 See section 4.5.2.

628 Mentioned by respondent 23 and confirmed by respondents 25 and 26 .

629 Mentioned by respondents 7, 8, 15, 16, 23, 27 and 28 .
} 


\section{Content: the 3E's - economy, efficiency and effectiveness}

As mentioned before, the content of this accountability relationship is only connected to economy, in the way the $A A$ has to be accountable towards $E Z$ on the money spend on their work. As is stated by one of the respondents, efficiency is not at all an issue for the AA, since they seem to be able to spend their time according to what they feel is necessary, there seems to be no accountability on their time spend and costs made towards EZ or the MAs. ${ }^{630}$ As was stated by one of the respondents: 'The main goal of the $A A$ seems to be to prevent the Minister of Finance facing problems. ${ }^{631}$

\section{Costs: absence of accountability deficit or overload}

As mentioned in the previous section, there is some tension between the AA being a national authority, falling under the authority of the Minister of Finance, and having a task to give assurance to the EC. This means the national interests can be at odds with the instructions and interests of the EC. This is a delicate balancing act for the AA. In the Dutch system there is criticism from different actors towards the $A A$, although the perception of some respondents is that the AA acts as much as possible according to the instructions of the $E C$, attributing to assurance for the $E C$ on the spending of SF in the member state. ${ }^{632}$ This tension, which is also related to a 'professional play between auditor and auditee, ${ }^{633}$ as one of the respondents mentioned, originates from the detailed instructions and norms given by the EC, as was just mentioned. It leads to a play where both the AA and MA try to influence each other and where they try to reach shared norms to be used in the implementation of the programme. ${ }^{634}$

Within the member state on national level the AA is also having a pivotal role, standing in between the ministries of Finance and $E Z .{ }^{635}$ On the one hand, the $A A$ (ADR) falls under the scope of the Ministry of Finance, but it is acting in its role as AA under the scope of EZ, being its client. What also contributes to this pivotal role is the fact that the AR is issuing a report on the national Declaration of Assurance primarily based on the auditwork by the AA. This declaration is signed by the Minister of Finance, which thereby has an explicit interest: because he is putting its signature under the declaration he wants to be assured that the system works well. This also means there is a possible influence from the ministry to the AA to make sure that

630 Mentioned by respondent 26.

631 Mentioned by respondent 26.

632 Mentioned by respondents 7, 8 and 28.

633 Mentioned by respondent 3.

634 Mentioned by respondent 8.

635 Mentioned by respondents 3, 15, 27 and 28. 
the results of its work are guaranteed enough to contribute to the declaration. ${ }^{636}$ In the Dutch system there is a certain hierarchy perceived between the ministries, of which the Ministry of Finance is on top. EZ however, is lower in the hierarchy, ${ }^{637}$ leading to a perceived accountability deficit, because of the fact that 'Dijksma will be reluctant to go against the judgment of Dijsselbloem. ${ }^{638}$ It then comes back to the main question: who has the authority to decide on what and which motivations play a role in the application of this authority? This didn't become ultimately clear from the interviews, but the answers of the respondents did touch on this aspect and made it clear there are different motives for the acting of the actors.

To conclude this section, there is an assumed divergence between both actors and although EZ has some formal mechanisms to influence the acting of the AA, it hardly uses these mechanisms.

As we have mentioned in the previous section, we have dealt with the elements of accountability overload in the national-European cluster in section 5.5.3, which is why we do not discuss it further on here.

\subsubsection{Conclusion on the relations in the national-European cluster}

\section{Coverage: is there an accountability relationship?}

When we look at the answers of the respondents related to the existence of accountability relationships, we see there is only one explicit accountability relationship mentioned: the one between the MA and the EC. Two indirect accountability relationships are mentioned, which are the relationship between $E Z$ and the $E C$, because of the fact that $E Z$ is formally accountable, but dependant on the implementation by the MAs, and the one between the MA and EZ, because EZ only has mechanisms in place to influence the acting of the MAs connected to the Rijkscofinanciering. Finally, the AA is only accountable to the EC on the performance of its work and to $E Z$ on the costs of its activities, which is why this relationship can be assessed as a partial accountability relationship.

\section{Content: the 3E's - economy, efficiency and effectiveness}

When we look at the content of these complete and indirect accountability relationships, we see that the focus is put on compliance (between MA and EC and AA and EC), as far as the respondents are concerned. The relationship between EZ and EC

636 Based on answers of respondent 28.

637 Explicitly stated by respondent 15 and implicitly stated by respondents 18,23 and 28 .

638 Mentioned by respondent 15, and confirmed by respondents 25, 26 and 28. Sharon Dijksma was the Secretary of State of EZ, responsible for Cohesion Policy at the time the interviews were conducted and Jeroen Dijsselbloem is the current Minister of Finance. 
is considered to deal with all elements and finally the respondents described that the relationship between $A A$ and $E Z$ focuses specifically on the element of economy ('what does the AA cost?').

\section{Costs: absence of accountability deficit or overload}

Finally, when we touch upon the elements of costs, we have seen that a lot of focus of the respondents was put on the perverse effect of the decommitment rule, leading to too much focus on the compliance element. This overall focus causes hesitation at the MAs to focus on efficiency and effectiveness, because this might lead to repayment of the funds to the EC: not only when compliance issues arise, but when also expressing focus on efficiency and effectiveness there is a risk the EC will reclaim of funds. This causes at the EC, EZ and MA a focus on spending, as opposed to a focus on giving funds to the best projects. It thus creates tension within the system.

Convergence is seen in most relationships (EZ and $E C, M A$ and $E C, M A$ and $E Z$ and $A A$ and $E C$ ), however, divergence is expected in the relationship between $A A$ and $E Z$, because of tensions on national level between the ministries of $E Z$ and Finance. This tension does not per definition lead to divergence, but when conflicts arise, this tension will play a role and leads to divergence.

When looking at the mechanisms in place, the respondents agree that especially the EC has strong mechanisms in place with the possibility to use payment interruptions and corrections and the sanctions connected to the use of the performance framework in the 2014-2020 period. $^{639}$

Regarding the elements of overload, the respondents have mentioned one explicit element to be visible, the one on high demands although in general these are not considered to be extraordinarily high. Also examples are given on the second and fourth element, with examples on how demands are having an effect of working against each other. This means in this cluster we have seen two elements of accountability overload present, related to mutually contradictory evaluation criteria and performance standards that lead to subversive behavior. The element on extremely high demands is seen to be partially present, because of the fact that demands are high, but are perceived to be 'explainably high',640

\subsection{Preliminary conclusion from the interviews}

This chapter is a summary of the responses of the respondents on the questions asked to them, based on to the questionnaire in Annex I. As add on to the questions

639 See footnotes 601 .

640 Mentioned by respondent 3. 
on coverage, context, content and costs, all respondents were questioned on what they think of accountability: to what extent do they perceive there is a situation of accountability deficit or overload and do they consider the current situation bad or good?

We highlight in this section how the respondents look at the requirements of 'good accountability', as mentioned in chapter 3 (section 5.6.1) and discuss the opinions of the respondents on the accountability situation (section 5.6.2). As mentioned in section 5.2, the (majority of) the second element, context, is left aside because these are deemed as less important to be dealt with in the interviews. Because of the fact that the respondents hardly were able to answer on questions on legal constraint, the part of the element questions were asked on, we leave the element of context in this section aside.

\subsubsection{The requirements of 'good accountability'}

As mentioned in section 5.2, the (majority of) the second element, context, is left aside because these are deemed as less important to be dealt with in the interviews. Because of the fact that the respondents hardly were able to answer on questions on legal constraint, the part of the element questions were asked on, we leave the element of context in this section aside.

\section{Coverage: is there an accountability relationship?}

When we look at the answers of the respondents related to the existence of accountability relationships, we see there are three explicit accountability relationships: the one between EP and EC, TK and EZ and the EC and the MA. The first two of these are connected to the element of democracy, relating to relationships between a democratically elected institution, respectively the EP on European en TK on national level, and the executing institution on both European and national level: the EC and the Ministry of EZ. The third direct accountability relationship that has been identified by the respondents is more of an operational nature: the one between the EC and the MA. The relationship between the EC and the Council is also mentioned and perceived as a direct accountability relationship by some respondents, but those respondents acknowledged that it is an informal accountability relationship because the Council is perceived to have a lot of power towards the EC, although it is not formally laid down in the Regulations.

Two indirect accountability relationships are mentioned, which are between EZ and the EC, because of the fact that EZ is formally accountable, but dependant on the implementation by the MAs, and the one between the MA and $E Z$, because $E Z$ only has mechanisms in place to influence the acting of the MAs connected to the Rijkscofinanciering. Finally, the $A A$ is only accountable to the $E C$ on the perfor- 
mance of its work and to EZ on the costs of its activities, which makes this a partial accountability relationship.

\section{Content: the 3E's - economy, efficiency and effectiveness}

When we look at the content of these complete, indirect and partial accountability relationships, we see that the focus is put on compliance (especially between MA and $E C$ and $A A$ and $E C$ ). This element is receiving a lot of attention because, as one of the respondents puts it, 'MAs are assessed on compliance.641 At the same time, the relationship between the EC and MA is also perceived to deal with the other elements, although in a less explicit way. Because of the fact that the MAs are specifically assessed on compliance, the focus of the AA is also on compliance. In general, although a lot of focus is put on compliance, the respondents perceive that all elements of the policy process chain are dealt with to some extent in the accountability relationships.

\section{Costs: absence of accountability deficit or overload}

With regard to the last element, the respondents considered that in a lot of relationships convergence is seen. On some relationships the respondents were not unanimous (EP-EC and Council-EC) and on one relationship, the one between $E Z$ and $A A$, respondents were clear that divergence is to be seen. Regarding the sanctioning mechanisms, in the European cluster these are considered to be weak, except for the mechanism in place for the EP, having the possibility to send the EC away. However, this mechanism is to be seen as a 'brute force weapon', ${ }^{642}$ as a theoretical possibility, therefore in effect not a real strong mechanism.

In the national cluster there is also considered to be convergence between the policy goals of the TK and EZ, where the same mechanism for the TK is in place as on European level, the possibility to send a minister away. However, just as in the European cluster, in practice this mechanism is perceived as weak, because it is not expected to be used for issues on Cohesion policy.

Finally, when we look at the national-European cluster, we can see that the respondents consider especially the EC has strong mechanisms in hand, with the possibility to use payment interruptions and corrections and the use of the performance framework in the 2014-2020 period. ${ }^{643}$ The mechanisms EZ has in place towards the MAs, as also mentioned in section 4.5.2, are perceived as weak by the respondents.

641 Mentioned by respondent 23.

642 See also footnote 468

643 See footnote 601 
With regard to the elements of accountability overload, these are mostly considered as absent by the respondents, although in the national-European cluster and national cluster the respondents gave some examples of some elements, where these are partly seen as present, focusing on mutually contradictory evaluation criteria and performance standard that lead to subversive behavior. Some respondents also consider the demands from the principals high (but not extraordinarily high). The performance standards are not seen to be (too) high.

\subsubsection{General perception of accountability situation}

Next to focusing on the requirements of 'good accountability', as mentioned in chapter 3, we have also asked the respondents in the interviews to judge the situation of Cohesion Policy in general. ${ }^{644}$ The first question (4.6a) was focusing on their evaluation on a scale from 1 to 10 whether there is a situation of accountability deficit (1) or accountability overload (10), or somewhere in between. The second question (4.6b) related to accountability in general in Cohesion Policy, and was asking whether the situation of accountability in Cohesion Policy in general is bad (1) or very good (10).

To start with, we have divided the respondents in two categories: the European cluster on the one hand and both the national and the national-European cluster on the other hand. ${ }^{645}$ In the first category, all respondents who were dealing with relations on European level were placed. The other respondents, also some of the respondents from the EC who were dealing primarily with the relations between the $E C$ and $E Z$ and the MAs, were set in the second category. Because almost all respondents from national level, for instance from $E Z$, are both dealing with the national and the national-European cluster (EC-EZ-MA-AA), we have chosen to take both categories, the national and the national-European cluster, together in one category to be able to give a better and more weighed view of the opinions of the respondents. Figure 27 gives an overview of the answers that have been given by the respondents. ${ }^{646}$

644 See questions 4.6a and 4.6b of the questionnaire in Annex I.

645 The three clusters mentioned here, European, national and national-European cluster, correspond with the division made in chapters 4 and 5 .

646 When asking the questions, we asked to set a number, but in some cases only a qualitative answer was given. Where this answer was clear enough, we have translated this answer into a number. In other cases where this was not clear, the answer was not translated into a number and thus not incorporated in this overview. This also leads to a difference in the amount of respondents: because of this, from the European cluster there were only a few respondents to answer question $4.6 \mathrm{a}$. 


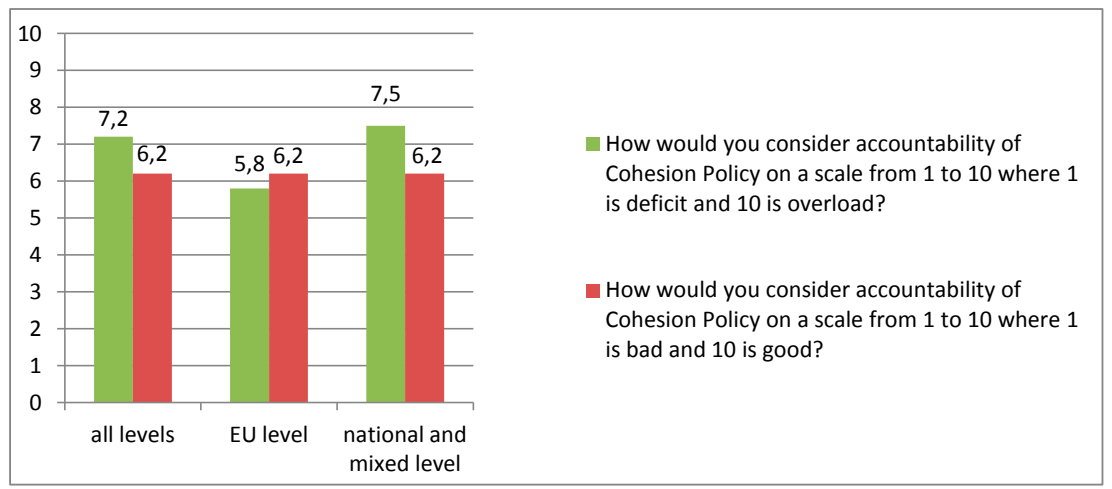

Figure 27. Overview of the average answers of respondents on the situation of accountability within Cohesion Policy

Firstly, we see that on the first question on accountability deficit versus overload (a), in general the situation is perceived by the respondents to head towards an accountability overload, with an average on all clusters of a 7,2 on a scale from 1-10. When we look at the answers given by respondents from the separate clusters, we see that the respondents in the European cluster are less pronounced regarding a possible accountability overload, with an average of 5,8 , where respondents from the national and the national-European cluster gave an average of 7,5. This means that respondents from the European cluster consider less that there is a situation of accountability overload, as opposed to respondents from the national and the national-European cluster. The division of answers on the scale is to be found in Figure 28. Two out of three (explicit) answers of respondents from the European

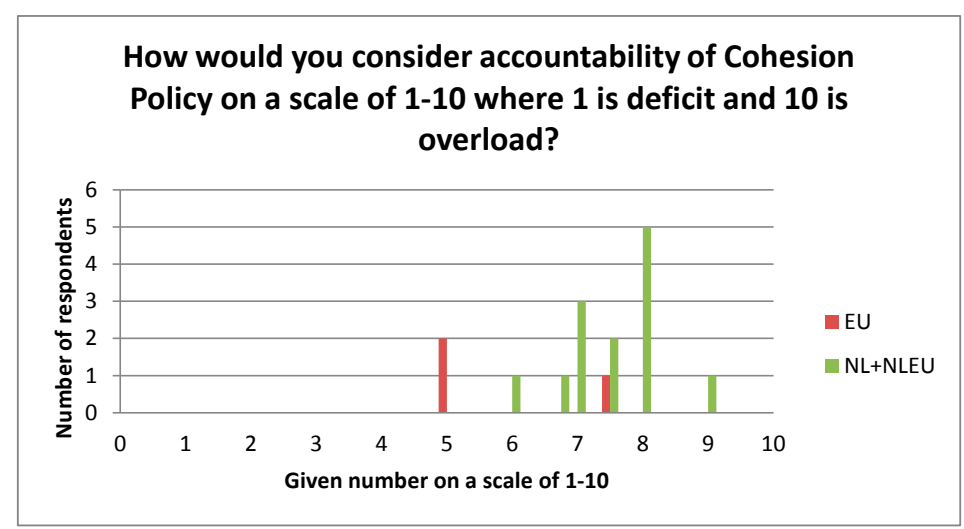

Figure 28. Overview of the separate answers of respondents on the first subquestion (a) on the situation of accountability within Cohesion Policy

This figure is based on $n=16$, because of the fact that not all respondents either were able to mention a number or gave an answer that could not explicitly be translated afterwards to a number. 
cluster were in the middle (a 5), whereas all respondents from the national and national-European cluster considered the situation to be explicitly more as a situation of overload, with given numbers between 6 and 8 .

When we look at the second question on the perception of the accountability situation as good or bad (b), we can see on average uniformity in the answers: the average of 6,2 on all levels is also equal to the average from the separate European, national and the national-European cluster (see Figure 27). What is interesting to see is that when we look into more detail at the individual numbers given by the respondents on this second question, to be found in Figure 29, the answers by the respondents, especially from the national and national-Europeancluster, varied more: two of the respondents were very negative on the general situation of accountability, and gave a 2 and a 3,5. When leaving those two explicit evaluations from the national and national European cluster aside, we can see that respondents from the European cluster were a bit more negative on the situation than the respondents from the national and thenational-European cluster: with an average of 6,2 of respondents from the European cluster compared to a 6,8 from respondents from the national and national-European cluster.

Although the number of respondents is too low to really give valid conclusions on the opinions of the respondents, what we can see in these answers is that the respondents in general feel there is a tendency towards an accountability overload (average of 7,2 on a scale of 1-10, where 1 is deficit and 10 overload). This is experienced more by respondents from the national and the national-European cluster,

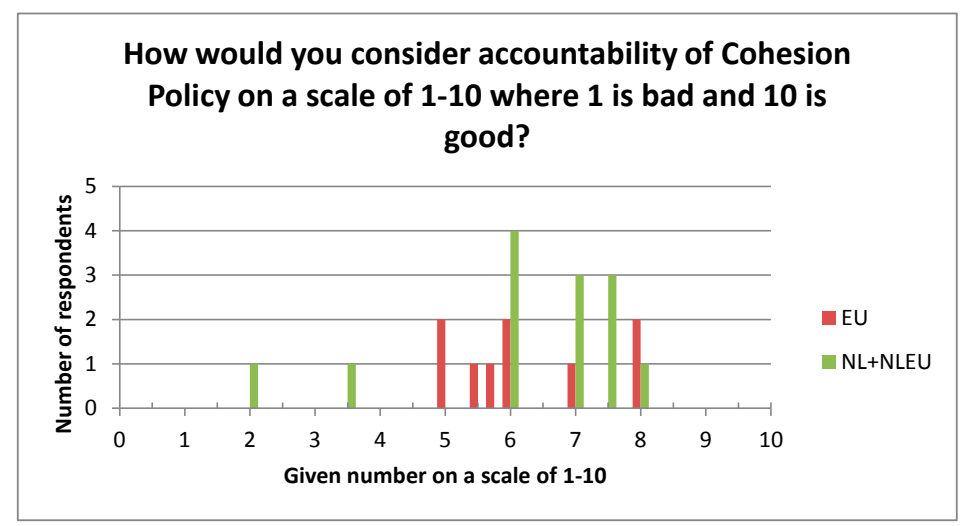

Figure 29. Overview of the separate answers of respondents on the second subquestion (b) on the situation of accountability within Cohesion Policy

This figure is based on $n=22$, because of the fact that not all respondents either were able to mention a number or gave an answer that could not explicitly be translated afterwards to a number. 
although we should be careful in saying this, because of the low responsiveness on this question of respondents from the European cluster (with only 3 respondents giving a clear answer from the European cluster towards 13 on the national and the national-European cluster).

With regard to the situation in general, which relates to the second question, we see that the average number given by all respondents matches the averages given by respondents from the European, the national and the national-European cluster, being a 6,2. However, individually, the respondents on national and nationalEuropean cluster are more divided, some of them being very skeptical, giving very low numbers, and others more positive than respondents from the European cluster. 



\section{6}

\section{Accountability and Cohesion Policy in the Netherlands}

\subsection{Introduction}

This chapter integrates the findings from chapter 4, based on document research, regulations and agreements, and chapter 5, based on interviews with respondents working with Cohesion Policy from all three clusters, being the European, the national and the national-European cluster (with the last cluster referring to the relationships between EC, EZ, MA and AA). We discuss the findings from both chapters mentioned previously connecting these with the requirements for 'good accountability' as mentioned in chapter 3.

An overview of the questions to be answered in this research in section can be found in Table 6.

The questions in the third and the fourth column, focusing on the single dimension, which relates to single accountability relationships, have been answered in the chapters 4 and 5 , based on both document research and interviews performed with actors working with Cohesion Policy. In this chapter we focus on the questions drafted in the last column, on the systemic dimension of accountability, focusing on Cohesion Policy as a whole, not on specific relationships or clusters. The following sections will follow the four main questions. Finally in section 6.6 a summary is given of the answers on the questions in the last column, following the four requirements and thus judging the situation of Cohesion Policy, focusing on ERDF in the Netherlands.

\subsection{Coverage: accountability relationships}

The first requirement of 'good accountability', as mentioned in chapter 3, focuses on the existence of accountability relationships within the system, and the question 


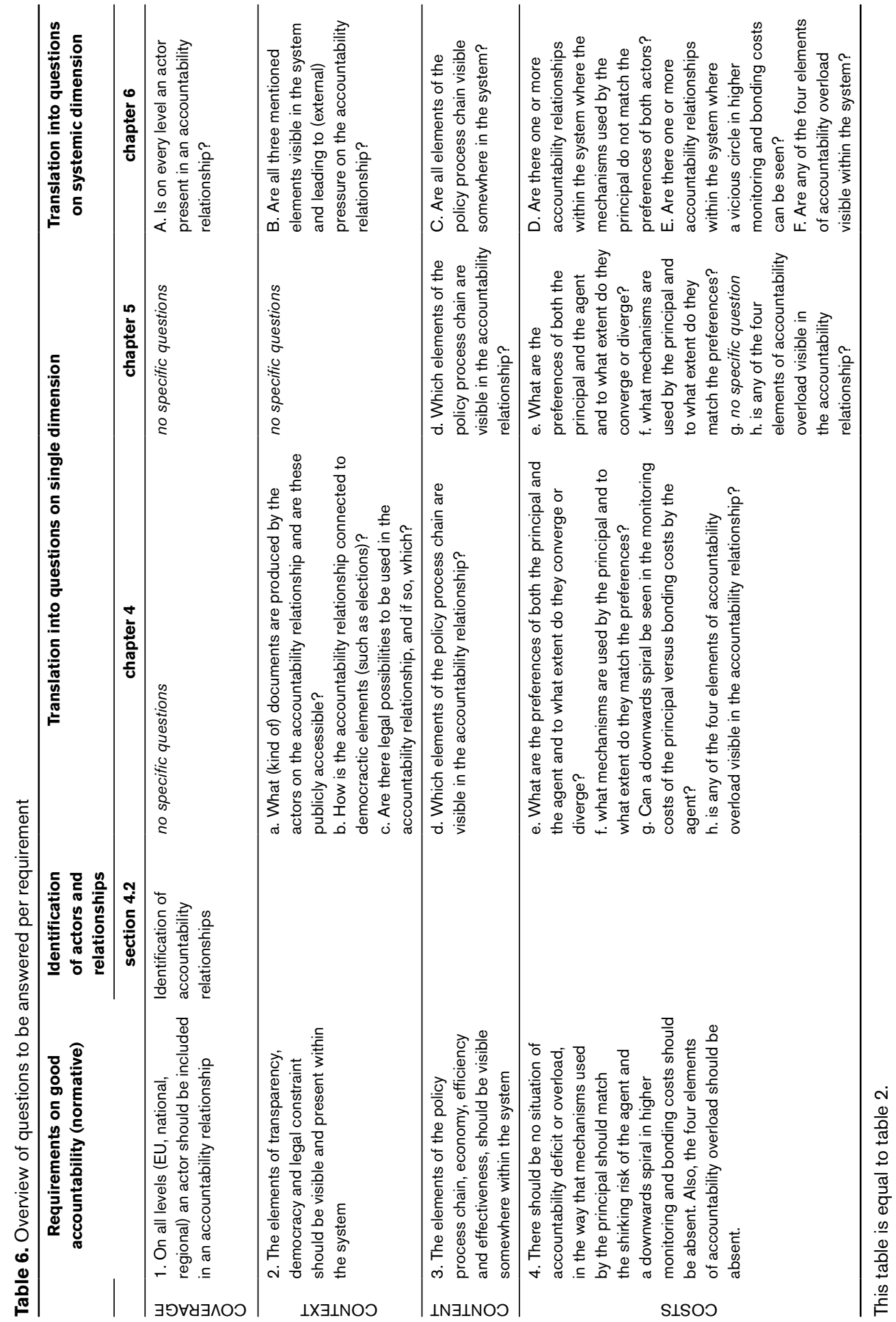


whether these are visible on all levels (EU, national and regional). The first requirement is formulated as follows:

\section{Requirement 1.}

On every level - European, national and regional - at least one actor should be present in an (complete) accountability relationship: either with an actor on the same level or on another level. Also, it should be clear on all accountability relationships which actors are accountable on what.

When we look at the relationships that were identified in both the document research of chapter 4 and the interviews of chapter 5 , we end up with the following relationships that are identified as accountability relationships (Figure 30).

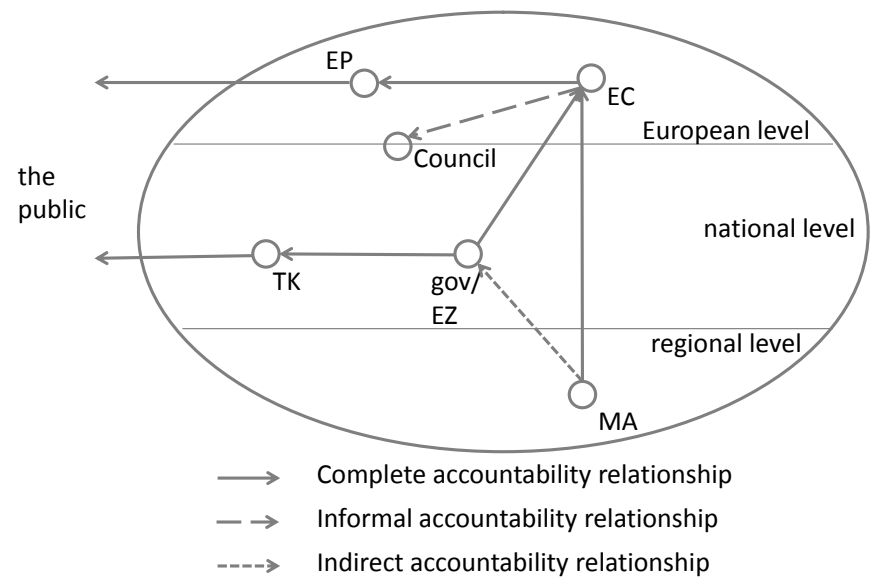

Figure 30. The actors and accountability relationships in Cohesion Policy

To start with, we can see there are two relationships connected to the element of democracy, in the way that both the EP andthe TK (the Dutch parliament) are chosen by the citizens (the public). This means that both the members of the EP and those of the TK are accountable to the electorate.

Secondly, we have identified two explicit relationships between the executive and legislative powers, in the European cluster between the EP and the EC and in the national cluster between the TK and (the Minister of) EZ.

Third, an explicit accountability relationship is identified both between the MA and $E C$, and $E Z$ and the EC, whereas both EZ and the MA are directly accountable 
to the EC. As we have mentioned, the EC has various mechanisms in place to make sure the MA and EZ are behaving as they should be. ${ }^{647}$ According to some of the respondents, the relationship between EZ and the EC should be labeled an indirect one ${ }^{648}$ but because the accountability relationship is directly mentioned in the Regulation and the fact that the relationship shows all characteristics of a complete accountability relationship, ${ }^{649}$ we consider it as complete.

Next to these direct and explicit accountability relationships, we have identified one informal and one indirect accountability relationship. The relationship between the EC and the Council does show signs of an accountability relationship. ${ }^{650}$ We have described that the first two steps of an accountability relationship are present, being the assignment of responsibilities and the obligation to report by the agent. Regarding the third step, information seeking and verification by the principal, we have described that this step is not clearly visible. Respondents have mentioned during the interviews that the focus of the Council in the 2007-2013 period has specifically been on the legislative phase of the policy cycle, where the Council has not been very active in the implementation phase. One of the respondents mentioned that it is to be expected that the Council will take a more active role also in the implementation phase of the 2014-2020 phase. ${ }^{651}$

In addition, there is no separate Council composition for Cohesion Policy. This makes it less likely that the Council is really active in seeking information on the execution by the EC and in performing verification activities. Also, we have identified in section 4.3.3 that explicit direction or control measures by the Council are absent. However, following information given by the respondents during the interviews, ${ }^{652}$ the Council is perceived to have more power than it formally has according to the Treaties. This means that although the Council does not have formal strong mechanisms in place to direct or control the EC, in effect the system seems to work as if it has these powers. As mentioned by the respondents, 'the Council is THE authority on European level,' 653 'the Council is stronger than the $E P^{\prime 654}$ and 'in the end it is the Council deciding: the EC never comes with a proposal that has not been discussed previously with the Council. ${ }^{655}$ In this, we conclude that the relationship

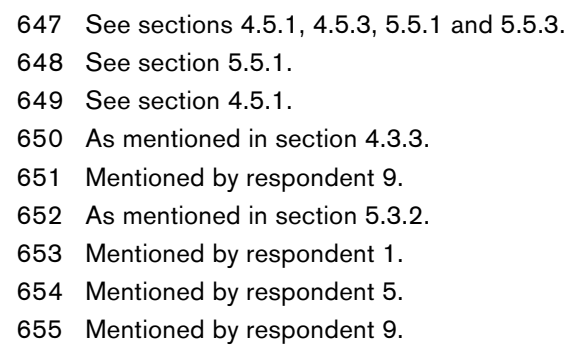


between the Council and the EC can be classified as an informal accountability relationship: showing steps of an explicit accountability relationship, without the third and fourth step explicitly being present.

Finally, we have identified one indirect relationship in the national-European cluster, between the MA and EZ. We have described ${ }^{656}$ that this is not an explicit accountability relationship, because of the fact that the MA is not accountable regarding the implementation of Cohesion Policy measures to EZ, but to the EC. Also, EZ is having the possibility to direct and control the MAs, but this is specifically related to Rijkscofinanciering, the national financial counterpart in the implementation of ERDF. EZ also has the possibility to use the NERPE law, ${ }^{657}$ by which it can reclaim unjustified funds from the regional authorities. However, until present this seems to be a theoretical possibility, since this law is only expect to be used when the EC is reclaiming funds from the member state, which EZ then will try to reclaim from the regional authorities. Until present, this possibility has not been used yet, and is expected to only be used in exceptional circumstances. This means that in practice, we consider the third and fourth step in this relationship to be absent.

To summarize, we consider these two last relationships as respectively an informal and indirect accountability relationship, formally having all elements in place, but effectively not, especially not for the third and fourth step.

There is one other actor we want to mention here: the AA. In chapter 5, based on the interviews, we have identified that the respondents consider that the AA is not directly accountable regarding the implementation of Cohesion Policy, but it is regarding its costs towards $E Z$ and regarding the way it performs its task towards the EC. Because the AA in fact operates as a monitoring agent ${ }^{658}$ for the EC, comparable to the role of the ECA and in the Dutch context the AR, we do not consider the $A A$ to be active as an agent or principal in an accountability relationship in Cohesion Policy.

Finally, we turn to the first question to be asked on the systemic level:

A. Is an actor present in an accountability relationship on every level (European, national and regional) or not?

656 See section 4.5.2.

657 See footnote 400 .

658 See section 2.2.1. 
When looking at the accountability relationships that have been identified, we conclude that this requirement is met in Cohesion Policy in the Netherlands. We have seen that at least one actor from each level (European, national and regional level) is active in an accountability relationship. Furthermore, in the Regulations it has been laid down which actor is accountable on what. This means that the agents in the respective accountability relationships are accountable to the respective principal on the implementation of the policy and thus the funds on the level concerned: EC towards the EP and the Council on European level, EZ on national level towards the EC and finally the MA on regional level towards the EC. The two relationships that are in connection with with the electorate, with the EP and the TK in the academic literature having been identified as explicit accountability relationships, show the citizens being the ultimate principals. ${ }^{659}$

\subsection{Context: transparency, democracy and legal constraint}

We now turn to the context of the relationships, which is about the characteristics of transparency, democracy and legal constraint, which play an essential role in accountability relationships. ${ }^{660}$ To start with, the element of transparency means that decision making should be opened up for the public, to make sure that actors are really accountable. Transparency gives extra pressure to actors to behave in a responsible manner, being aware that fuss creates negative publicity. Secondly, democracy connects policy making with the public 'as the ultimate principal.'.61 The idea is that this element of accountability gives pressure in the system to act accountable. As a third element, legal constraint is also essential, leading to a possibility to enforcement of the rules, or prevention of unfairness and abuse of power. This then leads us to the second requirement:

\section{Requirement 2.}

The elements of transparency, democracy and legal constraint should be visible and give enough pressure as a counterweight within the system.

659 Gustavsson, S., Christer Karlsson and T. Persson 2009. 'Examining the illusion of accountability', in S. Gustavsson (ed), The Illusion of Accountability in the European Union: Routledge, p. 4. See also Mulgan, R. 2003. Holding Power to Account. Palgrave MacMillan. p. 13.

660 See section 2.3.2.

661 Gustavsson, S., Christer Karlsson and T. Persson 2009. 'Examining the illusion of accountability', in S. Gustavsson (ed), The Illusion of Accountability in the European Union: Routledge, p. 4. See also Mulgan, R. 2003. Holding Power to Account. Palgrave MacMillan. p. 13. 
We start with discussing the element of democracy. For this, it is important that elected officials in parliaments, the legislative power, are accountable to the public, and that these parliaments are holding the executive powers to account. In this process an indirect accountability situation is formed between the electorate and the executive power (via the elected officials). This is seen on all levels, with the EP on European, the TK on national and PS on regional level. This means the element of democracy is formally present. However, on European level, this is effectively not working, ${ }^{662}$ because of the fact that elections for the EP are dominated by national issues. ${ }^{663}$ This means that effectively, democratic accountability on European level is lacking.

When looking at the national level, we see a similar picture: there is the formal possibility for the citizens to hold the members of TK accountable by elections. However, when we specifically look at Cohesion policy, we see there is hardly attention for it in the TK (see section 5.4.1). This means that the democratic element is, although it is formally present, not working properly.

Finally, when looking at regional level, we concluded that PS cannot hold the AB of SNN really accountable according to the procedures. Moreover, there is also on this level hardly any attention for the functioning of SNN in PS of the three provinces. ${ }^{664}$

Now we turn to the second element, that of transparency. We have concluded in section 4.3 that a lot of information on the implementation is made publicly available on European level, referring to documents of the (commissions in the) EP, legislative and background documents via the websites of EP and EC, and information disclosed on the website of DG REGIO. ${ }^{665}$ The Council conclusions on Cohesion Policy are published, but underlying information however is not, thus limiting the transparency of information. ${ }^{666}$

On the national level, referring to the TK, we have seen that all information used by TK members on Cohesion Policy is made publicly available and can be found on

662 See section 4.3.1.

663 Gustavsson, S., Christer Karlsson and T. Persson 2009. 'Examining the illusion of accountability', in S. Gustavsson (ed), The Illusion of Accountability in the European Union: Routledge, p. 4, based on Reif, K. and H. Schmitt 1980. 'Nine second-order national elections. Conceptual framework for the analysis of European election result. ', European Journal of Political Research, 3-44, and Hix, S. 2008. What's wrong with the European Union and how to fix it. See section 4.3.1.

664 See section 4.6.

665 See section 4.3.2.

666 See section 4.3.3. 
the internet. ${ }^{667}$ Also, the EU Trendrapport ${ }^{668}$ of the AR and its underlying references are publicly available, which contributes to transparency. However, most specific information concerning the relationship between $M A, E Z$ and $E C$ is not made publicly available, only in generalized form in the $A A R,{ }^{669} \mathrm{EU}$ Trendrapport or specific Annual reports that are published by the MAs. ${ }^{670} \mathrm{~A}$ lot of information that is exchanged between actors however is not made publicly available. This means that in general, we feel there is transparency, and it is improving with more explicit information in reports and 'naming and shaming' used by the $\mathrm{EC}$, but it is still possible to be further improved, especially on specific information communicated between the authorities.

Finally, the last element that is essential in accountability is the element of legal constraint. As we have mentioned in section 4.3.4, there is the possibility on European level for different institutions to bring a case before the ECJ. However, in Cohesion Policy this measure is hardly used. There is the possibility for member states to bring a case before the ECJ, but this also rarely happens. With regard to other actors than the member state (thus in the case of ERDF in the Netherlands the Ministry of EZ) it is not possible to bring a case before the ECJ, it is only possible via the member state in a case between the member state and the EC. This means that legal possibilities for some actors, the MA, CA and AA, being the responsible actors on national and regional level for the implementation, are essentially lacking.

To conclude this section, we refer to the second question to be answered on the systemic level:

$B$. Are all three mentioned elements visible in the system and leading to (external) pressure on the accountability relationship?

Our answer is that all elements are visible, but they are however only to a limited extent leading to (external) pressure in the system. In the case of the element of democracy, we have seen that real mechanisms for voters are lacking to hold the elected officials accountable. With regard to transparency, we have seen much has improved and a lot of information is made publicly available, but still specific information is lacking and not publicized. Finally, with regard to legal constraint, we have seen that on European level it is present and working properly, but for some

667 See section 4.4.2.

668 See for the latest version Algemene Rekenkamer 2015. 'EU Trendrapport 2015'. Den Haag: Algemene Rekenkamer.

669 See for the latest version European Commission 2015. 'Annual Activity Report 2015 DG Regional and Urban Policy'. Brussels: European Commission.

670 See for the latest version of the annual report of OP Noord Samenwerkingsverband Noord-Nederland 2015. 'Jaarverslag 2014 Operationeel Programma Noord-Nederland 2007-2013'. 
of the national authorities, such as the MA, it seems possibilities to bring a case before court are lacking. The only possibility for the MA to start a case on European level is through $E Z$, because the member state is the only public actor to start a case against European institutions such as the EC, this is not possible for - for instance - an MA.

\subsection{Content: the 3E's - economy, efficiency and effectiveness}

The third requirement we have drafted following the academic literature is on the content of the policy, on what accountability is all about. We have referred to the policy process chain, ${ }^{671}$ and the fact that accountability should not solely be on process elements, but also on the content of the policy, on economy, efficiency and effectiveness. This leads to the third requirement:

\section{Requirement 3.}

Economy, efficiency and effectiveness should all be visible somewhere in the system and on all levels at least one of the three elements should be visible.

What we have seen is that a lot of focus of actors in the system is being put on compliance issues. Although in most relationships the focus is not solely on compliance, we see that the focus is primarily lying on this topic. Economy is especially an issue when it comes to budgets and spending, particularly when negotiations take place on the distribution of funds, both on European level, the MFF negotiations, and on national level, the negotiations for the division of the available money in the Netherlands across funds and regions. During the implementation phase of the policy, economy is especially an issue when it comes to spending rates.

Efficiency is hardly dealt with, although in the new programming period 20142020 there has been attention for simplification measures, although these are especially directed towards beneficiaries, often having a counterproductive effect on administrative burden in the MCS for MAs. One of the examples of this has been given during the interviews, and is connected to the aim of simplification by enabling the use of tariffs approved by the EC in Horizon2020 projects. Additionally to this proposal, the EC has issued a comprehensive guidance document, offsetting the idea of simplification. ${ }^{672}$ What also gets clear is that effectiveness is receiving more and more attention, although in some cases a tension arises between compliance and effectiveness.

671 See section 2.3.3.

672 See also section 5.4.3. 
We have mentioned that the sanctioning mechanisms, of which the EC has the strongest in hand, directed towards member states and MAs, focuses in the 20072013 period almost entirely on compliance. Because of this, it is not strange that the focus in the system is almost entirely on compliance issues. When sanctioning mechanisms are focused on one specific item, the attention of both principals and agents will focus on that item. When looking at the 2014-2020 period, we have seen that next to compliance, the EC will also have sanctioning mechanisms directed at the performance of the programmes, connected to the performance reserve. ${ }^{673}$ Although we question whether these sanctioning mechanisms will really work, it shows that more attention is given to effectiveness and thus all elements, not only compliance, are expected to receive more attention than they did in the previous period. ${ }^{674}$ Hopefully it will leed to more balance in the system, to a less legalistic approach to Cohesion Policy.

Combining both the results from chapters 4 and 5 , we end up with the following figure (Figure 31 ) of the focus of relationships.

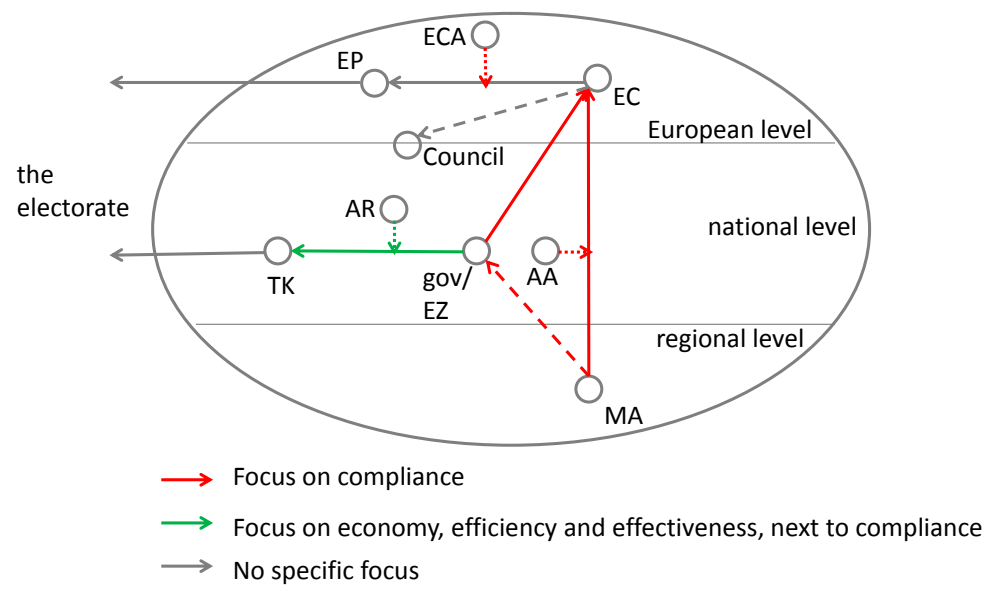

Figure 31. The focus of the accountability relationships in Cohesion Policy

As can be seen we have defined less relationships then mentioned in chapter 4 as specifically focusing on compliance. This is done because of the fact that the answers of the respondents in the interviews were less clear-cut than the findings in

673 See section 4.5.3.

674 See also section 5.5.1. 
chapter 4 based on the document analysis. Especially in the relationships between EP and EC and EC and Council the respondents were having the opinion that also other elements of the policy process chain than compliance were receiving some attention, for instance economy and performance. That is why we have given these relationships a grey color, showing no specific focus, or - put otherwise - showing signs of multiple elements of the policy process chain. However, we still see that the majority of the focus in the policy area is on compliance, especially in the nationalEuropean cluster.

This third requirement had been translated into the following question to be answered on the systemic dimension:

C. Are all elements of the policy process chain visible somewhere in the system?

Our answer to this question is that in the 2007-2013 period not all elements have been visible, attention for efficiency is lacking, the other elements are visible in a more or less quantity, with a lot of attention for compliance. This means we consider this requirement not to be met in the 2007-2013 period. However, improvements are expected in the 2014-2020 period, although we need to see whether there really will be changes in the focus of the actors in the policy area. A big fear of actors on national and regional level is that instead of a change of focus, there will be an extra focus and compliance will stay as important as it is now. That means that there will be an extra element actors will be held accountable on and will give the EC more mechanisms to sanction the member states and MAs.

Still, it is not to be expected that more focus is put on efficiency, this is still a lacking focus in the area of Cohesion Policy.

\subsection{Costs: absence of accountability deficit or overload}

Finally, we look at the fourth and last requirement, formulated as:

\section{Requirement 4.}

The situation within the policy area should be balanced in the way that there is no situation of accountability deficit or accountability overload.

We have split this fourth requirement into three parts. First, we look at the preferences of both the principals and agents in an accountability relationship, to see whether these preferences match or diverge. We consider that in a balanced situation, matching preferences should be accompanied by weak mechanisms to be used by the principal, and on the other hand in case of diverging preferences the principal needs strong mechanisms. 
It proved quite difficult, both based on document research (chapter 4) and the interviews with respondents (chapter 5), to get a clear view on the preferences of the actors. We discuss all relationships here, and afterwards translate the result into Table 7.

As also mentioned earlier, we do not specifically focus on the relation between both the EP and the TK and the electorate. ${ }^{675}$

\section{Policy preferences and mechanisms available}

To start with the European cluster, we have seen that both based on the document research of chapter 4 and the interviews in chapter 5 , it is still not explicit whether the policy preferences between EP and EC converge or diverge. For both characteristics we have seen examples: a focus on the general goals of Cohesion policy can on a general level be seen by both institutions, however we also see divergence in the focus on general issues (EP) versus implementing issues (EC) and the issue of the availability of funds on national level (EP), thus working towards personal interests.

With regard to the mechanisms available for the EP in this relationship, we have also seen there is not a clear answer: on the one hand it was mentioned that there is a formal, strong mechanism in place for the EP, especially targeted at the possible sending away of the EC by the EP. However, it was also mentioned that this possibility is 'a brutal force weapon, ${ }^{676}$ and that the EP also has a lot of weaker instruments to use to influence the EC.

Summarizing, we would conclude that in practice there is more convergence than divergence, with both the EP and EC focusing on the overall goal of Cohesion Policy. When we look at the mechanisms available, we would conclude that formally the EP has a strong mechanism available, thus leading to an imbalance. However, as mentioned, the EP will not use its 'brutal force weapon' for issues arising in Cohesion Policy. This means we conclude that there is a balance between the preferences of both the EP and EC and the mechanisms available for the EP and thus a low risk of an accountability deficit.

When we look at the second relationship, the one between the EC and the Council, we can see that there is divergence between the policy preferences of the EC and the Council. At a first glance, seeing the policy goals of Cohesion Policy in general and the obligations and goals of both institutions, one would consider there is convergence. However, as we have mentioned in both chapters 4 and 5 , in effect

675 See section 4.3.1.

676 Mentioned by respondent 1 . 
the Council is a collection of 28 member states, with each of them primarily focusing on its national interests. The Council also consists of different coalitions of member states within the institution, depending on the issues at stake, for instance to be seen in the coalitions of the 'friends of cohesion' versus netpayers. ${ }^{677}$ These national interests and the use of coalitions within the institution do not play an explicit role in the EC and thus lead to divergence in the effective policy preferences between both institutions.

Regarding the mechanisms available for the Council, we have mentioned earlier that the Council lacks formal mechanisms to have influence on the EC. However, we also concluded that in effect the Council is seen as a very strong institution, possibly even the strongest. As was stated by one of the respondents: 'it has no strong direct powers, but behind doors it has. ${ }^{678}$ This means we consider there is in effect a balance between the preferences of both actors and the mechanisms available, thus leading to a low risk of an accountability deficit or overload.

Now we will turn to the national cluster, with the relationship between TK and the Ministry of EZ. We have mentioned in the previous chapters convergence is seen in the policy preferences of both actors. Although in the TK the mainstream opinion is that SF should be used for member states who are lagging behind, and thus should not be available for the richer member states, ${ }^{679}$ both the TK and EZ take an interest in making sure the funds are spend to the maximum within the Netherlands.

When looking at the mechanisms available for the TK to influence $E Z$, we have seen there is a strong mechanism in the fact that the TK can send the minister away. However, because of the fact that Cohesion Policy is not seen as an important issue on national level, it is very unlikely this instrument is ever to be used for issues in Cohesion Policy. This means in practice, when this instrument is deemed as not effective in Cohesion Policy, only weak mechanisms remain.

One could state that formally there is a possibility for an accountability overload, with a situation of mainly convergence between both actors and a strong mechanism, but since this is not to be used in Cohesion Policy we consider this risk of an accountability deficit or overload in this relationship to be minimal. We conclude there is a balance in the policy preferences and the (effective) mechanisms in place.

677 See also section 5.3.2.

678 Mentioned by respondent 10.

679 See sections 5.3.2 and 5.4.1. 
After the European and national cluster, we now turn to the national-European cluster, focusing on the relationships between EZ and the EC, MA and the EC and finally MA and EZ.

On the relationship between EZ and the EC, we have concluded in chapter 4 there is a situation of divergence to be expected, because of the fact that on national level there is a focus on spending, where the EC is promoting the fair use of the funds. ${ }^{680}$ However, what is remarkable is that the respondents focus on the fact the EC also has a spending incentive because of the decommitment rule. ${ }^{681}$ This incentive on national and regional level in the $\mathrm{N}+2$ (or during the financial crisis and 2014-2020 period $\mathrm{N}+3$ ) rule, focusing on the fact that funds need to be spend within 2 years (or 3 years in case of $\mathrm{N}+3$ ). It is assumed by the respondents that, although there is no such thing as the $\mathrm{N}+2$ rule on European level, the $E C$ also has to make sure that funds are spend, ${ }^{682}$ because it would be politically undesirable to give a message the funds have not been spend. Interesting to see is that multiple respondents acknowledged that in the previous years absorption has been a very important, possibly the most important issue within the EC when it came to Cohesion Policy. However, it is perceived by the respondents that this is not primarily the case anymore, that more focus is put within the EC on spending the money wisely and on the best projects. This is expected to be specifically the case when it comes to the 2014-2020 period, but is already supposed to have its effect in the conclusion of the 2007-2013 period. With this in mind, we consider there is divergence to be seen in the relationship between the EC and the member states in general, because of the fact that the EC attaches more concern to effective spending where the member states are expected to be more focused on spending the available money in general, no matter on what. However, the Netherlands being a netpayer is probably one of the member states showing a low amount of divergence, also attaching importance to effective spending.

Regarding the mechanisms in place for the EC, these are similar for the EC towards both EZ and the MAs, and are quite strong considering the mechanisms that are mentioned in the Regulations, for instance suspension of payments and imposing financial corrections. ${ }^{683}$

When looking at both the preferences and the mechanisms available, we consider these to be in balance. It is expected that the majority of the member states focuses primarily on spending the available funds. In that case, the strong mechanisms available for the EC match the shirking risk of the member state, and thus shows

680 As was explicitly mentioned by respondent 14 .

681 See sections 5.3.1 and 5.5.1.

682 Mentioned by respondents 6, 17, 22 and 28.

683 See specifically articles 92 and $99-102$ of Regulation $1083 / 2006$. 
a balance. This means there is a low risk in this relationship on an accountability deficit or overload.

The relationships between the MA and the EC shows the same characteristics as the just discussed relationship between $E Z$ and the EC: the MA is supposed to focus primarily on having the available funds spend, the same as $E Z$ is supposed to focus on. At the same time, the mechanisms are also the same, because they are formally directed at the member state, but effectively come down at OP level and thus on the MA. With regard to this relationship, the respondents also mentioned they supposed convergence in the system, with the EC also aiming at spending of the funds. But as we just mentioned in discussing the relationship between EC and member state, we consider this to have changed at EC level since the 2014-2020 period, thus focusing more on effective spending end thus on selecting and financing suitable projects. This means that we expect to see more divergence, also in this relationship, which matches the strong mechanisms available for the EC. We consider the risk for an accountability deficit or overload thus low.

Finally, we deal with the relationship between EZ and the MA. We expect to see convergence between the policy preferences of both actors, targeted at spending the funds available. Of all relationships this one is probably the best example of expected convergence. However, the mechanisms available for EZ are quite strong, having the possibility to use the NERPE law ${ }^{684}$ and recover unduly paid funds from the MA. In potential, this is a situation with a risk of an accountability overload. Although the risk is perceived to be high, in practice we do not have examples of an accountability overload: EZ has not used the mechanisms available yet. As we

Table 7. The policy preferences and mechanisms available in the accountability relationships in Cohesion Policy

\begin{tabular}{lcccc}
\hline Relationship & $\begin{array}{c}\text { convergence or } \\
\text { divergence? }\end{array}$ & $\begin{array}{c}\text { strong or weak } \\
\text { mechanisms? }\end{array}$ & $\begin{array}{c}\text { Match or } \\
\text { mismatch? }\end{array}$ & $\begin{array}{c}\text { Risk on } \\
\text { accountability } \\
\text { overload or } \\
\text { deficit }\end{array}$ \\
\hline EP - EC & unclear & $\begin{array}{c}\text { formal strong, } \\
\text { informal weak }\end{array}$ & low \\
\hline Council - EC & divergence & $\begin{array}{c}\text { formal weak, but in } \\
\text { effect strong }\end{array}$ & $\sqrt{ }$ & low \\
\hline TK - EZ & convergence & $\begin{array}{c}\text { formal strong, } \\
\text { in CP weak }\end{array}$ & $\sqrt{ }$ & low \\
\hline$E C-E Z$ & divergence & strong & $\sqrt{ }$ & low \\
\hline$E C-M A$ & divergence & strong & $\sqrt{ }$ & low \\
\hline$E Z-M A$ & convergence & strong & $X$ & medium \\
\hline
\end{tabular}

684 See footnote 400 . 
also mentioned in section 4.5.2, this possibility is expected to only be used in cases where European institutions, for instance the EC, order the reclaim of misused funds. Thus we consider the risk on accountability overload as medium.

We have put the conclusions on the preferences and mechanisms available in the six accountability relationships in Table 7 .

We have seen there is one relationship with a higher risk on an accountability overload, there are no relationships with a higher risk on an accountability deficit to be seen (which would have been the case when divergence coincides with weak mechanisms).

\section{Downwards spiral}

This second part focuses on a possible situation where there is a downwards spiral with both high(er) monitoring and bonding costs. When this situation is increasing, we consider this to be a situation of accountability overload. ${ }^{685}$ We have identified such a downwards spiral in one relationship, being the relationship between the EC and MA. As we have mentioned in section 4.5.3, in the relationship between both actors we do see signs of an accountability overload, because of the fact that the demands on the MA are getting higher each period. In the 2007-2013 period the consequences of an error rate above $2 \%$ for two successive years has turned out to be an important compliance measure of the EC. For instance, in the year 2013, 121 new payment interruptions were issued by the EC. ${ }^{686}$ Comparing that to the total of approximately 250 OPs in Cohesion Policy in the 2007-2013 period, it shows that almost 50\% of the OPs were confronted in 2013 with a payment interruption. Also, when we look at the new programming period 2014-2020, MAs will also have to report and be focused on the performance of their programmes, next to the compliance measures that are still in place. ${ }^{687}$ It is expected that these extra measures on performance will aggravate the monitoring costs. Interesting to see in this respect is that the AA that is acting in fact as a monitoring agent of the EC is not paid by the principal, the EC, but by the member states. This also makes it easier for the EC to pose high demands on national authorities, including on the AA.

Some respondents stated that the ECA is perceived to be one of the drivers behind such a strong focus on compliance during the previous years. ${ }^{688}$ According

685 See section 2.3.5.

686 See European Commission 2014. 'Annual Activity Report 2013'. Brussels: European Commission. p. 44.

687 See section 4.5.3.

688 Mentioned by respondents 10 and 16 . 
to other respondents, the effect of the DAS seems to have disappeared. ${ }^{689}$ It is thus questionable whether the EC is focusing on compliance because of pressure of the ECA or because of other reasons. These examples do however show the existence of a downwards spiral within the system.

\section{Characteristics of accountability overload}

Finally, we considered whether any of the four characteristics of an accountability overload, as mentioned by Bovens, ${ }^{690}$ are to be seen. These four characteristics are, when a regime:

a. imposes extraordinarily high demands on the agent's limited time and energy;

b. contains a comparatively large number of mutually contradictory evaluation criteria for the agent;

c. contains performance standards that extend way beyond their own and comparable authorities' good practices;

d. contains performance standards that seem particularly conducive to goal displacement or subversive behavior.

We have mentioned we consider a situation of accountability as overload when we identify at least one of these four criteria. ${ }^{691}$

We have seen that there are two relationships that are possibly susceptible to accountability overload, when the above mentioned characteristics of an accountability overload are concerned.

First, there is the relationship between the EP and EC, where the EP is said to have high demands towards the $E C$, focusing on all aspects of the implementation of Cohesion Policy. ${ }^{692}$ As was stated by one or the respondents, the EC is considered to be 'some kind of supergod,' ${ }^{693}$ being able to answer all kind of questions of the EP. With many questions to be answered by the EC, this leaves less time for the employees of the EC to spend on other implementation issues. ${ }^{694}$ The question is whether these demands are extraordinarily high. We consider answering questions of the EP as a basic task of the EC, however, it should be within certain limits. Because of the mentioning by multiple respondents, we consider thus the risk of an accountability overload in this relationship to be medium.

689 Mentioned by respondents 3 and 24.

690 Bovens, M., T. Schillemans and P. 't Hart 2008. 'Does public accountability work? An assessment tool', Public Administration, 86, 225-242, p. 229. See also section 2.3.5.

691 See section 3.4.

692 See sections 4.3.2 and 5.3.1.

693 Mentioned by respondent 5.

694 Mentioned by respondent 10. 
The second relationship that was mentioned where we can see two characteristics of an accountability overload is the relationship between $\mathrm{EC}$ and $\mathrm{MA},{ }^{695}$ which we have also mentioned as an example where a downwards spiral of high monitoring and bonding costs can be seen. As has been mentioned both in chapters 4 and 5 , the demands on the MA are high, although they are 'explainable high'696: because of the fact that the rules are applicable to all OPs and MAs, and the fact that some MAs are not performing well, the demands on MAs on the implementation of the policy are perceived as explainable high.

What we also see in this relationship is that there is a perverse tendency for MAs (and also for member states) to focus on selecting the projects that meet the compliance criteria best: or stated differently, projects that have costs that best fit in the compliance system. This can be seen as subversive behavior. When an MA has to select costs in its OP, it is advantageous to focus on projects with costs that lead to as less discussion as possible. Intrinsically this does not necessarily lead to a focus on the best projects, what in the end should be the focus on. This means that OPs or MAs that have focused more on compliance issues will be awarded above OPs or MAs that have selected the best suitable projects in their programme, not necessarily being the projects that are compliance-wise viable. But in the end, it is also the wish of the EC to have selected the projects that contribute to the Cohesion Policy goals.

We consider the characteristic of high performance standards to be absent, although we have mentioned this characteristic in chapter 4. Considering the answers of the respondents in section 4, we agree that the performance standards are not too high, although they are now used in a way that (possibly) leads to an accountability overload. With regard to the last characteristic, the existence of mutually contradictory evaluation criteria, we consider the examples that have been given to fit best under the characteristic of subversive behavior we just mentioned .

\section{Conclusion on accountability deficit and overload}

To be able to give an answer to this question, we will have to answer the following three questions on the systemic dimension:

G. Are there one or more accountability relationships within the system where the mechanisms used by the principal do not match the preferences of both actors?

$H$. Are there one or more accountability relationships within the system where a downwards spiral in higher monitoring and bonding costs can be seen?

695 See section 4.5.3 and 5.5.3.

696 Mentioned by respondent 3. 
I. Are any of the four elements of accountability overload visible within the system?

To start with the first question, we have found one relationship where there is a risk of an accountability overload, because of the preferences of both actors and the mechanisms in place for the principal: the relationship between EZ and the MA. Although there is some convergence to be seen, EZ has quite strong mechanisms in place with the NERPE law ${ }^{697}$ and the ability to recover unduly paid funds. Although we have not seen examples where EZ has used these mechanisms, we do consider this a risk for an accountability overload.

In answering question $\mathrm{H}$ we have shown that a downwards spiral can be seen in the relationship between the EC and MA, with increasing costs for both actors with each programming period, ending up with the application of the performance reserve in the 2014-2020 period.

And finally, with reference to question I, we have seen that in the relationships between EP and EC and EC and MA some characteristics of an accountability overload are visible.

Figure 32 shows the risks for an accountability deficit or overload.

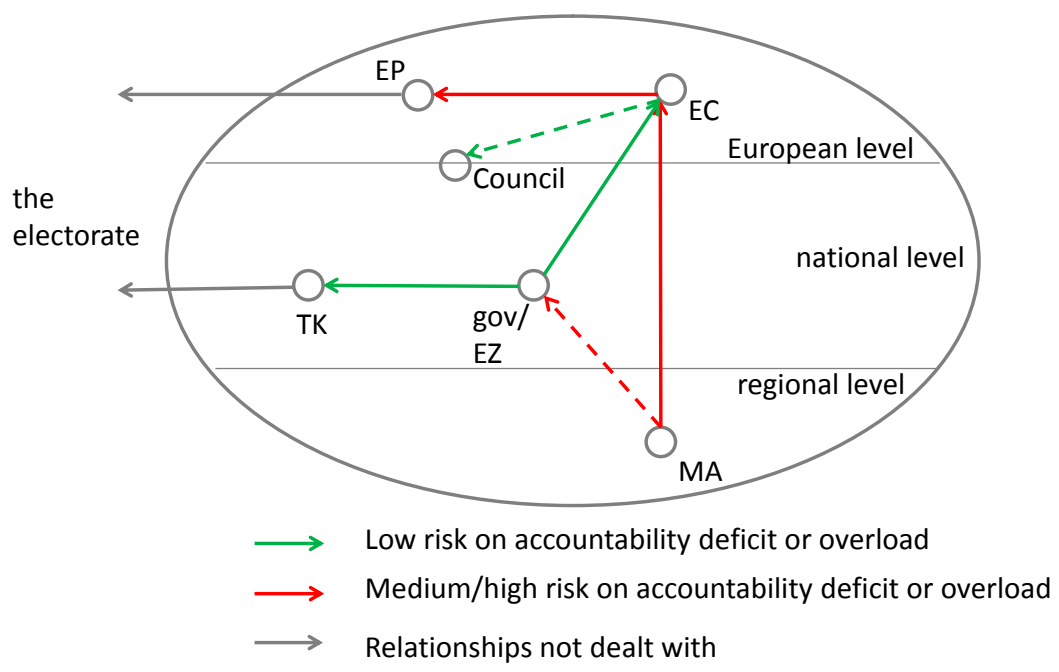

Figure 32. The risk of accountability deficit or overload in Cohesion Policy

697 See footnote 400. 


\subsection{Summary and answer to the main research question}

To summarize this chapter, and in fact to conclude on our research question, we now turn to the questions on systemic level. Combining all the answers on these questions given in the previous sections leads to the overview in Table 8. This overview enables us to answer the main research question:

Based on the results in Table 8, we conclude there is not a situation of 'good accountability' in Cohesion Policy, when specifically focusing on the regional ERDF operational programmes in the Netherlands. Some aspects are not sufficiently covered in the current situation, such as attention for efficiency and effectiveness when it comes to the policy process chain, and we have also seen signs of accountability overload in the system, leading to extra pressure on actors.

In the next and final chapter, we discuss some more specific issues and policy implications of our findings, as well as possible avenues for further research. 
Table 8. Overview of questions and answers on systemic level

\begin{tabular}{|c|c|c|c|c|}
\hline & $\begin{array}{l}\text { Requirements on } \\
\text { good accountability } \\
\text { (normative) }\end{array}$ & $\begin{array}{l}\text { Translation } \\
\text { into questions } \\
\text { on systemic } \\
\text { dimension }\end{array}$ & $\sqrt{ } / \mathbf{x}$ & Answers \\
\hline 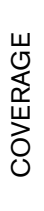 & $\begin{array}{l}\text { 1. On all levels (EU, } \\
\text { national, regional) } \\
\text { an actor should } \\
\text { be included in } \\
\text { an accountability } \\
\text { relationship }\end{array}$ & $\begin{array}{l}\text { A. Is on every level } \\
\text { an actor present in } \\
\text { an accountability } \\
\text { relationship? }\end{array}$ & $\sqrt{ }$ & $\begin{array}{l}\text { On all levels one or more actors are present } \\
\text { in an accountability relationship }\end{array}$ \\
\hline $\begin{array}{l}\text { 文 } \\
\text { 岁 } \\
\text { ○ } \\
0\end{array}$ & $\begin{array}{l}\text { 2. The elements } \\
\text { of transparency, } \\
\text { democracy and legal } \\
\text { constraint should be } \\
\text { visible and present } \\
\text { within the system }\end{array}$ & $\begin{array}{l}\text { B. Are all three } \\
\text { mentioned elements } \\
\text { visible in the system } \\
\text { and leading to } \\
\text { (external) pressure } \\
\text { on the accountability } \\
\text { relationship? }\end{array}$ & $x$ & $\begin{array}{l}\text { All three are visible, however these are not } \\
\text { leading to sufficient (external) pressure: } \\
\text { some documentation that could lead to } \\
\text { naming and shaming and thus pressure } \\
\text { is not publicly available, democracy is not } \\
\text { working preperly on EU level and (direct) } \\
\text { legal constraint for MA's towards EC is } \\
\text { limited. }\end{array}$ \\
\hline $\begin{array}{l}\sum_{W} \\
\text { 号 } \\
\text { U }\end{array}$ & $\begin{array}{l}\text { 3. The elements of the } \\
\text { policy process chain, } \\
\text { economy, efficiency } \\
\text { and effectiveness, } \\
\text { should be visible } \\
\text { somewhere within the } \\
\text { system }\end{array}$ & $\begin{array}{l}\text { C. Are all elements } \\
\text { of the policy } \\
\text { process chain visible } \\
\text { somewhere in the } \\
\text { system? }\end{array}$ & $x$ & $\begin{array}{l}\text { Especially efficiency is lacking in the } \\
\text { system, and also effectiveness is not really } \\
\text { dealt with in the } 2007-2013 \text { period. This } \\
\text { is expected to improve (a bit) in the 2014- } \\
2020 \text { period. }\end{array}$ \\
\hline $\begin{array}{l}\infty \\
\qquad \\
0 \\
0\end{array}$ & $\begin{array}{l}\text { 4. There should } \\
\text { be no situation of } \\
\text { accountability deficit } \\
\text { or overload, in the } \\
\text { way that mechanisms } \\
\text { used by the principal } \\
\text { should match the } \\
\text { shirking risk of } \\
\text { the agent and a } \\
\text { downwards spiral in } \\
\text { higher monitoring and } \\
\text { bonding costs should } \\
\text { be absent. Also, } \\
\text { the four elements } \\
\text { of accountability } \\
\text { overload should be } \\
\text { absent. }\end{array}$ & $\begin{array}{l}\text { D. Are there one or } \\
\text { more accountability } \\
\text { relationships within } \\
\text { the system where } \\
\text { the mechanisms } \\
\text { used by the principal } \\
\text { do not match the } \\
\text { preferences of both } \\
\text { actors? } \\
\text { E. Are there one or } \\
\text { more accountability } \\
\text { relationships within } \\
\text { the system where } \\
\text { a vicious circle in } \\
\text { higher monitoring } \\
\text { and bonding costs } \\
\text { can be seen? } \\
\text { F. Are any of the } \\
\text { four elements of } \\
\text { accountability } \\
\text { overload visible } \\
\text { within the system? }\end{array}$ & $x$ & $\begin{array}{l}\text { Three relationships show a risk of an } \\
\text { accountability overload, namely between } \\
\text { EP and EC, EC and MA and EZ and MA. }\end{array}$ \\
\hline
\end{tabular}





\section{7}

\section{Discussion and outlook for further research}

\subsection{Introduction}

This chapter is the concluding chapter of this research. In section 7.2 we touch upon some interesting issues and developments connected to this research. Afterwards, in section 7.3 we focus on the academic contribution of this research and possibilities for further research.

\subsection{Discussion}

In this section we touch upon some specific issues that were addressed shortly in this research, especially in the interviews (to which we will also refer in this chapter) but deserve more attention. These issues by and large relate to those issues that were put forward in the introductory chapter as 'triggers' for the research.

To start this discussion, this research shows that shared management between both European and national level is one of the main problems of Cohesion Policy. Because of the fact that both the EC on European level and the member state, in the case of ERDF in the Netherlands the Ministry of EZ, on national level are responsible for the implementation of Cohesion Policy, a blurred situation has emerged leading to accountability overload issues. However, as the requirements of 'good accountability' have shown, this accountability focuses primarily on legality and economy, thus not on the policy process chain as a whole. This research has shown that attention for efficiency and especially effectiveness is lacking, although improvements are expected from the 2014-2020 period.

Shared management also leads to political pressure on both national and European level to make sure that funds are spend as they should be, which in turn can be seen as a 'brake' on transparency: when things go wrong, it is not in the interest of the member states to go public with that information. 
Finally, shared management and the indistinct demarcation of responsibilities between actors, as can be seen on all levels, also leads to risks of accountability overload. With multiple actors responsible, both on national and European level, there is a risk that all of them want to prevent problems and thus will be as strict as needed to prevent these problems, causing a 'roofing-tile construction, ${ }^{698}$ where all actors point at another actor when it comes to responsibility.

Shared management is in the current situation necessary when it comes to Cohesion Policy. As we have shown in this research, the current situation does lead to problems with accountability, further improvements should be made in this respect. Without improvements, support for Cohesion Policy and thus also for the EU in general, is expected to erode (further). When thinking about the problems that come with accountability and possible future improvements, one of the ideas could be to think about a system for Cohesion Policy without shared management. Below we will mention some options and directions and discuss the implications. First, we will start with issues referring to a different set up of Cohesion Policy, in which the 'national envelop' will disappear (section 7.2.1), as this is the starting point of shared management and, as we have mentioned earlier, one of the triggers for a perverse tension to spend the funds. In section 7.2.2 we will then look the current set up and discuss some of the current limitations and possible improvements that can be taken into account when looking at the post 2020 period.

\subsubsection{A radical rethink of Cohesion Policy}

\section{Are all 28 member states entitled to the funds?}

When it comes to thinking about the future, one of the discussions that is also seen on national level in the Netherlands is the question whether all 28 member states are automatically entitled to funds from Cohesion Policy. This is an important starting point. In the last decades all member states were entitled to funds, and thus a substantive reason was to be found why the member states needed these funds and how these funds were supposed to be spend. This is a typical situation of 'target follows money': it all starts with money, and when it is available, thinking is started on how it will be spend. But suppose there would be a situation where it starts with a target: what are the problems of a region and what are the solutions that are suitable for that region? What is needed to solve it and how much money is needed to solve it? In this ideal situation of 'money follows target' the whole chain of spending is more logical and leads to more focus on efficiency and effectiveness, what is lacking 
in the current situation. Improvements are seen in the 2014-2020 period with the obligation to use a RIS, ${ }^{699}$ which led to a focus on strength and weaknesses within the region. However, by having the 'national envelop' already on the shelf, a situation of 'target follows money' is created which hinders effective spending.

Here the Dutch schizophrenic position on Cohesion Policy comes to the fore: the Dutch government on the one hand promotes that SF should solely be directed at the member states lagging behind - and thus preventing funds to flow to 'the richer' member states, ${ }^{700}$ - but on the other hand when the allocations are discussed, it still claims a part of the available funds.

Thinking about an ideal situation, and taking the problems of Cohesion Policy into account, as discussed in this research, the question should be asked whether all member states are automatically entitled to the funds. A 'No' to this question would lead to a fundamental and completely different discussion about Cohesion Policy than in the past. However, the interests at stake are enormous, and have formed an obstacle to change the situation until now.

\section{European added value?}

When thinking about a situation where 'national envelops' disappear, the question of European added value comes around. During the interviews, two respondents started a discussion on whether Regional Policy should be organized on the European level. ${ }^{701}$ Based on the subsidiarity principle, ${ }^{702}$ they argue that it should be discussed whether regional economic policy in fact should not be a national issue, instead of a European, referring to the idea of the European added value: SF should be used when there is a specific European added value, which is in most cases where SF are used not directly visible. The Regulations allow the regional authorities that draft an OP a lot of freedom in choosing the focus of the OPs, often leading to focus on points for improvements of the region. One could easily say that focusing on these priorities could also be funded by national funds.

Rather, as one of the respondents pointed out, ${ }^{703}$ Cohesion Policy should be targeted at European level, instead of national level, allowing competition between projects and partnerships across the member states. In the current situation the role of member states in the area of Cohesion Policy is rather large, whereas the

699 Also mentioned 'smart specialization strategy' in the 1303/2013 Regulation, where it is set as ex ante conditionality. See Annex XI of Regulation 1303/2013.

700 See for instance Van 't Hof, S. 2011. 'Kabinet slacht kip met gouden eieren', Binnenlands Bestuur. See also section 5.3.2.

701 Mentioned by respondents 11 and 12 .

702 Article 3 of the Treaty on the functioning of the European Union.

703 Mentioned by respondent 14. 
relationships between the actors should be more balanced, also giving more room for regions. This leads to a plea to especially focus on the role of regions and less on member states, and more specifically for a focus on the (possible) added value of Cohesion Policy on European level, thus creating more competition between regions for funds. However, as said, the current situation with a large role for member states does not allow such a change to happen.

Although thinking about such a change in the set up of Cohesion Policy is important and needed, also when looking at the issues of accountability within the current situation, we will not go into more detail of such a change and the implications thereof. That can be a subject for further research (see also section 7.3).

\subsubsection{Improvements in the current system of Cohesion Policy}

Although thinking about a radical change in Cohesion Policy is important, this research has especially given rise to the possibilities of changes in the current system. In this section we will therefore touch upon issues connected to this current situation. We will discuss the strong position of member states, the question on who is accountable on what, perverse tensions in the system, the materiality threshold, the use of 'the carrot and the stick,' the question whether all member states should be treated the same, the use of the national declaration and tensions within the national system.

\section{Cohesion Policy as multilevel governance: three-dimensional system with a strong position for member states}

To start with, as one of the respondents mentioned, although on the European level the accountability system in Cohesion Policy seems to be two-dimensional, with accountability relations between institutions on the one hand and member states at the other, the system is actually more complicated, because the regional level also is incorporated in the system, even on European level. ${ }^{704}$ We thus see in practice, based on the examples given in this research and the focus of the different relationships, that Cohesion Policy is a perfect example of multilevel governance. Different people might have different roles in the negotiating arena. This is especially seen in the EP, with MEPs reflecting their political color, their national and/or sometimes even regional origin. There can be national lines in the negotiations, for instance the Dutch position that Cohesion Policy should be directed at member states that are lagging behind. This position is not only disseminated by representatives of the member state, but also by MEPs. However, regions and their representatives are in 
favor of receiving funds from Cohesion Policy, because it enables them to achieve goals within the region. These regional representatives often do not publicly disseminate they are in favor of limiting SF to less developed countries. This may lead to varying positions of actors in the European arena, although they are representing the same member state. This shows the European arena is about negotiating and decision making between actors of all levels. This makes different policy areas, such as Cohesion Policy where the regions as a third level play an important role, interconnected and creates a three-dimensional instead of a two-dimensional picture. With a view to the future, it is interesting to see what role cities are going to play as a fourth level. With the set-up of the Urban Agenda, which is envisaged to lead to a consolidated agenda during the Dutch EU presidency in the first half of 2016, it is to be expected that cities will gain a position in the pursuit of EU2020 goals. In the future, it is thinkable that SF are also to be linked to the role of cities. This might possibly lead to a fourth level within SF, although this remains to be seen.

When studying Cohesion Policy, it is important to keep this multi-dimensional character in mind.

In this context, we would also like to consider the position of the member state. From this research, one can conclude that the position of the member states in this policy area is rather large. The member state has (or can have) a lot of influence on the implementation of the policy, and at the same time the member states together have a large voice in the policy making stage within the Council. As we have mentioned in section 5.3.2, there are different coalitions within the Council when it comes to Cohesion Policy, with specifically a division between net-payers and 'friends of Cohesion', the net receivers. One respondent argued that the position of the member states in this framework is too strong, the decision-making and implementation should be less in the domain of the member states. There needs to be more focus for the European added value. In the view of this respondent, 'the current system is not functional anymore, everyone wants to have its voice heard, wants to have its own objectives and its favorite themes. This has increased the complexity of Cohesion Policy. ${ }^{105}$

\section{Who is accountable on what, and how to be accountable?}

The main question underlying the study of 'good accountability' is the question who is accountable on what, and also whether the actors who are accountable really take this responsibility. As one of the respondents stated: 'Everyone seems to be responsible for spending the money, but no one is taking responsibility for spend- 
ing it properly. ${ }^{706}$ In the end, the EC is responsible on European level, especially in a political way to the EP and in a less formal way also to the Council ('It is clear the Council has powers, although these have not been formally assigned to it.).,707 To help the EP perform its task, the ECA also has an important role, specifically on the compliance aspects with the DAS. Member states, also responsible for the implementation on the basis of shared management, ${ }^{708}$ are accountable to the EC, but do that in a hardly transparent way. In some exceptional cases, such as the publication by 14 member states of the Annual Summary of $2011,{ }^{709}$ information is published, as is also the case with most Annual reports drafted by the MAs (in the Netherlands), which can be found on the websites of the MA. ${ }^{710}$ All other information that is send to the EC is processed in annual reports of the EC, especially in the AAR. ${ }^{711}$ Although these reports have become more specific with the years, still not all relevant information is made publicly available which hinders accountability. The EC can take a stronger role in this, being the responsible actor on European level, but as a respondent stated: 'the EC has influence, but doesn't want to take it."

This is also seen on the national level, where in the Netherlands the Ministry of $E Z$ is the responsible ministry for ERDF. Its accountability is specifically directed towards the TK, with also a role for the national Court of Auditors, the AR, in drafting a report as annex with the national DAS, ${ }^{713}$ and the 'EU Trendrapport. ${ }^{714}$ However, just as in the European context, the question of accountability also holds on the national level: although the Secretary of State of EZ is accountable to the TK on the implementation of ERDF, the implementation of the funds is performed on regional level, by regional actors, not being directly accountable to EZ. On this level, (political) accountability is often limited and most of the times not transparent. ${ }^{715}$ This all means that it seems to be clear on a detailed level which actor is accountable to whom on what, but it is also the question whether these actors can be held account-

706 Mentioned by respondent 3.

707 Mentioned by respondent 10.

708 See for instance section 1.3.3.

709 To be found at http://www.rijksoverheid.nl/bestanden/documenten-en-publicaties/brieven/2013/02/14/ structuurfondsen-2011-annual-summary-2011/as-structuurfondsen-2011.pdf, retrieved at 14-06-2015.

710 See for instance for information the website of SNN, managing authority of OP Noord-Nederland, on www.snn.eu/subsidies/subsidieprogramma-2007-2013, retrieved at 14-06-2015.

711 See for the latest version on Cohesion Policy European Commission 2015. 'Annual Activity Report 2015 DG Regional and Urban Policy'. Brussels: European Commission.

712 Mentioned by respondent 17.

713 See for the latest version Algemene Rekenkamer 2015. 'Rapport bij de Nationale verklaring 2015'. Den Haag: Algemene Rekenkamer.

714 See for the latest version Algemene Rekenkamer 2015. 'EU Trendrapport 2015'. Den Haag: Algemene Rekenkamer.

715 Mentioned by respondent 12. 
able - as in the case of the EC on European level, when member states implement the policy and in the case of EZ on national level, when regional authorities, the MAs, implement the policy in the end.

\section{Perverse tensions: spending or effective spending?}

Another important consideration that is to be drawn from the research is the fact there is a perverse tension on all levels to have the funds spend. This is originating in the decommitment rule, ${ }^{716}$ which proscribes that funds that are not used within two or three years in an OP automatically are decommitted by the EC. This means that all actors, especially on national and regional level, have a tendency to spend the money, notwithstanding the fact whether the spending is done to effective projects. As one of the respondents stated: 'you can smell from a distance that this money needs to be spend.717 On European level, as was mentioned by some respondents, this tendency is also seen at the EC, because when member states have parts of their funds decommitted, the EC will not be having a 'good conversation' with the EP. ${ }^{718}$ Although multiple respondents mentioned this aspect, some also noticed that this was primarily a focus of the past, whereas since a few years the EC is more focusing on better performance and spending ('more or quicker absorption turning into good absorption, ${ }^{719}$ ).

One of the respondents mentioned there should be more competition within government levels to be able to have it lead to more effectiveness. ${ }^{720}$ This competition is only seen on European and national level in the battle for the funds: on European level in the negotiations for the MFF, where decisions are made on which member state receives which share of the funds. After this decision, these amounts are felt as 'possession' of the respective member state, although it has not been used yet for projects. Without competition, there is no need for the member states to spend the funds sensibly.

The same holds for the national level, where after the negotiations on the MFF are finished, a national battle begins between MAs within the member state to receive as high a share as possible. After these funds are distributed, there is virtually no need to spend them sensibly. What we see however in the Netherlands is that since multiple programming periods, less funds get available for the Netherlands. Having less funds available also leads to more competition: there is more to choose from with regard to projects, because money gets scarce. Did some MAs in the

716 Or $\mathrm{N}+2$ or $\mathrm{N}+3$ rule. See sections 4.5.1 and 4.5.3..

717 Mentioned by respondent 3.

718 Mentioned by respondents 8, 14 and 28.

719 Mentioned by respondent 19.

720 Mentioned by respondent 3. 
2007-2013 period, for instance MA Noord, have some problems with achieving the $\mathrm{N}+2$ thresholds in certain years, in the 2014-2020 period it is expected that these thresholds will be more easily reached. With less funds available and still a lot of beneficiaries applying for funds, the best projects can be selected, because there is less threat of not reaching the $\mathrm{N}+3$ threshold.

On the other hand, whereas there are goals formulated for the policy to attain or contribute to, it seems often hard nót to reach these goals. This is because of the fact that in the formulation of the goals of the policy, the delivered outcome is taken into account, thus leading to a push on formulating not too high goals. There is a need for more focus on effectiveness which also requires strong formulation of goals and monitoring them during the implementation phase. Fortunately, in the 2014-2020 period more focus will be put on effectiveness of the policy and the EU also has given targets to MAs in the drafting of OPs: at least $20 \%$ of the available funds in an OP should be targeted at low carbon economy. However, there are on OP level no targets put on the effects of this obligation.

To conclude this issue, we have seen some improvements in the focus of programmes in the 2014-2020 period, but still the focus of the EC is on the availability of funds (20\% for low carbon economy), instead of on the effectiveness of those measures. Also, more focus will be put on performance, on what the MAs have mentioned they would achieve with the programme, but still it is primarily up to the MAs to inform the EC on this and the Regulation is leaving room for the performance reserve to be re-negotiated when not reached. Discussion on the goals of Cohesion Policy is therefore further encouraged.

\section{Materiality threshold of $2 \%$}

As mentioned earlier in this research, the EC uses a materiality threshold of $2 \%$ for the error rate. ${ }^{721}$ In practice, this threshold is applied on the yearly error rate, which means that when an OP has an error rate above this $2 \%$, it will be assessed by the EC whether corrections or improvements should be made. However, as was also mentioned by some of the respondents, ${ }^{722}$ taking the character of ERDF projects in the Netherlands into account, it is not very logical to consider this threshold as a yearly one. The projects in the Netherlands that are receiving ERDF grants are often very large, quite often with more than a million euro's of costs, take a lot time, often more than 2-3 years, are complex and very diverse. This means that various cost categories are used, all with their specific obligations and rules. Because of the $A w B$, projects are granted a subsidy according to their application, but the definitive

721 See sections 1.1 and 4.5.3.

722 Mentioned by respondents 8 and 18 . 
amount of subsidy is calculated on the basis of a 'vaststellingsverzoek' or 'eindafrekening' (final account at the end of the project). This means that all assessments done before this final account are preliminary and can be revised. This is different than the process most other member states use for granting ERDF funds, where often the grants awarded are also the final account. The system with error rates used by the EC, where a yearly assessment or closure is possible, is rather conflicting with the Dutch system of granting subsidies. In practice, a situation where costs have been corrected in the subsequent year may lead to a determined error by the AA in the year before, because the correction had not been made at that time. Respondents therefore suggest to take the materiality threshold as a threshold for the complete programming period, thereby better suit the Dutch situation of granting ERDF funds to beneficiaries. However, since most other countries do not encounter problems with this system of assessing error rates, it is not to be expected that this will change.

\section{The carrot and the stick}

When referring to inducing actors to act in a certain way, in the case of this research principals inducing the agents to show certain behavior, a comparison can be made to 'the carrot and the stick' approach, referring to a donkey who on the one hand walks on in the direction of a carrot in front of his nose, and moves away from the possibility to be hit by a stick. Or put otherwise: on the one hand inducing mechanisms should be used, whereas on the other punishments should be in place.

When we look at the situation in Cohesion Policy, we can see that on the one hand the stick is a firm one: in the way that the EC has strong mechanisms in place to influence the behavior of the agents, in this case the member states and regions (MAs). On the other hand, the carrot has been a small one in the 2007-2013 period, but it has grown in the 2014-2020 period: the EC is more and more also focusing on a stimulating strategy, with more dialogue, for instance in the stage of formulating the OP. It will always be of importance to search for a balance between both mechanisms to make sure the agents are not only punished when errors are made, but also rewarded for a good implementation.

\section{Do all 28 need to be treated the same?}

This point also leads us to touch upon another important question in Cohesion Policy: do all 28 member states need to be treated exactly the same? We know that the member states differ enormously: in their structure, their problems, the funds available, the culture, and more. What we see in the current situation is that the Regulations are drafted in such a way that all member states fit in, in one way or another. We plead it should be possible to make specific arrangements with the $\mathrm{EC}$ on member state and maybe even MA level, to respect the specific situation in 
member states and regions. Of course the EC tries to differentiate when needed, but at the same time member states are confronted with exactly the same rules and procedures. The Netherlands for instance has specific regulations on SISA, ${ }^{723}$ issues a national declaration, the $A A$ has a 'contract of confidence' with the $E C,{ }^{724}$ why isn't there room or possibility to make specific agreements with the EC on how controls are performed in the member state?

\section{The national declaration}

What we see is that in the 2007-2013 situation, accountability is formally taken on European level by the Director-General of DG REGIO in the AAR, signing a declaration on the declaration of assurance. ${ }^{725}$ On the regional level formal accountability was lacking until the 2014-2020 period, when the management declaration, to be signed by the director of the MA, was introduced. ${ }^{726}$ We can see that on national level an obligatory national declaration to be signed is still lacking. As we mentioned previously, ${ }^{727}$ the use of a national declaration is voluntarily, four member states have issued declarations: Denmark, Sweden, the UK and the Netherlands. ${ }^{728}$ From a formal and theoretical point of view, this declaration is filling an accountability gap, because on national level accountability on the spending of Cohesion Policy is lacking. This is also the reason the Netherlands is attaching relevance to issuing a national declaration: as netpayer, the Netherlands is focusing on the effective use of the funds and it feels it should give the good example for other member states. The Netherlands has tried with the 2012 revision of the FR to get it an obligatory instrument, but there was too little support for this of the other member states.

From an academic point of view, this declaration would fill the gap, and it would make it possible for other institutions, such as the ECA, to focus on other elements than primarily compliance, because the member states then have taken over that responsibility.

However, and that is also something that was mentioned multiple times during the interviews, to get the national declaration obligatory is almost unrealistic: because there is too much resistance, and because the situation in the different member states is too diverse: how should such a declaration be issued in a federal system

723 SISA stands for single information and single audit, based on the idea that beneficiaries should provide information only once and only one audit is performed on the costs declared.

724 Based on article 73 of Regulation 1083/2006.

725 See for the latest version European Commission (2015). Annual Activity Report 2015 DG Regional and Urban Policy. Brussels, European Commission.

726 Article 125, section 4 under e, following article 59 section 5 under a of the Financial Regulation.

727 See especially section 4.5.1.

728 The UK has ceased issuing a national declaration after 2011. 
like in Germany? In the current situation, it would be like flogging on a dead horse. However, we consider this to be an element that would add something to the accountability process, and no matter what other member states do, we feel the national declaration is adding to the accountability situation of Cohesion Policy in the Netherlands.

For the Netherlands, it is also important to make use of the declaration on European level: how can it be used in the context on Cohesion Policy, what should be added or changed to it to make it possible for the EC to make use of this declaration? One of the respondents argued that the declaration is of no use on European level, 'because it looks at separate elements of the funds, the added value is then limited. ${ }^{729}$ The Netherlands should aim at a situation where issuing the declaration would lead to more benefits than in the current situation, to negotiate advantages for member states who do issue a declaration. But this is something to be done in the following revision of the FR, or the next programming period (2021-2027). This then would be a good example of a carrot, put in the example of the carrot and the stick.

\section{Tensions in relationships on national level}

When talking about the national declaration, we also should look the relationships on national level. The image that is arising from the interviews is that there is a tension on national level between ministries, which also seems to have effect in the implementation of the policy. The AA, falling under the scope of the Minister of Finance has, next to its formal role of being $A A$, also a role in the substantiation of the national declaration. Although there is no need for both roles to be contradictory, it is seen as a (possible) juggle between the position of the Netherlands in spending the funds, having interest in making sure it is spend correctly enough (the interest of EZ as member state), and the fact that it should be spend completely correctly (the interest of Ministry of Finance in ensuring complete compliance with the rules and procedures). ${ }^{730}$ In effect, EZ is the responsible ministry for the implementation of the funds, but because of the Netherlands being a net-payer and the interest it is attaching to the correct spending of funds, the influence of the Minister of Finance is undeniable in the system. As was stated by one of the respondents: 'Dijksma will be reluctant to go against the judgment of Dijsselbloem." ${ }^{731}$ This is having its effect also on Cohesion Policy, leading to a reluctant position at EZ.

729 Mentioned by respondent 20.

730 As implied by respondent 28.

731 Mentioned by respondent 15, and confirmed by respondents 25, 26 and 28. Sharon Dijksma was the Secretary of State of EZ, responsible for Cohesion Policy at the time the interviews were conducted and Jeroen Dijsselbloem is the Minister of Finance. 
However, EZ as the responsible ministry has an important role in the system, together with the mechanisms available, to make sure MAs and the AA act as they are supposed to do. However, as multiple respondents stated, ${ }^{732} \mathrm{EZ}$ does not seem to take its role on national level, leaving the responsibility of implementing Cohesion Policy primarily to the regional authorities. Also towards the AA, EZ is not acting as it is capable to do, possibly because of the tension between ministries as just described earlier. Although there is no need to act when the process is running smoothly, the current situation in the Netherlands is not smooth which means action needs to be taken. And on national level EZ is the ministry having the position to do that.

\subsection{Possibilities for further research}

This research has focused on accountability within Cohesion Policy in the Netherlands, specifically on regional ERDF OPs. This case study has taken the concept of accountability, as elaborated in academic literature, to a practical level, by applying it to Cohesion Policy in the Netherlands. As we have mentioned in chapter 1, there are hardly any examples in the academic literature where the concept of accountability is applied to a specific case study. In this respect, this research is of considerable added value to the academic literature. This research can also form the basis for further research. In that regard below some suggestions are made.

\section{Expansion of case study}

First of all, this research focused on the Netherlands as a case study, which had different reasons. First of all, in the Netherlands there has been a lot of debate between authorities during the past years on accountability and what it should really be focusing on. Secondly, the Netherlands has more than decades of experience with ESIFs and has a pronounced implementation system in place. Focusing on one of the (old) EU-12 member states makes it possible to judge the system of implementation on its existence, not having to take difficulties with new systems in account, as would possibly be the case in the (new) EU-16 member states.

With the analytical framework of this research, which has made the concept of accountability operational in order for it to be used in a case study, it is possible to also study the systems of other member states to look for differences and comparisons. Such research will make it possible to find out whether there is a good situation of accountability in the member states, and thus of Cohesion Policy on European level. 


\section{Relationships between actors}

Secondly, another future possibility for additional research would be to look at the relationships between actors on the national-European cluster, to find out whether the Dutch situation is unique or specific; the blurred situation between MA, EZ and $E C$ is complicating implementation on the national level and it would be interesting to see whether this situation is present in other member states as well. Is it a situation typical for Cohesion Policy and multilevel governance, or is it a typical Dutch situation, leading to complications in the implementation of Cohesion Policy?

\section{Alleviation of the pressure of audits and controls}

Third, we have seen in this research that a lot of focus is put on compliance, leading to a lot of pressure for MAs and especially for beneficiaries, which have not been the main focus of this research. Therefore, it would be interesting to perform research on options for alleviation of this administrative burden. Would $\mathrm{SISA}^{733}$ be an option to be used on European level and if so, how should it be imbedded to have it lead to a lower pressure of audits?

\section{National declaration}

Another possible topic for further research would be the national declaration, its history and possibilities for the future. It would be interesting to explore whether this mechanism would have the potential to have an influence in the accountability system of various European policy areas. Is it possible to be used as an extra mechanism in the accountability of SF?

\section{The future of Cohesion Policy}

As we have pointed out in section 7.2.1, this research also gives rise for thinking about a major change in Cohesion Policy, leaving the 'national envelop' aside and focus on the European added value of Cohesion Policy and European funds. Such a rethinking must have already been started in 2015 in and around the EC, with the starting of thinking about the post 2020 period. This also makes it a perfect opportunity for researchers to dive into this subject and provide discussion from academics on the implications of such changes.

\subsection{Final words}

To finish with, it is important to note that we have been focusing on pressures and tensions from and within the system, leading to incentives for the different actors in the system to behave in a certain way. As is also said on the banking sector after the 
banking crisis between 2008 and 2012, it is the system that is showing perverse tensions, not the people working in it. The same holds for Cohesion Policy: it is not necessarily said that all member states and all MAs are acting in a perverse or noneffective way. On the contrary, a lot of respondents from authorities argued they are acting according to what they think is important and although they often recognize the perverse incentives, they do not necessarily act according to these incentives. What should be important, as is also mentioned by one of the respondents, ${ }^{734}$ is that a learning cycle is created within the system, which gives all actors insight in their role, behavior and the incentives towards it, and the role and behavior of other actors. The system should thrive for improvement all the time, and it is essential that all actors within the system will contribute to this learning cycle.

Thus, let us not cause a revolution, but let us make this evolution work. 




\section{Literature list}

Abromeit, H. 2009. 'Accountability and democracy', in S. Gustavsson (ed), The Illusion of Accountability in the European Union: Routledge.

Algemene Rekenkamer 2011. 'EU Trendrapport 2011'. Den Haag: Algemene Rekenkamer.

Algemene Rekenkamer 2013. 'EU Trendrapport 2013'.

Algemene Rekenkamer 2014. 'EU Trendrapport 2014'. The Hague: Algemene Rekenkamer.

Algemene Rekenkamer 2014. 'Rapport bij de Nationale verklaring 2014': Algemene Rekenkamer.

Algemene Rekenkamer 2015. 'EU Trendrapport 2015'. Den Haag: Algemene Rekenkamer.

Algemene Rekenkamer 2015. 'Rapport bij de Nationale verklaring 2015'. Den Haag: Algemene Rekenkamer.

Arrow, K.J. 1984. 'The Economics of Agency'.

Bache, I. 2008. 'Researching Multi-level Governance', CINEFOGO/Univeristy ot Trento conference on The Governance of the European Union: Theory, Practices and Myths. Brussels.

Bachtler, J., I. Begg, L. Polverari and D. Charles 2013. 'Evaluation of the Main Achievements of Cohesion Policy Programmes and Projects over the Longer Term in 15 Selected Regions (from 1989-1993 Programme Period to the Present)'. Glasgow and London: European Policies Research Centre, University of Strathclyde and London School of Economics.

Bachtler, J. and M. Ferry 2013. 'Conditionalities and the Performance of European Structural Funds: A Principal-Agent Analysis of Control Mechanisms in European Cohesion Policy', Regional Studies.

Barca, F. 2009. 'An agenda for a reformed cohesion policy - a place-based approach to meeting European Union challenges and expectations'.

Becker, S., E. P. and E. M. 2010. 'Going NUTS: the effect of EU Structural Funds on regional performance ', Journal of Public Economics, 94, 578-590.

Bergman, T. 2000. 'The European Union as the next step of delegation and accountability', European Journal of Political Research, 37, 415-429.

Beugelsdijk, M. and S.C.W. Eijffinger 2005. 'The Effectiveness of the Structural Policy in the European Union: an Emperical Analysis for the EU-15 in 1995-2001', Journal of Common Market Studies, 43, 37-51.

Börzel, T.A. 1998. 'Organizing Babylon - On the different conceptions of Policy Networks', Public Administration, 76, 253-273.

Bovens, M. 2007. 'Analysing and Assessing Accountability: a Conceptual Framework', European Law Journal, 13, 447-468. 
Bovens, M., T. Schillemans and P.'t Hart 2008. 'Does public accountability work? An assessment tool', Public Administration, 86, 225-242.

Bovens, M. 2010. 'Two concepts of Accountability: Accountability as a virtue and as a Mechanism', West European Politics, 33, 946-967.

Busuioc, E.M. 2010. 'The Accountability of European Agencies: Legal Provisions and Ongoing Practices.' Uitgeverij Eburon, Delft.

Braun, D. and D.H. Guston 2003. 'Principal-agent theory and research policy: an introduction', Science and Public Policy, 30, 302-308.

Council of the European Union 2006. 'Decision of 6 October 2006 on Community Strategic Guidelines on Cohesion'.

Curtin, D., P. Mair and Y. Papadopoulos 2010. 'Positioning Accountability in European Governance: An introduction', West European Politics, 33, 929-945.

Damen, M. and N. Groenendijk 2012. 'Performance auditing in EU Cohesion Policy: what do we know and what should we know?', ECSA-C 9th Biennial conference 'Europe in an Age of Austerity: Integration, Desintegration, or Stagnation?'. Ottawa, pp. 1-12.

Davies, A. 2001. Accountability: A Public Law Analysis of Government by Contract. Oxford: Oxford University Press.

Davies, S. and L. Polverari 2011. 'Financial Accountability and European Union Cohesion Policy', Regional Studies, 45, 695-706.

Day, P. and R. Klein 1987. Accountabilities. Five public services. Travistock Publications Ltd.

Denters, S.A.H. 1995. 'De parlementaire democratie', in J.W. Van Deth and P.A. Schuszler (eds), Nederlandse Staatkunde. Een elementaire inleiding.: Countinho, pp. 85-103.

van Dooren, W., G. Bouckaert and J. Halligan 2010. Performance Management in the Public Sector. Routledge.

Dowding, K. 2004. 'Interpretation, Truth and Investigation: Comments on Bevir and Rhodes.', British Journal of Politics and International Relations, 6, 136-142.

Dowdle, M.W. 2006. 'Public accountability, conceptual, historical and epistemic mappings', in M.W. Dowdle (ed), Public Accountability. Designs, Dilemma's and Experiences: Cambridge University Press, pp. 1-29.

Dubnick, M.J. and J.B. Justice 2004. 'Accounting for Accountability', 2004 Annual Meeting of the American Political Science Association.

Dyrberg, P. 2002. 'Accountability and Legitimacy: What is the Contribution of Transparency?', in A. Arnull (ed), Accountability and Legitimacy in the EU: Oxford University Press, pp. 81-96.

Ederveen, S., H.L.F.d. Groot and R. Nahuis 2006. 'Fertile soil for Structural Funds? A Panel data Analysis of the Conditional Effectiveness of European Cohesion Policy', KYKLOS, 59, 17-42.

European Commission 2008. 'Cohesion Policy 2007-2013. National Strategic Reference Frameworks'. Brussels: European Commission.

European Commission 2010. 'Ex-Post Evaluation of Cohesion Policy Programmes 2000-06 cofinanced by the ERDF (objective 1\&2)': European Commission.

European Commission 2010. 'Investing in Europe's future. Fifth report on economic, social and territorial cohesion': European Commission. 
European Commission 2011. 'Employment, Social Affairs and Inclusion Directorate General 2010 Annual Activity Report '. Brussels: European Commission.

European Commission 2012. 'Simplifying Cohesion Policy for 2014-2020'.

European Commission 2012. 'Treaty of the European Union and the Treaty on the functioning of the European Union', 2012/C 326/01.

European Commission 2012. 'Why was it necassary to change the budgetary and spending rules in the Financial regulation?': European Commission.

European Commission 2013. 'Annual Activity Report 2012': DG Regional and Urban Policy.

European Commission 2013. 'Cohesion policy: Strategic report 2013 on programme implementation 2007-2013': European Commission.

European Commission 2014. 'Annual Activity Report 2013'. Brussels: European Commission.

European Commission 2014. 'Communication from the Commission to the European Parliament, to the Council and to the European Court of Auditors on the adoption of the interinstitutional Working group recommendations for the establishment and use of National Declarations': European Commission.

European Commission 2014. 'EU cohesion funding - key statistics'.

European Commission 2014. 'Implementation Guidance e-cohesion'.

European Commission 2014. 'Investment in growth and jobs. Promoting development and good governance in EU regions and cities. Sixth report on economic social and territorial cohesion...

European Commission 2015. 'Annual Activity Report 2015 DG Regional and Urban Policy'. Brussels: European Commission.

European Commission 2015. 'Synthesis of the Commissions' management achievements in 2014': European Commission.

European Council 2014. 'Council adopts cohesion policy package for 2014-2020', in European Council (ed). Brussels.

European Council 2014. 'Press Release of the 3294th Council meeting of Economic and Financial Affairs'.

European Court of Auditors 'The European Court of Auditors. The DAS Methodology'.

European Court of Auditors 2013. 'Annual Report on the Implementation of the Budget'. Luxembourg: European Court of Auditors.

European Court of Auditors 2014. 'Annual report on the implementation of the budget'. Luxembourg: European Court of Auditors.

European Court of Auditors 2014. 'EU funded airport infrastructures: poor value for money', Special Report: European Court of Auditors.

European Court of Auditors 2014. 'Gaps, overlaps and challenges: a landscape review of EU accountability and public audit arrangements'. Luxembourg: European Court of Auditors.

European Parliament 2012. 'Macro-economic conditionalities in Cohesion Policy': European Parliament, Directorate General for Internal Policies.

Feenstra, P. 2001. 'ESF subsidies moesten wel mis gaan', Trouw.

Finn, P. 1993. 'Public Trust and Public Accountability', Australian Quarterly, 65, 50-59. 
Fisher, E. 2004. 'The European Union in the Age of Accountability', Oxford Journal of Legal Studies, 24, 495-515.

Follesdal, A. and S. Hix 2006. 'Why There is a Democratic Deficit in the EU: a Response to Majone and Moravcsik', Journal of Common Market Studies, 44, 533-562.

van der Giessen, M. 2014. Coping with complexity. Cross-border cooperation between The Netherlands and Germany.

Goodin, R.E. 2003. 'Democratic accountability: the Distinctiveness of the Third Sector', European Journal of Sociology, 44.

Gräßle, I. 2008. 'Working document on the role and functioning of supervisory and control systems for structural operations': European Parliament, pp. 1-10.

Groenendijk, N. 1997. 'A principle-agent model of corruption', Crime, Law \& Social Change, 207-229.

Gustavsson, S., C. Karlsson and T. Persson eds. 2009. The illusion of accountability in the European Union. Routledge.

Gustavsson, S., Christer Karlsson and T. Persson 2009. 'Examining the illusion of accountability', in S. Gustavsson (ed), The Illusion of Accountability in the European Union: Routledge.

Gustavsson, S., C. Karlsson and T. Persson 2009. 'Taking accountability seriously', in S. Gustavsson (ed), The Illusion of Accountability in the European Union, pp. 170-175.

Harlow, C. and R. Rawlings 2007. 'Promoting Accountability in Multilevel Governance: A Network Approach', European Law Journal, 13, 542-562.

Hawkins, D.G. 2006. 'Delegation under anarchy: states, international organizations, and principal-agent theory', in D.G. Hawkins, D.A. Lake, D.L. Nielson and M.J. Tierney (eds), Delegation and Agency in international organizations. Cambridge: Cambridge University Press, pp. 3-38.

Hix, S. 2008. What's wrong with the European Union and how to fix it.

van 't Hof, S. 2011. 'Kabinet slacht kip met gouden eieren', Binnenlands Bestuur.

Hooghe, L. 1996. 'Building a Europe with the Regions: The Changing Role of the European Commission', in L. Hooghe (ed), Cohesion Policy and European Integration: Building multilevel governance, pp. 89-126.

Hooghe, L. 1996. Cohesion Policy and European Integration: Building multilevel governance. Oxford university Press.

Hooghe, L. 1996. 'Reconciling EU-Wide Policy and National Diversity', in L. Hooghe (ed), Cohesion Policy and European Integration: building multilevel governance, pp. 1-24.

Hooghe, L. and G. Marks 2001. Multi-level Governance and European integration. Rowman and Littlefield Publishers Inc.

de Jong, H.M. 1995. 'De Constitutionele Monarchie', in J.W. Van Deth and P.A. Schuszler (eds), Nederlandse Staatkunde. Een elementaire inleiding.: Coutinho.

Karlsson, C. 2009. 'EU Treaty Reform and Accountability', in S. Gustavsson (ed), The Illusion of Accountability in the European Union.

Ketelaars, V., B.J.t. Berge, H.G.A.M. Cremers, P.J.A. Heuts and A.P.M. Linders 2012. 'Onderzoek naar de impact van de concept-Structuurfondsverordeningen 2014-2020 op de administratieve lasten en uitvoeringskosten van de Europese Structuurfondsen in Nederland': ERAC BV. 
Kickert, W. 1993. 'Complexity, Governance and Dynamics: Conceptual Explorations of Network Management', in J. Kooiman (ed), Modern Governance: New Government-Society Interactions: Sage.

Koppell, J.G.S. 2005. 'Pathologies of Accountability: ICANN and the Challenge of 'Multiple Accountabilities Disorder.", Public Administrations Review, 65, 94-107.

Lindberg, S.I. 2013. 'Mapping accountability: core concept and subtypes', International Review of Administrative Sciences, 79, 202-226.

Mairate, A. 2006. 'The 'Added-Value' of European Union Cohesion Policy', Regional Studies, 40.2, 167-177.

Mashaw, J.L. 2006. 'Accountability and institutional design: some thoughts on the grammar of governance', in M.W. Dowdle (ed), Public Accountability. Designs, Dilemma's and Experiences, pp. 115-156.

Marks, G., L. Hooghe and K. Blank 1996. 'European Integration from the 80s: State-Centric vs. Multilevel Governance', Journal of Common Market Studies, 34, 341-378.

Mendez, C. and J. Bachtler 2011. 'Administrative reform and unintended consequences: an assessment of the EU cohesion policy 'audit explosion", Journal of European Public Policy, 18, 746-765.

Molle, W. 2007. European Cohesion Policy. Routledge.

Moravcsik, A. 2002. 'In Defence of the 'Democratic Deficit': Reassessing Legitimacy in the European Union', Journal of Common Market Studies, 40, 603-624.

Mulgan, R. 2003. Holding Power to Account. Palgrave MacMillan.

Mulgan, R. 2000. "Accountability': an ever expanding concept?', Public Administration, 78, 555-573.

Mulgan, R. 2008. 'The Processes of Public Accountability', Australian Journal of Public Administration, $56,25-36$.

NRC, 2001. 'Rapport-Koning over ESF overtuigt Brussel niet'.

Oliver, D. 1991. 'Government in the United Kingdom: The Search of Accountability, Effectiveness and Citizenship': Open University Press.

Papadopoulos, Y. 2007. 'Problems of Democratic Acountability in Network and Multilevel Governance', European Law Journal, 13, 469-486.

Papadopoulos, Y. 2010. 'Accountability and Multilevel Governance: More Accountability, Less Democracy?', West European Politics, 33, 1030-1049.

Polverari, L., J. Bachtler, S. Davies, S. Kah, C. Mendez, R. Michie and H. Vironen 2014. 'Balance of Competences Cohesion Review: Literature Review on Cohesion Policy'.

Polverari, L. 2015. 'Does Devolution Increase Accountability? Emperical Evidence from the Implementation of European Union Cohesion Policy', Regional Studies, 49, 1074-1086.

Reif, K. and H. Schmitt 1980. 'Nine second-order national elections. Conceptual framework for the analysis of European election result. ', European Journal of Political Research, 3-44.

Rubin, E. 2006. 'The Myth of non-bureaucratic accountability and the anti-administrative impulse', in M.W. Dowdle (ed), Public Accountability. Designs, Dilemma's and Experiences, pp. 52-82.

Samenwerkingsverband Noord-Nederland 2015. 'Jaarverslag 2014 Operationeel Programma NoordNederland 2007-2013'.

Shapiro, S.P. 2005. 'Agency Theory', Annual Review of Sociology, 31, 263-284. 
Sharma, A. 1997. 'Professional as Agent: knowledge assymetry in agency exchange.', The Academy of Management Review, 22, 758-798.

Sinclair, A. 1995. 'The Chameleon of accountability: forms and discourses', Accounting, Organizations and Society, 20, 219-237.

Slaughter, A.-M. 2000. 'Agencies on the Loose? Holding Government Networks Accountable', in G. Bermann, M. Herdegen and P. Lindseth (eds), Transatlantic Regulatory Co-operation: Oxford University Press.

Stratulat, C. and J.A. Emmanouilidis 2013. 'The European Parliament elections 2014. watershed or, again, washed out?', Discussion Paper: European Policy Centre.

Thomas, P.G. 1998. 'The Changing Nature of Accountability', in B. Guy Peters and D.J. Savoie (eds), Taking Stock: Assessing Public Sector Reforms Canadian Centre for Management Development, pp. 348-393.

Veldman, W., P.M.v.d. Zanden and M.A.v. Ruremonde 2015. '3e rapportage inzake 'pijnpunten' in de controle van EFRO subsidies in Nederland': Commissie Goede Diensten.

Vesely, A. 2013. 'Accountability in Central and Eastern Europe: concept and reality ', International Review of Administrative Sciences, 79, 310-330.

Waterman, R.W. and K.J. Meijer 1998. 'Principal-Agent Models: An Expansion?', Journal of Public Administration Research and Theory, 8, 173-202.

Willems, T. and W.v. Dooren 2012. 'Coming to terms with Accountability', Public Management Review, 14, 1011-1036.

Willems, T. 2014. 'Democratic accountability in public-private partnerships: the curious case of Flemish school infrastructure', Public Administration, 92, 340-358.

Zalewska, M. and O.J. Gstrein 2013. 'National Parliaments and their Role in European Integration: The EU's Democratic Deficit in Times of Economic Hardship and Political Insecurity', Bruges Political Research Papers. Bruges: College of Europe. 




\section{ANNEX I - QUESTIONNAIRE USED FOR THE INTERVIEWS}

\section{General questions}

Name interviewee:

Organization:

What is your role within the organization? [if relevant, short]

\section{Relationships and accountability}

1.1 To what actors/institutions is the organization accountable to? Is there also a possibility for these actors to pose sanctions? Yes/no If so, on what and in what manner?

What examples can be given on this/these accountability relationship(s)?

1.2 What actors/institutions are accountable to the organization concerned? Does the organization have a possibility to pose sanctions? Yes/no If so, on what and in what manner?

What examples can be given on this/these accountability relationship(s)?

\section{Compliance, economy, efficiency and effectiveness}

After questions on accountability relationships, we will now focus on the policy process chain, which is forming the basis of the principle of 'sound financial management,' which is also used in Cohesion Policy. This chain consists of the following elements:

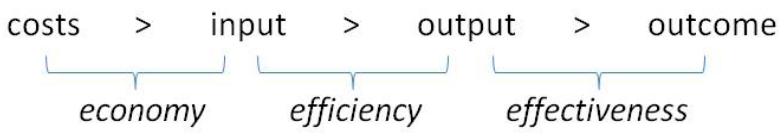

2.1 What would you say your organization focuses mostly on in Cohesion Policy: compliance, economy, efficiency or effectiveness?

2.2 Is there attention for all three E's? yes/no

2.3 Can you give examples of the attention for the $3 E$ 's?

2.4 Is there enough attention in the policy area on efficiency and effectiveness? Yes/no

2.5 Does it need improvement and if so how?

2.6 a. What do the Council, EP and EC focus on and what should they focus on?

Council: compliance / economy / efficiency / effectiveness EP: compliance / economy / efficiency / effectiveness

EC: compliance / economy / efficiency / effectiveness 
2.6 b. What do the TK, government/EZ and MA focus on and what should they focus on?

TK: compliance / economy / efficiency / effectiveness government: compliance / economy / efficiency / effectiveness MA: compliance / economy / efficiency / effectiveness

\section{Goals of the organization and mechanisms to influence actors}

In this chapter we will look at evidence whether there is a situation of accountability deficit or overload in one or more relationships.

Actors all have their own preferences in their acting. They pursue specific policy goals and try to get the result as close to their preferences as possible.

3.1 Towards which specific policy goals does your organization work as far as Cohesion Policy is concerned?

3.2 Policy goals: good spending, low error rates, implementing issues, timely spending of all funds

a. To your opinion, what are the policy goals of the EC, as far as Cohesion Policy is concerned?

b. To your opinion, what are the policy goals of the EP, as far as Cohesion Policy is concerned?

c. To your opinion, what are the policy goals of the Council, as far as Cohesion Policy is concerned?

d. To your opinion, what are the policy goals of the EC, EP and Council, as far as Cohesion Policy is concerned?

e. To your opinion, what are the policy goals of the TK and the government, as far as Cohesion Policy is concerned?

f. To your opinion, what are the policy goals of the AA and MA?

3.3 Mechanisms to influence other actors: persuasion, incentives, direction

a. What mechanisms does the Council have to influence the acting of the EC?

b. What mechanisms does the EP have to influence the acting of the EC?

c. What mechanisms does the EC have to influence the acting of the government?

d. What mechanisms does the EC has to influence the acting of the MA?

e. What mechanisms does the TK has to influence the acting of the government?

f. What mechanisms does the government have to influence the acting of the AA? 
g. What mechanisms does the government have to influence the acting of the MA?

3.4 Do you consider these mechanisms strong or weak and why [per mechanism]?

3.5 If we take all these mechanisms together, should there be stronger of weaker mechanism, or are these in proportion?

\section{Costs of managing Cohesion Policy}

4.1 What is your opinion on the costs of managing and controlling Cohesion Policy, are these proportionate?

\subsection{High demands}

a. Does the EP pose extraordinarily high demands on the EC?

b. Does the Council pose extraordinarily high demands on the EC?

c. Does the EC pose extraordinarily high demands on the government?

4.3 Evaluation criteria

a. Are mutually contradictory evaluation criteria used by the EP?

b. Are mutually contradictory evaluation criteria used by the Council?

c. Are mutually contradictory evaluation criteria used by the EC?

4.4 Performance standards

a. Are the performance standards of the EP too high for the EC?

b. Are the performance standards of the Council too high for the EC?

c. Are the performance standards of the EC too high for the government?

4.5 Evaluation criteria and behavior

a. Are evaluation criteria used by the EP that lead to different behavior of the EC than aimed at by the EP?

b. Are evaluation criteria used by the Council that lead to different behavior of the EC than aimed at by the EP?

c. Are evaluation criteria used by the EC that lead to different behavior of the government than aimed at by the EC?

4.6 Evaluation criteria and behavior

a. How would you consider accountability within Cohesion Policy in general on a scale of 1 to 10 , where 1 is deficit and 10 is overload?

b. How would you consider accountability within Cohesion policy in general on a scale of 1 to 10 , where 1 is bad and 10 is good? 


\section{Legal constraint}

5.1 In this research I will also look at the legal pressures within the system. An example is the possibility to bring a dispute to court. Which legal pressures is your organization confronted with or active in?

5.2 Can you give examples of cases [on Cohesion Policy] before Court or other another judicial actor between actors we discussed? 



\begin{tabular}{|c|c|}
\hline $\begin{array}{c}\text { Translation into questions on single } \\
\text { dimension }\end{array}$ & $\begin{array}{l}\text { Translation into questions on } \\
\text { systemic dimension }\end{array}$ \\
\hline no specific questions & $\begin{array}{l}\text { A. Is on every level an actor } \\
\text { present in an accountability } \\
\text { relationship? }\end{array}$ \\
\hline $\begin{array}{l}\text { a. What (kind of) documents are } \\
\text { produced by the actors on the } \\
\text { accountability relationship and are } \\
\text { these publicly accessible? } \\
\text { b. How is the accountability }\end{array}$ & $\begin{array}{l}\text { B. Are all three mentioned } \\
\text { elements visible in the system } \\
\text { and leading to (external) } \\
\text { pressure on the accountability } \\
\text { relationship? }\end{array}$ \\
\hline $\begin{array}{l}\text { d. Which elements of the policy } \\
\text { process chain are visible in the } \\
\text { accountability relationship? }\end{array}$ & $\begin{array}{l}\text { C. Are all elements of the policy } \\
\text { process chain visible } \\
\text { somewhere in the system? }\end{array}$ \\
\hline $\begin{array}{l}\text { e. What are the preferences of both } \\
\text { the principal and the agent and to } \\
\text { what extent do they converge or } \\
\text { diverge? } \\
\text { f. what mechanisms are used by the } \\
\text { principal and to what extent do they } \\
\text { match the preferences? } \\
\text { g. Can a downwards spiral be seen } \\
\text { in the monitoring costs of the } \\
\text { principal versus bonding costs by } \\
\text { the agent? } \\
\text { h. is any of the four elements of } \\
\text { accountability overload as } \\
\text { mentioned by Bovens visible in the } \\
\text { accountability relationship? }\end{array}$ & $\begin{array}{l}\text { D. Are there one or more } \\
\text { accountability relationships } \\
\text { within the system where the } \\
\text { mechanisms used by the } \\
\text { principal do not match the } \\
\text { preferences of both actors?? } \\
\text { E. Are there one or more } \\
\text { accountability relationships } \\
\text { within the system where a } \\
\text { vicious circle in higher } \\
\text { monitoring and bonding costs } \\
\text { can be seen? } \\
\text { F. Are any of the four elements } \\
\text { mentioned by Bovens visible } \\
\text { within the system? }\end{array}$ \\
\hline
\end{tabular}

Questions (with $\mathrm{X}$ related to the actor concerned)

To what actors/institutions is the organisation account Is there also a possibility for those actors to pose sanc What examples can be given of this accountability rela what actors/institutions are accountable to the organi Does the organisation have a possibility to pose sancti What examples can be given of this accountability rela Which legal pressures is your organization confronted Can you give examples of cases [on Cohesion Policy] b between actors we discussed?

What would you say your organization focuses mostly economy, efficiency or effectiveness?

Is there attention for all three E's (yes/no)

Can you give examples of attention for the 3E's?

Is there enough attention for the 3E's in Cohesion Poli

Does it need improvement and how?

What do the Council, EC and EP focus at and what shou What do TK, EZ and MA focus at and what should they Towards which specific policy goals does your organis concerned?

To your opinion, what are the policy goals of the EC as To your opinion, what are the policy goals of the EP as To your opinion, what are the policy goals of the Coun To your opinion, what are the policy goals of the EC, C concerned?

To your opinion, what are the policy goals of the TK an

To your opinion, what are the policy goals of the AA ar What mechanisms does the Council have to influence weak mechanisms? And should these be stronger or w What mechanisms does the EP have to influence the $\mathrm{E}$ mechanisms? And should these be stronger or weaker What mechanisms does the EC have to influence the $A$ weak mechanisms? And should these be stronger or w What mechanisms does the EC have to influence the $A$ weak mechanisms? And should these be stronger or w What mechanisms does the TK have to influence the $g$ strong or weak mechanisms? And should these be stro What mechanisms does EZ have to influence the AA? I And should these be stronger or weaker or are these $c$ What mechanisms does EZ have to influence the MA? And should these be stronger or weaker or are these o Do you consider these mechanisms of the actor strong If we take all these mechsnisms together, should theri these in proportion?

What is your opinion on the costs of managing and con proportionate? Does EP pose extraordinarily high demands on the EC:
criteria used by the EP? Are the performance standard performance standards of the EP lead to subversive b€

Does the Council pose extraordinarily high demands o evaluation criteria used by the Council? Are the perfo too high? Do the performance standards of the Counci Does EC pose extraordinarily high demands on the MS criteria used by the EC? Are the performance standard performance standards of the EC lead to subversive be How would you consider accountability of Cohesion Pc is deficit and 10 is overload? 


\section{ANNEX II - INTERVIEWS: DEFINING THE QUESTIONS PER ACTOR}

\begin{tabular}{|c|c|c|c|c|c|c|c|c|c|}
\hline & EC & EP & Council & ECA & TK & EZ/gov & $A R$ & AA & MA \\
\hline itable to? & $\mathrm{x}$ & $\mathrm{x}$ & $x$ & $x$ & $x$ & $x$ & $x$ & $x$ & $x$ \\
\hline tions? yes/no and if yes on what manner? & $\mathrm{x}$ & $\mathrm{x}$ & $x$ & $x$ & $\mathrm{x}$ & $x$ & $x$ & $x$ & $x$ \\
\hline ationship? & $\mathrm{x}$ & $\mathrm{x}$ & $\mathrm{x}$ & $\mathrm{x}$ & $\mathrm{x}$ & $\mathrm{x}$ & $\mathrm{x}$ & $x$ & $x$ \\
\hline isation concerned? & $\mathrm{x}$ & $\mathrm{x}$ & $\mathrm{x}$ & $\mathrm{x}$ & $\mathrm{x}$ & $\mathrm{x}$ & $x$ & $\mathrm{x}$ & $\mathrm{x}$ \\
\hline tions? yes/no and if yes on what manner? & $\mathrm{x}$ & $\mathrm{x}$ & $x$ & $x$ & $\mathrm{x}$ & $x$ & $\mathrm{x}$ & $x$ & $x$ \\
\hline ationship? & $\mathrm{x}$ & $\mathrm{x}$ & $x$ & $\mathrm{x}$ & $\mathrm{x}$ & $x$ & $\mathrm{x}$ & $x$ & $x$ \\
\hline with or active in? & $\mathrm{x}$ & $\mathrm{x}$ & $x$ & $\mathrm{x}$ & $\mathrm{x}$ & $\mathrm{x}$ & $\mathrm{x}$ & $x$ & $x$ \\
\hline before Court or other another judicial actor & $\mathrm{x}$ & $\mathrm{x}$ & $\mathrm{x}$ & $\mathrm{x}$ & $\mathrm{x}$ & $\mathrm{x}$ & $\mathrm{x}$ & $\mathrm{x}$ & $\mathrm{x}$ \\
\hline & & & & & & & & & \\
\hline \multirow[t]{3}{*}{ I on in Cohesion Policy: compliance, } & $\mathrm{x}$ & $\mathrm{x}$ & $\mathrm{x}$ & $x$ & $\mathrm{x}$ & $x$ & $x$ & $x$ & $x$ \\
\hline & $\mathrm{x}$ & $\mathrm{x}$ & $x$ & $x$ & $\mathrm{x}$ & $x$ & $\mathrm{x}$ & $\mathrm{x}$ & $x$ \\
\hline & $\mathrm{x}$ & $\mathrm{x}$ & $\mathrm{x}$ & $\mathrm{x}$ & $\mathrm{x}$ & $\mathrm{x}$ & $\mathrm{x}$ & $x$ & $\mathrm{x}$ \\
\hline \multirow[t]{2}{*}{ icy? (yes/no) } & $x$ & $\mathrm{x}$ & $\mathrm{x}$ & $x$ & $\mathrm{x}$ & $x$ & $x$ & $\mathrm{x}$ & $x$ \\
\hline & $x$ & $x$ & $x$ & $\mathrm{x}$ & $x$ & $\mathrm{x}$ & $x$ & $x$ & $x$ \\
\hline uld they focus at? & $x$ & $x$ & $x$ & $x$ & & & & & \\
\hline focus at? & & & & & $\mathrm{x}$ & $x$ & $\mathrm{x}$ & & $x$ \\
\hline ;ation work, as far as Cohesion Policy is & $\mathrm{x}$ & $x$ & $x$ & $x$ & $x$ & $x$ & $x$ & $\mathrm{x}$ & $\mathrm{x}$ \\
\hline s far as Cohesion Policy is concerned? & & $\mathrm{x}$ & $x$ & & & $x$ & & $\mathrm{x}$ & $x$ \\
\hline is far as Cohesion Policy is concerned? & $\mathrm{x}$ & & $x$ & & & & & & \\
\hline רcil as far as Cohesion Policy is concerned? & $x$ & $\mathrm{x}$ & $x$ & & & & & & \\
\hline Oouncil and EP as far as Cohesion Policy is & & & & $x$ & & & & & \\
\hline nd the government as far as Cohesion Policy & & & & & $x$ & $\mathrm{x}$ & $x$ & & \\
\hline ind MA's? & $\mathrm{x}$ & $\mathrm{x}$ & & & & & $\mathrm{x}$ & $\mathrm{x}$ & $x$ \\
\hline $\begin{array}{l}\text { the EC? Would you consider these strong or } \\
\text { Neaker or are these ok? }\end{array}$ & $\mathrm{x}$ & $\mathrm{x}$ & $\mathrm{x}$ & $\mathrm{x}$ & & & & & \\
\hline $\begin{array}{l}\text { EC? Would you consider these strong or weak } \\
\text { r or are these ok? }\end{array}$ & $\mathrm{x}$ & $\mathrm{x}$ & $\mathrm{x}$ & $\mathrm{x}$ & & & & & \\
\hline $\begin{array}{l}\text { MS? Would you consider these strong or } \\
\text { Neaker or are these ok? }\end{array}$ & $\mathrm{x}$ & $\mathrm{x}$ & & $\mathrm{x}$ & & $\mathrm{x}$ & $\mathrm{x}$ & & \\
\hline $\begin{array}{l}\text { MA? Would you consider these strong or } \\
\text { Neaker or are these ok? }\end{array}$ & $\mathrm{x}$ & $\mathrm{x}$ & & & & $\mathrm{x}$ & $\mathrm{x}$ & $\mathrm{x}$ & $\mathrm{x}$ \\
\hline $\begin{array}{l}\text { government? Would you consider these } \\
\text { onger or weaker or are these ok? }\end{array}$ & & & & & $\mathrm{x}$ & $\mathrm{x}$ & $x$ & & \\
\hline $\begin{array}{l}\text { Would you consider these strong or weak? } \\
\text { ok? }\end{array}$ & & & & & $\mathrm{x}$ & $\mathrm{x}$ & $\mathrm{x}$ & $\mathrm{x}$ & $x$ \\
\hline $\begin{array}{l}\text { Would you consider these strong or weak? } \\
\text { ok? }\end{array}$ & & & & & $\mathrm{x}$ & $\mathrm{x}$ & $\mathrm{x}$ & $\mathrm{x}$ & $\mathrm{x}$ \\
\hline gor weak and why? & $\mathrm{x}$ & $\mathrm{x}$ & $x$ & $x$ & $\mathrm{x}$ & $x$ & $x$ & $\mathrm{x}$ & $x$ \\
\hline re be stronger of weaker mechanism, or are & $\mathrm{x}$ & $\mathrm{x}$ & $\mathrm{x}$ & $\mathrm{x}$ & $\mathrm{x}$ & $\mathrm{x}$ & $\mathrm{x}$ & $\mathrm{x}$ & $\mathrm{x}$ \\
\hline ntrolling Cohesion Policy, are these & $x$ & $x$ & $x$ & $x$ & $x$ & $x$ & $x$ & $x$ & $x$ \\
\hline $\begin{array}{l}\text { ? Are mutually contradictory evaluation } \\
\text { ds of the EP for the EC too high? Do the } \\
\text { 'ehaviour by the EC? }\end{array}$ & $\mathrm{x}$ & $\mathrm{x}$ & & $x$ & & & & & \\
\hline $\begin{array}{l}\text { on the EC? Are mutually contradictory } \\
\text { rrmance standards of the Council for the EC } \\
\text { il lead to subversive behaviour by the EC? }\end{array}$ & $\mathrm{x}$ & & $\mathrm{x}$ & $\mathrm{x}$ & & & & & \\
\hline $\begin{array}{l}\text { S/MA? Are mutually contradictory evaluation } \\
\text { ds of the EC for the MS/MA too high? Do the } \\
\text { ehaviour by the MS/MA? }\end{array}$ & $\mathrm{x}$ & & & $\mathrm{x}$ & & $\mathrm{x}$ & $\mathrm{x}$ & $\mathrm{x}$ & $\mathrm{x}$ \\
\hline 'olicy in general on a scale of 1 to 10 , where 1 & $x$ & $\mathrm{x}$ & $\underline{x}$ & $x$ & $x$ & $x$ & $x$ & $x$ & $\mathrm{x}$ \\
\hline
\end{tabular}





\section{ANNEX III - LIST OF RESPONDENTS}

\section{European Commission}

- Hélène Laueriere, team leader Inter-institutional relations UNIT DDG1.01. Date of interview: April 27, 2015

- Kris Magnus, programme manager UNIT F2 Germany and the Netherlands, combined interview with Marlies Peters. Date of interview: April 27, 2015

- Marlies Peters, programme manager UNIT F2 Germany and the Netherlands, combined interview with Kris Magnus. Date of interview: April 27, 2015

\section{European Parliament}

- Lambert van Nistelrooij, MEP for CDA. Date of interview: March 17, 2015.

- Matthijs van Miltenburg, MEP for D66. Date of interview: March 31, 2015.

- Thomas Zandstra, European Added Value Unit, Directorate for Impact Assessment and European Added Value, European Parliament. Date of interview: March 31, 2015.

- Diána Haase, Research Administrator, Policy Department B: Structural and Cohesion Policies, DG IPOL. Date of interview: March 31, 2015.

\section{(European) Council}

- Harry Oldersma, permanent representation of the Netherlands at the Council. Date of interview: April 20, 2015.

- Ana Maria Dobre, Political administrator General Secretariat, Council of the European Union. Date of interview: April 27, 2015.

\section{European Court of Auditors}

- Alex Brenninkmeijer, Member of the Court. Date of interview: March 18, 2015.

- Kevin Deceunink, Financial auditor ERDF. Date of interview: March 18, 2015.

- Peggy Vercauteren, Financial auditor ESF. Date of interview: March 18, 2015.

- Robert Markus, Head of Unit EAFRD Financial Audit. Date of interview: March $18,2015$.

\section{Ministry of EZ}

- Hans Kaandorp, coordination unit Structural Funds. Date of interview: April 23, 2015.

- Odilia Knap, Member of the Board of Ministry of EZ. Date of interview: May 22, 2015.

- Yvette Lammers, coordination unit Structural Funds. Combined interview with Chris Poppe. Date of interview: April 23, 2015. 
- Chris Poppe, coordination unit Structural Funds. Combined interview with Yvette Lammers. Date of Interview: April 23, 2015.

- Ineke Hoving, coordination unit Structural Funds. Date of interview: April 23, 2015.

\section{Tweede Kamer (House of Representatives)}

- Julie d'Hondt, EU-advisor of the Tweede Kamer der Staten-Generaal, combined interview with Ruben Dijkstra, EU-advisor. Combined interview on March 12, 2015.

- Ruben Dijkstra, EU-advisor of the Tweede Kamer der Staten-Generaal, combined Het interview with Julie d'Hondt, EU-advisor. Combined interview on March 12 , 2015.

\section{Algemene Rekenkamer}

- Kees Vendrik, boardmember of Algemene Rekenkamer. Date of interview: May 29, 2015

- Paul Neelissen, EU-auditor, combined interview with Anet van Schijndel, EUauditor. Date of interview: May 26, 2015.

- Anet van Schijndel, EU-auditor, combined interview with Paul Neelissen, EUauditor. Date of interview: May 26, 2015.

\section{Audit authority of ERDF in the Netherlands (Audit Dienst Rijk)}

- Stan van Elten, ERDF manager ADR. Date of interview: June 2, 2015

- Peter Vlasveld, Head of AA, ADR. Date of interview: May 26, 2015

\section{Management authorities of ERDF in the Netherlands}

- Ruud van Raak, programme manager MA West. Date of interview: May 26, 2015

- Henri van Voorn, controller MA Noord, combined interview with Roelof Jansma, programme manager MA Noord. Date of interview: June 12, 2015.

- Roelof Jansma, programme manager MA Noord, combined interview with Henri van Voorn controller MA Noord. Date of interview: June 12, 2015 




\section{Nederlandse samenvatting}

Het Cohesiebeleid van de Europese Unie (EU), ook wel het Europese Regionaal beleid genoemd, kent al decennia lang ernstige problemen met het afleggen van verantwoording (accountability). Zo is er discussie over de effectiviteit van het beleid: wordt daadwerkelijk bijgedragen aan het verkleinen van de economische verschillen tussen lidstaten en regio's binnen de EU? Daarnaast spelen er al jaren lang problemen met het financieel management van het Cohesiebeleid: de Europese Rekenkamer heeft nog geen enkele keer een positieve betrouwbaarheidsverklaring afgegeven (Déclaration d'Assurance, DAS, geïntroduceerd in 1995), en bovendien zijn de foutfracties van het Cohesiebeleid altijd al hoog geweest. Verder ligt de focus in de verantwoording voornamelijk op financieel management, met nadruk op foutfracties, onregelmatigheden, benutting van middelen (absorption rates) en maar nauwelijks op de behaalde resultaten (effectiviteit) van het beleid. Daarnaast speelt in de Nederlandse context de ESF-problematiek van begin jaren negentig een grote rol, die speelde bij Arbeidsvoorzieningen, de organisatie achter de arbeidsbureaus. Nederland heeft vanwege deze problemen in 2001 een hoge boete gekregen van de EU en dat heeft geleid tot een handelswijze op nationaal niveau die tot doel heeft om een dergelijke situatie in de toekomst te allen tijde te voorkomen.

Dit onderzoek richt zich op de wijze waarop verantwoording wordt afgelegd over het Cohesiebeleid in Nederland (accountability) en op de vraag of dit een goede situatie betreft (dus of er sprake is van 'good accountability'). Daarbij wordt uitgegaan van vier voorwaarden voor een situatie van 'good accountability,' gevat in een normatief kader. Dit kader is gebaseerd op de wetenschappelijke literatuur over accountability en geformuleerd in dit onderzoek. Er wordt uitgegaan van de definitie 
van accountability zoals opgesteld door Bovens, ${ }^{735}$ waarbij de focus ligt op 'wie legt aan wie verantwoording af, waarover, waarom voelt de actor zich verplicht om verantwoording af te leggen, en waarom ervaart hij dat hij accountable is?'

Het onderzoek gebruikt de principaal-agent theorie om de relaties tussen twee actoren en hun onderlinge gedrag te beschrijven. Deze theorie kent aan de ene kant de principaal, die zich richt op het behalen van een bepaald resultaat, en aan de andere kant de agent, die door de principaal wordt gecontracteerd om een bepaald resultaat voor hem te behalen. De theorie gaat er van uit dat beide actoren verschillende voorkeuren hebben, die uiteindelijk leiden tot welvaartsverlies voor de principaal. De hoofdvraag in deze theorie is op welke wijze de principaal de agent kan sturen in het gewenste gedrag, en ook welke maatregelen de agent heeft om zo veel mogelijk vrijheid in zijn handelen te behouden, zodat hij zijn eigen voorkeuren zoveel als mogelijk kan volgen.

Accountability is nauw verbonden met de principaal-agent theorie, in die zin dat de agent de principaal moet informeren over zijn handelen en de behaalde resultaten, waarbij hij aldus verantwoording aflegt aan de principaal, hij is accountable.

Naast de principal-agent theorie gebruikt dit onderzoek ook multilevel governance als perspectief, waarbij wordt ingezoomd op diverse actoren op verschillende niveaus van het maken van beleid : Europees, nationaal en regionaal niveau. De wetenschappelijke literatuur over multilevel governance, ontstaan in de jaren ' 90 met publicaties van Hooghe en Marks, ${ }^{736}$ is van oudsher voornamelijk gericht op het Cohesiebeleid en leent zich uitstekend om dit beleidsveld nader te bestuderen.

Dit onderzoek richt zich op de situatie van het Cohesiebeleid in Nederland, meer specifiek op het Europees Fonds voor Regionale Ontwikkeling (EFRO), ${ }^{737}$ één van de structuurfondsen naast het Cohesiefonds (CF) en het Europees Sociaal Fonds (ESF). De focus ligt op EFRO omdat dit fonds het meest geschikt is voor onderzoek gericht op multilevel governance: Nederland ontvangt geen bijdrage vanuit het CF en het ESF wordt landelijk uitgevoerd. Bij de uitvoering van EFRO in Nederland zijn de drie genoemde niveaus betrokken: Europees, nationaal en regionaal, wat dit fonds uitermate geschikt maakt voor een dergelijk onderzoek. Zoals vastgelegd in

735 Bovens, M. 2007. 'Analysing and Assessing Accountability: a Conceptual Framework', European Law Journal, 13, 447-468.

736 Zie bijvoorbeeld Hooghe, L. 1996. Cohesion Policy and European Integration: Building multilevel governance. Oxford university Press. en Marks, G., L. Hooghe en K. Blank 1996. 'European Integration from the 80s: State-Centric vs. Multi-level Governance', Journal of Common Market Studies, 34, 341378.

737 De Engelse afkorting voor EFRO is ERDF. 
de Europese verordeningen die ten grondslag liggen aan het Cohesiebeleid, dient een Management Autoriteit (MA) van een regio ${ }^{738}$ voor elke periode van zeven jaar (programmaperiode) een Operationeel Programma (OP) op te stellen, waarin de zogenaamde 'interventielogica' van de regio wordt uitgewerkt, waarbij wordt ingegaan op de maatregelen die de regio wenst te nemen en met name hoe de beschikbare middelen (subsidies) worden ingezet. Het onderzoek richt zich met name op de periode van 2007 tot 2013 maar benoemt daar waar relevant ook de ontwikkelingen in de periode van 2014 tot 2020 .

De onderzoeksvraag die in het onderzoek wordt beantwoord is de volgende:

In hoeverre is er sprake van een situatie van 'good accountability' in het EU Cohesiebeleid in Nederland waar het gaat om de regionale operationele EFRO programma's in de 2007-2013 periode en daarna?

Het onderzoek start met een beschrijving van de wetenschappelijke literatuur over accountability en over accountability in een multi-level situatie. ${ }^{739}$ Daarna wordt het normatieve kader van 'good accountability' uitgewerkt en nader beschreven, gebaseerd op de wetenschappelijke literatuur. ${ }^{740}$ Dit leidt tot een onderscheid in vier elementen, namelijk bereik (coverage), context, inhoud (content) en kosten (costs). Vervolgens worden de actoren beschreven die zichtbaar zijn in het Cohesiebeleid, zowel op Europees, nationaal en regionaal niveau. Ook wordt de relatie tussen die actoren beschreven. ${ }^{741} \mathrm{Na}$ deze beschrijving volgt een overzicht van de mening van de actoren zelf, gebaseerd op interviews met personen werkzaam in het veld, en alle betrokken actoren representerend. Bij deze interviews is het opgestelde normatieve kader als basis gebruikt. ${ }^{742}$ Daarna worden conclusies getrokken over de vraag of er sprake is van 'good accountability', gebaseerd op zowel documentonderzoek als de interviews. ${ }^{743}$ Tot slot wordt ingegaan op de beleidsimplicaties van de uitkomsten van dit onderzoek en worden suggesties gedaan voor vervolgonderzoek. ${ }^{744}$

738 In Nederland zijn er zowel in de 2007-2013 periode als in de 2014-2020 voor EFRO vier regionale programma's opgesteld, Noord, Zuid, West en Oost en daarnaast een grensoverschrijdend programma (INTERREG).

739 Zie hoofdstuk 2.

740 Zie hoofdstuk 3.

741 Zie hoofdstuk 4.

742 Zie hoofdstuk 5.

743 Zie hoofdstuk 6.

744 Zie hoofdstuk 7. 
Allereerst: wat wordt er in de wetenschappelijke literatuur besproken over accountability? Accountability kan worden gezien als een proces, dat bestaat uit vier onderdelen:

1. Toewijzen van verantwoordelijkheden;

2. Rapporteren door de agent;

3. Het vergaren van informatie of onderzoeken van verkregen informatie en verificatie daarvan door de principaal;

4. Handhaven door de principaal, mogelijk leidend tot sancties voor de agent.

Daarbij zijn drie zaken relevant:

- Wie zijn de actoren in de accountability relatie?

- Wat is het onderwerp van de accountability relatie? Gebaseerd op de zogenoemde policy-process-chain, waar ligt de nadruk op, op zuinigheid (economy), efficiency of effectiviteit?

- Door middel van welk mechanisme wordt naleving afgedwongen door de principaal en hoe sterk is het effect van dit mechanisme?

Daarnaast volgen uit de wetenschappelijke literatuur drie (systeem-)kenmerken van accountability:

a. Democratie: de verbinding tussen instituties en 'het volk', waarbij deze laatste gezien wordt als de ultieme principaal. Alle relaties binnen het accountability kader in het openbaar bestuur hebben een directe of indirecte verbinding met de democratische relaties tussen kiezers en volksvertegenwoordigers, hoewel de mening van 'het volk' niet bestaat: er is geen gedeelde mening of bedoeling en deze zijn dus altijd vaag.

b. Transparantie: besluitvorming behoort transparant te zijn voor een ieder, in die zin dat besluitvormers uitleg behoren te geven over de besluiten die zijn genomen en waarom die zo zijn uitgevallen.

c. Juridische beperkingen: wettelijke grenzen in wetgeving en jurisprudentie zijn noodzakelijk om ongelijkheid te voorkomen, als ook misbruik van macht. Besluitvorming dient binnen deze grenzen te blijven, waarbij rechtbanken zorgdragen voor de handhaving.

Uit de principaal-agent theorie, zoals net ook genoemd, blijkt dat er sprake is van informatie-asymmetrie tussen de principaal en de agent, die uiteindelijk leidt tot welvaartsverlies voor de principaal. Groenendijk ${ }^{745}$ beschrijft dat er een risico bestaat dat de principaal en agent in een negatieve spiraal met steeds hogere kosten terecht 
komen: steeds hoger wordende inspectie- en preventiekosten voor de principaal leiden tot hogere verhullings- en afleidingskosten voor de agent en vice versa.

Bovens ${ }^{746}$ gaat nader in op de begrippen accountability-tekort (deficit) en accountability-overbelasting (overload). Hij schetst een situatie van een tekort als een situatie 'waar bestuurders teveel mogelijkheden en ruimte hebben en zij onvoldoende worden ingeperkt door de verplichting om verantwoording af te leggen over hun handelen aan de fora die de macht hebben om hen sancties op te leggen. ${ }^{747}$ Anders gezegd: een situatie waar onvoldoende waarborgen zijn om machthebbers ervan te weerhouden om buiten hun boekje te gaan.

Een situatie van overbelasting daarentegen, wordt door Bovens vertaald in vier elementen die leiden tot een situatie met teveel, tegenstrijdige of verkeerde criteria, criteria die verder gaan dan gebruikelijk of criteria die afleiden van waar het werkelijk om gaat, waarover de agent toch verantwoording moet afleggen. In feite een situatie van 'teveel van het goede.'

Er zijn ook bijdragen geleverd in de wetenschappelijke literatuur gericht op accountability in de EU. Deze laten zien dat de EU specifieke problemen heeft, bijvoorbeeld waar het gaat om de relatie tussen actoren op de verschillende niveaus, de focus die voornamelijk ligt op financiële accountability (in tegenstelling tot bijvoorbeeld een focus op effectiviteit van het beleid) en het feit dat mechanismen om naleving af te dwingen op Europees niveau lijken te ontbreken.

Wanneer we kijken naar de actoren die zichtbaar zijn in de implementatie van EFRO, met een focus op de Nederlandse situatie, dan zien we op Europees niveau de (Europese) Raad, de Europese Commissie (EC), het Europees Parlement (EP), het Europese Hof van Justitie (EhvJ) en de Europese Rekenkamer (ER). Op nationaal niveau zien we de Tweede Kamer (TK), de regering en in de uitvoering het ministerie van Economische Zaken (regering/EZ), de nationale rechtbanken, de Algemene Rekenkamer (AR) en de Audit Autoriteit (AA, Audit Dienst Rijk, onderdeel van het Ministerie van Financiën). Tot slot is de Management Autoriteit (MA) als verantwoordelijke actor op regionaal niveau genoemd. In Figuur 33 zijn de actoren en relaties zichtbaar.

746 Bovens, M., T. Schillemans and P.t. Hart 2008. 'Does public accountability work? An assessment tool', Public Administration, 86, 225-242.

747 lbid. p. 229. 


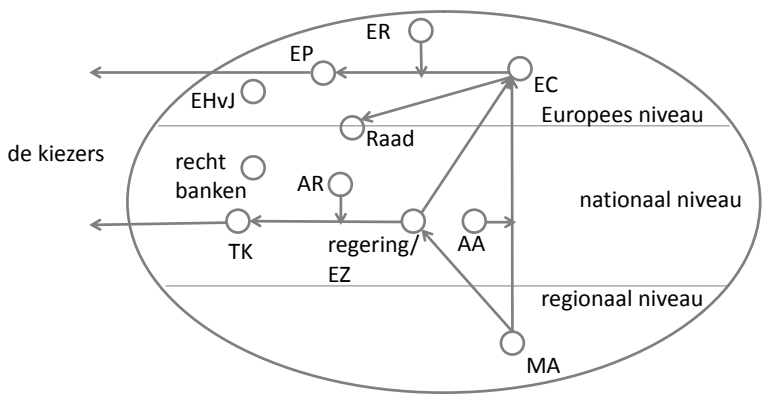

Figuur 33. De actoren en indeling van de relaties

Het normatieve kader dat is opgesteld richt zich op zowel de individuele relaties (single dimension) als op het systeem als geheel met daarin alle relaties (systemic dimension). Met betrekking tot de systemic dimension zijn vier voorwaarden geformuleerd die, wanneer aan alle is voldaan, leiden tot een situatie van 'good accountability:' de gewenste situatie. De conclusie met betrekking tot de beoordeling van deze voorwaarden wanneer het gaat om de Nederlandse situatie bij EFRO luidt als volgt.

1. Op elk niveau - Europees, nationaal en regionaal - moet ten minste één actor zichtbaar zijn in een accountability-relatie: hetzij met een actor op hetzelfde niveau, hetzij met een actor op een ander niveau. Daarnaast moet het duidelijk zijn in alle accountability-relaties welke actoren verantwoording afleggen over wat.

De relaties die zijn geïdentificeerd als accountability-relaties zijn de volgende.

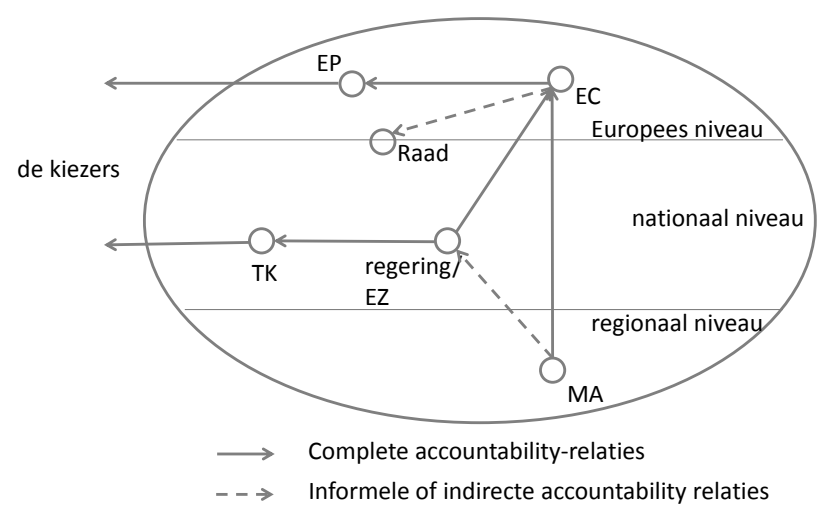

Figuur 34. De actoren en accountability-relaties in het Cohesiebeleid 
Hieruit kan geconcludeerd worden dat aan de eerste voorwaarde is voldaan, minstens één actor uit elk level is zichtbaar in een accountability-relatie. Daarnaast is in de regelgeving, de Europese verordeningen, vastgelegd welke actor verantwoording aflegt over wat.

2. De kenmerken transparantie, democratie en juridische afbakening moeten in het systeem aanwezig zijn en voldoende tegenwicht geven in het systeem.

Uit het onderzoek wordt duidelijk dat alle elementen aanwezig zijn, maar dat zij slechts in beperkte mate zorgen voor tegenwicht in het systeem. Wanneer we bijvoorbeeld kijken naar transparantie, dan wordt duidelijk dat de afgelopen jaren al veel is verbeterd en steeds meer informatie openbaar beschikbaar komt, maar nog steeds wordt bepaalde relevante informatie niet openbaar toegankelijk gemaakt.

Als het gaat om democratie, dan wordt duidelijk dat kiezers slechts in beperkte mate de gekozen volksvertegenwoordigers verantwoordelijk kunnen houden.

Tot slot, met betrekking tot juridische beperkingen, blijkt uit dit onderzoek dat op Europees niveau het systeem wel lijkt te werken, waar op nationaal niveau mogelijkheden voor de MA's ontbreken om een casus voor een rechter te brengen. Feitelijk ontbreekt dit element daardoor op nationaal niveau.

Al met al wordt deze voorwaarde als niet voldaan beoordeeld.

3. Zuinigheid, efficiency en effectiviteit moeten ergens in het systeem zichtbaar zijn en op alle niveaus moet minstens één van de drie elementen zichtbaar zijn.

De volgende figuur geeft een overzicht van de focus van de verschillende relaties.

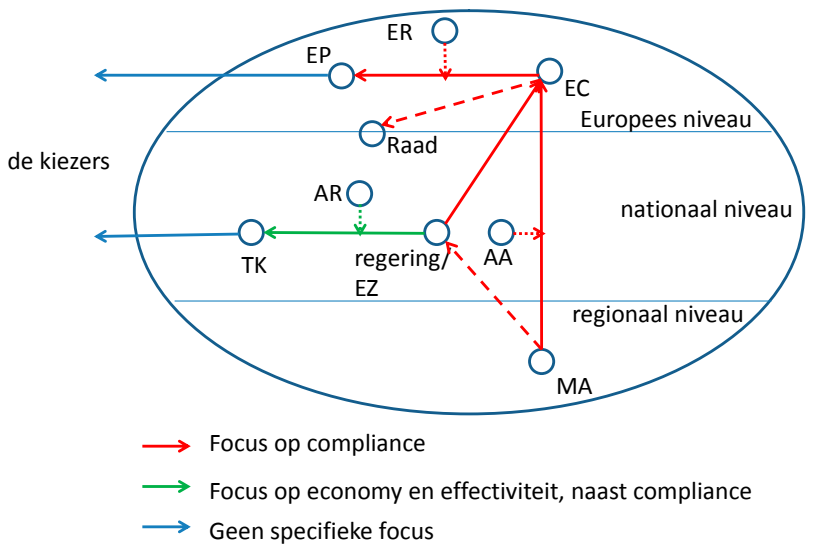

Figuur 35. De focus van de accountability relaties in het Cohesiebeleid 
Het onderzoek toont aan dat er nauwelijks aandacht is voor efficiency, terwijl er erg veel focus ligt op compliance, oftewel in hoeverre aan regelgeving en eisen wordt voldaan. Dat leidt tot de conclusie dat niet aan deze voorwaarde wordt voldaan in de 2007-2013 periode. Echter, in de 2014-2020 periode worden hier wel verbeteringen verwacht, met name door een toenemende aandacht voor de effectiviteit van het beleid. De aandacht voor efficiency zal echter naar verwachting nog steeds onvoldoende zijn.

4. De situatie in het systeem moet in balans zijn, in die zin dat er geen sprake is van een accountability-tekort, noch van een situatie van overbelasting.

Deze voorwaarde is in de operationalisatie in drie onderdelen verdeeld.

Het eerste onderdeel gaat in op de voorkeuren van principalen en agenten in het systeem, en gaat na in hoeverre die voorkeuren overeenkomen (convergeren) of verschillen (divergeren), en welke mechanismen de principaal vervolgens heeft om de agent te sturen. In een situatie van convergentie is de gewenste situatie dat de principaal zwakke mechanismen beschikbaar heeft, in een situatie van divergentie zijn sterke mechanismen nodig.

Duidelijk wordt dat er slechts één relatie is waar de voorkeuren en mechanismen niet bij elkaar passen: in de relatie tussen EZ en de MA. Hier heeft EZ sterke mechanismen (sterke wettelijke bevoegdheden om de MA te dwingen tot bepaald gedrag) terwijl de voorkeuren van EZ en de MA convergeren (beide gericht op het snel bestedenvan de beschikbare subsidie).

In het tweede onderdeel kijken we naar een eventuele negatieve spiraal die steeds hogere kosten voor zowel de principaal (monitoring costs) en de agent (bonding costs) laat zien. Een dergelijke spiraal is zichtbaar in de relatie tussen de EC en MA. We hebben gezien dat de eisen voor de MA's steeds strenger worden met elke programmaperiode en ook door de respondenten als steeds hogere eisen worden ervaren.

Tot slot kijken we als derde onderdeel naar de kenmerken van een situatie van accountability overbelasting (accountability overload), zoals genoemd door Bovens. ${ }^{748}$ In zowel de relaties tussen het EP en de EC en de EC en MA zijn enkele van deze kenmerken zichtbaar.

748 Bovens, M., T. Schillemans and P.t Hart 2008. 'Does public accountability work? An assessment tool', Public Administration, 86, 225-242. p. 229. 
De combinatie van deze drie onderdelen leidt tot de conclusie dat er geen sprake is van een evenwichtige situatie, vooral niet in de relaties tussen EP en EC, EC en $M A$ en $E Z$ en MA.

De eindconclusie ten aanzien van de vraag of er sprake is van een goede situatie, wanneer het gaat om accountability ('good accountability') in de casus van de regionale EFRO OP's in de 2007-2013 periode, is dat daarvan géén sprake is. Bepaalde kenmerken ontbreken op bepaalde niveaus (juridische beperkingen op nationaal niveau), aandacht voor effectiviteit van het beleid en vooral voor efficiency is (te) zeer beperkt, en er zijn in een aantal relaties ook tekenen zichtbaar van een situatie van overbelasting (accountability overload).

Dit onderzoek geeft daarnaast aanleiding om een aantal specifieke onderwerpen nader te belichten (zie hoofdstuk 7). Eén van die onderwerpen is bijvoorbeeld de impact van het principe van 'shared management', typisch voor Cohesiebeleid, wat inhoudt dat er een gedeelde verantwoordelijkheid is voor zowel de EC als de lidstaten wanneer het gaat om de implementatie van het Cohesiebeleid. Het onderzoek laat zien dat shared management feitelijk leidt tot een situatie waarin de verantwoordelijkheden tussen de actoren onduidelijk zijn en leidt tot politieke druk op zowel Europees als nationaal niveau. Deze politieke druk zet uiteindelijk een rem op transparantie: wanneer er zaken op nationaal niveau mis gaan, is het niet in het belang van de lidstaat om dat duidelijk te maken waardoor het risico groter wordt dat zaken onder de pet worden gehouden. Een tweede risico van 'shared management' is dat alle actoren, zowel op Europees als nationaal niveau, vanwege die politieke druk de risico's op fouten (en een slechte naam) willen verkleinen en daardoor zo strikt mogelijk de regelgeving interpreteren, en wanneer het gaat om verantwoordelijkheid vooral naar anderen wijzen. Dit laat zien dat er voldoende redenen zijn om de implementatie van het Cohesiebeleid nader te (blijven) bestuderen. 



\section{About Maaike Damen}

Maaike Damen - Koedijk (1980) completed secondary school at OSG Sevenwolden at Heerenveen (VWO, with annotation Gymnasium) and afterwards studied Public Administration and Public Policy (Bestuurskunde) at University of Twente. After her graduation in 2003, she started working with Structural Funds (ESF) at a vocational training centre in Emmen (ROC Drenthe College). Afterwards, starting in 2004, she has worked for the grant consultancy firm PNO Consultants BV in Groningen for five years, focusing on the compliance of grant projects specifically for public clients. Following this job, she worked for a short period of time for Rijksuniversiteit Groningen (2009/2010) and Stichting Icare (2010/2011), in a position focusing on respectively the compliance of grants (Rijksuniversiteit Groningen, ERDF) and acquisition of grants (Icare).

Since 2012, she works for SNN, a cooperating agency of the Dutch provinces of Fryslân, Groningen and Drenthe. In her work, she is focusing on the accountability of ERDF towards the national government and the EC and has a coordinating role in executing the ERDF programme in the northern part of the Netherlands. 
